\title{
Untersuchungen zu \\ Struktur-Funktionsbeziehungen in der \\ tRNA-ähnlichen Struktur des Rüben-Gelbmosaik-Virus
}

\author{
Dissertation \\ zur Erlangung des Doktorgrades \\ der Mathematisch-Naturwissenschaftlichen Fakultäten \\ der Georg-August-Universität zu Göttingen
}

\author{
vorgelegt von \\ Christian Klug \\ aus Uelzen
}

Göttingen 2003 
D 7

Referent: $\quad$ PD Dr. A. Schwienhorst

Korreferent: $\quad$ Prof. Dr. C. Gatz

Tag der mündlichen Prüfung: 21.01.2004 


\section{Inhaltsverzeichnis}

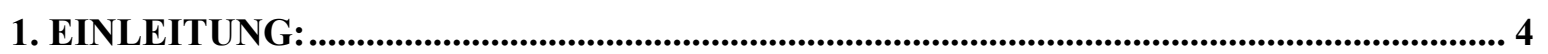

1.1. TRNA'S .......................................................................................................................... 4

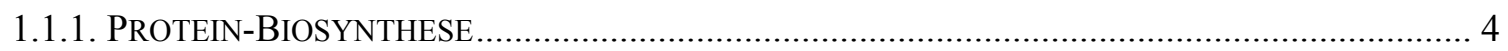

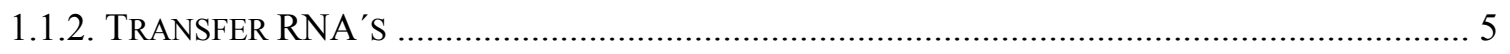

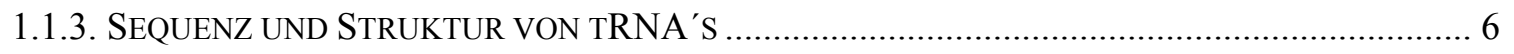

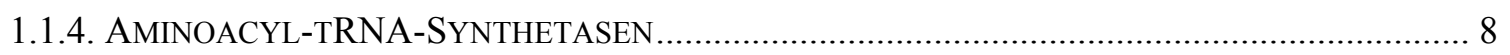

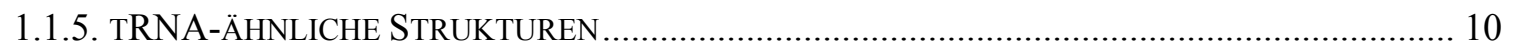

1.2. DAS RÜBEN-GELBMOSAIK-VIRUS (TYMV) ......................................................... 11

1.2.1. AUFBAU UND LEBENSZYKLUS ......................................................................... 11

1.2.2. TRNA-ÄHNLICHE STRUKTUR UND PSEUDOKNOTEN AM 3'-ENDE DES TYMV-GENOMS .. 15

1.3. AUFGABENSTELLUNG ................................................................................................... 20

2. MATERIAL UND METHODEN ................................................................................ 21

2.1. MATERIALIEN............................................................................................................. 21

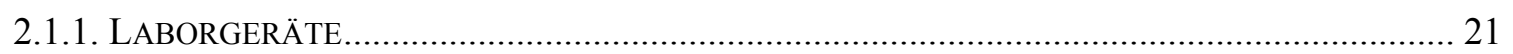

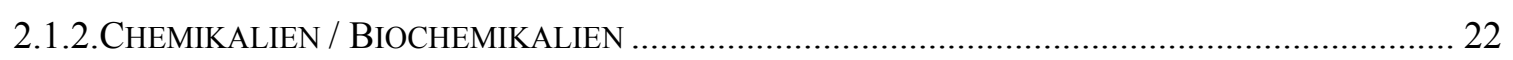

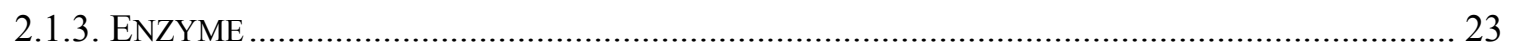

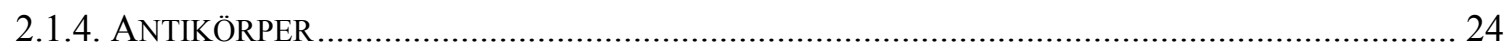

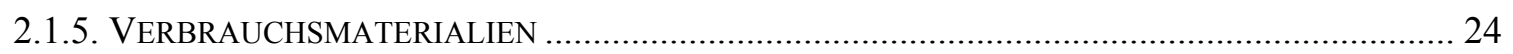

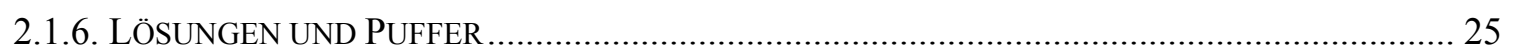

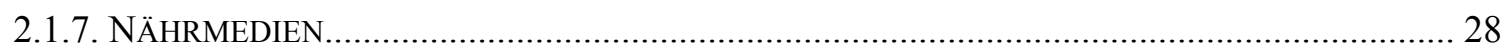

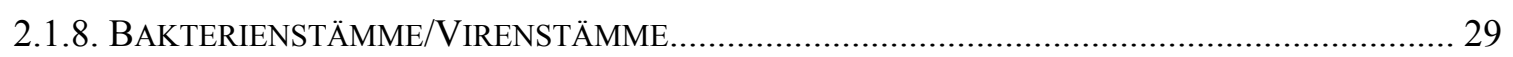

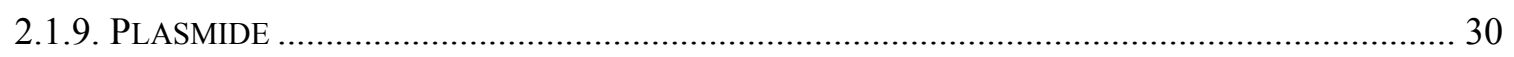

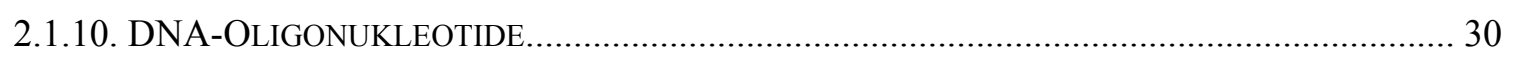

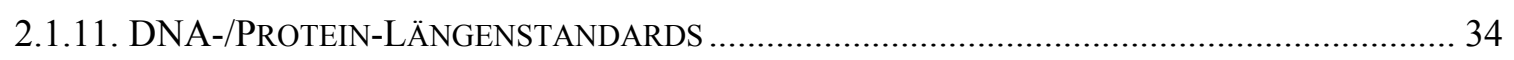

2.2. METHODEN ........................................................................................................................ 35

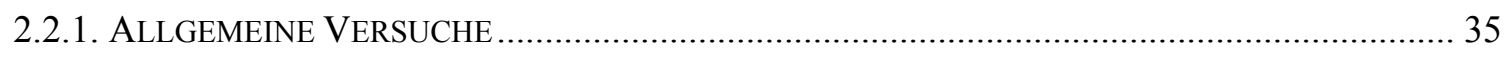

2.2.1.1. STERILISATION VON LÖSUNGEN UND MATERIAL ................................................ 35

2.2.1.2. KULTIVIERUNG VON BAKTERIEN (AGARPLATTEN) .............................................. 35

2.2.1.3. FLÜSSIGKULTUREN FÜR SEQUENZIERUNGEN ….................................................. 36

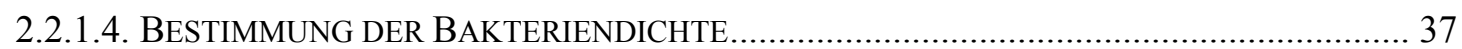

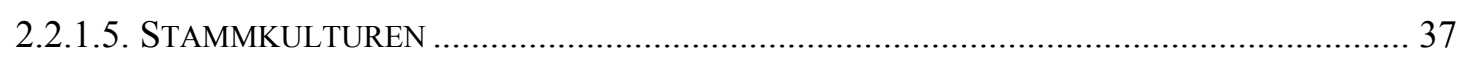

2.2.1.6. PLASMIDPRÄPARATIONEN (REINIGUNG VON NUKLEINSÄUREN) ............................. 37

2.2.1.7. PHENOLEXTRAKTION (REINIGUNG VON NUKLEINSÄUREN) .................................... 38

2.2.1.8. ETHANOLFÄLLUNG (REINIGUNG VON NUKLEINSÄUREN) ..................................... 38

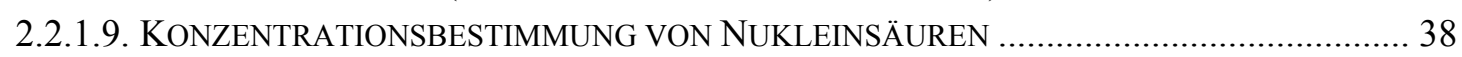

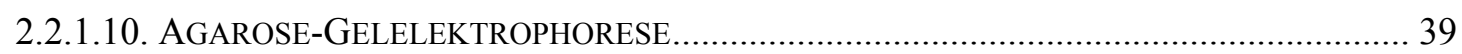

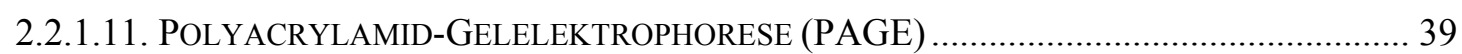

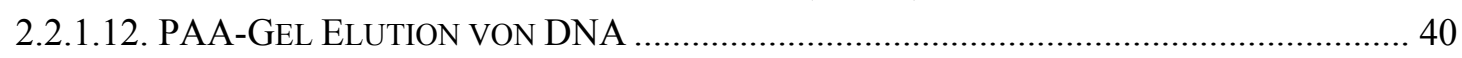

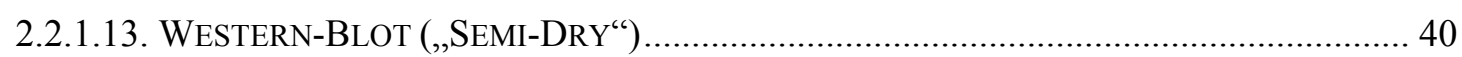

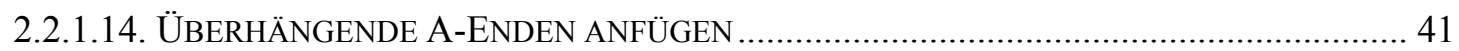

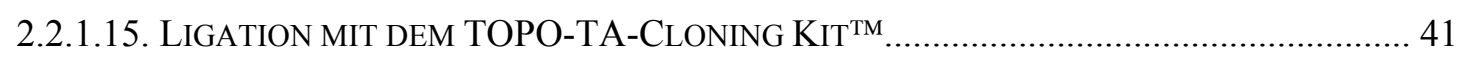

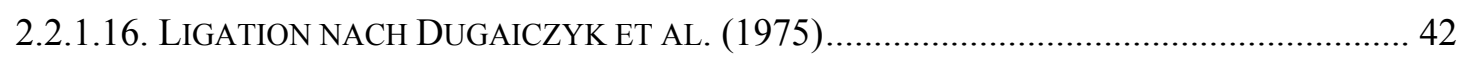

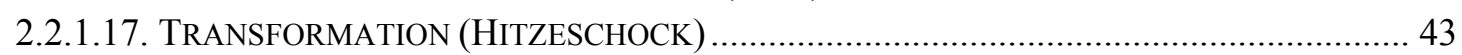




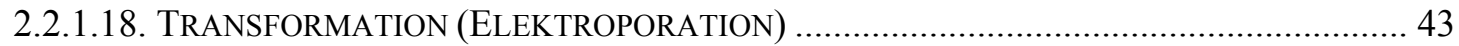

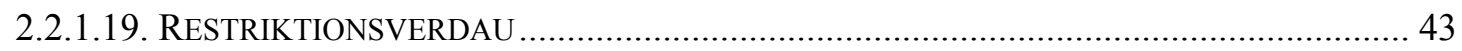

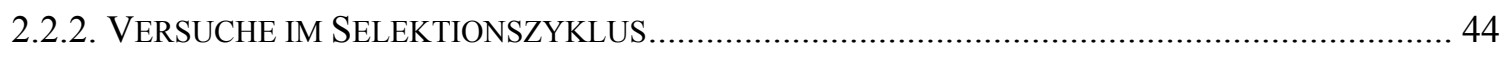

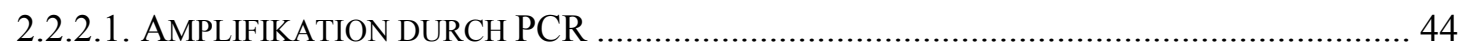

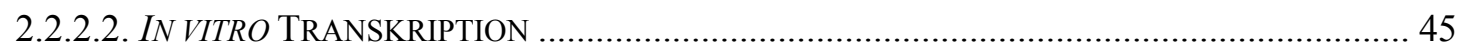

2.2.2.3. REINIGUNG VON RNA-TRANSKRIPTEN DURCH HPLC-GELFILTRATION....................... 46

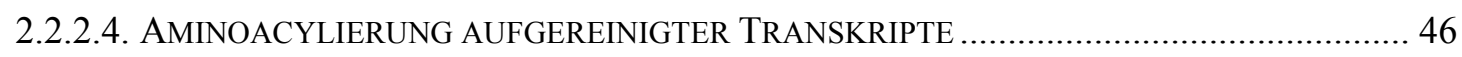

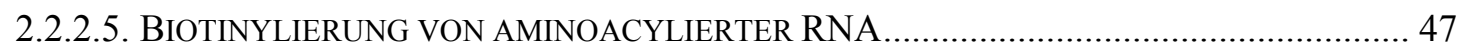

2.2.2.6. IMMOBILISIERUNG AUF DYNABEADS M-280 STREPTAVIDIN ...................................... 47

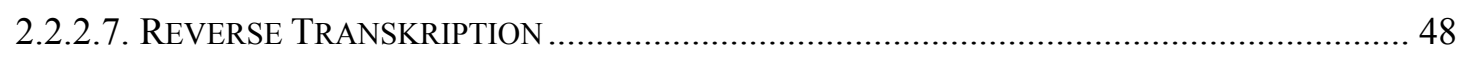

2.2.2.8. MESSUNG VON AMINOACYLIERUNGS-PLATEAUS ....................................................... 48

2.2.3. VERSUCHE ZUR IN VITRO REPLIKATION VON TYMV-VARIANTEN..................................... 49

2.2.3.1. IN VITRO (-)-STRANG-SYNTHESE VON TYMV-RNA DURCH VIRUSEIGENE RNA-

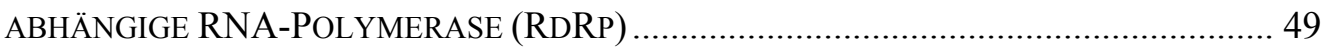

2.2.3.2. AUFNAHME DES ZEITLICHEN VERLAUFS VON AMINOACYLIERUNG UND (-)-STRANG-

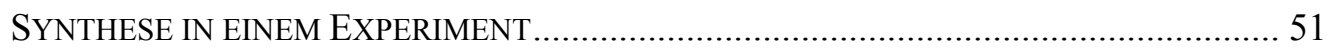

2.2.4. VERSUCHE ZUR IN VIVO REPLIKATION VON TYMV-VARIANTEN ..................................... 52

2.2.4.1. IN VITRO TRANSKRIPTION VON TYMV-TLS-VARIANTEN IM GESAMT-GENOMKONTEXT ZUR TRANSFEKTION VON PFLANZENZELLEN ......................................... 52

2.2.4.2. UNTERHALT EINER FLÜSSIG-ZELL-KULTUR DER ACKERSCHMALWAND (ARABIDOPSIS

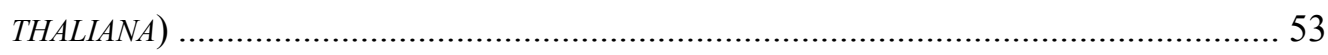

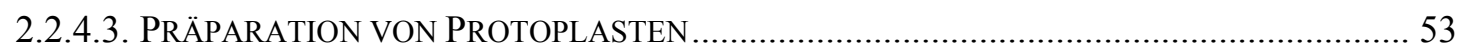

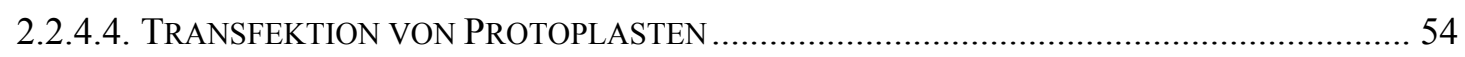

2.2.4.5. ISOLIERUNG VON TYMV AUS TRANSFIZIERTEN ARABIDOPSIS-PROTOPLASTEN ........ 54

2.2.4.6. WACHSTUMSBEDINGUNGEN FÜR CHINAKOHL-PFLANZEN (BRASSICA PEKINENSIS) ... 55

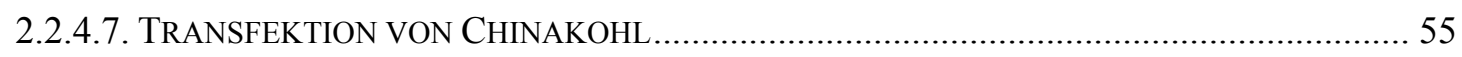

2.2.4.8. TYMV-ISOLIERUNG NACH DUNN UND HITCHBORN (1965)...................................... 55

2.2.4.9. PRÄPARATION VON VIRUSEIGENER RNA-ABHÄNGIGER RNA-POLYMERASE AUS INFIZIERTEN CHINAKOHL-PFLANZEN (BRASSICA PEKINENSIS) ............................... 57

3. ERGEBNISSE .................................................................................................................................................. 59

3.1. SELEKTION FUNKTIONALER VARIANTEN DER TRNA-ÄHNLICHEN STRUKTUR DES

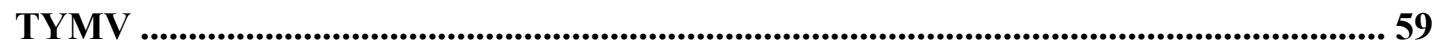

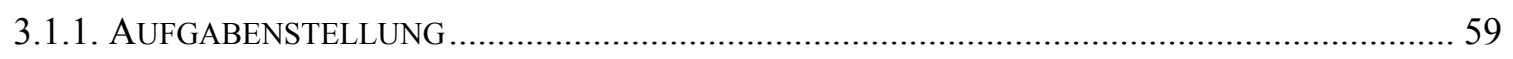

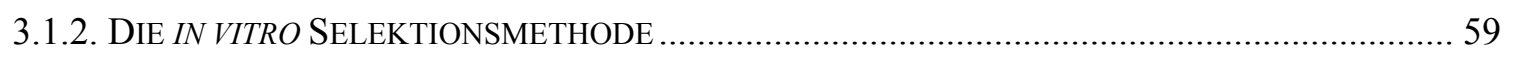

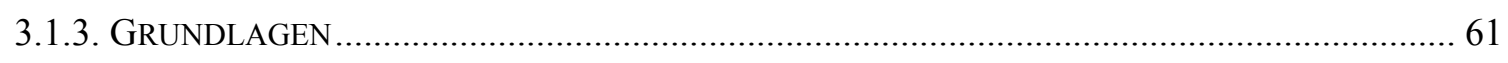

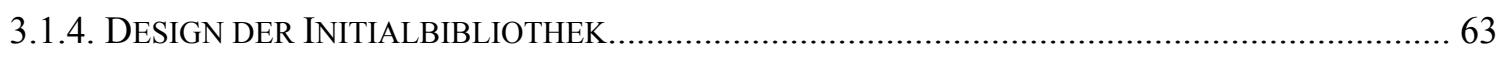

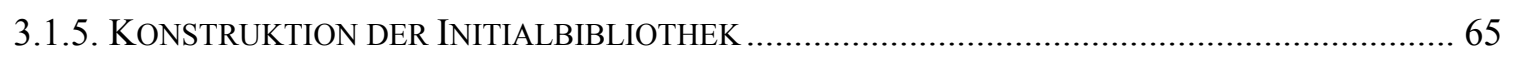

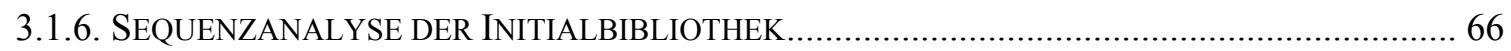

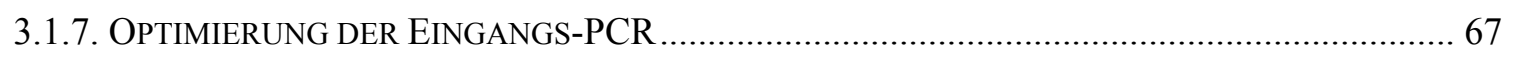

3.1.8. IN VITRO SELEKTIONSRUNDEN DER BIBLIOTHEK/OPTIMIERUNGEN DER BEDINGUNGEN ... 68

3.1.9. ANALYSE DER AMINOACYLIERUNGSAKTIVITÄT DER BIBLIOTHEK ................................... 72

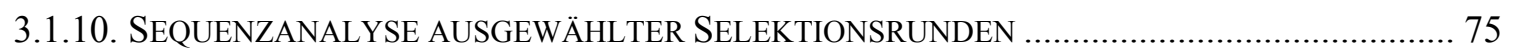

3.2. VERSUCHE ZUR IN VITRO REPLIKATION DES TYMV ...................................................... 78

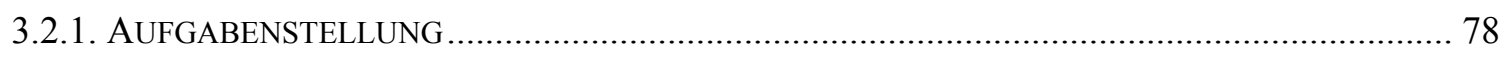

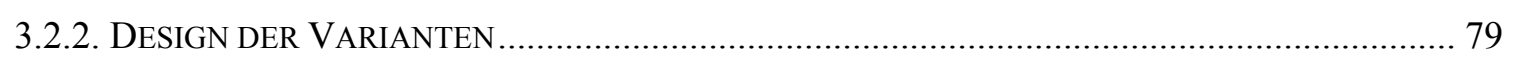




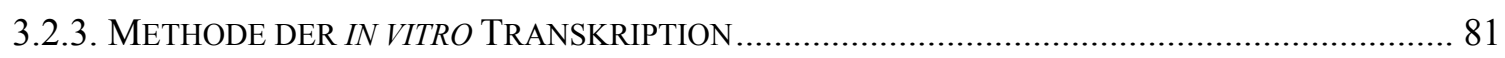

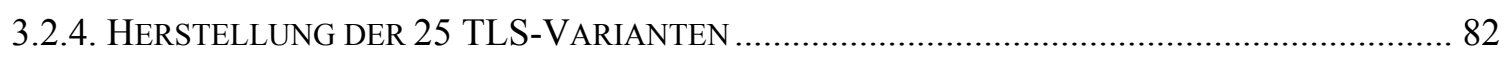

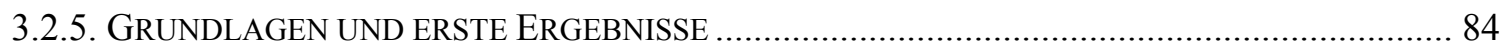

3.2.6. ERGEBNISSE DER IN VITRO (-)-STRANG-SYNTHESEN MIT/OHNE VALYLIERUNG UND

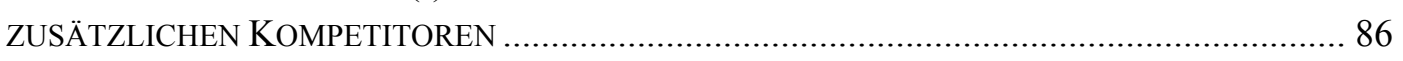

3.3. EXPERIMENTE ZUR IN VIVO AMPLIFIKATION VON TYMV-TLS-VARIANTEN .................96

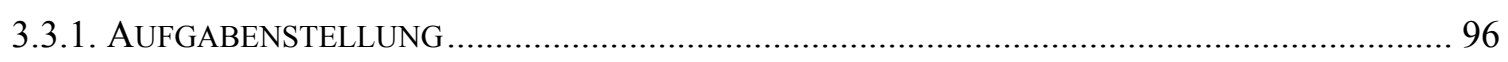

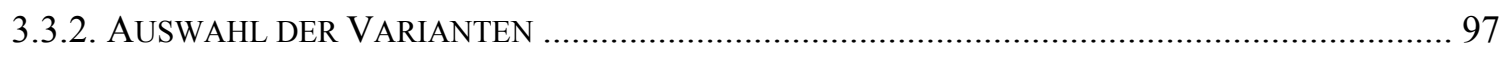

3.3.3. HERSTELLUNG VON 4 TLS-VARIANTEN IM GESAMT-GENOM-KONTEXT ............................ 98

3.3.4. ERGEBNISSE DER TRANSFEKTION/INFEKTION VON BRASSICA PEKINENSIS MIT TYMV-

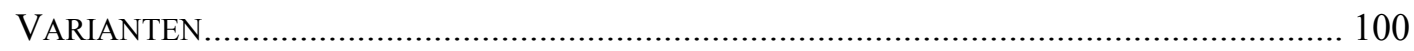

3.3.5. IN VIVO EXPERIMENTE MIT ARABIDOPSIS THALIANA-FLÜSSIGKULTUREN............................ 104

3.3.6. PRÄPARATION VON VIRALER RNA-ABHÄNGIGER RNA-POLYMERASE AUS

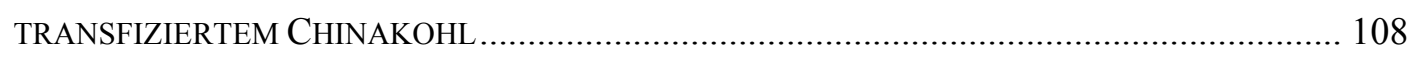

3.4. MESSUNG DER KINETISCHEN PARAMETER DER VALYLIERUNG EINZELNER TYMV-TLS-

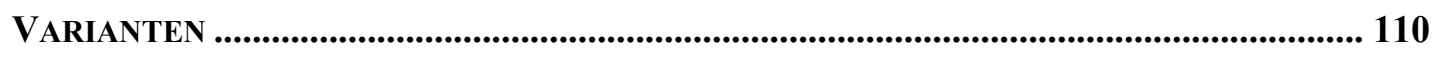

4. DISKUSSION .............................................................................................................................................. 115

4.1. IN VITRO SELEKTION DER BIBLIOTHEK LIB D ................................................................ 115

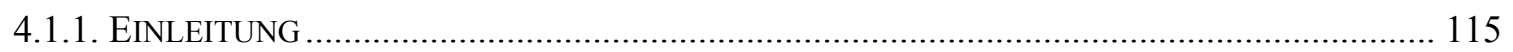

4.1.2. DIE IN VITRO SELEKTIONSMETHODE ……................................................................ 115

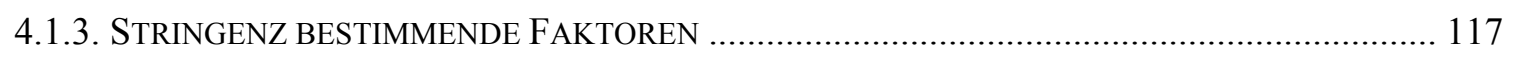

4.1.4. VERLAUF DES EXPERIMENTES / ENTWICKLUNG DER VALYLIERUNGSPLATEAUS............. 118

4.1.5. INITIALBIBLIOTHEK UND SELEKTIERTE VARIANTEN ......................................................

4.2. EXPERIMENTE ZUR IN VITRO REPLIKATION............................................................. 122

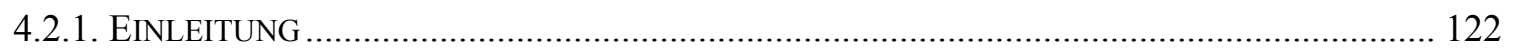

4.2.2. DIE METHODE DER IN VITRO (-)-STRANG SYNTHESE ..................................................... 123

4.2.3. VERGLEICHENDE IN VITRO (-)-STRANG SYNTHESE DER 25 TYMV-TLS-VARIANTEN...... 124

4.3. AMPLIFIKATION VON TYMV-TLS-VARIANTEN IN PFLANZENZELLEN ........................... 129

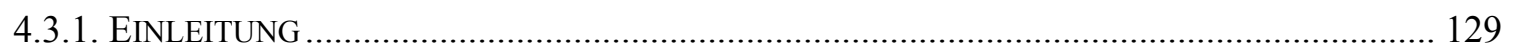

4.3.2. METHODEN DER TRANSFEKTION VON PFLANZENZELLEN..........................................................

4.3.3. TRANSFEKTION/INFEKTION VON BRASSICA PEKINENSIS UND ARABIDOPSIS THALIANA-

PROTOPLASTEN DURCH 4 AUSGEWÄHLTE TYMV-TLS-VARIANTEN ............................... 132

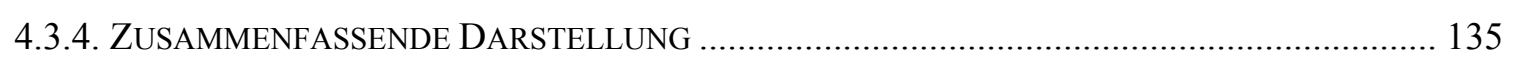

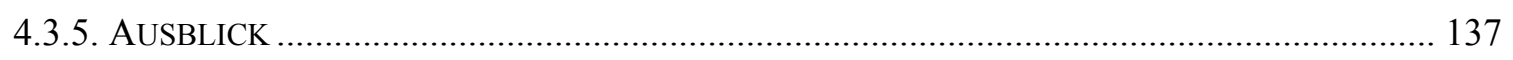

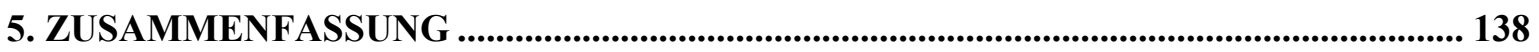

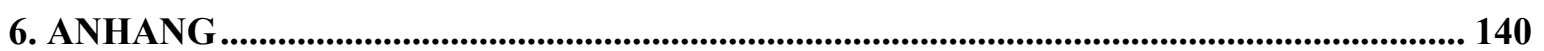

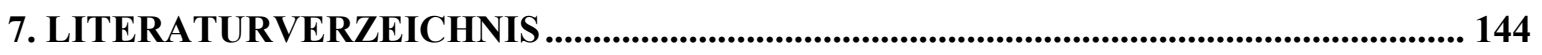

8. DANKSAGUNGEN ................................................................................................................................. 164

9. LISTE DER VERÖFFENTLICHUNGEN UND VORTRÄGE........................................ 165

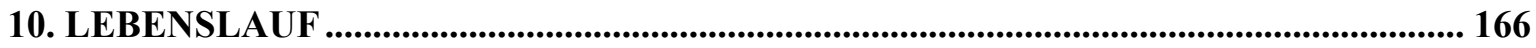




\section{Einleitung:}

\section{1. tRNA's}

\subsubsection{Protein-Biosynthese}

Die Protein-Biosynthese ist eine der zentralen biochemischen Abläufe in der belebten Natur. In ihr wird Information über die Aminosäure-Sequenz von Proteinen von sogenannter Boten- oder Messenger-Ribonukleinsäure (mRNA) in eine Polypeptid-Kette übersetzt. Im Allgemeinen ist die Information der mRNA wiederum ursprünglich durch Desoxyribonukleinsäure (DNA) festgeschrieben. Die Abfolge der vier Basen Adenin, Guanin, Cytosin und Thymin in DNA (und RNA mit Uracil statt Thymin) ist dabei entscheidend. Ribonukleinsäuren (RNA's) spielen in der Protein-Biosynthese als Überträgermoleküle eine wichtige Rolle:

Im ersten Schritt, der Transkription, werden informationstragende Abschnitte der DNA (Gene) durch DNA-abhängige RNA-Polymerasen abgelesen und in RNA-Moleküle überführt.

Bei Prokarionten sind diese „Messenger“-RNA's (mRNA's) oftmals aus codierenden (informationstragenden) und nicht codierenden Bereichen zusammengesetzt, d.h. sie sind polycistronisch aufgebaut. In höheren Organismen sind mRNA's häufig monocistronisch und werden posttranskriptional modifiziert. Z.B. kann am 3'-Ende polyadenyliert werden, das 5'-Ende kann durch eine Cap-Struktur verändert sein, die RNA's können durch „Splicen“ (Ausschneiden nicht codierender Sequenzbereiche) oder „Editing“ (Austausch oder Insertion von einzelnen bis wenigen Nukleotiden) in Sequenz oder Länge verändert werden.

Im zweiten Schritt, der Translation, werden diese „reifen“ (modifizierten) mRNA's durch ein Ribosom erkannt und ihr Informationsgehalt ausgelesen, d.h. in Aminosäureketten umgeschrieben. Dies geschieht mit Hilfe von Adaptermolekülen, den Transfer-RNA's (tRNA). Diese werden spezifisch von Aminoacyl-tRNA-Synthetasen mit Aminosäuren beladen (siehe Punkt 1.1.4.). Nach der Initiation der Translation, bei der, außer dem Ribosom und der mRNA, Initiationsfaktoren (IF-1,2 und 3), GTP und fMet-tRNA $\mathrm{f}_{\mathrm{fet}}$ beteiligt sind, erfolgt in der Elongation die eigentliche Peptidsynthese. In Prokaryontenzellen bildet der Elongationsfaktor-Tu mit GTP und einer Aminoacyl-tRNA einen ternären Komplex, der dann an die A-Bindestelle des Ribosoms binden kann. Spaltung von GTP zu GDP und anschließende Konformationsänderung entläßt EFTu•GDP. Die Regeneration zu EF-Tu•GTP findet durch den Elongationsfaktor-Ts statt. Die spezifische Bindung der Aminoacyl-tRNA in der A-Bindestelle des Ribosoms erfolgt durch Interaktion von Basen-Tripletts (Codon) auf der mRNA mit dem komplementären Anticodon auf der tRNA. Von der peptidtragenden tRNA in der P-Bindestelle des 
Ribosoms wird nun die Aminosäurekette durch eine Peptidyltransferaseaktivität des Ribosoms auf die Aminosäure der tRNA in der A-Bindestelle übertragen. Das Voranschreiten des Ribosoms auf der mRNA findet mittels EF-G•GTP statt, welches dem Komplex EF-Tu•GTP•Aminoacyl-tRNA strukturell stark ähnelt. EF-G•GTP verdrängt dabei vermutlich die Peptidyl-tRNA aus der A- in die P-Bindestelle Die Termination findet an den Tripletts UAG, UAA und UGA statt. Sie werden durch die Freisetzungsfaktoren (,Release-Factor") RF-1 und 2 erkannt und bewirken zusammen mit RF-3 die Übertragung der Aminosäurekette auf $\mathrm{H}_{2} \mathrm{O}$ (Hydrolyse) und das Abdissoziieren der beiden Untereinheiten des Ribosoms von der mRNA.

Diese Darstellung soll verdeutlichen, daß für eine effektive Translation tRNA's mit einer Vielzahl von Proteinen interagieren müssen. Sie müssen allgemeine Merkmale z.B. für die Interaktion mit EF-Tu und dem Ribosom besitzen, gleichzeitig müssen sie aber auch spezifisch aminoacylierbar sein, um Fehlbeladung und darauf folgenden Falscheinbau einer Aminosäure in das Protein zu verhindern (Chapeville et al., 1962).

Außerdem muß eine korrekt beladene tRNA mittels Anticodon spezifisch mit dem jeweils komplementären Codon im richtigen Leserahmen wechselwirken.

\subsubsection{Transfer RNA's}

Francis Crick stellte als Erster die Vermutung auf, daß es ein Adapter-Molekül geben müßte, welches zwischen DNA-Information und Protein-Sequenz steht (Crick, 1955). Die erste tRNA wurde dann 1958 auch auf experimentellem Wege gefunden (Hoagland et al., 1958).

In ihrer wichtigen Rolle in der Biochemie der Zelle müssen tRNA's mit vielen verschiedenen Proteinen/Enzymen interagieren. Z.B. müssen Vorläufer-tRNA's, die häufig zu mehreren auf ein und demselben Transkript versammelt sind, ausgeschnitten werden (Nakajima et al., 1981). Dies geschieht am 5'-Ende durch RNaseP. Das 3'-Ende wird durch RNaseD bis zur CCA-Sequenz verkürzt. Zu kurz synthetisierte Moleküle werden durch (ATP:CTP)-Nukleotidyl-Transferasen mit einem korrekten 3`-CCA-Ende versehen. Für die Protein-Biosynthese muß tRNA außerdem mit der zugehörigen Aminosäure beladen werden, dazu muß sie spezifisch mit einer Aminoacyl-tRNA-Synthetase interagieren. Die nachfolgende stabile Erkennung der beladenen RNA durch das Ribosom ist nur möglich bei vorheriger Bindung von EF-Tu in Prokaryonten, bzw. von eEF1A (vormals EF-1 $\alpha$ ) in höheren Organismen. Transfer RNA's müssen zusätzlich mit mehreren Untereinheiten des Ribosoms interagieren können. Alle diese Kontakte werden im Wesentlichen durch Wasserstoffbrücken, ionische Bindungen und Van der WaalsWechselwirkungen vermittelt, die je nach Interaktionspartner an unterschiedlichen Positionen zustande kommen können. 
Um derartig verschiedene und komplexe Bindungen eingehen $\mathrm{zu}$ können, stellt die Sequenz und Struktur von tRNA's vermutlich einen Kompromiß bezüglich all dieser Anforderungen (oder Funktionen) dar. Das heißt, daß jeder Interaktionspartner hinreichend gut, aber nicht optimal gebunden wird.

Mit der Struktur von tRNA's beschäftigt sich der folgende Punkt.

\subsubsection{Sequenz und Struktur von tRNA's}

Die Sequenz (Primärstruktur) bisher bekannter tRNA's besteht aus 74 bis 93 Ribonukleotiden. Alle diese tRNA's besitzen ein ungepaartes NCCA-3'-Ende, wobei das „N“ für die Diskriminatorbase steht, die für die spezifische Aminoacylierung wichtig ist (Crothers et al., 1972). Kanonische tRNA's (nach den am weitesten verbreiteten Grundprinzipien aufgebaut) zeigen 15 konservierte und 8 semi-konservierte Nukleotide (nur Pyrimidine oder Purine; Abb.: 1, A). Diese sind zumeist an der dreidimensionalen Stabilisierung des Moleküls beteiligt.

A

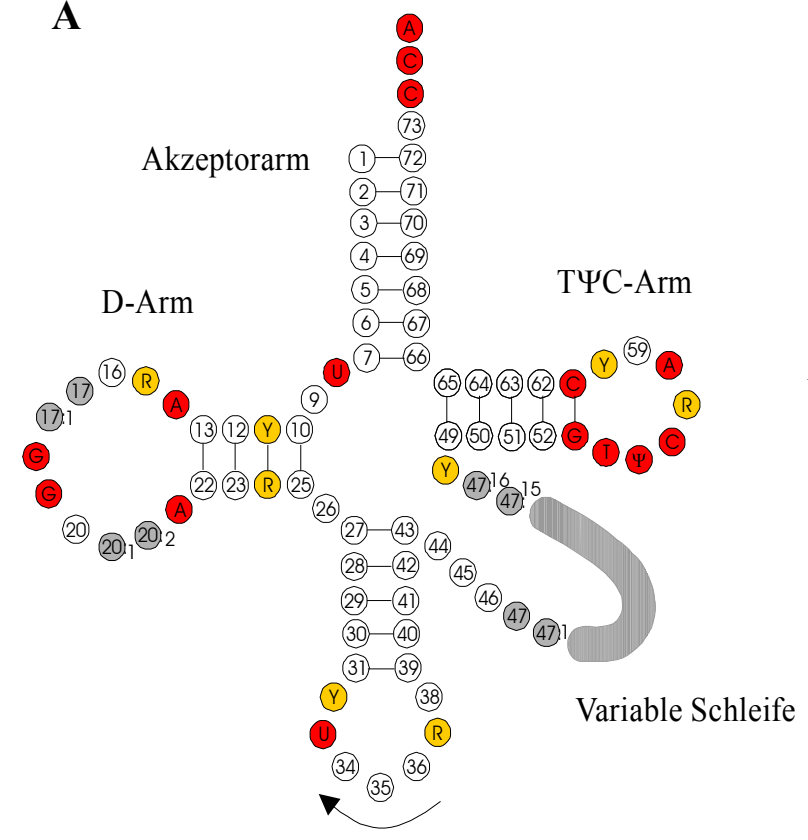

B

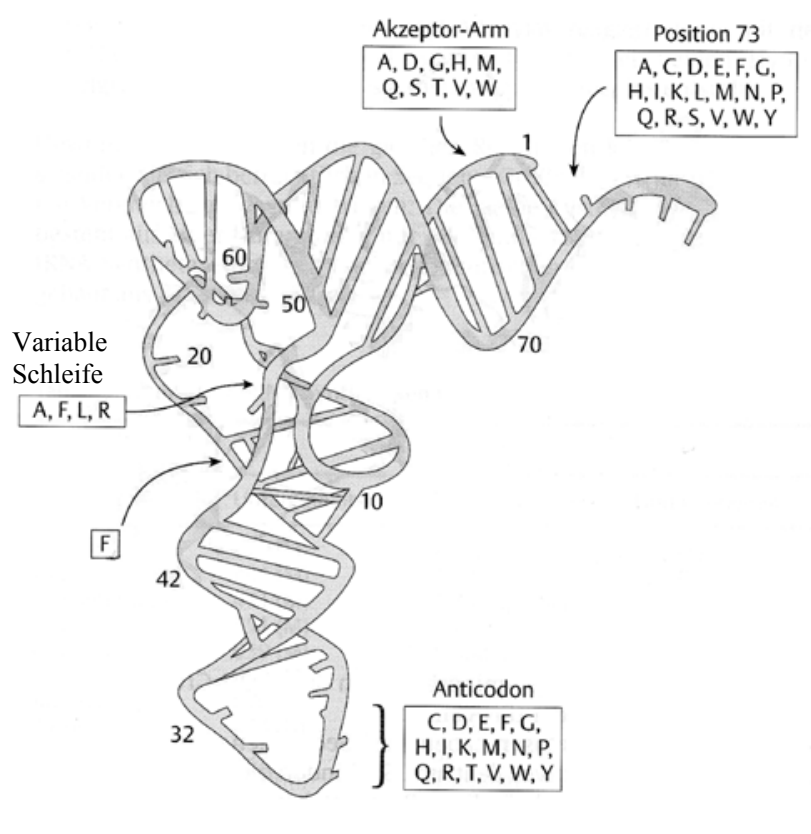

Abb.: 1,

A) Kanonische Kleeblattstruktur von tRNA's. In rot sind Positionen konservierter, in gelb semikonservierter Basen angegeben. Positionen ohne Konservierung sind weiß, solche, die nicht in jeder tRNA-Variante auftreten, sind grau dargestellt.

B) 3-dimensionale L-Struktur von tRNA`s. Die Erkennungsregionen verschieden spezifischer AminoacyltRNA-Synthetasen (stellvertretend ist die jeweils übertragene Aminosäure im Ein-Buchstabencode angegeben) sind durch die Pfeile markiert (modifiziert nach Saks M. et al., 1994). 
Einige der Basen im RNA-Molekül werden zusätzlich posttranskriptional modifiziert (Björk et al., 1987; Limbach et al., 1994). Ein Ribothymidin und Pseudouridin in der TSchleife und ein Dihydrouridin in der D-Schleife gehören zu den konservierten Basen. Diese Modifikationen können für die Tertiär-Struktur (Hall et al., 1989; Helm et al., 1998), als Anti-Determinante in der Aminoacylierung (Giegé et al., 1993b; McClain, 1993a; McClain, 1993b; Pütz et al., 1994; Saks et al., 1994) und in der Stabilisierung der CodonAnticodon Wechselwirkung (Adamiak and Gornicki, 1985; Yokohama and Nishimura, 1995) eine Rolle spielen.

Zur Sekundärstruktur der tRNA gehört die Ausbildung von Helices und Schleifen. Diese Strukturen kommen durch das auf sich Zurückfalten der Einzelstrang-RNA auf sich selbst zustande. Wasserstoffbrückenbindungen zwischen verschiedenen Basen führen so zur sogenannten Kleeblattstruktur (Abb.: 1, A). Sie besteht aus Akzeptorarm, D-Arm (D steht

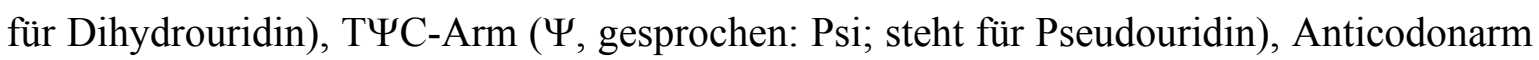
und der variablen Schleife. Die unterschiedliche Länge dieser Schleife bei verschiedenen tRNA's ermöglicht die Einteilung in zwei Klassen. Klasse I (ca.75\% aller tRNA's) besteht aus tRNA's mit kurzen variablen Schleifen von 3-5 Nukleotiden, Klasse II (ca.25\%) besitzt variable Schleifen von 13-21 Nukleotiden und es können bis zu 5 Basenpaarungen bei ihnen auftreten (Lewin, 1998).

Die Tertiärstruktur von tRNA's beschreibt die Faltung des Moleküls im 3-dimensionalen Raum (Abb.: 1, B). Wichtige Elemente sind vor allem konservierte und semi-konservierte Nukleotide, wie man durch Röntgenstrukturaufnahmen oder NMR-Messungen von verschiedenen tRNA's gefunden hat, z.B.: (Kim et al., 1974; Robertus et al., 1974; Stout et al., 1978; Woo et al., 1980; Westhof et al., 1985; Rould et al., 1989; Cusack et al., 1996; Cusack et al., 1998). Es handelt sich dabei meist um Wasserstoffbrückenbindungen zwischen zwei oder drei Nukleotiden des RNA-Moleküls. Zusätzlich stapelt die Helix des T-Arms auf die des Akzeptorarmes und die Helix des D-Armes stapelt auf die des Anticodonarms. Dadurch entsteht die charakteristische L-Struktur (Abb.: 1, B). Der Winkel zwischen den beiden Armen des umgekehrten „L“ beträgt bei den bekannten tRNA's zwischen 90 und $100^{\circ}$. Der Abstand des aminoacylierbaren 3'-CCA-Endes und dem Anticodon beträgt so 75 bis $80 \AA$.

Zur 3-dimensionalen Struktur können u.a. auch postranskriptional modifizierte Basen innerhalb der tRNA direkt (Ermöglichen neuer Wechselwirkungen) oder indirekt (Verhinderung von Wechselwirkungen) beitragen (Yokoyama et al., 1987; Hall et al., 1989; Perret et al., 1992; Derrick and Horowitz, 1993; Helm et al., 1998). Für tRNA's wurden bereits viele verschiedene Modifikationen an verschiedenen Positionen innerhalb des Moleküls beschrieben (Björk et al., 1987; Limbach et al., 1994; Grosjean et al., 1995; Limbach et al., 1995; Sprinzl et al., 1998). Einige dieser modifizierten Basen sind vielen tRNA's gemeinsam, z.B. das $\Psi_{55}$ (Pseudouridin) in der T-Schleife und das namensgebende Dihydrouridin der D-Schleife. 
Modifizierte Basen an den Positionen 34 und 37 können auch die Wechselwirkungen vom Codon der mRNA und dem Anticodon der tRNA in Anwesenheit des Ribosoms stabilisieren (Adamiak and Gornicki, 1985; Björk, 1992; Yokohama and Nishimura, 1995). Sie können aber auch bewirken, daß die Spezifität der Aminoacylierungsreaktion gesteigert wird, indem sie als sogenannte Antideterminante die Bindungsfähigkeit an eine Aminoacyl-tRNA-Synthetase verringert, die eine, der tRNA nicht zugehörige, Aminosäure überträgt (Pütz et al., 1994).

\subsubsection{Aminoacyl-tRNA-Synthetasen}

Aminoacyl-tRNA-Synthetasen (aaRS) katalysieren die spezifische Veresterung ihrer zugehörigen tRNA's (Isoakzeptoren) mit der entsprechenden Aminosäure. Dabei wird jede der 20 Aminosäuren durch (mindestens) eine ,eigene“ Synthetase erkannt, die strukturell dabei sehr unterschiedlich sein können (Schimmel, 1987; Lapointe and Giegé, 1991; Arnez and Moras, 1997). Da der genetische Code degeneriert ist, also mehrere Basentripletts (Codons) einer mRNA für dieselbe Aminosäure codieren können, gibt es relativ häufig mehrere tRNA's mit unterschiedlichen Anticodons, aber der gleichen Aminosäurespezifität. Diese tRNA's werden Isoakzeptoren genannt. Die Regionen der tRNA's, in denen die jeweils spezifischen Erkennungsmerkmale von den Synthetasen erkannt werden, sind in Abbildung 1B dargestellt.

Damit Aminoacyl-tRNA-Synthetasen ihre Isoakzeptor-tRNA's mit der Aminosäure beladen können, muß diese in einem ersten Schritt aktiviert werden (Abb.: 2). Dabei greift

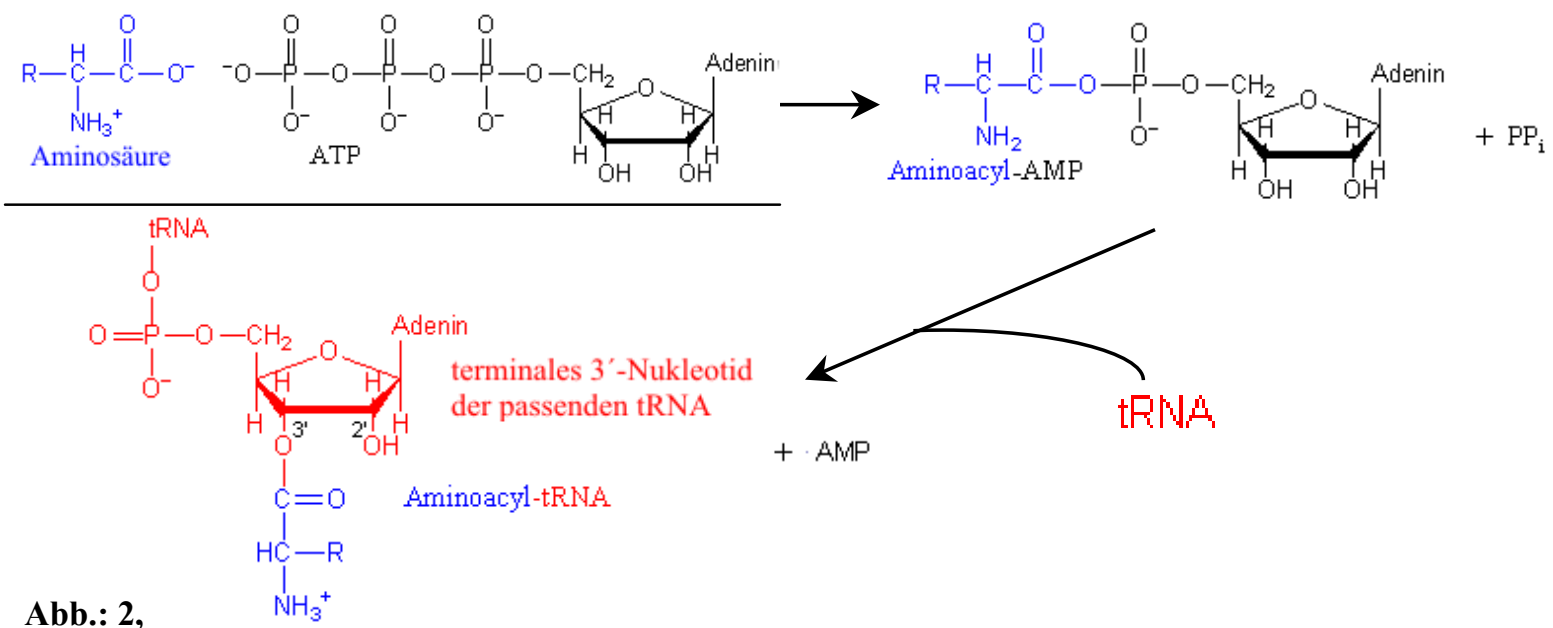

2-Schritt Reaktion der Aminoacylierung des 3'-terminalen Nukleotids von tRNA's katalysiert durch Aminoacyl-tRNA-Synthetasen. In einer ersten Reaktion wird die Aminosäure mittels ATP aktiviert. Anschließend reagiert die 3'- oder 2'-Hydroxylgruppe des 3'-terminalen Nukleotids der tRNA mit dem Aminoacyl-Adenylat. Am Ende ist die Aminoacyl-tRNA entstanden und AMP und Pyrophosphat sind Nebenprodukte der beiden Reaktionen. „R“ innerhalb der Aminosäure steht für die unterschiedlichen Seitenketten. 
in Anwesenheit von Magnesium-Ionen $\left(\mathrm{Mg}^{2+}\right)$ der Sauerstoff der $\alpha$-Carboxygruppe der Aminosäure nukleophil das in $\alpha$-Position liegende Phosphat des ATP an. Dadurch entsteht ein energiereiches Aminoacyl-Adenylat und anorganisches Pyrophosphat (PPi). Die energiereiche Bindung zwischen der Aminosäure und AMP kann nun (wieder unter Beteiligung von $\mathrm{Mg}^{2+}$ ) durch die 2'- oder 3'-Hydroxylgruppe der Ribose des 3'-terminalen Nukleotids der tRNA gelöst werden, indem der $\alpha$-Kohlenstoff des Aminoacyl-Restes angegriffen wird. Nach Freisetzung von AMP ist die tRNA mit der Aminosäure, je nach der katalysierenden Synthetase, an der 2'- oder 3'-Position der Ribose des endständigen Nukleotids verestert. Tatsächlich ist die Aminosäure als Orthoester-Intermediat zwischen der 2'- und 3'-Position gebunden. Es wurde berichtet, daß dieser Zustand im ternären Komplex der Aminoacyl-tRNA mit EF-Tu•GTP stabilisiert wird (Forster et al., 1994; Smith et al., 1995).

Die Spezifität dieser Reaktion wird z.T. durch die Struktur und innerhalb der tRNA gelegenen Determinanten (und Anti-Determinanten) gewährleistet (Giegé et al., 1993b; McClain, 1993a; Schmitt et al., 1993; Pütz et al., 1994; Saks et al., 1994). Jede Synthetase erkennt dabei ein eigenes Muster an ihren zugehörigen tRNA's. Insbesondere die Anticodon-Schleife, variable Schleife, Akzeptor-Helix und das Nukleotid der Position 73 sind in die Erkennung involviert (Abb.: 1, B) (de Duve, 1988).

Bei der Beladung von tRNA's können trotz der spezifischen und unspezifischen Wechselwirkungen zwischen RNA und Enzym Fehler auftreten. So wird z.B. von der Valyl-tRNA-Synthetase mit bis zu 1\% Häufigkeit Threonin auf das $3^{\prime}$-Ende der tRNA ${ }^{\text {Val }}$ übertragen. Um die Genauigkeit der Reaktion zu erhöhen, gibt es in vielen Synthetasen eine Pre-Transfer- (kinetisches Proofreading) und eine Post-Transfer-Korrektur (Editing oder chemisches Proofreading). Bei ersterer wird die fälschlicherweise aktivierte Aminosäure schneller wieder hydrolisiert, als sie auf die tRNA übertragen werden kann (Hopfield, 1974; Freist, 1989). Beim Editing wird die falsch mit der tRNA veresterte Aminosäure mittels einer speziellen „Editing Domäne“ (Schmidt and Schimmel, 1995; Fukai et al., 2000) wieder abgespalten, bevor die Aminoacyl-tRNA freigesetzt werden kann (Bonnet and Ebel, 1972; Jakubowski, 1993; Francklyn et al., 1997; Nureki et al., 1998). Dieses Editing ist bisher nur in einigen Synthetasen der Klasse I (ValRS, IleRS, LeuRS, MetRS) gefunden worden. Die Determinanten auf der RNA sind dabei von denen für die Aminoacylierungsreaktion verschieden (Hale et al., 1997).

Die Synthetasen lassen sich nach Struktur und funktionellen Eigenschaften in zwei Klassen unterteilen (Eriani et al., 1990). Die Enzyme der Klasse I (ValRS, ArgRS, CysRS, GlnRS, GluRS, IleRS, LeuRS, MetRS, TrpRS, TyrRS) liegen als Monomer vor (außer TyrRS und TrpRS, sie sind Dimere) und übertragen die Aminosäure auf das 2'-OH der Ribose des terminalen Adenosins der tRNA (Arnez and Moras, 1997). Sie erkennen das Ende des Akzeptor-Arms der tRNA von der kleinen Furche her (Rould et al., 1989). Dabei ist die Variable Schleife vom Enzym weg gerichtet (Abb.: 3, A). 
A

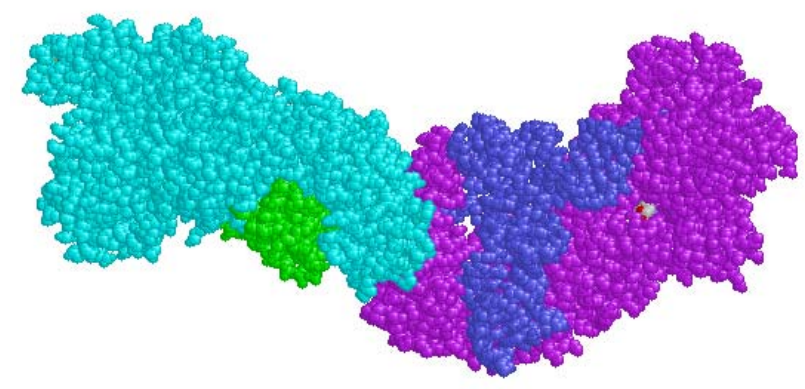

B

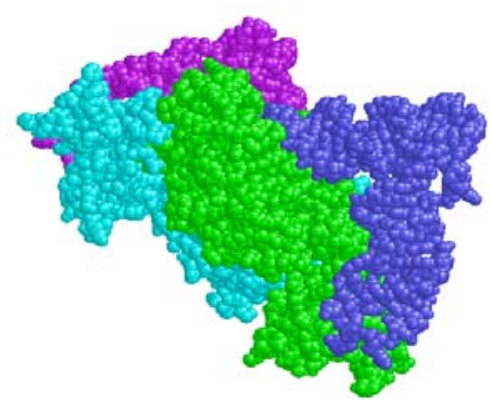

Abb.: 3,

Darstellung zweier Aminoacyl-tRNA-Synthetasen mit gebundenen tRNA's (dunkelblau). Die Strukturen wurden durch Röntgenkristallographie ermittelt.

A) Klasse I: Valyl-tRNA-Synthetase (Thermus thermophilus) im Komplex mit tRNA ${ }^{\text {Val }}$. Die RNA wird von der Seite der D-Schleife erkannt (Fukai et al., 2000).

B) Klasse II: Aspartyl-tRNA-Synthetase (Saccharomyces cerevisiae) im Komplex mit tRNA ${ }^{\text {Asp }}$. Die RNA wird von der entgegengesetzten Seite der Variablen Schleife her erkannt (Ruff et al., 1991).

Die Aminoacyl-tRNA-Synthetasen der Klasse II (HisRS, AlaRS, AspRS, GlyRS, LysRS, PheRS, ProRS, SerRS, ThrRS) sind Di- oder Tetramere und übertragen die jeweilige Aminosäure auf das 3'-OH des 3'-terminalen Nukleotids der tRNA (Sprinzl and Cramer, 1975; Hecht, 1979; Ruff et al., 1991). Nur PheRS koppelt die Aminosäure an das 2'-OH (Eriani et al., 1990). Diese Enzymklasse (II) erkennt, anders als die Enzyme der Klasse I, ihre tRNA's von der Seite der variablen Schleife und bildet Kontakte zur großen Furche des äußeren Endes des Akzeptor-Arms aus (Abb.: 3, B) (Ruff et al., 1991).

\subsection{5. tRNA-ähnliche Strukturen}

Neben den konventionellen Molekülen existieren tRNA's und tRNA-ähnliche Moleküle, die in Sequenz, Struktur und Funktion den bisher beschriebenen nicht genau entsprechen. In Mitochondrien zeigen tRNA's häufig strukturelle Abweichungen von der Konvention, die u.a. sogar die Deletion des gesamten D-Armes umfassen können (Arcari and Browlee, 1980; de Bruijn and Klug, 1983; Dirheimer et al., 1995).

Auch in einigen mRNA's kommen tRNA-ähnliche Strukturen vor. Die für die thrRS aus $E$. coli codierende mRNA etwa enthält eine tRNA ${ }^{\text {Thr }}$-ähnliche Struktur (Moine et al., 1988). Die Translation der mRNA wird durch das eigene Genprodukt in einem Rückkopplungsmechanismus reguliert.

In sogenannten tmRNA's (funktionell wie tRNA und mRNA in einem Molekül) werden die, einer tRNA nur noch am 3'-Terminus ähnlichen, 3'-terminalen Fragmente durch Synthetasen aminoacyliert (Muto et al., 1998). Die Aufgabe der tmRNA ist es nun, in der Elongation blockierte Ribosomen so zu binden, daß die Peptidkette auf ihre Aminosäure übertragen wird. Anschließend wird dann ein Decapeptid ansynthetisiert, das durch die 
tmRNA selbst codiert wird und als Abbausignal für das Protein dient (Keiler et al., 1996; Felden et al., 1997).

Außerdem können innerhalb von mRNA's tRNA-ähnliche Strukturen für die Regulation der Genexpression, z.B. von HisRS, ThrRS und MetRS aus Escherichia coli, wichtig sein (Ames et al., 1983; Springer et al., 1989; Dardel et al., 1990).

Kanonische tRNA's werden von Retroviren als Primer für die Initiation der reversen Transkription benutzt (und bei einigen mit verpackt). Beispielsweise verwendet das Avian Myeloblastosis Virus (AMV) tRNA ${ }^{\text {Trp }}$ (Flint, 1976), MMLV tRNA ${ }^{\text {Pro }}$ (Bishop, 1978) und das Human Immunodeficiency Virus (HIV) die tRNA ${ }^{\text {Lys }}$ (Barat et al., 1989).

Dagegen sind tRNA-ähnliche Strukturen Bestandteil des Genoms einiger Pflanzenviren, wie auch im Folgenden ausgeführt wird.

\subsection{Das Rüben-Gelbmosaik-Virus (TYMV)}

\subsubsection{Aufbau und Lebenszyklus}

Das Rüben-Gelbmosaik-Virus (Turnip Yellow Mosaic Virus, TYMV; Abb.: 4) wurde erstmals bereits 1949 von Markham und Smith beschrieben (Markham and Smith, 1949). Es gehört zur Familie der Tymoviren und ist wie Tobamo-, Bromo-, Cucumo-, Hordei- und Furoviren ein (+)-Strang RNA-Virus (Mans et al., 1991; Florentz and Giegé, 1995; Goodwin and Dreher, 1998).

Häufig durch Käfer übertragen, infiziert er Pflanzen der Familie Brassicaceae (Kreuzblütler), wie z.B. Brassica pekinensis (Chinakohl), Brassica napus (Raps) und Arabidopsis thaliana (Ackerschmalwand). Die infizierten Wirtspflanzen zeigen zuerst lokale Symptome an den Blättern, die erstmals mit dem Virus in Kontakt gekommen sind. Sie äußern sich in relativ wenigen gelben Flecken (Läsionen), deren Fläche, aber nicht Anzahl, während der Infektion zunimmt. Später entwickeln sich Läsionen und von den Blattnerven ausgehende gelbe Areale über die gesamte Pflanze (systemische Symptome). In einem späteren Stadium ist fast die gesamte Oberfläche der Blätter hellgrün bis gelb verfärbt und die Pflanze bleibt in ihrem Wachstum hinter dem von nicht infizierten zurück (Hirth and Givord, 1988).

Das Kapsid des Virus ist ein Ikosaeder (Abb.: 4) und besteht aus 180 sequenz-identischen Kopien des Hüllproteins mit einer Masse des Monomers von 20.133Da (Katouzian-Safadi and Berthet-Colominas, 1983; Canady et al., 1996). Das Hüllprotein kommt im Kapsid in drei verschiedenen Formen vor (A, B und C), die sich in Sekundär- und Tertiärstruktur leicht unterscheiden. Die Hülle des Virus wird dabei von Pentameren der A-Form (Abb.: 4, A, gelb) und Hexameren der B- und C-Form (Abb.: 4, A, oben, blau und grün) gebildet, 
A

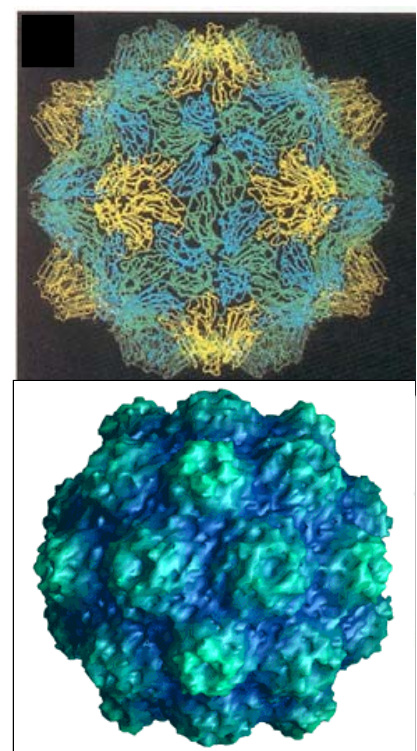

B

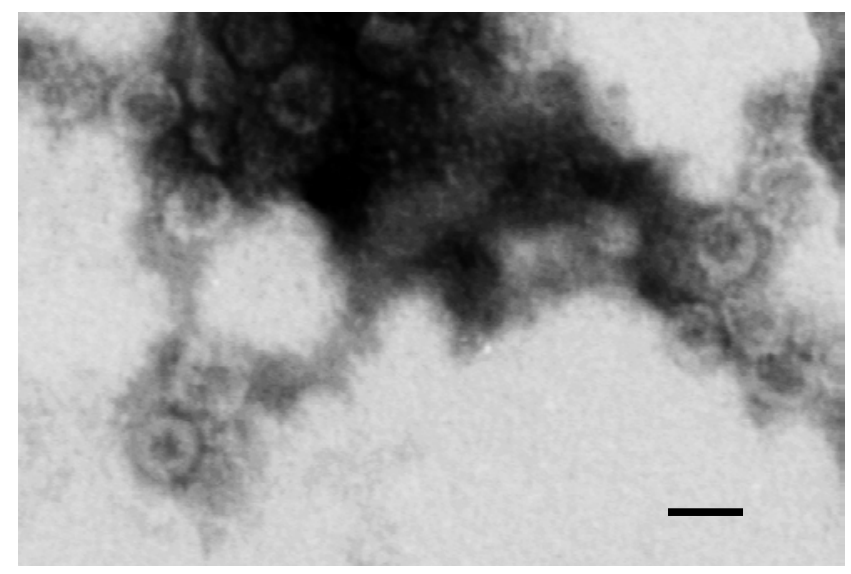

Abb.: 4,

Das Rüben-Gelbmosaik-Virus (TYMV).

A) Darstellung des Kapsids $\left(90^{\circ}\right.$ gedreht zueinander). Die Struktur wurde durch röntgenkristallographische

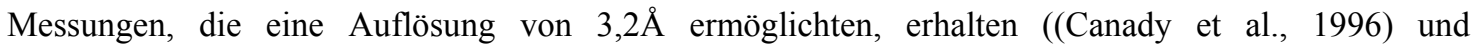
http://www.sdsc.edu/GatherScatter/Gssummer96/mcpherson.html)

B) Elektronenmikroskopische Aufnahme einer TYMV-Präparation. Es sind mehrere leere Kapside sichtbar. Der schwarze Balken entspricht ca. 30nm. Durchführung der EM-Abbildung von Prof. Mayer (Institut für Mikrobiologie und Genetik, Göttingen).

die jeweils einer Ausbuchtung an der Kapsidoberfläche entsprechen (Jacrot et al., 1977; Canady et al., 1996). Die Pentamere sind ca. $4 \AA$,höher““ als die Hexamere (Mellema and Amos, 1972; Canady et al., 1996).

Die RNA innerhalb des Kapsids ist vermutlich nur über wenige Histidine der Hülle und Polyamine (zumeist Spermidin mit bis $\mathrm{zu}$ 1\% des Virus-Gesamtgewichtes (Beer and Kosuge, 1970)) ,,befestigt““.

Polyamine sollen die negativen Ladungen der RNA neutralisieren und so die Verpackung aufrecht erhalten (Hirth and Givord, 1988), womit auch der gemessene geringe Kontakt der RNA zur Hülle erklärt wird (Jacrot et al., 1977; Canady et al., 1996).

Das Genom des TYMV umfaßt 6318nt einer einzelsträngigen RNA. Es gibt mehrere unterschiedliche Stämme des Virus, von denen der „Strasbourg“-Stamm (Europa) und der „Blue-Lake“-Stamm (Australien) die bekanntesten sind (Morch et al., 1988; Keese et al., 1989; Dreher and Bransom, 1992). Die genomische RNA ist besonders Cytosin-reich (ca. $40 \%$ ) und enthält dabei nur einen geringen Guanin-Anteil (ca. 17\%) (Morch et al., 1988). Es wurde vermutet und für die 5' nicht-translatierte Region (5'-UTR) auch gezeigt, daß dies zu ausgeprägten Sekundär- und Tertiärstrukturen führt (Hellendoorn et al., 1996), die für die Verpackung der RNA wichtig sind (Briand et al., 1975; Kaper, 1975; Jonard et al., 1976; Hartman et al., 1978; Hellendoorn et al., 1997). Neueste Forschungen zeigen sogar 
einen Einfluß der 5'-proximalen Haarnadelschleife der 5'-UTR in der Transkription und Translation (Bink et al., 2003).

Das Genom ist polycistronisch organisiert (Abb.: 5). Es besteht aus drei offenen Leserahmen (ORF1, 2, 3), von denen der 5'-proximale ORF ein sogenanntes ,silent gene“ ist. In Wirtszellen wird eine subgenomische RNA (693nt) synthetisiert, worüber dieses Gen dann exprimiert wird (Gargouri et al., 1989; Giegé et al., 1993a).

Die genomische RNA des TYMV besitzt, wie alle Tymo-, Furo-, Bromo- und Tobamoviren, eine Cap-Struktur am 5'-Ende und das 3'-Ende ist in eine tRNA-ähnliche Struktur (siehe Punkt 1.2.2.) gefaltet (Dreher, 1999; Fechter et al., 2001). Auch die subgenomische RNA des TYMV umfaßt eine Cap-Struktur und beinhaltet die TLS am 3'Ende (Pleij et al., 1976; Gargouri et al., 1989), die wie das Genom valyliert wird (Giegé et al., 1978).

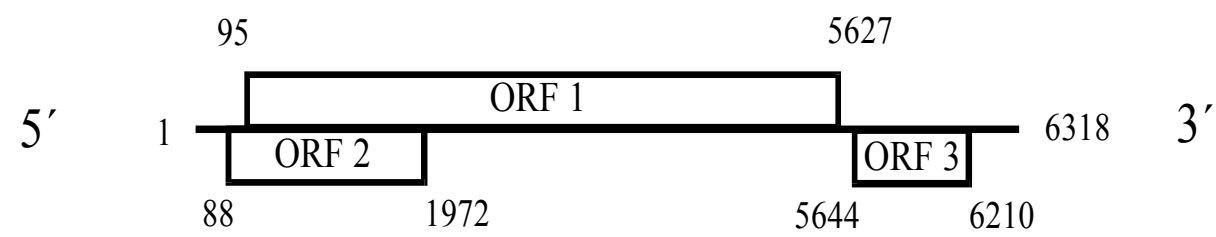

Abb.: 5,

Polycistronische Organisation des TYMV-Genoms. ORF1 codiert ein Polyprotein, das u.a. eine RNAabhängige RNA-Polymerase beinhaltet, ORF2 codiert ein Protein, daß für die Ausbreitung des Virus über die ganze Pflanze wichtig ist und ORF3 enthält die genetische Information für das Hüllprotein.

Das TYMV-Genom ist hoch organisiert, ca. 97\% von ihm codiert für ein Protein, während nicht-codierende Bereiche am 5'-Ende 87nt und am 3'-Ende 105nt umfassen (Morch et al., 1988; Hellendoorn et al., 1996).

Der ORF1 codiert für ein Polyprotein, dessen DNA-Sequenz konservierte funktionale Motive aufweist, die auf die Existenz einer RNA-Polymerase-, Proteinase-, Helikase- und Methyltransferase-Domäne im Protein schließen läßt (Koonin and Dolja, 1993; Rozanov et al., 1995). Die intrinsische Proteinase-Domäne schneidet in vitro das Polyprotein in ein Nterminales 140kDa- und ein C-terminales 66kDa-Fragment (Bransom et al., 1991; Kadaré et al., 1995; Bransom et al., 1996). Vom 66kDa-Fragment wird angenommen, daß es die RNA-abhängige RNA-Polymerase (RdRp) enthält (Koonin, 1991; Deiman et al., 1997b). Beide Fragmente des Polyproteins sind dabei für die Replikation des Virus wichtig (Weiland and Dreher, 1989). Die in vivo-Bestandteile der gesamten viralen Replikase (vom Virus und eventuell vom Wirt) sind dabei bis heute nicht bekannt.

ORF2 überlappt fast vollständig mit ORF1. Seine informationstragende Sequenz ist aber im Leserahmen verschoben und das Initiationscodon befindet sich 7nt näher zum 5'-Ende des Genoms (Bozarth et al., 1992). Das 69kDa Protein, das von ORF2 codiert wird, ist für die Ausbreitung des Virus in der Pflanze zwingend notwendig (Bozarth et al., 1992). 
ORF3 codiert für das 20kDa Hüllprotein (Pleij et al., 1976).

Trotz der langen Bekanntheit des TYMV konnte sein Lebenszyklus bisher nicht vollständig aufgeklärt werden. Im Folgenden sollen bekannte Tatsachen und begründete Vermutungen kurz dargestellt werden.

Das Virus wird durch Insekten auf eine Wirtspflanze übertragen und dringt dann vermutlich in eine gesunde Pflanzenzelle ein.

Die Entpackung hängt vermutlich vom $\mathrm{pH}$-Wert der Zelle ab. Es ist bekannt, daß Virionen empfindlich auf $\mathrm{pH}-$ Veränderungen reagieren. In zunehmend basischer Umgebung wird die Hülle instabiler (Virudachalam et al., 1985; Mutombo et al., 1993; Leimkuhler et al., 2001). Wahrscheinlich verlieren die Polyamine und Hüllproteine durch Protonierungen die Fähigkeit negative Ladungen der RNA ausreichend zu neutralisieren und die RNA ändert ihre Konformation und expandiert, so daß die Virushülle aufbricht (Kaper, 1975; Pleij et al., 1977; Katouzian-Safadi et al., 1985; Witz et al., 1993; Canady et al., 1996). Es wird angenommen, daß ein Pentamer (siehe Abb.: 4, A) verloren geht und die RNA durch das entstehende Loch entweicht (Keeling and Matthews, 1982; Katouzian-Safadi and BerthetColominas, 1983; Adrian et al., 1992; Canady et al., 1996).

Die genomische RNA ist über 9nt an beiden Enden komplementär zueinander (Morch et al., 1988) und könnte daher zeitweise ringförmig vorliegen und entginge so einer vorzeitigen Degradation. Die 3 '-terminale TLS (Punkt 1.2.2.) wird (in vitro) um ein Adenosin-Nukleotid verlängert, um ein vollständiges CCA-Ende zu erhalten (Litvak et al., 1973b) und kann dann valyliert werden (Pinck et al., 1970; Yot et al., 1970). Vermutlich wird dadurch die Expression des ORF1 (Polyprotein) gesteigert (Barends et al., 2003), wodurch die Replikation (indirekt durch die Valylierung (Tsai and Dreher, 1991)) effizienter wird.

Die Replikation findet in Chloroplasten statt (Lafleche and Bové, 1971), die virus-induziert (offenbar durch das 140kDa-Protein des ORF1 (Prod'homme et al., 2003)) zu einem sogenannten Polyplasten verklumpen (Renaudin et al., 1976; Matthews, 1991). Die äußeren Membranen der Chloroplasten werden, ebenfalls virus-induziert, zu kleinen peripheren Vesikeln (Abb.: 6) eingestülpt (Hatta et al., 1973; Hatta and Matthews, 1976). In ihnen sitzt die virale Replikase (Prod'homme et al., 2001) und dort wird (vermutlich virale) RNA synthetisiert (Garnier and Bové, 1976). Es gibt Hinweise, daß an der Öffnung der Vesikel die Virus-Partikel zusammengesetzt werden (Abb.: 6) (Hatta and Matthews, 1976).

Die Verpackung von TYMV-RNA soll dabei durch lichtabhängige pH-Erniedrigung im Chloroplasten ausgelöst werden (Rohozinski and Hancock, 1996). Eventuell werden bei niedrigem $\mathrm{pH}$ Poly-C's protoniert und bilden dann Tertiärstrukturen aus, die daraufhin mit Hüllproteinen interagieren und die Verpackung initiieren (Rohozinski and Hancock, 1996; Hellendoorn et al., 1997; Bink et al., 2003). 
A

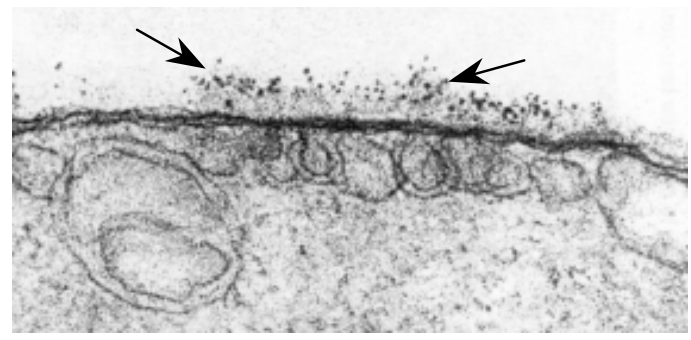

B

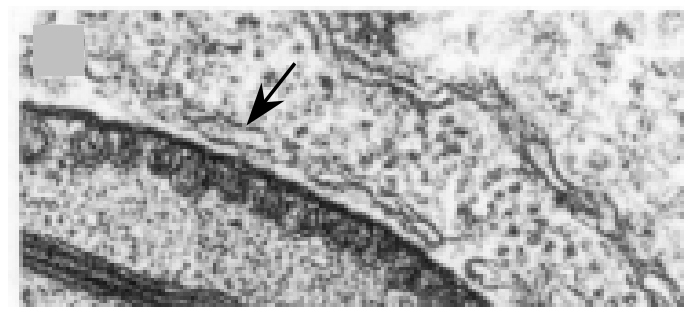

Abb.: 6,

Elektronenmikroskopische Aufnahmen der inneren und äußeren Membran der Chloroplasten aus TYMVinfizierten Pflanzenzellen (Chinakohl) (Hatta and Matthews, 1976). Deutlich sichtbar sind die virusinduzierten Vesikel (Einstülpungen der Membranen).

A) Die Pfeile deuten auf Chloroplasten-nahe Ferritin-markierte Antikörper, die virale HüllproteinMultimere binden.

B) Die Öffnungen der Vesikel liegen vermutlich häufig in der Nähe zum Endoplasmatischen Retikulum (Pfeil) der Zelle, durch das das Hüllprotein bereitgestellt werden könnte, um die Virus-RNA zu verpacken.

\subsection{2. tRNA-ähnliche Struktur und Pseudoknoten am 3'-Ende des TYMV-Genoms}

Breits vor fast 40 Jahren gab es erstmals Hinweise, daß es eine tRNA-ähnliche Struktur am 3'-Ende des Genoms von TYMV geben könnte (Beljanski, 1965).

Heute ist bekannt, daß das 3'-Ende vieler Pflanzenviren in eine sogenannte tRNA-ähnliche Struktur (TLS) faltet (Rietveld et al., 1982; Mans et al., 1991). Diese Struktur wird in vivo aminoacyliert, dabei wird die virale RNA innerhalb der gleichen taxonomischen Gruppe immer mit der gleichen Aminosäure beladen (eine Ausnahme ist der Cowpea Stamm des Tabak Mosaik Virus (CcTMV, ein Tobamovirus), der valyliert, statt histidinyliert wird (Beachy et al., 1976)). Tymoviren, wie TYMV (Joshi et al., 1978; Joshi et al., 1982b) oder das Kakao-Gelbmosaik-Virus (CYMV) (Pinck et al., 1972), werden valyliert. Tobamoviren, wie z.B. das Tabak Mosaik Virus (TMV) (Öberg and Philipson, 1972; Litvak et al., 1973a) werden histidinyliert und das Brome Mosaik Virus (BMV), wird wie alle Bromoviren, tyrosyliert (Hall et al., 1972; Loesch-Fries and Hall, 1982). Von zwei bekannten Cucumoviren wird eines ebenfalls tyrosyliert (Cucumber Mosaik Virus, CMV) (Kohl and Hall, 1974) und das Hordeivirus BSMV (Barley Stripe Mosaik Virus) besitzt die gleiche Spezifität in der Aminoacylierung (Agranovsky et al., 1981).

Die TLS des TYMV umfaßt die 3'-terminalen 82 Nukleotide des Genoms und einer subgenomischen RNA (Abb.: 7). Die 4 Haarnadelschleifen (I-IV) in der Sequenz nehmen dabei eine Tertiärstruktur ein, die die einer tRNA imitiert (vergleiche Abb.: 7, B und E, bzw. 7, C und 1, B). Die Haarnadelschleife II ist dabei der T-Schleife, Haarnadelschleife III der Anticodon-Schleife und Haarnadelschleife IV der D-Schleife von kanonischen tRNA's analog. Vier ungepaarte Nukleotide zwischen Haarnadelschleife II und III 
A

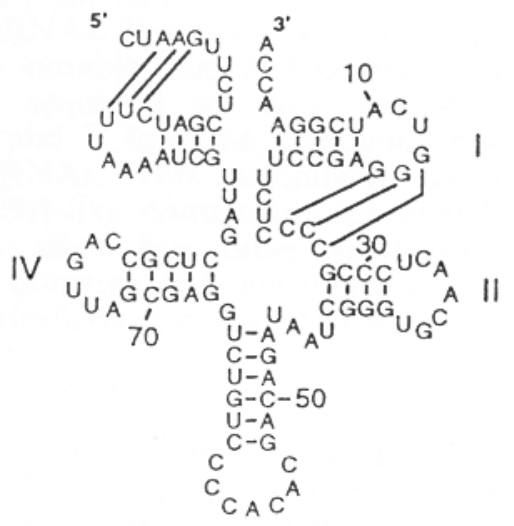

III

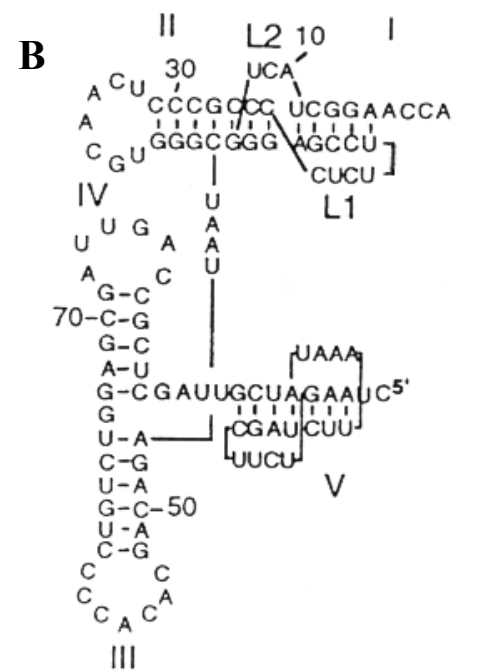

C

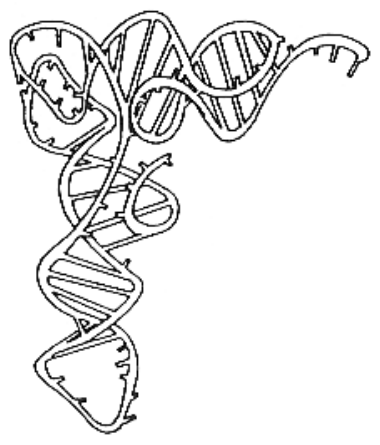

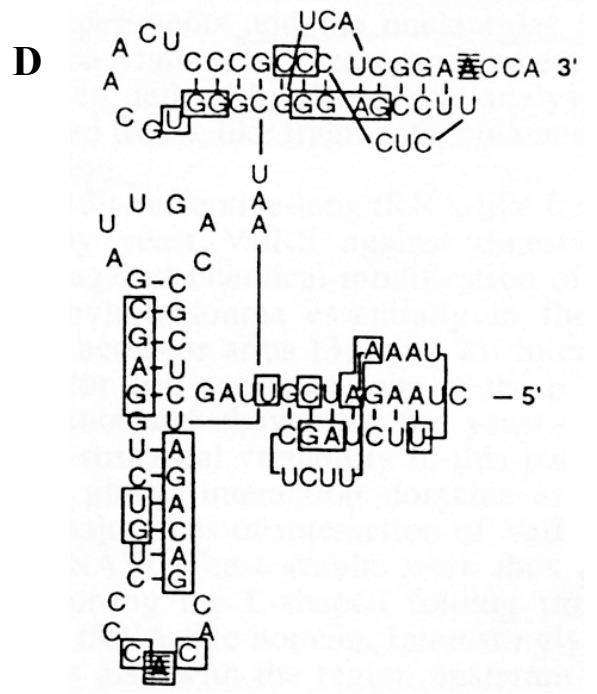

$\mathbf{E}$

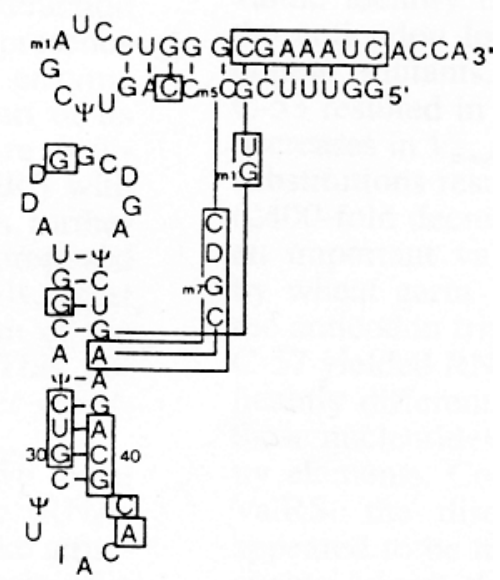

Abb.: 7,

2- und 3-dimensionale Darstellungen der tRNA-ähnlichen Struktur des TYMV (82nt) und einer tRNA ${ }^{\text {Val }}$ (76nt). Die Nummerierung der Nukleotide der TLS beginnt, anders als bei tRNA's, vom 3'-Ende her.

A) Sekundärstruktur der letzten 110nt des TYMV-Genoms. Die Haarnadelschleifen der TLS sind mit römischen Zahlen nummeriert. Mit den langen schwarzen Linien wurden Basenpaarungen markiert, die zur Tertiärstruktur des Pseudoknotens führen (Giegé et al., 1993a).

B) Sekundärstruktur der letzten 110nt in der L-förmigen Konformation (nur die 82 letzten nt). Die Pseudoknoten im Akzeptor-Arm (mit der L1- und L2-Schleife) und vor der TLS sind sichtbar (Giegé et al., 1993a).

C) Modell der Tertiärstruktur der letzten 84nt des TYMV-Genoms (Rietveld et al., 1983). Es wurde durch Daten von Probing-Experimenten und in Analogie zu tRNA's erstellt.

D) Darstellung der Kontaktstellen der letzten 110nt mit der Valyl-tRNA-Synthetase aus S. cerevisiae (Florentz and Giegé, 1986). Die wichtigsten Determinanten für die Valylierung sind $\mathrm{A}_{56}, \mathrm{~A}_{4}$ (durch mehrfache Streichung markiert) und außerdem besitzen $\mathrm{C}_{54}$ und $\mathrm{C}_{53}$ Einfluß auf die Aminoacylierung (Florentz et al., 1991; Dreher et al., 1992; Wientges et al., 2000).

E) Kontaktstellen der tRNA ${ }^{\text {Val }}$ aus $S$. cerevisiae mit der zugehörigen ValRS (Favorova et al., 1981). 
entsprechen der Variablen Schleife in tRNA's und werden Scharnier-Region genannt. Der Teil der TLS, der dem Akzeptor-Arm einer tRNA analog ist, zeigt als besondere Struktur einen Pseudoknoten (erstmals entdeckt im TYMV in der Arbeitsgruppe von Prof. Pleij, Niederlande (Rietveld et al., 1982)). Heute ist bekannt, daß Pseudoknoten in der belebten Natur weit verbreitet sind (ten Dam et al., 1992; Westhof and Jaeger, 1992). In der TYMVTLS besteht er aus den zwei Schleifen L1 und L2 (Abb.: 7, B), denen jeweils eine A-Helix gegenüber liegt (L1-S2, L2-S1). Die beiden Helices S2 und S1 und die Helix der Haarnadel II stapeln aufeinander, so daß eine quasi-kontinuierliche A-Helix in der Länge eines Akzeptor-Armes einer tRNA entsteht (Pleij, 1994; Kolk et al., 1998b). L2 liegt dabei in der kleinen Furche von S1. L1 überspannt nur mit 2 Nukleotiden $\left(\mathrm{C}_{21}, \mathrm{U}_{22}\right)$ die große Furche von S2, U24 stapelt dagegen auf U25 der S2-Helix und auch das Nukleotid an Position 23 stapelt noch teilweise auf $U_{24}$ (Kolk et al., 1998b). Damit sind beide Schleifen von der Seite der Erkennung durch die Klasse I Valyl-tRNA-Synthetase abgewandt und ragen kaum über die seitliche Oberfläche der Helices hinaus (Kolk et al., 1998a; Kolk et al., 1998b). Die „Verpackung“ der L1- und L2-Schleife könnte eine Voraussetzung dafür sein, daß die TLS in vitro auch durch die Klasse II Histidin-tRNA-Synthetase beladen werden kann (Rudinger et al., 1992).

Die tRNA-ähnliche Struktur imitiert nicht nur eine tRNA, sie interagiert auch mit vielen tRNA-spezifischen Proteinen. Dies sind z.B. Elongationsfaktoren EF-Tu und eEF1A (Litvak et al., 1973a; Joshi et al., 1984; Joshi et al., 1986), RNase P (Prochiantz and Haenni, 1973; Guerrier-Takada et al., 1988), (CTP, ATP):tRNA-Nukleotidyl-Transferase (Litvak et al., 1973b) und Valyl-tRNA-Synthetase, z.B. aus der Bäckerhefe (Florentz et al., 1991) und Weizenkeim (Pinck et al., 1970; Yot et al., 1970; Dreher et al., 1992; Florentz and Giegé, 1995).

Die TLS von TYMV kann offenbar auch mit Ribosomen interagieren, wobei es die Translation des viralen ORF1 stimmuliert und sein 3'-terminales Valin mit in das entstehende Protein einbaut (Barends et al., 2003). Frühere Publikationen hatten dagegen keine Beteiligung der TLS an der Protein-Biosynthese berichtet (Haenni et al., 1982).

Das kürzeste Fragment des TYMV-Genoms, daß noch effizient valyliert wird ist $82 \pm 2 \mathrm{nt}$ groß (Joshi et al., 1982a). Es sind aber auch Nukleotide außerhalb der TLS (Abb.: 7, D) an unspezifischen Kontakten zur ValRS beteiligt (Florentz and Giegé, 1986; Dreher et al., 1988). Diese, vermutlich zwischen 82 und 159 gelegenen Positionen, sollen die Aminoacylierungseffizienz von entsprechend langen in vitro-Transkripten verbessern (Dreher et al., 1988). Es gibt aber ebenfalls Hinweise, daß die geringere Aminoacylierungseffizienz von kürzeren Transkripten durch nicht-virale Nukleotide am 5 '-Ende der Transkripte (in den Experimenten von 1988) verursacht worden sein könnte (Mans et al., 1990). 
Für die spezifische Valylierung der TLS sind insbesondere die Nukleotide $\mathrm{A}_{56}$ (konserviert in den meisten valylierbaren TLS-enthaltenden Pflanzenviren und tRNA's (Van Belkum et al., 1987; Mans et al., 1991; Sprinzl et al., 1998)), $\mathrm{C}_{55}$ und $\mathrm{C}_{53}$ der Anticodon-Schleife und das $\mathrm{A}_{4}$ (entspricht der Diskriminatorbase) wichtig (Florentz et al., 1991; Dreher et al., 1992; Wientges et al., 2000). Außerdem führt die Stabilisierung oder die Zerstörung des Pseudoknotens in TLS-Varianten zu deutlichen Verringerungen der Valylierungseffizienz. Geringere Destabilisierung (z.B. durch Insertionen in L1) zeigt dagegen keine größeren Effekte (Mans et al., 1992).

Die TLS des TYMV interagiert, wie die von TMV und BMV (Chapman and Kao, 1999; Osman et al., 2000), mit der viralen RNA-abhängigen RNA-Polymerase. (Mouchès et al., 1974; Deiman et al., 1997b). Im Fall des TYMV ist hauptsächlich das nicht basengepaarte 3'-ACCA-Ende nötig, um eine effiziente (-)-Strang Synthese zu gewährleisten (Deiman et al., 1997a; Singh and Dreher, 1997; Deiman et al., 1998; Singh and Dreher, 1998). Die Transkription beginnt dabei nicht mit dem terminalen Adenosin-Nukleotid, sondern mit dem nachfolgenden C. Veränderungen der Struktur des Pseudoknotens bis hin zu seiner Zerstörung haben nur eine etwa 2 fache Verringerung der Transkriptionseffizienz zur Folge (Singh and Dreher, 1997). Es wurden keine Basen-spezifischen Interaktionen der RdRp mit der L1-, L2-Schleife oder der S1-Helix des Pseudoknotens gefunden (Deiman et al., 1997a). Außerdem ist bisher nicht bekannt, ob Wirtsproteine Bestandteil der VirusGesamt-Replikase sind und dadurch eventuell die Spezifität der RNA-Synthese verbessert wird.

Für TYMV ist seine TLS (Skuzeski et al., 1996) und dessen Aminoacylierung (Tsai and Dreher, 1991) essentiell für eine effiziente Infektion von Wirtspflanzen (Abb.: 8). Speziell TLS-Varianten, die durch Mutationen in der Anticodon-Schleife verringerte Valylierungseffizienzen (angegeben mit $\mathrm{V}_{\max } / \mathrm{K}_{\mathrm{M}}$ ) aufwiesen, zeigten bei Pflanzen- und Protoplasten-Infektionen im allgemeinen auch verringerte Amplifikationswerte (Tsai and Dreher, 1991).

Zusätzlich ist bekannt, daß dabei die Identität der Aminosäure am 3'-Ende der TLS von Valin nach Methionin gewechselt werden kann. Effizient methionylierbare Varianten amplifizieren dann auch relativ effizient in Pflanzen (Dreher et al., 1996).

Aus dieser Beobachtung wurde abgeleitet, daß Elongationsfaktoren des Wirtes, wie beim Bakteriophagen Q $\beta$ (Blumenthal and Carmichael, 1979), Bestandteil der viralen Replikase sein könnten (Giegé, 1996). 


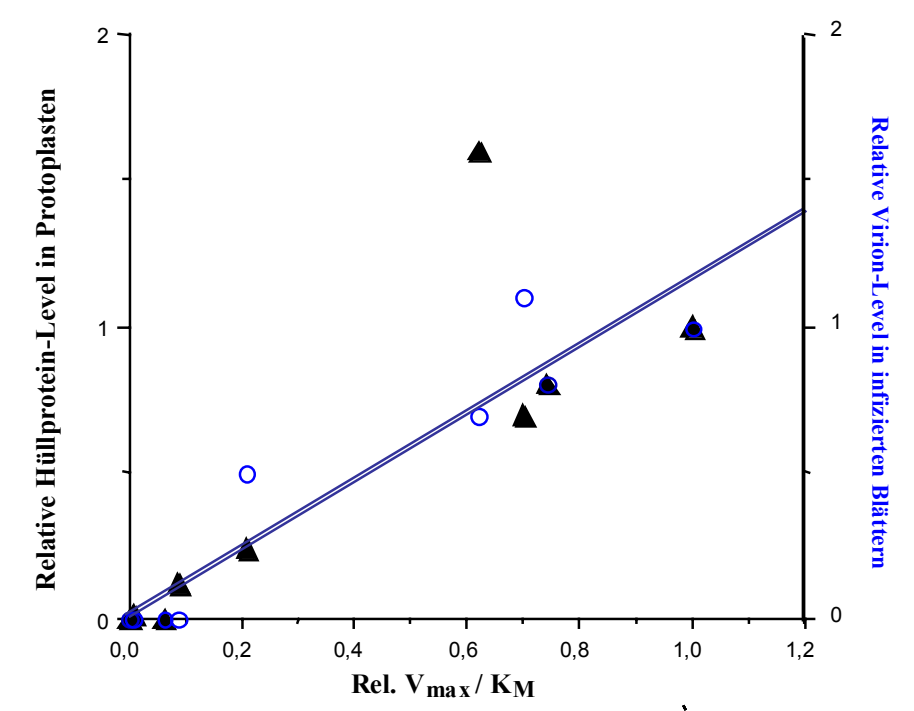

Abb.: 8,

Zusammenhang zwischen der in vitro-Valylierungseffizienz $\left(\mathrm{V}_{\max } / \mathrm{K}_{\mathrm{M}}\right)$ und Amplifikation des $\mathrm{TYMV}$, gezeigt an der relativen Virionenproduktion in infizierten Blättern (o) und der relativen HüllproteinSynthese in Protoplasten ( $\mathbf{A}$ ). Der Wildtyp entspricht dem Wert 1,0 (nach: Tsai and Dreher, 1991)).

Die Funktion der tRNA-ähnlichen Struktur könnte neben der Translationsstimmulierung des Polyproteins (Barends et al., 2003) und der Erkennungsregion der Replikase (Deiman et al., 1997a; Singh and Dreher, 1997) auch die eines einfachen Telomers sein, mit der (CTP, ATP):tRNA-Nukleotidyl-Transferase als „Telomerase“, wie es von Weiner und Maizels postuliert wurde (Weiner and Maizels, 1987; Weiner and Maizels, 1999).

Die Vermutung, die TLS könnte zur Stabilisierung des Genoms benötigt werden (Rao et al., 1989), wurde durch neuere Studien nicht bestätigt (Skuzeski et al., 1996).

Dagegen ist bis heute nicht abschließend geklärt, ob die Aminosäure am 3'-Ende des Genoms als Primer in der Replikation dienen könnte (eventuell eEF1A vermittelt). Die Aminosäure entspräche damit der Rolle der entsprechenden Aminosäuren RNA-terminaler Proteine, wie etwa aus dem Bacillus subtilis-Phagen F29 (Ser), dem Streptococcus pneumoniae-Phagen CP-1 (Thr) und dem Escherichia coli/Salmonella typhimuriumPhagen PRD1 (Tyr) und den tierischen Adenoviren (Ser) (Kornberg and T.A., 1992). 


\subsection{Aufgabenstellung}

Die Frage nach dem Zusammenhang der Aminoacylierung der tRNA-ähnlichen Struktur des TYMV und der Replikation des Virus konnte bisher nicht abschließend geklärt werden. Auch die kürzlich berichtete Beobachtung der Translationsstimmulierung für das von ORF1 codierte Polyprotein durch die TLS läßt diese Frage offen. Der Einfluß der Aminoacylierung auf die Effizienz der Proteinsynthese erscheint relativ gering, so daß eine weitere, bisher unbekannte Funktion der Aminosäure am 3'-Ende des TYMV-Genoms (und der subgenomischen RNA) möglich erscheint.

Es ist bekannt, daß weniger effizient als der Wildtyp valylierbare TLS-Varianten des TYMV in vivo ebenfalls weniger effizient amplifizieren (Abb.: 8) (Tsai and Dreher, 1991). Dies könnte auf den Einfluß der Aminoacylierung der TLS auf die Replikation hindeuten.

Ein Ziel der Arbeit war es daher, näher zu untersuchen, ob die Valylierung der TLS auch wichtig für die Replikation des TYMV ist.

Dazu sollten TLS-Varianten hergestellt werden, die effizienter und weniger effizient als der Wildtyp valylierbar sind. Sie sollten durch in vitro Selektion einer teilrandomisierten TLS-RNA-Bibliothek gefunden oder es sollten Varianten mit bekannten Eigenschaften aus früheren Selektionen benutzt werden. Die Varianten mit verschiedenen Eigenschaften in Valylierungseffizienz und Struktur, bzw. Sequenz sollten dann in vitro valyliert/nicht valyliert und in vivo auf ihre Replikationsfähigkeit hin miteinander verglichen werden.

Außerdem sollte untersucht werden, in wie weit eEF1A Einfluß auf die Replikation nehmen kann oder ob das EF-Tu-bindende Antibiotikum Puromycin die RNA-abhängige RNA-Polymerase (katalytischer Bestandteil der Replikase) inhibieren kann. In der Literatur wurde beschrieben, daß die Aminosäure-Identität am 3'-Ende der TLS von Valin nach Methionin geändert werden kann (Dreher et al., 1996), wodurch die Beteiligung von eEF1A (als Protein, das verschiedene Aminosäuren akzeptieren würde) an der Replikase eine nahe liegende Möglichkeit zu sein scheint. Wenn dies nicht der Fall wäre, so könnte das Antibiotikum Puromycin eventuell die RdRp direkt hemmen.

Zusätzlich sollten durch eine in vitro Selektion einer in Haarnadelschleife II, IV und der Scharnier-Region randomisierten TLS-RNA-Bibliothek optimal valylierbare Varianten isoliert werden. Aus früheren Versuchen (Klug, 2000) und aus der Literatur gibt es Hinweise, daß diese Regionen wichtig für die korrekte Faltung der TLS, ähnlich wie in kanonischen tRNA's, sein könnten (Giegé et al., 1990; de Smit et al., 2002). Wenn sich Konsensus-Sequenzen aus den optimal valylierbaren Varianten ergeben sollten, wäre dies ein Hinweis, daß es tatsächlich Nukleotid-Positionen in diesen Regionen gibt, die wichtig für die Valylierung sind. 


\section{Material und Methoden}

\subsection{Materialien}

\subsubsection{Laborgeräte}

Zur Durchführung der Versuche benutzte Geräte:

HPLC-System (mit TSK G3000-Säule, Amersham Pharmacia Biotech

Größenausschluß-Chromatographie), (Braunschweig)

Peristaltik-Pumpe, Elektrophoresekammer

(GNA-100, für Agarose-Gele)

Vortex-Gerät (Genie 2)

Power-Supply

Elektrophoresekammer (für PAGE),

Trio-Thermocycler (PCR-Gerät)

Scintillationszähler (Tri-Carb 1900CA)

Magnetische Fällvorrichtung (Halter für

Reaktionsgefäße)

Laborzentrifuge (Kühlzentrifuge),

Thermomixer, Vacuumzentrifuge

Phosphor Imager (BAS 1500)

Pipetten $(2,20,100,200,1000 \mu 1)$

Ultraschallgerät (Branson Sonifier W-250) Heinemann (Schwäb. Gmünd)

Quarzküvetten (100 $\mu 1,1 \mathrm{~cm}$ Schichtdicke) Hellma (Müllheim/Baden)

Laborzentrifuge (Tischzentrifuge),

Laborzentrifuge (Kühlzentrifuge)

Beheizbarer Magnetrührer (Ikamag RCT) IKA-Labortechnik (Staufen)
Hettich (Tuttlingen)
Fuji Photo Film Co., LTD (Kanagwa, Japan)

GILSON, Medical Electronics (Frankreich) 
Spektrophotometer (Uvikon 933),

Ultrazentrifuge

Nanopore-Wasser-Anlage

Sterilbank

Mörser

Sartorius Feinwaage

Western-Blot Apparatur (,Sammy-Dry“)

pH-Meter (526)

Kühlzentrifuge (RC5C; mit Rotor SS34)

Pflanzenwuchsschrank (Z2100E)
Kontron Instruments (Eching bei München)

Millipore (Eschborn)

PRETTL Laflow-Prozeßtechnik (Bempflingen)

Roth (Karlsruhe)

Sartorius (Göttingen)

Schleicher \& Schüll (Dassel)

Schütt Labortechnik (Göttingen)

Sorvall Instruments (Bad Homburg)

Weiss Technik (Reiskirchen)

\subsubsection{Chemikalien / Biochemikalien}

Chemikalien wurden in den Versuchen mit dem Reinheitsgrad ,pro analysis“, im Fall der HPLC-Lösungen mit „HPLC-Grade“, verwendet.

Bezogen wurden sie von den Firmen: Fluka (Neu-Ulm), Merck (Darmstadt), Roth (Karlsruhe), Serva (Heidelberg), Sigma (Deisenhofen).

Folgende Biochemikalien wurden verwendet:

dNTPs, GMP, RNasin (RNase-Inhibitor), Boehringer (Mannheim)

total-tRNA aus $S$. cerevisiae,

total-tRNA aus E. coli

Bacto-Peptone

Hefeextrakt

Cap-like Structure Analog

Agar Bacteriological, Trypton
DIFCO (Dreieich)

GIBCO/BRL (Eggestein)

New England Biolabs (Frankfurt)

OXOID (Wesel) 
Sulfo-NHS-Biotin

RNasin

Aqua Roti-Phenol pH 4,5 , mit TE pH 8,0 äquilibriertes Phenol, D-Mannitol, $\alpha$-D(+)-Glukose, $\mathrm{D}(+)$-Saccharose, TEMED

Gamborg's B5 Basal Medium with minimal Organics, L-Valin, Lubrol W, Phosphoenolpyruvat, rNTPs, Spermidin

Radioaktiv markierte Chemikalien:

L- ${ }^{3} \mathrm{H}-$ Valin $(265 \mathrm{mCi} / \mathrm{mmol})$,

$\alpha-{ }^{32} \mathrm{P}-\mathrm{ATP}(800 \mathrm{Ci} / \mathrm{mmol})$, $\alpha-{ }^{32} \mathrm{P}-\mathrm{UTP}(800 \mathrm{Ci} / \mathrm{mmol})$

\subsubsection{Enzyme}

Verwendete Enzyme:

Mikrococcen Nuklease

AMV-Reverse Transkriptase,

DNaseI (RNase frei), T4-DNA-Ligase

EcoRI, Eco72I, Cfr9I (XmaI Analog), T7-RNA-Polymerase

$B s t$ NI, SmaI, XmaI, Vent DNA-Polymerase

Taq DNA-Polymerase (Ampli-Taq)

Cellulase (Onozuka R-10)
Pierce (Oud-Beijerland, Niederlande)

Promega (Madison, USA)

Roth (Karlsruhe)

Sigma (Deisenhofen)

Amersham (Braunschweig)

Hartmann Analytic (Braunschweig)

Boehringer (Mannheim)

MBI-Fermentas (St.Leon-Rot) New England Biolabs (Frankfurt) Perkin Elmer (Branchburg, USA) Serva (Heidelberg) 
Enhanced Avian Reverse Transkriptase, Sigma (Deisenhofen)

Pectolyase, Pyruvat-Kinase

Für die Reaktionen der Enzyme wurden die entsprechenden mitgelieferten 10xReaktionspuffer verwendet (Ausnahme: die AMV-Reverse-Transkriptase wurde mit 10xPCR-Puffer für Ampli-Taq benutzt).

Die Valyl-tRNA-Synthetase (ValRS, aus Saccharomyces cerevisiae nach dem Protokoll von D. Kern (Kern et al., 1975) präpariert) wurde freundlicherweise von J. Pütz (IBMC du CNRS, Strasbourg, Frankreich) zur Verfügung gestellt.

RNA-abhängige-RNA-Polymerase (RdRp) wurde nach einem Protokoll von B. Deiman (1997) aus infizierten Chinakohlpflanzen präpariert (Punkt 2.2.4.9.).

\subsubsection{Antikörper}

TYMV

1. Antikörper:

Anti-TYMV-Hüllprotein (DSMZ, Braunschweig), Verdünnung 1:1000

2. Antikörper:

Anti-Mouse-AP (Alkalische Phosphatase; DSMZ, Braunschweig), Verdünnung 1:1000

EF-Tu (aus Mycoplasma; Escherichia coli)

1. Antikörper:

Anti-EF-Tu-Antikörper (aus dem Labor von Chr. K. Biebricher, Max-Planck-Institut für Biophysikalische Chemie, Göttingen), Verdünnung 1:1000

2. Antikörper:

Anti-Rabbit-AP (Sigma, Deisenhofen), Verdünnung 1:2500

\subsubsection{Verbrauchsmaterialien}

Die allgemeinen Verbrauchsmaterialien, wie Pipettenspitzen, Reaktionsgefäße und ähnliches, wurden bei Eppendorf (Hamburg), Falcon, Sarstedt (Nümbrecht), Roth (Karlsruhe), Schleicher \& Schüll (Dassel), Nalge und Nunc (Göttingen) erhalten.

Centricon 30 (Mikrokonzentratoren) Amicon (Witten)

Küvetten für die Elektroporation Bio-Rad (München) 


$\begin{array}{ll}\text { WHATMANN 3MM Chr Filterpapier } & \text { Biometra (Göttingen) } \\ \text { Scintillationscocktail Ultima Gold XR } & \text { Canberra-Packard (Frankfurt/M) } \\ \text { Dynabeads M-280 Streptavidin } & \text { Deutsche Dynal (Hamburg) } \\ \text { TOPO-TA-Cloning }{ }^{\circledR} \text {-Kit } & \text { Invitrogen (Groningen, Niederlande) } \\ \text { Dialyse-Nitrozellulose-Plättchen } & \text { Millipore Corporation (Bedford, USA) } \\ \left(0,025 \mu \text { m, } \varnothing 13 \mathrm{~mm}^{\circ}\right) & \\ \text { RNeasy Plant Mini }{ }^{\circledR} \text { Kit } & \text { Qiagen (Hilden) } \\ \text { Dialyseschlauch } & \text { Serva (Heidelberg) } \\ \text { Siliciumcarbid } & \text { Sigma (Deisenhofen) }\end{array}$

\subsubsection{Lösungen und Puffer}

Alle Lösungen, die für Arbeiten mit RNA und DNA benötigt wurden, wurden mit doppelt destilliertem Wasser angesetzt und sterilfiltriert oder autoklaviert.

Alle Lösungen, die nicht völlig keimfrei sein mußten, wurden mit doppelt destilliertem Wasser angesetzt und nicht weiter sterilisiert.

\begin{tabular}{|c|c|}
\hline Ampicillin-Stammlösung & $\begin{array}{l}\text { 100mg/ml Ampicillin (Na-Salz) in } \\
\mathrm{H}_{2} \mathrm{O} \text {, sterilfiltriert } \\
\text { (im Medium 1:1000 verdünnt) }\end{array}$ \\
\hline Chloramphenicol-Stammlösung & $\begin{array}{l}\text { 34mg/ml Chloramphenicol in Ethanol, } \\
\text { sterilfiltriert } \\
\text { (im Medium 1:1000 verdünnt) }\end{array}$ \\
\hline P1-Puffer & $\begin{array}{l}50 \mathrm{mM} \text { Tris } / \mathrm{HCl} \quad \mathrm{pH} 8,0 \\
10 \mathrm{mM} \text { EDTA }\end{array}$ \\
\hline P2-Puffer & $\begin{array}{l}200 \mathrm{mM} \mathrm{NaOH} \\
1 \%(\mathrm{w} / \mathrm{v}) \mathrm{SDS}\end{array}$ \\
\hline P3-Puffer & $2,55 \mathrm{M} \mathrm{KAc}$ \\
\hline
\end{tabular}


TE

$\mathrm{NaAc}$

Loading Buffer

(denaturierend)

Loading Buffer

(Nativ)

TAE

TBE

APS

Protogel

Ethidiumbromidstammlösung

SDS-PAGE Laufpuffer

(Protein)

SDS-PAGE Sammelgelpuffer

(4x; Protein)

SDS-PAGE Trenngelpuffer

(4x; Protein)

SDS-PAGE Sammelgel (5\%)

(12ml; Protein)

SDS-PAGE Trenngel (10\%)

(18ml; Protein)
10mM Tris/HCl $\mathrm{pH} 8,0$

$1 \mathrm{mM}$ EDTA

3M Natriumacetat / Essigsäure pH 5,2

$80 \%$ Formamid

$10 \mathrm{mM}$ EDTA

0,025\% Xylencyanol/Bromphenol $\mathrm{pH} 8,0$

$50 \%$ Glyzerin

$1 \mathrm{mM}$ EDTA

0,025\% Xylencyanol/Bromphenol $\mathrm{pH} 8,0$

$10 \mathrm{mM}$ Tris/Acetat $\quad \mathrm{pH} 8,0$

$1 \mathrm{mM}$ EDTA

90mM Tris/Borat $\quad \mathrm{pH} 8,0$ 2mM EDTA

10\% (w/v) Ammoniumpersulfat

$30 \%(\mathrm{v} / \mathrm{v})$ Acrylamid

$0,8 \%(\mathrm{v} / \mathrm{v})$ Bisacrylamid

$10 \mathrm{mg} / \mathrm{ml}$ Ethidiumbromid (Verdünnung im Gel-Bad: 1:10.000 in $\mathrm{H}_{2} \mathrm{O}$ )

$33 \mathrm{mM}$ Tris/HCl

190mM Glycin

$0,1 \%(\mathrm{w} / \mathrm{v}) \mathrm{SDS} \quad \mathrm{pH} 8 ; 3$

$0,5 \mathrm{M}$ Tris/HCl

$0,4 \%(\mathrm{w} / \mathrm{v}) \mathrm{SDS} \quad \mathrm{pH} 6,8$

1,5M Tris/HCl

$0,4 \%(\mathrm{w} / \mathrm{v}) \mathrm{SDS} \quad \mathrm{pH} 8,8$

$3 \mathrm{ml} 4 \mathrm{x}$ Sammelgelpuffer

$2 \mathrm{ml} \mathrm{30 \%} \mathrm{Protogel}$

$7 \mathrm{ml} \mathrm{H}{ }_{2} \mathrm{O}$

$50 \mu 110 \%$ APS

$25 \mu 1$ TEMED

4,5ml 4x Trenngelpuffer

$6 \mathrm{ml} \mathrm{30 \%} \mathrm{Protogel}$

$7,5 \mathrm{ml} \mathrm{H}_{2} \mathrm{O}$

$80 \mu 110 \%$ APS

$40 \mu 1$ TEMED 
SDS-PAGE Probenpuffer (Protein)

SDS-PAGE Färbelösung (Protein)

SDS-PAGE Entfärbelösung (Protein)

PBS

BCIP-Stammlösung

NBT-Stammlösung

HPLC-Laufpuffer

Verdünnungspuffer für ValRS aus Bäckerhefe

MR4,5

MR2

HB\&W-Puffer

Tu-Puffer 2,5ml 4x Sammelgelpuffer

$3 \mathrm{ml} 10 \%$ SDS

$300 \mu 1 \beta$-Mercaptoethanol

2,5ml 80\% Glyzerin

$100 \mu 12 \%$ Bromphenolblau

45\% (v/v) Methanol

$10 \%(\mathrm{v} / \mathrm{v})$ Essigsäure

$0,2 \%(v / v)$ Coomassie Blue R250

5\% (v/v) Essigsäure

$8 \mathrm{~g} / 1 \mathrm{NaCl}$

$0,2 \mathrm{~g} / 1 \mathrm{KCl}$

$1,44 \mathrm{~g} / 1 \mathrm{Na}_{2} \mathrm{HPO}_{4}$

$0,24 \mathrm{~g} / 1 \mathrm{KH}_{2} \mathrm{PO}$

$\mathrm{pH} \mathrm{7,4}$

50mg/ml BCIP (5-Brom-4-Chlor-3-Indolyl-

Phosphat $\mathrm{p}$-Toluidinsalz) in Dimethylformamid

$75 \mathrm{mg} / \mathrm{ml}$ NBT (Nitroblautetrazolium Chlorid) in 70\% Dimethylformamid

$0,2 \mathrm{M} \mathrm{NaAc}$

$1 \%$ Methanol pH 6,0

10\% Glyzerin

$10 \mathrm{mM} \beta$-Mercaptoethanol

$100 \mathrm{mM}$ Hepes/KOH pH 7,2

0,2mM Dithiotreithol (DTT)

$225 \mathrm{mM}$ Tris/ $\mathrm{HCl}$

$270 \mathrm{mM} \mathrm{KCl}$

$112,5 \mathrm{mM} \mathrm{MgCl} \mathrm{m}_{2}$

4,5mM Glutathion (reduziert)

$33 \mu \mathrm{l}$ MR4,5

$15 \mu \mathrm{rATP}(100 \mathrm{mM})$

$7,5 \mu \mathrm{l}$ Valin $(1 \mathrm{mM})$

$19,5 \mu \mathrm{l} \mathrm{H}_{2} \mathrm{O}$

10mM Hepes

$1 \mathrm{M} \mathrm{NaCl} \quad \mathrm{pH} 7,2$

$50 \mathrm{mM}$ Tris $/ \mathrm{HCl}$

$7 \mathrm{mM} \mathrm{MgCl}_{2}$

$60 \mathrm{mM} \mathrm{NH}_{4} \mathrm{Cl}$ 
Zell-Medium

(Pflanzen-Zell-Kultur)

Proto-Medium

(Protoplasten)

PEG-Lösung

(Protoplasten)

Enzym-Lösung

(Protoplasten)

Puffer A

(RdRp-Präp.)

Puffer D

(RdRp-Präp.) 3,2g/1 Gamborg's B5 Basal Medium with minimal organics

$30 \mathrm{~g} / 1 \mathrm{D}(+)$-Saccharose

$1 \mu \mathrm{M}$ 1-Naphtalen-Essigsäure (NAA)

$\mathrm{pH}$ 5,8 (eingestellt mit $\mathrm{KOH}$ )

3,2g/1 Gamborg's B5 Basal Medium with minimal organics

$1 \mathrm{M}$ Glukose

0,25M Mannitol

Nach vollständiger Lösung:

$1 \mu \mathrm{M}$ 1-Naphtalen-Essigsäure (NAA) $\mathrm{pH} \mathrm{5,8}$ (eingestellt mit $\mathrm{KOH}$ )

$25 \%$ PEG 6000

0,45M Mannitol

$0,1 \mathrm{M} \mathrm{Ca}\left(\mathrm{NO}_{3}\right)_{2} \bullet 4 \mathrm{H}_{2} \mathrm{O}$

pH 9,0 (eingestellt mit $0,1 \mathrm{M} \mathrm{NaOH}$ ) sterilfiltriert

$0,1 \%$ Pectolyase

$2 \%$ Cellulase (Onozuka R10)

$12 \%$ Sorbitol

Zur besseren Lösung $\mathrm{pH}$ 7,0 (eingestellt mit

$\mathrm{KOH}), 3 \mathrm{~h}$ rühren,

pH 5,8 (eingestellt mit $6 \mathrm{M} \mathrm{HCl}$ ), sterilfiltriert,

Lagerung bei $-20^{\circ} \mathrm{C}$ für maximal 2 Monate

50mM Tris/HCl pH 7,4

$15 \mathrm{mM} \mathrm{MgCl}_{2}$

$8,7 \%(\mathrm{v} / \mathrm{v})$ Glyzerin

$0,1 \%(\mathrm{v} / \mathrm{v}) \beta$-Mercaptoethanol

25mM Tris/ $\mathrm{HCl}$ pH 7,4

$7,5 \mathrm{mM} \mathrm{MgCl}_{2}$

$0,5 \mathrm{mM}$ EDTA $(\mathrm{pH} 8,5)$

$20 \%(\mathrm{v} / \mathrm{v})$ Glyzerin

$2 \mathrm{mM}$ DTT

\subsubsection{Nährmedien}

Um Nährmedien zu sterilisieren, wurden sie für $20 \mathrm{~min}$. bei $120^{\circ} \mathrm{C}$ und 1,2 bar Überdruck autoklaviert. Hitzelabile Komponenten wie z.B. Antibiotika, IPTG und X-Gal wurden sterilfiltriert und nach Abkühlen des Mediums auf ca. $50^{\circ} \mathrm{C}$ zugegeben, bzw. auf Agarplatten appliziert. 
Nährmedien: Für Flüssigkulturen wurde zumeist das Komplexmedium dYT, für Agarplatten LB (Luria Bertani) verwendet.

Bei Klonierungen wurde im Rahmen der Transformation das SOC-Medium verwendet.

dYT

LB-Medium

$\mathrm{LB}_{\text {Amp }}-$ Medium

LB-Agar

SOC-Medium 16g/1 Trypton

$10 \mathrm{~g} / 1$ Hefeextrakt

$5 \mathrm{~g} / 1 \mathrm{NaCl}$

10g/1 Trypton

$5 \mathrm{~g} / 1$ Hefeextrakt

$10 \mathrm{~g} / \mathrm{l} \mathrm{NaCl}$

LB-Medium mit $50 \mu \mathrm{g} / \mathrm{ml}$

Ampicillin (Lagerung von Medium/Platten bei $\left.4^{\circ} \mathrm{C}\right)$

\author{
LB-Medium \\ 15g/1 Bacto-Agar \\ 20g/1 Trypton \\ $5 \mathrm{~g} / 1$ Hefeextrakt \\ $10 \mathrm{~g} / \mathrm{l} \mathrm{NaCl}$ \\ nach dem Autoklavieren sterilfiltriert \\ zugegeben: \\ $10 \mathrm{mM} \mathrm{MgCl} 2$ \\ $10 \mathrm{mM} \mathrm{MgSO} 4$ \\ 20mM Glucose
}

\subsubsection{Bakterienstämme/Virenstämme}

TYMV-Stamm:

Australischer "Blue Lake” Stamm (Keese et al., 1989).

XL1-Blue (recA1 endA1 gyrA96 thi-1 hsdR17 supE44 relA1 lac $\left[\mathrm{F}^{\prime}\right.$ proAB lacI $^{\mathrm{q}} \mathrm{Z} \Delta \mathrm{M} 15$ $\left.\left.\operatorname{Tn} 10\left(\operatorname{Tet}^{\mathrm{r}}\right)\right]\right)$

Dieser Stamm (Stratagene) ist u.a. Endonuklease (endA1)- und Rekombinationsdefizient. Aufgrund dieser Tatsache konnte eine spezielle Plasmid-Aufreinigung durchgeführt werden (Punkt 2.2.1.6.).

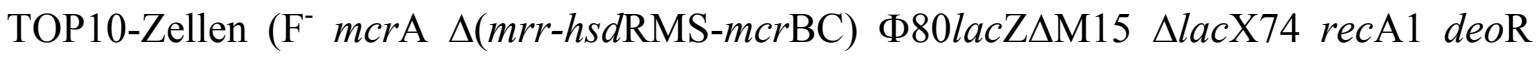

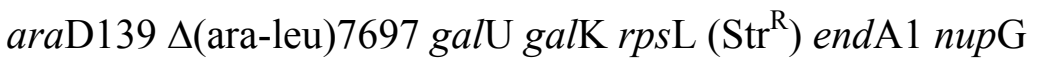

Dieser E.coli-Stamm (Invitrogen) wurde für Sequenzierungsvorarbeiten eingesetzt. 


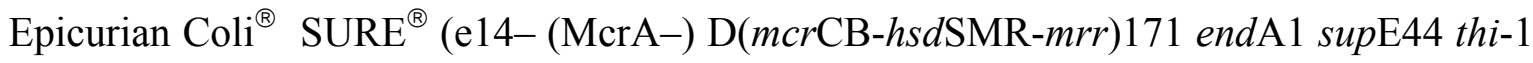

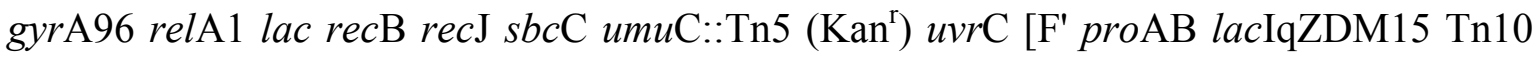
$\left(\right.$ Tet $\left.\left.\left.^{\mathrm{r}}\right)\right]\right)$

(Stratagene)

BL21 (B F' dcm ompT hsdS( $\left.\mathrm{r}^{-}-\mathrm{m}_{\mathrm{B}^{-}}\right)$gal $\left.\lambda(\mathrm{DE} 3)\right)$

(Stratagene)

\subsubsection{Plasmide}

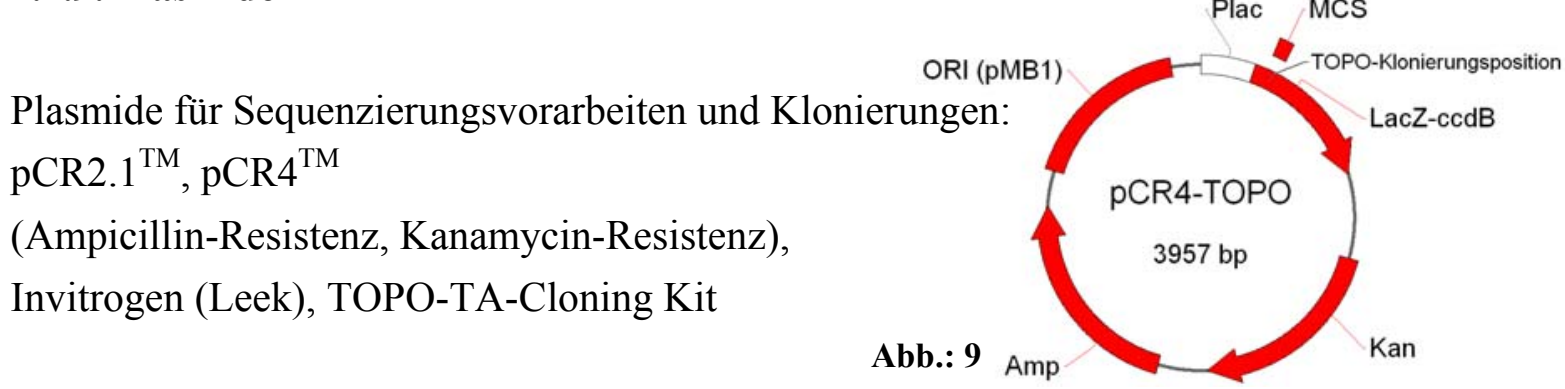

Plasmid für TLS-RNA-Synthese:

pUC19

(Ampicillin-Resistenz),

MBI-Fermentas

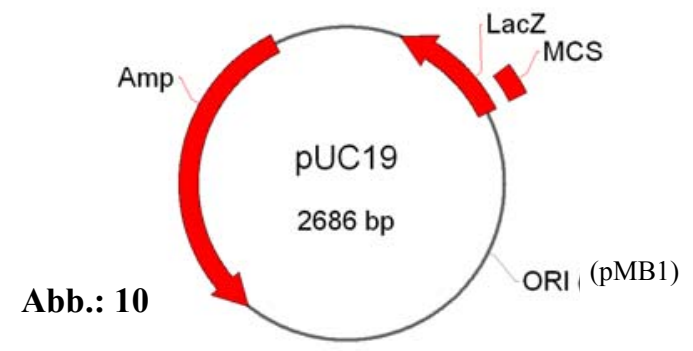

Plasmid mit volle-Länge-TYMV-Genom (DNA-codiert): pACBL 16

(Chloramphenicol-Resistenz), erhalten durch Maarten de Smit (Universität Leiden, Niederlande)

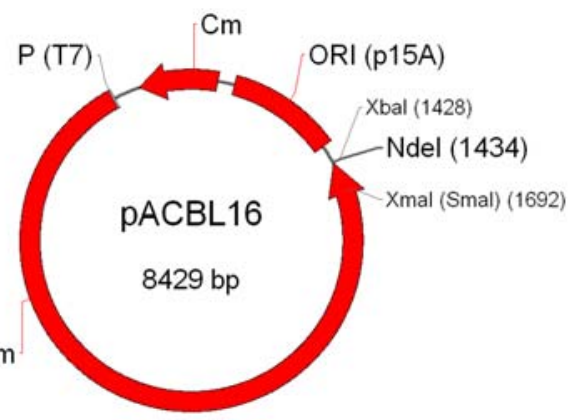

\subsubsection{DNA-Oligonukleotide}

Die DNA-Oligonukleotide wurden von NAPS (Göttingen, Deutschland), Biometra (Göttingen) und Sigma-ARK (Darmstadt) bezogen.

Die tRNA-ähnliche Struktur des TYMV-Wildtyps (82nt) plus 9 weiterer Nukleotide wurde auf DNA- und RNA-Ebene um zwei Guanosin-Nukleotide ergänzt, um eine bessere Transkribierbarkeit der DNA-Matrize durch T7-RNA-Polymerase zu erreichen. Der Basenaustausch zeigte keinen Einfluß auf die Aminoacylierbarkeit (Wientges, 1998). 
TYMV-Rev

5'-TGG TTC CGA TGA CCC TCG GAA GAG GGG CGG G-3'

(NAPS)

TYMV-T7

5'-GCT AAT ACG ACT CAC TAT AGG AAT CGT TAG CTC GC-3'

Die unterstrichene Sequenz zeigt den T7-Promotor für die Transkription der Bibliothek Lib D an. (NAPS)

TY-B-5

5'-GCT AAT ACG ACT CAC TAT AGG GCT CGC CAG TTA GCG AGG TCT-3'

Die unterstrichene Sequenz zeigt den durch PCR an die Matrize (TYMV-WT) angefügten T7-Promotor. (NAPS, Biometra)

TY-Val-3'

5'-TGG TTC CGA TGA CCC TCG GA-3'

(NAPS, Biometra)

TYMV - WT

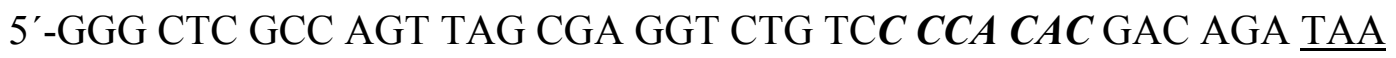
TCG GGT GCA ACT CCC GCC CCT CTT CCG AGG GTC ATC GGA ACC A-3'

Fett gedruckt ist die Region der Anticodon-Schleife; unterstrichen sind die Bereiche, die variabler Schleife (,Scharnier-Region“) und T-Loop einer tRNA analog sind. (NAPS)

TYMV - Lib D

5'-GCT AAT ACG ACT CAC TAT AGG AAT CGT TAG CTC GCN NNN NNG CGA GGT CTG TCC CCN CAC GAC AGA NNN NCG GGN NNN NNN CCC GCC CCT CTT CCG AGG GTC ATC GGA ACC A-3'

Unterstrichen ist der Bereich des T7-Promotors. Doppelt unterstrichen ist die Region der Anticodon-Schleife, „N“ steht für randomisierte Position in der Sequenz. Randomisiert wurden T-, D-Loop, variable Schleife und Position 56. (NAPS)

Oligonukleotide zur Herstellung der 25 TLS-Varianten. Fett gedruckt sind die Sequenzen der Anticodonschleife (,AC“) oder der L1-Schleife („L“). Bezogen wurden sie von NAPS: AC-WT

5'-GCT AAT ACG ACT CAC TAT AGG GCT CGC CAG TTA GCG AGG TCT GTC CCC ACA CGA CAG ATA ATC GGG TGC AAC TCC CGC CC-3' 
AC-8-40

5'-GCT AAT ACG ACT CAC TAT AGG GCT CGC CAG TTA GCG AGG TCT GTC ACT ACA CGA CAG ATA ATC GGG TGC AAC TCC CGC CC-3'

AC-8-3

5'-GCT AAT ACG ACT CAC TAT AGG GCT CGC CAG TTA GCG AGG TCT GTC AAA ACG CGA CAG ATA ATC GGG TGC AAC TCC CGC CC-3'

AC-8-39

5'-GCT AAT ACG ACT CAC TAT AGG GCT CGC CAG TTA GCG AGG TCT GTC ACG ACT CGA CAG ATA ATC GGG TGC AAC TCC CGC CC-3'

AC-Kon

5'-GCT AAT ACG ACT CAC TAT AGG GCT CGC CAG TTA GCG AGG TCT GTC TCT ACA CGA CAG ATA ATC GGG TGC AAC TCC CGC CC-3’

AC-Anti

5'-GCT AAT ACG ACT CAC TAT AGG GCT CGC CAG TTA GCG AGG TCT GTC GGA CAC TGA CAG ATA ATC GGG TGC AAC TCC CGC CC-3'

L1

5'-TGG TTC CGA TGA CCC TCG GAA AAA AGG GGC GGG-3'

L2

5'-TGG TTC CGA TGA CCC TCG GAA AAA GGG GCG GG-3'

L3

5'-TGG TTC CGA TGA CCC TCG GAA AAG GGG CGG G-3'

L4

5'-TGG TTC CGA TGA CCC TCG GAA AGG GGC GGG-3'

L5

5'-TGG TTC CGA TGA CCC TCG GAA GGG GCG GG-3'

L6

5'-TGG TTC CGA TGA CCC TCG GAG GGG CGG G-3'

L7

5'-TGG TTC CGA TGA CCC TCG GAG GAA AAG GGC GGG-3'

L8

5'-TGG TTC CGA TGA CCC TCG GAG GTG GGC GGG-3'

L9

5'-TGG TTC CGA TGA CCC TCG GAC GAG GGC GGG-3'

L10

5'-TGG TTC CGA TGA CCC TCG GAG AAA GGG CGG G-3'

L11

5'-TGG TTC CGA TGA CCC TCG GAG TAA GGG CGG G-3'

L12

5'-TGG TTC CGA TGA CCC TCG GAT CGC GGG CGG G-3' 
TY-Eco-5

5'-CGA ATT CGC TAA TAC GAC TCA CTA TAG GGC TCG CCA GTT AGC GAG GTC T-3'

TY-Bst-Eco-3'

\section{5'-CGA ATT $\boldsymbol{C} \boldsymbol{C} \boldsymbol{T} \boldsymbol{G} \boldsymbol{G}$ T TCC GAT GAC CCT CGG A-3'}

Doppelt unterstrichen sind EcoRI-Schnittstellen, kursiv-fett ist eine Bst NI-Schnittstelle markiert.

Oligonukleotide zur Herstellung von TYMV-TLS-Varianten im Gesamt-Genom-Kontext. Bezogen von Sigma-ARK:

TY-60-Repl-8-40

5'-GAC CCT CGG AGA AAG GGC GGG AGT TGC ACC CGA TTA TCT GTC GTG TAG TGA CAG ACC TCG-3'

TY-60-Repl-WT(C)

5'-GAC CCT CGG AGG GGC GGG AGT TGC ACC CGA TTA TCT GTC GTG TGG GGA CAG ACC TCG-3'

TY-60-Repl-8-40

5'-GAC CCT CGG AGG AAA AGG GCG GGA GTT GCA CCC GAT TAT CTG TCG TGT AGT GAC AGA CCT CG-3'

TY-Repl-1

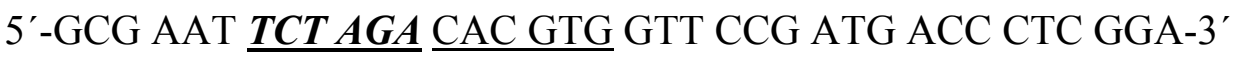

Unterstrichen ist eine Eco72I-Schnittstelle. Kursiv-fett unterstrichen ist eine $X b a \mathrm{I}-$ Schnittstelle.

TY-Repl-3

5'-GCG AAT TCC CCG GGT CAA AGA TTC AAT T-3'

Fett unterstrichen ist eine XmaI (SmaI)-Schnittstelle.

Oligonukleotide zur Sequenzierung revers transkribierter TYMV-RNA aus infizierten Pflanzen:

TY-short-Val-3'

5'-TGG TTC CGA TGA-3'

TYMV7

5'-TGG TTC CGA TGA CCC TCG G-3'

TY-pACBL-Rev

5' -ACC CAG ATC ACC AAG ACC TAC-3'

TD-PCR 4

5'-GAT GAA CCC CCG GTC AAA G-3' 


\subsubsection{DNA-/Protein-Längenstandards}

DNA-Standard:

pUC19

(2686bp Vektor, MspI geschnitten; MBI Fermentas)

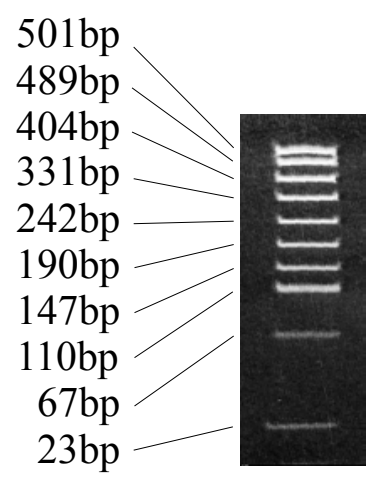

Abb.: 12 $\lambda$ DNA (Eco47I) AvaII

(MBI Fermentas)
Smart Ladder 200-10000bp

(Eurogentec, Seraing, Belgien)

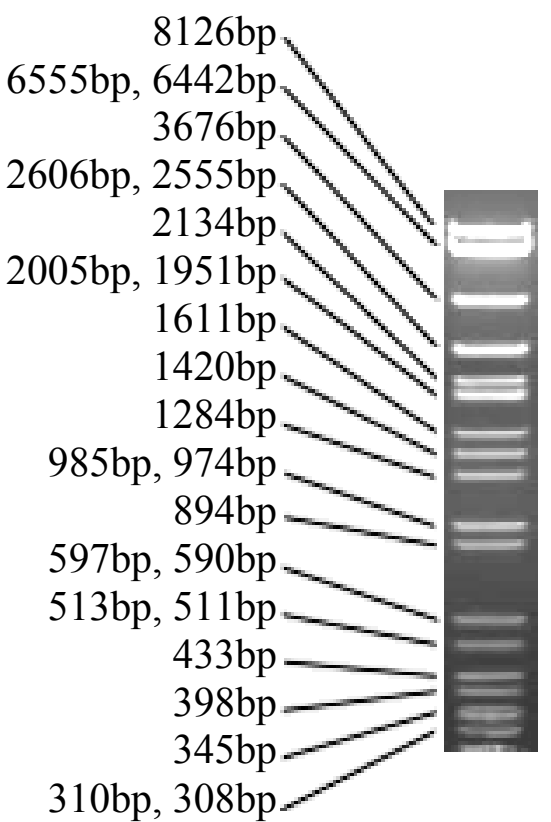

Abb.: 13

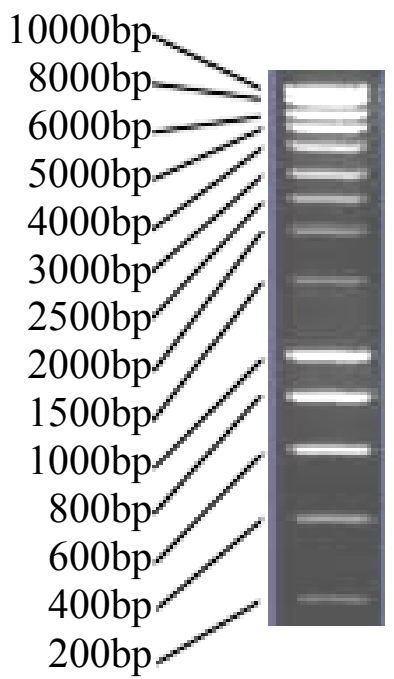

Abb.: 14 
Protein-Standard:

Kaleidoskop

(Bio-Rad, München)

Proteine: Myosin, $\beta$-Galactosidase, BSA,

Carbonic anhydrase, Sojabohne

Trypsin-Inhibitor, Lysozym,

Aprotinin

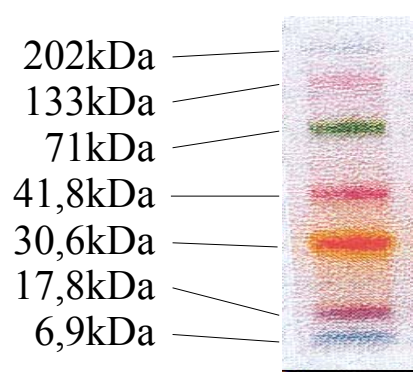

Abb.: 15

Protein-Ladder

(MBI Fermentas)

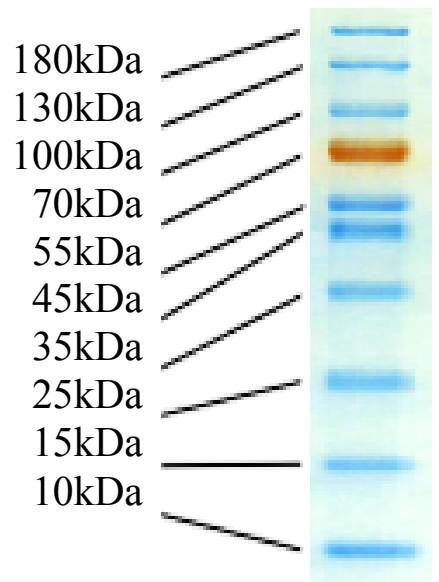

Abb.: 16

\subsection{Methoden}

\subsubsection{Allgemeine Versuche}

\subsubsection{Sterilisation von Lösungen und Material}

Zur Vorbereitung von hitzestabilen Glaswaren wurden diese für $20 \mathrm{~min}$ bei $181^{\circ} \mathrm{C}$ gebacken. Hitzestabile Lösungen wurden für $20 \mathrm{~min}$ bei $121^{\circ} \mathrm{C}$ und 1 ,2bar Überdruck autoklaviert. Hitzelabile Lösungen wurden durch einen Membranfilter (Sartorius, Millipore) mit der Porengröße 0,2 $\mu \mathrm{m}$ sterilfiltriert.

\subsubsection{Kultivierung von Bakterien (Agarplatten)}

Für Sequenzierungen und Klonierungen wurden PCR-Produkte und kleine DNA-Moleküle über verschiedene Methoden in Plasmide ligiert (TOPO-TA-Klonierung, Punkt 2.2.1.14 oder Ligation, Punkt 2.2.1.15) und in E. coli-Zellen eingebracht (Transformation 2.2.1.16 und 17). Kompetente E. coli-Zellen wurden dann direkt mit dem Ligationsansatz 
transformiert. Nach der Separation einzelner Kolonien durch Verwendung von Agarplatten, wurde eine Plasmid-Aufreinigung vorgenommen und das Insert sequenziert.

Im Fall der Klonierung über das TOPO-TA-Cloning Kit mit pCR2.1 ${ }^{\mathrm{TM}}$ wurden die Bakterien auf Ampicillin-haltigen LB-Agar-Platten ausplattiert, auf die zuvor je $40 \mu 1 \mathrm{X}$ Gal (40mg/ml, X-Gal in Dimethylformamid) und IPTG (100mM) verteilt wurden. Die Platten wurden bei $37^{\circ} \mathrm{C}$ vorgewärmt und getrocknet.

IPTG wurde zur Induktion des $\mathrm{P}_{\text {lac }}$-Promotors auf dem Vektor benötigt. Die $\beta$ Galactosidase, die nachfolgend codiert ist (lacZ-Gen), kann im intakten (nativen) Zustand das Substrat X-Gal unter Entstehung eines blauen Produktes spalten. Im Fall der erfolgreichen Klonierung ist die Expression des LacZ-Gens allerdings aufgrund eingeführter Stop-Codons und einer Leserahmenverschiebung unterbunden.

Im Fall der Klonierung über den Vektor pCR4-TOPO ${ }^{\mathrm{TM}}$ wurde Ampicillin-haltiger LBAgar verwendet. Ein auf dem Plasmid codiertes $c c d$ B-Gen selektiert Bakterien aus, die kein Insert im Plasmid tragen.

Zur Selektion des Plasmids pUC19 wurde ebenfalls Ampicillin-haltiger LB-Agar verwendet.

Zur Selektion des Plasmids pACBL16 wurde Chloramphenicol-haltiger LB-Agar verwendet

Je $200 \mu \mathrm{l}$ der Bakteriensuspension des Transformationsansatzes wurden auf den entsprechenden LB-Platten ausplattiert und die Platten über Nacht bei $37^{\circ} \mathrm{C}$ inkubiert.

Mehrere Kolonien (bei pCR2.1 weiße und schwach blaue Kolonien) wurden dann in $5 \mathrm{ml}$ dYT-Flüssigkulturen (mit dem entsprechenden Antibiotikum) angeimpft.

Nach Umwickeln der Petrischalen mit Parafilm zum Schutz vor Austrocknung wurden die Platten bei $4^{\circ} \mathrm{C}$ gelagert.

\subsubsection{Flüssigkulturen für Sequenzierungen}

Für Mini-Plasmidpräparationen wurden 5ml dYT-Medium (plus Plasmid-spezifisches Antibiotikum) in Glasröhrchen mit Einzelkolonien von Agarplatten angeimpft und über Nacht bei $37^{\circ} \mathrm{C}$ geschüttelt. 


\subsubsection{Bestimmung der Bakteriendichte}

Für die Bestimmung der Bakteriendichte von Flüssigkulturen wurde die Absorption der Zellsuspension bei einer Wellenlänge von $600 \mathrm{~nm}\left(\mathrm{OD}_{600}\right)$ in PolystyrolHalbmikroküvetten gemessen. Als Referenz wurde reines Medium verwendet.

\subsubsection{Stammkulturen}

Zum Anlegen langfristiger Stammkulturen wurden jeweils $200 \mu \mathrm{l}$ einer über Nacht gewachsenen Flüssigkultur mit $300 \mu 1$ sterilem $50 \%$ igen Glyzerin vermischt und bei $-70^{\circ} \mathrm{C}$ gelagert. Diese Kulturen können mehrere Jahre aufbewahrt werden.

\subsubsection{Plasmidpräparationen (Reinigung von Nukleinsäuren)}

Wegen der Verwendung des XL1-Blue-Stammes von E.coli konnte das folgende Protokoll durchgeführt werden (nach Giorgia Riboldi, persönliche Mitteilung).

In diesem Stamm werden keine (bekannten) Endonukleasen exprimiert, weshalb man bei der Plasmid-Aufreinigung keine so schnelle und vollständige Protein-Abtrennung wie sonst üblich benötigt.

Je $1,5 \mathrm{ml}$ einer Über-Nacht-Kultur wurden $2 \mathrm{~min}$ bei $4^{\circ} \mathrm{C}$ und $14.000 \mathrm{rpm}$ in $1,5 \mathrm{ml}$ Reaktionsgefäßen abzentrifugiert, das Zellpellet wurde dann in 200 $\mu 1$ P1-Puffer (mit RNase A; Qiagen) resuspendiert. Anschließend wurden 300 $\mu$ 1 P2-Puffer (Lysis-Puffer, Qiagen) zum Aufschließen der Zellen durch SDS und Denaturierung von DNA und Proteinen durch $\mathrm{NaOH}$ zugegeben. Daraufhin wurde das Reaktionsgefäß $10 \mathrm{mal}$ umgeschwenkt. Nach 5 minütiger Inkubation auf Eis wurden weitere 300 $\mu 1$ P3-Puffer (Neutralisations-Puffer, Qiagen) zugegeben, um durch schlagartige Neutralisation des Ansatzes, denaturierte genomische DNA (lange DNA-Bruchstücke), Proteine und andere Zellbestandteile (z.B. Lipide) ausfallen zu lassen. Die hohe K-Salzkonzentration führt zum Ausfallen des SDS als K-Salzkomplex und in der Folge zum „Einfangen“ der denaturierten Bestandteile der Lösung. Kleine Plasmid-Moleküle sind in der neutralisierten Lösung zur Renaturierung fähig und bleiben daher in Lösung. Das Reaktionsgefäß wurde nun wiederum 10 mal umgeschwenkt und dann 5 min auf Eis inkubiert. Danach wurde der Ansatz $15 \mathrm{~min}$ bei $4^{\circ} \mathrm{C}$ und $14.000 \mathrm{rpm}$ abzentrifugiert und der Überstand in ein neues Reaktionsgefäß überführt. Der Überstand wurde mit 1:1 Volumen $(800 \mu l)$ Isopropanol gefällt, um die im Ansatz vorhandene, zirkuläre Plasmid-DNA zu fällen und in neues Lösungsmittel überführen $\mathrm{zu}$ können. Anschließend wurde für $10 \mathrm{~min}$ bei $4^{\circ} \mathrm{C}$ und 14.000rpm zentrifugiert. Das Pellet wurde mit 500 $\mu 1$ 70\% Ethanol gewaschen und luftgetrocknet. Dann wurde es in $32 \mu 1 \mathrm{H}_{2} \mathrm{O}$ resuspendiert. Schließlich wurden $8 \mu \mathrm{l}(4 \mathrm{M})$ $\mathrm{NaCl}$ und $40 \mu 1$ 13\% (v/v) PEG 8000 zugegeben. Durch diese zusätzliche Fällung wird die 
Reinheit der abschließend gefällten DNA erhöht. Zentrifugation für $15 \mathrm{~min}$ bei $4^{\circ} \mathrm{C}$ und 14.000rpm lieferten ein DNA-Pellet, das mit 500 $\mu 1$ 70\% Ethanol gewaschen und luftgetrocknet wurde. Zu letzt wurde die DNA in $20 \mu 1 \mathrm{H}_{2} \mathrm{O}$ aufgenommen.

\subsubsection{Phenolextraktion (Reinigung von Nukleinsäuren)}

Zur Entfernung von Proteinverunreinigungen aus RNA- und DNA-Lösungen wurden diese mit dem gleichen Volumen Phenol pH 8,0 (bzw. pH 4,5 für RNA) vermischt, kräftig gevortext und die Phasentrennung durch 1 minütige Zentrifugation bei $14.000 \mathrm{rpm}$ beschleunigt.

Der wässrige Überstand wurde vorsichtig abgenommen und ein- bis zweimal mit wassergesättigtem Ether ausgeschüttelt. Anschließend wurde die RNA mit Ethanol gefällt.

\subsubsection{Ethanolfällung (Reinigung von Nukleinsäuren)}

Zur Fällung mit Ethanol wurde die RNA bzw. DNA-Lösung mit 1/10 Volumen 3M NaAc pH 5,2 und 3 bzw. 2,5 Volumina Ethanol $\left(100 \%\right.$ p.a., $\left.-20^{\circ} \mathrm{C}\right)$ versetzt, gevortext und mindestens $30 \mathrm{~min}$. bei $-70^{\circ} \mathrm{C}$ oder über Nacht bei $-20^{\circ} \mathrm{C}$ gelagert.

Das Präzipitat wurde $30 \mathrm{~min}$. bei $4^{\circ} \mathrm{C}$ mit $14000 \mathrm{rpm}$ in einer Tischzentrifuge abzentrifugiert. Gegebenenfalls wurde das Pellet dann mit 80\%igem (für RNA) bzw. $70 \%$ igem (für DNA) Ethanol gewaschen und erneut $15 \mathrm{~min}$. wie oben beschrieben zentrifugiert. Der Überstand wurde sorgfältig abgenommen und das Pellet ca. 10min. an der Luft trocknen gelassen.

Schließlich wurde die RNA, bzw. DNA in $\mathrm{H}_{2} \mathrm{O}$ aufgenommen und die Konzentration mittels Messung der Absorption bei 260nm bestimmt.

\subsubsection{Konzentrationsbestimmung von Nukleinsäuren}

Die DNA- bzw. RNA-Konzentration einer Lösung wurde durch die Messung der Absorption bei $260 \mathrm{~nm}$ in einer $60 \mu \mathrm{l}$ Schwarzwand-Quarzküvette gegen eine Referenz mit identischem Puffer ohne Nukleinsäure ermittelt.

Dabei entspricht die optische Dichte (OD) bei 260nm folgenden Konzentrationen:

(Quelle: Novagen, Heidelberg, Katalog 1994, S.72)

$\begin{array}{lll}\text { für } & \text { dsDNA: } & \mathrm{OD}_{260} \bullet 50=\text { DNA-Konzentration }(\mathrm{mg} / \mathrm{ml}) \\ \text { für } & \text { ssRNA: } & \mathrm{OD}_{260} \bullet 40=\text { RNA-Konzentration }(\mathrm{mg} / \mathrm{ml}) \\ \text { für } & \text { ssDNA (Oligos): } & \text { OD260 } 230=\text { Oligo-Konzentration }(\mathrm{mg} / \mathrm{ml})\end{array}$

Die Konzentration von TYMV-RNA-Varianten wurde nach J. Wientges (Wientges, 1998) bestimmt: 
Für TYMV-RNA's: $\quad$ OD260 $\quad 35=$ Oligo-Konzentration $(\mathrm{mg} / \mathrm{ml})$

Durch den Vergleich der Absorption bei 260 und bei 280nm läßt sich die Reinheit der Nukleinsäurelösung bestimmen. Wenn der Quotient $\mathrm{OD}_{260} / \mathrm{OD}_{280}$ unter 1,8 liegt, so ist die Nukleinsäure mit Protein oder Phenol verunreinigt (Sambrook et al., 1989).

\subsubsection{Agarose-Gelelektrophorese}

Im Restriktionsverdau entstandene Fragmente von Plasmid-DNA wurden durch AgaroseGelelektrophorese (2\%, w/v) analysiert.

Die Gele wurden in 1xTAE-Puffer angesetzt. Die Agarose wurde durch Erhitzen im Mikrowellenherd gelöst und nach Abkühlung auf ca. $50^{\circ} \mathrm{C}$ in eine vorbereitete Gelform gegossen. Es wurde ein analytischer Kamm mit 11 Kammern und je ca. $20 \mu 1$ Volumen eingesetzt. Nach dem Erstarren des Gels wurde es in die mit 1xTAE-Puffer gefüllte Kammer eingesetzt und der Kamm entfernt.

Die Proben wurden mit 1 Volumen Probenpuffer (nativ) gemischt, aufgetragen und bei $70 \mathrm{~V}$ in das Gel eindringen gelassen. Anschließend wurde die Spannung auf 100V erhöht.

Nach dem Lauf wurde das Gel für ca. 20min in ein EtBr-Bad gelegt.

Das Bandenmuster der durch die Interkalation des EtBr unter UV-Licht (254nm) fluoreszierenden DNA wurde unter Verwendung eines Gelbfilters fotografiert.

\subsubsection{Polyacrylamid-Gelelektrophorese (PAGE)}

Für die Auftrennung der in vitro Transkriptions- und PCR-Produkte wurden vertikale 10, 12 oder 15\%ige (v/v) native oder denaturierende Polyacrylamid-Gelelektrophoresen (PAGE) nach Ogden und Adams (Ogden and Adams, 1987) durchgeführt.

Die denaturierenden Gele enthielten 8M Harnstoff als chaotropes Agens. Die Polymerisation wurde durch die Zugabe von $25 \mu 1$ TEMED und 50 $\mu 1$ 10\%iger APS-Lösung pro $10 \mathrm{ml}$ Gelvolumen gestartet. Die Gellösung wurde dann blasenfrei zwischen zwei Glasplatten gegossen, die durch zwei Abstandshalter (,Spacer“), welche auch die Dicke des Gels definieren, an den Seiten begrenzt werden. Die Gele polymerisierten mindestens $20 \mathrm{~min}$ aus. Als Elektrophoresepuffer wurde 1xTBE-Puffer verwendet. Pro Gel (ca. $6 \times 8 \times 0,05 \mathrm{~cm}$ ) wurden $25 \mathrm{~mA}$ (bei nicht begrenzter Voltstärke) eingestellt und die Elektrophorese für ca. 35min durchgeführt. Bei der Verwendung größerer Gele (ca. 20x20x0,1cm) zur Auftrennung radioaktiv markierter RNA wurden 30W bei nicht begrenzter Volt- und Amperestärke für 50min eingestellt 


\subsubsection{PAA-Gel Elution von DNA}

Um RNA-Populationen sequenzieren zu können, wurden diese mittels reverser Transkription (Punkt 2.2.2.7.) und anschließender PCR (Punkt 2.2.2.1.) in doppelsträngige DNA übersetzt. Die doppelsträngige DNA wurde über $12 \%$ ige, native, präparative PAAGele aufgetrennt (Punkt 2.2.1.11.). Um möglichst nur Fragmente der gewünschten Länge (z.B. 107bp) zu klonieren (kleinere Fragmente werden in der Ligation bevorzugt eingebaut), wurde die Bande der entsprechenden Größe ausgeschnitten, das Gelstück in kleine Stücke zerteilt und über Nacht in 100-200 $\mu$ TE-Puffer bei $4^{\circ} \mathrm{C}$ eluiert. Am nächsten Tag wurde der Ansatz 1 Stunde bei $60^{\circ} \mathrm{C}$ inkubiert und anschließend 5min. mit 13.000rpm abzentrifugiert. Der Überstand wurde Ethanol-gefällt (1 Stunde, $\left.-80^{\circ} \mathrm{C}\right)$, nach Zentrifugation für $20 \mathrm{~min}$. bei $4^{\circ} \mathrm{C}$ und $13.000 \mathrm{rpm}$ luftgetrocknet und in $10-30 \mu 1 \mathrm{H}_{2} \mathrm{O}$ aufgenommen.

Dann wurde durch $\mathrm{OD}_{260}$-Messung die DNA-Konzentration bestimmt. Im Falle von $\mathrm{OD}_{260}$-Werten kleiner als 0,005 wurde die Konzentration zusätzlich durch eine analytische Gelelektrophorese bestimmt.

Die eluierte DNA wurde direkt für anschließende Klonierungen, bzw. Ligationen verwendet.

\subsubsection{Western-Blot (,Semi-Dry“)}

Eine Methode, um definierte Proteine aus einem Polyacrylamid-Gel sichtbar zu machen, ist die Überführung der Proteine auf eine PVDF-Membran und anschließende Anfärbung über Antikörper.

Um Proteine aus einem Gel auf eine PVDF-Membran zu überführen, wird zwischen einer Kathoden- und einer Anoden-Platte einer Western-Blot Apparatur der folgende Papier/GelStapel geschichtet. Auf die Anodenplatte werden 2 Filterpapiere (auf Gelgröße zugeschnitten) gelegt. Sie wurden zuvor mit Puffer I (300mM Tris/HCl, pH 10,4) getränkt. Darauf wird 1 Filterpapier (in Gelgröße) gelegt, das mit Puffer II (25mM Tris/HCl, pH 10,4) getränkt ist. Nun wird die entsprechend zugeschnittene PVDF-Membran (vorher in Methanol getränkt) aufgelegt. Auf diese wird nun das Gel geschichtet, das vorher $5 \mathrm{~min}$. in Kathodenpuffer (25mM Tris/HCl, $\mathrm{pH} 9,4 ; 40 \mathrm{mM}$ L-Norleucin) gelegen hat. Zuletzt werden 3 Filterpapiere aufgelegt, die mit Kathodenpuffer getränkt sind. Alle Bestandteile wurden luftblasenfrei aufeinander gelegt. Nach Auflegen der Kathodenplatte wurde die einzustellende Stromstärke nach der Formel:

Stromstärke $=$ Gesamtgelfläche $\left(\mathrm{cm}^{2}\right) \cdot 2,5 \mathrm{~mA}$

bestimmt. Die Dauer des Blotvorganges betrug ca.1h.

Anschließend wurden Proteine spezifisch mit Antikörpern markiert und durch eine Enzymreaktion angefärbt. Hierzu wurde die mit Proteinen beladene Membran aus dem Blot in einen Plastikbeutel gelegt und 15ml BB-Puffer (5g Magermilchpulver in $100 \mathrm{ml}$ 
PBS) zugegeben. Die Proteine des Milchpulvers sollen unselektiv freie Bindeplätze der Membran absättigen, um den unspezifischen Farbhintergrund zu verringern. Der Beutel wurde luftblasenfrei verschweißt und $2 \mathrm{~h}$ bei Raumtemperatur oder über Nacht bei $4^{\circ} \mathrm{C}$ geschwenkt. Die Membran wurde nun in einen neuen Beutel überführt und $10 \mathrm{ml}$ Puffer BBT (Puffer BB $+0,05 \%$ Tween 20) mit entsprechender Verdünnung des 1. Antikörpers (Punkt 2.1.4.) wurden zugegeben und luftblasenfrei verschweißt. Etwa für $2 \mathrm{~h}$ wurde bei Raumtemperatur geschwenkt. Danach wurde die Membran in ca. 100ml PBST (PBS + $0,05 \%$ Tween 20) für 10min. gewaschen. Alle Waschschritte finden unter leichtem Schwenken statt. Jetzt wurde 4 mal für je 5min. mit ca. 100ml PBS gewaschen. Anschließend wurde der 2. Antikörper (Punkt 2.1.4., kovalent verbunden mit Alkalischer Phosphatase) aufgebracht. 10ml PBS/BBT (1:1) mit der entsprechenden Verdünnung des 2. Antikörpers wurden mit der Membran luftblasenfrei in einem Plastikbeutel verschweißt. Dieser wurde für 1h bei Raumtemperatur geschwenkt. Nachdem die Membran nun 10min. in 100ml PBST gewaschen wurde, wurde nochmals 4 mal für je 5min. mit 100ml PBS gewaschen. Die Färbung der Membran wird in 50ml Entwicklungspuffer $+150 \mu 1 \mathrm{NBT},+$ $200 \mu 1$ BCIP in Dunkelheit und Ruhe durchgeführt. Nachdem Proteinbanden ausreichend gut sichtbar geworden waren, wurde die Membran mit $\mathrm{H}_{2} \mathrm{O}$ gewaschen und getrocknet.

\subsubsection{4. Überhängende A-Enden anfügen}

Für die Ligation von PCR-Produkten in linearisierten pCR2.1 ${ }^{\mathrm{TM}}$ oder $\mathrm{pCR} 4^{\mathrm{TM}}$, die überhängende T-Enden besitzen, müssen zunächst einzelne überhängende AdeninNukleotide an die 3'-Enden der PCR-Produkte angefügt werden. Dies geschah durch den Einsatz einer thermostabilen DNA-Polymerase (Ampli-Taq), die wegen ihrer intrinsischen Transferaseaktivität ein zusätzliches Adenin am 3'-Ende der synthetisierten DNA anhängt. Eine solche Reaktion muß kurz vor der Ligation durchgeführt werden, da die überhängenden A-Enden instabil sind und mit der Zeit wieder abgebaut werden (längere Aufbewahrung, auch bei $-80^{\circ} \mathrm{C}$, führt zu signifikant niedrigeren Ausbeuten).

Dazu wurden $10 \mu 1$ des PCR-Ansatzes nach erneuter Zugabe von 0,3 $\mu 1$ Ampli Taq [5U/ $\mu 1]$ (Perkin Elmer, Branchburg, USA) für $10 \mathrm{~min}$ bei $72^{\circ} \mathrm{C}$ inkubiert. Anschließend wurden die PCR-Produkte teilweise durch Phenolextraktion und Ethanolfällung sowie Waschen mit $70 \%$ Ethanol gereinigt und der Niederschlag in $10 \mu 1 \mathrm{H}_{2} \mathrm{O}$ aufgenommen.

\subsubsection{Ligation mit dem TOPO-TA-Cloning $\mathrm{Kit}^{\mathrm{TM}}$}

Zur Klonierung der selektierten RNA-Varianten wurde die RNA mittels Reverser Transkription (RT) in DNA umgeschrieben, durch PCR amplifiziert (,RT-PCR“) und 
anschließend mit dem TOPO-TA-Cloning Kit von Invitrogen (Leek, Holland) oder durch herkömmliche Ligation (Punkt 2.2.1.16.) in das Plasmid pCR2.1 ${ }^{\mathrm{TM}}$ oder pCR4 ${ }^{\mathrm{TM}}$ kloniert. Im TOPO-TA-Cloning Kit ist ein linearisierter Vektor mit einem einzelnen ThymidinÜberhang an beiden 3'-Enden enthalten. An beide Enden des Vektors ist kovalent Topoisomerase I gebunden. Ein DNA-Fragment wird über die überhängenden Nukleotide gebunden und durch die Topoisomerase innerhalb von $5 \mathrm{~min}$. ligiert, wonach, nach Zugabe einer „Stop“-Lösung, das Enzym abgespalten wird (Shuman, 1994).

Für die Ligation sollten 0,5 bis $4 \mu$ PCR-Ansatz (10-20ng/ $\mu$ l) bei einer durchschnittlichen Insertlänge von 400 bis 1000 Basenpaaren mit $1 \mu \mathrm{l}$ Vektor $(10 \mathrm{ng} / \mu \mathrm{l})$ gemischt und dann zu $5 \mu 1$ Endvolumen mit sterilem Wasser aufgefüllt werden. Der Ansatz wurde für $5 \mathrm{~min}$. bei Raumtemperatur inkubiert. Dann wurde eine „Stop“-Lösung zugegeben und 10sec. vermischt. Der Ansatz wurde kurz auf Eis gelagert (maximal 20min.), bis er in der Transformation (Punkt 2.2.1.17.) eingesetzt wurde.

\subsubsection{Ligation nach Dugaiczyk et al. (1975)}

Für die, alternativ zum Protokoll des TOPO-TA-Cloning Kit, durchgeführten Ligation wurde zuerst eine Berechnung der Vektorkonzentration durchgeführt.

Nach der Theorie von Dugaiczyk et al. (Dugaiczyk et al., 1975) kann die Vektorkonzentration bestimmt werden, bei der die Rezirkularisierung des linearisierten Vektors wahrscheinlich wird.

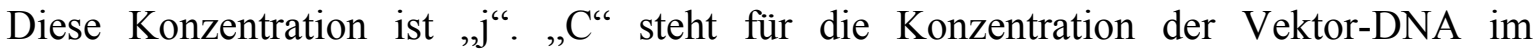
Ligations-Ansatz.

$$
\mathrm{C}_{\text {DNA }} \ll \mathrm{j}(\mu \mathrm{g} / \mu \mathrm{l})=\frac{51,1}{\text { (Molekülmasse }_{\text {Vektor-DNA })^{0,5}}}
$$

Für den Standard-Ligationsansatz wurde $1 / 5$ des j-Wertes Vektor-DNA eingesetzt. $1 / 5$ ist ein Richtwert, um die Rezirkularisierung und Konkatemerbildung des Vektors, die bei der Konzentration $\mathrm{j}$ und darüber wahrscheinlich sind, zu minimieren. Zum Vektor wurde in der Regel der 20 oder 200 fache Überschuß an Insert eingesetzt.

$10 \mu 1$ Ansatz setzten sich wie folgt zusammen:

$1 \mu 1 \quad$ Insert-DNA (z.B.: 0,027 $\mu \mathrm{g}$ eines 104bp-Inserts bei 1:20 Überschuß)

$1 \mu 1 \quad 10 x$ Ligase-Puffer

$2,6 \mu \mathrm{l}$ Vektor (z.B.: pCR2.1 $\left.{ }^{\mathrm{TM}} ; 0,025 \mu \mathrm{g} / \mu \mathrm{l}\right)$

$4,4 \mu \mathrm{l} \quad \mathrm{H}_{2} \mathrm{O}$

$1 \mu \mathrm{l}$ T4-DNA-Ligase 
Grundsätzlich wurde ein Religationsansatz (ohne Insert) als Kontrolle mitbearbeitet.

Die Ligation ist über Nacht bei $14^{\circ} \mathrm{C}$ oder wenige Stunden bei Raumtemperatur inkubiert worden.

\subsubsection{Transformation (Hitzeschock)}

$200 \mu 1$ XL1-Blue kompetente Zellen wurden auf Eis aufgetaut und anschließend mit $5 \mu 1$ Ligationsansatz vermischt. Nach 30min. Inkubation auf Eis wurde ein Hitzeschock durchgeführt $\left(2 \mathrm{~min}\right.$. bei $\left.42^{\circ} \mathrm{C}\right)$. Danach wurde $2 \mathrm{~min}$. auf Eis inkubiert, dann schließlich $1 \mathrm{ml}$ auf $30-37^{\circ} \mathrm{C}$ temperiertes SOC-Medium zugegeben und 1 Stunde bei $37^{\circ} \mathrm{C}$ inkubiert. Die Zellen wurden jetzt 3min. mit 4000rpm abzentrifugiert und das Pellet in 200 $\mu 1$ SOCMedium wieder aufgenommen. Die gesamte Menge wurde auf LB+Amp+X-Gal+IPTGPlatten ausplattiert und über Nacht bei $37^{\circ} \mathrm{C}$ inkubiert (Punkt 2.2.1.2.).

\subsubsection{Transformation (Elektroporation)}

$50 \mu 1$ XL1-Blue kompetente Zellen wurden auf Eis aufgetaut und anschließend mit $2 \mu 1$ Ligationsansatz (Punkt 2.2.1.15./16., bei Bedarf dialysiert) vermischt. Der Ansatz wurde nun in eine Elektroporationsküvette $(50 \mu$ l Volumen) gegeben und für wenige Sekunden unter $1,7 \mathrm{kV}$ Spannung gesetzt. Sofort danach wurde $1 \mathrm{ml}$ SOC-Medium zugegeben, alles in ein neues Reaktionsgefäß gefüllt und für $1 \mathrm{~h}$ bei $37^{\circ} \mathrm{C}$ gekurt. Die Zellen wurden jetzt in 3 min. bei 4000rpm und Raumtemperatur pelletiert. Der Überstand wurde bis auf etwa $200 \mu \mathrm{l}$ abgenommen und nach Resuspendieren der Zellen wurden diese auf Agar-Platten mit entsprechendem Antibiotikum ausplattiert und über Nacht bei $37^{\circ} \mathrm{C}$ inkubiert (Punkt 2.2.1.2.).

\subsubsection{Restriktionsverdau}

Um vorselektierte Klone auf ein gewünschtes Insert hin zu überprüfen, oder um Umklonierungen durchzuführen, wurde ein Restriktionsverdau (mittels Endonukleasen) durchgeführt und dieser anschließend mit Hilfe eines 12\% PAA-Gels analysiert.

Da Volumina, DNA- und Enzymmenge variabel sind, wird hier nur ein Beispiel-Ansatz aufgeführt. Ein $20 \mu 1$-Ansatz wurde wie folgt pipettiert:

$5 \mu \mathrm{l} \quad$ DNA (mehrere $\mu \mathrm{g})$

$2 \mu 1 \quad 10 x$ Puffer für Restrikionsendonuklease

$12 \mu \mathrm{l} \quad \mathrm{H}_{2} \mathrm{O}$

$1 \mu \mathrm{l}$ Restrikionsendonuklease (i.d.R. 10U/ $\mu 1$;maximal $1 / 10$ des Ansatzes) 
Der Ansatz wurde für mindestens 1 Stunde, meist über Nacht bei $37^{\circ} \mathrm{C}$ inkubiert.

\subsubsection{Versuche im Selektionszyklus}

\subsubsection{Amplifikation durch PCR}

Diese Methode wurde nicht ausschließlich in der in vitro Selektion benutzt. Wenn in verschiedenen Experimenten von den hier aufgeführten Parametern abgewichen wurde, wurden diese Abweichungen in den Ergebnissen beschrieben.

Ausgehend von einzelsträngigen Oligonukleotiden wurden doppelsträngige DNA-Matrizen hergestellt (z.B. Lib D) und amplifiziert. Die Ausgangs-Oligonukleotide der Bibliothek waren chemisch, in den weiteren Selektionszyklen durch reverse Transkription hergestellt.

Durch den Einsatz einer thermostabilen DNA-Polymerase und entsprechender Oligonukleotide lassen sich DNA-Sequenzen zwischen den Oligonukleotidbindungsstellen amplifizieren.

Für eine Standard-PCR (Gesamtvolumen: 100 $\mu$ l) wurden folgende Komponenten in PCRReaktionsgefäßen zusammengegeben:

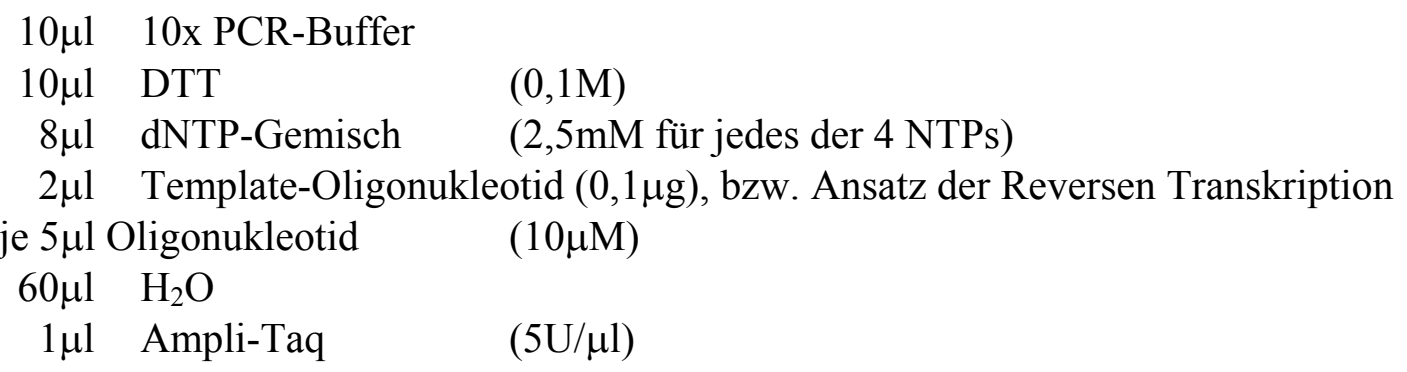

Es wurden nun Temperaturzyklen zur Denaturierung, Hybridisierung und Polymerisationsreaktion durchgeführt.

Die Reaktion fand unter folgenden Bedingungen statt (für die Bibliothek Lib D):

Es wurden 1-2 vorangehende Temperaturzyklen mit der Denaturierungstemperatur $94^{\circ} \mathrm{C}$ (2min.), der Hybridisierungstemperatur $62^{\circ} \mathrm{C}$ (3min.) und der Polymerisationstemperatur $72^{\circ} \mathrm{C}$ (3min.) durchgeführt. Anschließend folgten 10-20 Temperaturzyklen mit der Denaturierungstemperatur $94^{\circ} \mathrm{C}\left(30 \mathrm{sec}\right.$.), der Hybridisierungstemperatur $69^{\circ} \mathrm{C}(45 \mathrm{sec}$.) und der Polymerisationstemperatur $72^{\circ} \mathrm{C} \quad(45 \mathrm{sec}$.$) . Die Hybridisierungstemperaturen$ unterschieden sich je nach verwendetem Oligonukleotid („Primer"), von den ersten Zyklen. Abschließend wurde für 10min. die Polymerisationstemperatur von $72^{\circ} \mathrm{C}$ eingestellt.

Die PCR-Ansätze wurden ohne weitere Reinigung bei $-20^{\circ} \mathrm{C}$ gelagert und ebenso ohne Aufreinigung zur Transkription eingesetzt. Außerdem wurde die Analyse mittels eines nativen 12\%igen Polyacrylamid-Gels durchgeführt (Punkt 2.2.1.11.). 


\subsubsection{In vitro Transkription}

Die doppelsträngigen DNA-Templates aus der PCR wurden in RNA umgesetzt, um den eigentlich zu selektierenden bzw. zu messenden Pool zu erhalten.

Der Reaktionsmix für einen ca. $250 \mu \mathrm{l}$ in vitro Transkriptionsansatz (Tsk-Ansatz) setzte sich folgendermaßen zusammen:

$\begin{array}{clc}10 \mu \mathrm{l} & \text { Tris/HCl } & \mathrm{pH} 8,1(1 \mathrm{M}) \\ 5,5 \mu \mathrm{l} & \mathrm{MgCl}_{2} & (1 \mathrm{M}) \\ 2,5 \mu \mathrm{l} & \text { Spermidin } & (0,1 \mathrm{M}) \\ 2,5 \mu \mathrm{l} & \text { DTT } & (0,5 \mathrm{M}) \\ 1 \mu \mathrm{l} & \text { RNasin } & (40 \mathrm{U} / \mu \mathrm{l}) \\ 5 \mu \mathrm{l} & \text { Triton X100 } & (0,5 \%) \\ \text { je } 20 \mu \mathrm{l} & \text { rNTPs } & (50 \mathrm{mM}) \\ 80 \mu \mathrm{l} & \text { GMP } & (50 \mathrm{mM}) \\ 40 \mu \mathrm{l} & \text { PCR-Ansatz } & \\ 15 \mu \mathrm{l} & \text { H } & \\ 10 \mu \mathrm{O} & \text { T7-RNA-Polymerase }\end{array}$

Der Ansatz wurde bei RT gemischt und dann 3-4 Stunden bei $37^{\circ} \mathrm{C}$ inkubiert.

Danach wurde die DNA-Matritze durch Zugabe von $2 \mu 1$ DNaseI (10U/ $\mu 1$, RNase-frei) und weiteren $15 \mathrm{~min}$ Inkubation bei $37^{\circ} \mathrm{C}$ abgebaut.

Anschließend wurden $25 \mu \mathrm{l}$ EDTA $(0,5 \mathrm{M})$ zugegeben, um die Funktion der T7-RNAPolymerase durch Komplexierung zweiwertiger Ionen zu unterbinden und das Enzym von der RNA zu lösen.

Hiernach wurde zweimal mit Phenol extrahiert, mit Ether das Phenol ausgeschüttelt und anschließend mit Ethanol gefällt (Volumina jeweils 1:1; Punkt 2.2.1.7./8.; das Pellet wurde in $110 \mu \mathrm{l} \mathrm{H}_{2} \mathrm{O}$ aufgenommen).

Bei der in vitro Transkription erhält man in der Regel ein Gemisch aus RNA der richtigen Länge (N-Transkript) und RNAs mit mehreren zufällig addierten nicht codierten Nukleotiden (N+1- und N+2-Transkripte; (Milligan et al., 1987; Milligan and Uhlenbeck, 1989a). Der Anteil an N- und N+1-Transkripten ist von der einzelnen T7-RNAPolymerase-Präparation sowie z. T. von der Sequenz der Transkripte abhängig (Wientges, 1998). Im vorliegenden Fall der TYMV-Varianten zeigten die Analyse aller durchgeführten analytischen Polyacrylamid-Gele, daß die Transkription keine erkennbaren Mengen an verlängerten Produkten lieferte.

Die weitere Aufreinigung erfolgte über HPLC-Gelfiltration. Diese Aufreinigungsmethode erlaubt in der Regel keine Trennung von N- und N+1-Transkripten. Diese Gelfiltration wurde benutzt, um nach dem Ende von chemischen Reaktionsabläufen (z.B. RNASynthese) überschüssige kleine Moleküle abzutrennen (z.B., NTP's, Valin). 


\subsubsection{Reinigung von RNA-Transkripten durch HPLC-Gelfiltration}

Zur Aufreinigung der RNA-Bibliotheken nach der Transkription, der Aminoacylierung bzw. der Biotinylierung wurde eine HPLC-Gelfiltration über eine Progel TSKG3000SW $\mathrm{XL}_{\mathrm{X}}$-Säule von Tosohaas (Stuttgart) an einem HPLC System („Äkta-Explorer“) von Amersham Pharmacia Biotech (Braunschweig) durchgeführt.

Die Chromatographie fand mit einer Flußrate von $0,6 \mathrm{ml} / \mathrm{min}$ mit dem Laufpuffer $0,2 \mathrm{M}$ $\mathrm{NaAc}$ pH 6,0 $+1 \%$ Methanol statt. Das über Absorptionsmessung $(\lambda=260 \mathrm{~nm})$ detektierte RNA-haltige Eluat, wurde manuell aufgefangen und betrug etwa $1,5 \mathrm{ml}$.

Je $300 \mu \mathrm{l}$ des Eluats wurden mit $20 \mu \mathrm{l} \mathrm{NaAc}(3 \mathrm{M}) \mathrm{pH} 5,2$ (1/10 Volumen) und 1,2ml Ethanol (4x Volumen) gefällt und die Pellets in $20 \mu \mathrm{l}\left(40 \mu \mathrm{l}\right.$ nach Biotinylierung) $\mathrm{H}_{2} \mathrm{O}$ vereinigt. Für die Aminoacylierung wurde eine Absorptionsmessung bei $260 \mathrm{~nm}$ durchgeführt.

\subsubsection{Aminoacylierung aufgereinigter Transkripte}

In der Selektion wurden 100pmol RNA nach thermischer Denaturierung $\left(60^{\circ} \mathrm{C}\right)$ in einem Endvolumen von $100 \mu 1$ mit 5000pmol der jeweiligen Aminosäure (ggf. teilweise mit ${ }^{3} \mathrm{H}$ markiert) mit verschiedenen Konzentrationen der jeweiligen Aminoacyl-tRNA-Synthetase aus Hefe (zwischen 20 und 0,1nM, je nach Stringenz) für verschiedene Zeiten (zwischen 15 und $1 \mathrm{~min}$., je nach Stringenz) bei $30^{\circ} \mathrm{C}$ inkubiert.

Für die Aminoacylierung wurden die Puffer MR2 (Punkt 2.1.6.) und ein Verdünnungsansatz der Synthetase verwendet.

Verdünnung der Valyl-tRNA-Synthetase: $\quad 0,6 \mu \mathrm{l}$ ValRS $(20 \mu \mathrm{M})$

59,4 $\mu \mathrm{l}$ Verdünnungspuffer (siehe Punkt 2.1.6.)

100pmol aufgereinigte RNA in $40 \mu 1 \mathrm{H}_{2} \mathrm{O}$ wurden für 1 min bei $60^{\circ} \mathrm{C}$ denaturiert. Dann wurden $50 \mu \mathrm{l} \mathrm{MR} 2$ zugegeben und für mindestens $3 \mathrm{~min}$. bei $30^{\circ} \mathrm{C}$ inkubiert, um eine Renaturierung der RNA zu erreichen. Dann wurden $10 \mu \mathrm{l}$ ValRS (entsprechend verdünnt zu $20 ; 2 ; 0,4 ; 0,1 \mathrm{nM})$ zugegeben und für 15,5 oder $1 \mathrm{~min}$. bei $30^{\circ} \mathrm{C}$ inkubiert. Die Endkonzentration der ValRS betrug 20nM.

Zum Abstoppen der Reaktion wurde zunächst der pH-Wert durch Zugabe von $10 \mu 13 \mathrm{M}$ $\mathrm{NaAc}$ pH 5,2 zum Sauren hin verschoben und dann die $\mathrm{Mg}^{2+}$-Ionen durch Zugabe von $10 \mu 1$ 0,5M EDTA komplexiert. Durch saure Phenolextraktion ( $\mathrm{pH} 4,5)$ und anschließendes zweimaliges Waschen mit wassergesättigtem Ether wurde die Synthetase abgetrennt und die RNA durch Zugabe von 0,1 Volumen 3M NaAc und 3 Volumen Ethanol gefällt. Saures Phenol wurde benutzt, um die energiereiche Bindung zwischen Aminosäure und RNA stabil zu halten. 
Zur Abtrennung der freien Aminosäure wurde anschließend eine HPLC-Gelfiltration (Punkt 2.2.2.3.) durchgeführt.

\subsubsection{Biotinylierung von aminoacylierter RNA}

Die Biotinylierung der aminoacylierten RNA wurde mit wasserlöslichem Sulfo-NHSBiotin bei pH 8,0 auf Eis mit 3000-fachem Überschuß an Biotin durchgeführt.

Dazu wurden 100pmol RNA aus der Aminoacylierung nach Phenolextraktion, HPLCReinigung und Ethanolfällung in $20 \mu \mathrm{l} \mathrm{H}_{2} \mathrm{O}$ aufgenommen und $4 \mu \mathrm{l} 0,3 \mathrm{M}$ Hepes pH 5,25 (eisgekühlt) hinzugegeben.

Durch Zugabe von 10,7 $\mu$ l 0,3M Hepes pH 9,63 (eisgekühlt) wurde der pH-Wert auf 8,0 eingestellt, und es wurden sofort $4 \mu 1$ einer frisch angesetzten Sulfo-NHS-Biotin-Lösung $\left(0,8 \mathrm{mg} / 40 \mu \mathrm{l} \mathrm{H}_{2} \mathrm{O}\right)$ zugegeben. Die Probe wurde kurz kräftig durchmischt und für 1 Stunde auf Eis inkubiert.

Anschließend wurde das freie Biotin durch Reinigung mittels HPLC-Gelfiltration (Punkt 2.2.2.3.) abgetrennt (um RNA und RNA-Aminosäure-Bindung stabil zu halten, ist der pHWert des Laufpuffers auf 6,0 eingestellt). Die biotinylierte RNA wurde zuletzt durch Zugabe von 0,1 Volumen 3M NaAc und 3 Volumen Ethanol gefällt.

\subsubsection{Immobilisierung auf Dynabeads M-280 Streptavidin}

Die biotinylierten RNAs wurden auf magnetischen Kügelchen, an deren Oberfläche Streptavidin gekoppelt ist (Dynabeads M-280 Streptavidin), immobilisiert.

Zunächst wurden $1000 \mu \mathrm{g}$ der Dynabeads M-280 Streptavidin (10mg/ml) unter Zuhilfenahme der magnetischen Fäll-Vorrichtung 3x mit je 100 $\mu 1$ HB\&W-Puffer vorgewaschen.

Nach HPLC-Reinigung und Ethanolfällung der biotinylierten RNA wurde der Niederschlag in $40 \mu \mathrm{H}_{2} \mathrm{O}$ aufgenommen. Die entstandene RNA-Lösung wurde auf die magnetisch gefällten Kügelchen gegeben und für 10min unter leichtem Schütteln bei Raumtemperatur inkubiert. Anschließend wurden die Kügelchen 4x mit je 100 $\mu 1$ HB\&W und einmal mit $100 \mu 1 \mathrm{H}_{2} \mathrm{O}$ gewaschen.

Schließlich wurden die sie in $50 \mu 1 \mathrm{H}_{2} \mathrm{O}$ aufgenommen und in ein neues Reaktionsgefäß überführt. In dieser Form wurde die auf den Kügelchen immobilisierte RNA bei $-20^{\circ} \mathrm{C}$ gelagert. Sie wurde vorzugsweise jedoch möglichst schnell mittels Reverser Transkription (Punkt 2.2.2.7.) in DNA umgeschrieben. 


\subsubsection{Reverse Transkription}

Für die Herstellung von cDNA der selektierten RNAs wurde eine Reverse Transkription mit AMV-Reversen Transkriptase und einem zum 3'-Ende der RNA komplementären Primer (TY-Val-3' oder TY-B-ValNeu-3') durchgeführt.

Für eine Standard-Reverse Transkription (Gesamtvolumen: 100 $\mu$ l) wurden folgende Komponenten in PCR-Reaktionsgefäßen zusammengegeben:

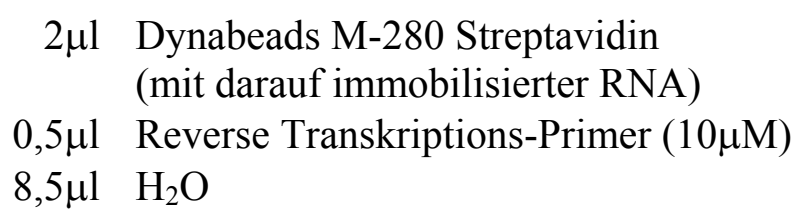

Dieses Gemisch wurde für $1 \mathrm{~min}$. auf $96^{\circ} \mathrm{C}$ erhitzt und für $15 \mathrm{~min}$. bei der AnnealingTemperatur des Reversen Transkriptions-Primers $\left(60^{\circ} \mathrm{C}\right)$ inkubiert.

Dannach wurden weitere Komponenten zugegeben:

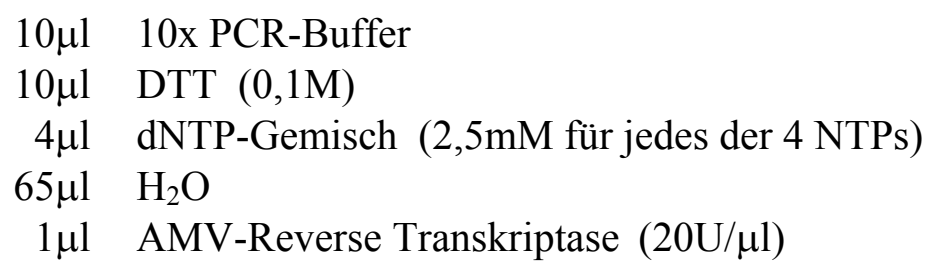

Der Ansatz wurde dann für $45 \mathrm{~min}$. bei $42^{\circ} \mathrm{C}$ inkubiert und anschließend bei $-20^{\circ} \mathrm{C}$ gelagert. Der Ansatz konnte ohne weitere Behandlung direkt in eine PCR eingesetzt werden (Wientges, 1998).

\subsubsection{Messung von Aminoacylierungs-Plateaus}

Bei der Ermittlung des Aminoacylierungs-Plateaus wurde der Anteil an aminoacylierter RNA nach Einstellung des Gleichgewichtszustandes mit einem modifizierten Protokoll nach Eigner \& Loftfield (Eigner and Loftfield, 1974) ermittelt. Dabei wurden 100pmol der jeweiligen RNA-Variante mit einer bestimmten Synthetase-Konzentration (20nM) unter den in Punkt 2.2.2.4. genannten Bedingungen mit teilweise ${ }^{3} \mathrm{H}$-markierter Aminosäure inkubiert.

$$
\begin{array}{lll}
\text { MR2 }\left({ }^{3} \mathrm{H}\right): & 22 \mu \mathrm{l} & \text { MR4,5 (Punkt 2.1.5.) } \\
& 10 \mu \mathrm{l} \quad \text { rATP }(100 \mathrm{mM}) \\
& 13,5 \mu \mathrm{l} \text { 3 } \mathrm{H}-\text { Valin } \\
& 4,5 \mu \mathrm{l} \quad \text { Valin }(1 \mathrm{mM})
\end{array}
$$


Es wurden $15 \mu \mathrm{l}$ bei $0 \mathrm{~min}$. und je $20 \mu \mathrm{l}$ Aliquots bei 3, 6, 9, 15min. entnommen, auf ein gekennzeichnetes Stück Whatman 3MM Papier pipettiert und in 5\% eisgekühltem TCA gefällt. Anschließend wurde die säurelösliche freie Aminosäure durch dreimaliges, jeweils achtminütiges Waschen mit 5\% TCA entfernt. Dann wurden die Papier-Scheibchen mit technischem Ethanol gewaschen (8min), um die TCA-Lösung zu entfernen und die Trocknung der Papier-Scheibchen zu erleichtern. Schließlich wurden die PapierScheibchen in der Mikrowelle getrocknet (3mal, 2min.), in Röhrchen mit $3 \mathrm{ml}$ Scintillations-Cocktail getaucht und die Radioaktivität mit dem Scintillationszähler für $2 \mathrm{~min}$. gemessen.

Die spezifische Aktivität (SA) der radioaktiven Aminosäure wurde ermittelt, indem $2 \mu 1$ des Aminoacylierungs-Puffers (MR2), die 200pmol der radioaktiven Aminosäure entsprechen, auf ein Whatman 3MM Papier-Scheibchen pipettiert wurden. Dieses wurde an der Luft getrocknet und wie oben beschrieben in $3 \mathrm{ml}$ Scintillations-Cocktail getaucht und die Radioaktivität gemessen. Die radioaktive Aminosäure diffundierte in das Papier hinein, so daß ein Teil der Zerfälle aufgrund der geringen Energie der $\beta$-Strahlung des Tritium-Zerfalls von dem Papier abgeschirmt und damit nicht gemessen wurde. Dagegen bleibt die mit TCA gefällte aminoacylierte RNA auf der Oberfläche des PapierScheibchens, so daß die Tritium-Zerfälle nicht abgeschirmt wurden. Daher mußten die gemessenen Zählimpulse der freien Aminosäure mit dem Korrekturfaktor 4 multipliziert werden, um die spezifische Aktivität zu ergeben, die der TCA gefällten aminoacylierten RNA entsprach (Francklyn et al., 1992; Wientges, 1998).

\subsubsection{Versuche zur in vitro Replikation von TYMV-Varianten}

Die Versuche zur Replikation wurden zum Teil in der Arbeitsgruppe von C.W.A. Pleij am Institut für Chemie an der Universität Leiden (Niederlande) durchgeführt.

\subsubsection{In vitro (-)-Strang-Synthese von TYMV-RNA durch viruseigene RNA- abhängige RNA-Polymerase (RdRp)}

Die in vitro Transkriptionen wurden nach einem Protokoll von Birgit Deiman (Deiman et al., 1997b, Deiman, 1997 \#2614), bzw. in Anlehnung an diese durchgeführt.

In einigen Transkriptions-Experimenten wurden valylierte mit nicht-valylierten TYMVRNA's (85nt-Varianten) verglichen. In diesen Fällen wurde erst eine Aminoacylierung durchgeführt und die Ansätze zur Transkription wurden nachfolgend mit modifizierten Volumina zugegeben. 
20 $\mu$ l-Ansatz zur Valylierung von TYMV-Varianten:

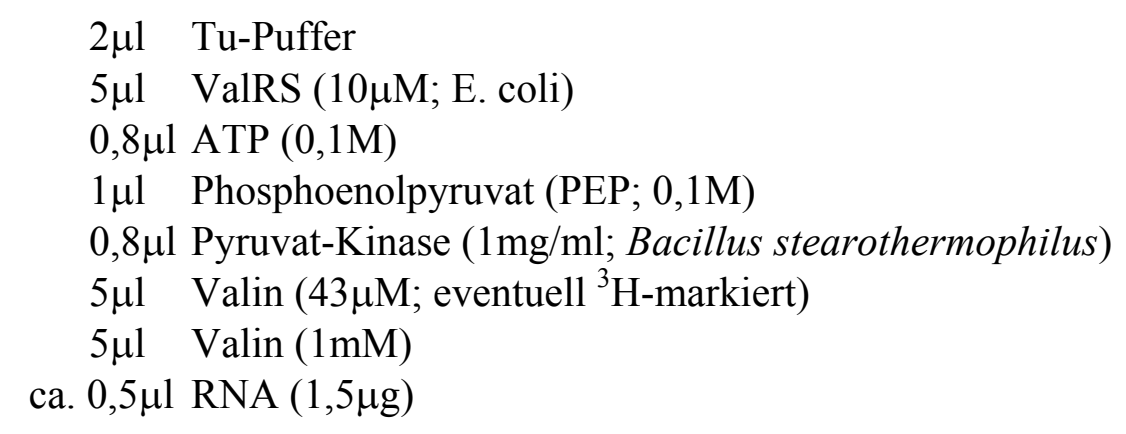

Die Ansätze der nicht zu valylierenden RNA's enthielten statt Valin, ValRS und PyruvatKinase nur $\mathrm{H}_{2} \mathrm{O}$.

Die Reaktion wurde für $40 \mathrm{~min}$. bei $30^{\circ} \mathrm{C}$ durchgeführt. In einigen Versuchen folgte nun eine Phenolextraktion und anschließendes Ausschütteln mit Ether (Punkt 2.2.1.7., in diesem Fall wurde vor der Phenolextraktion ein Referenzmolekül zugegeben). Statt einer Ethanol-Fällung wurde der Ether $10 \mathrm{~min}$. bei $30^{\circ} \mathrm{C}$ bei geöffnetem Reaktionsgefäß abgedampft.

In der nach einem Protokoll von Birgit Deiman (Deiman et al., 1997b; siehe Punkt 2.2.4.9) aufgereinigten RNA-abhängigen RNA-Polymerase (RdRp)-Präparation mußte vor der Transkription endogene Virus-RNA abgebaut werden, um sicherzustellen, daß ausschließlich neu zugegebene RNA als Matrize vorlag. Zu diesem Zweck wurde Mikrococcen-Nuklease (m.c.n.) eingesetzt:

\begin{tabular}{c|c|l}
$\begin{array}{c}\text { Ansatz nach Original- } \\
\text { Protokoll }\end{array}$ & Modifizierter Ansatz & \\
\hline $20 \mu \mathrm{l}$ & $20 \mu \mathrm{l}$ & RdRp \\
\hline $5 \mu \mathrm{l}$ & $5 \mu \mathrm{l}$ & $\mathrm{CaAc}(0,01 \mathrm{M})$ \\
\hline $3,9 \mu \mathrm{l}$ & $3,9 \mu \mathrm{l}$ & Tris/HCl $\mathrm{pH} 9,0$ \\
\hline $1,5 \mu \mathrm{l}$ & $1,5 \mu \mathrm{l}$ & m.c.n. $(17,4 \mathrm{U} / \mu \mathrm{l})$ \\
\hline $49,6 \mu \mathrm{l}$ & $37,1 \mu \mathrm{l}$ & $\mathrm{H}_{2} \mathrm{O}$ \\
\hline $80 \mu \mathrm{l}$ & $67,5 \mu \mathrm{l}$ &
\end{tabular}

Die Ansätze wurden $30 \mathrm{~min}$. bei $14^{\circ} \mathrm{C}$ inkubiert. Danach wurde die Reaktion mit $4,3 \mu \mathrm{l}$ Ethylenglycol-bis-2-aminoethyl-tetra-Essigsäure (EGTA, 0,1M) abgestoppt und 10min. auf Eis stehen gelassen. 
Um geeignete Reaktionsbedingungen für die RdRp zu erhalten, wurde der folgende Ansatz pipettiert und insgesamt zur RNA $(1,5 \mu \mathrm{g})$ gegeben. Darauf wurde sofort der RdRp/Mikrococcen-Nuklease-Ansatz gegeben.

\begin{tabular}{c|c|l}
$\begin{array}{c}\text { Ansatz nach original- } \\
\text { Protokoll }\end{array}$ & Modifizierter Ansatz & \\
\hline $1,6 \mu \mathrm{l}$ & $1,4 \mu \mathrm{l}$ & $\mathrm{MgCl}_{2}(0,5 \mathrm{M})$ \\
\hline $0,3 \mu \mathrm{l}$ & $0,3 \mu \mathrm{l}$ & $\mathrm{DTT}(1 \mathrm{M})$ \\
\hline $3 \times 2,6 \mu \mathrm{l}$ & - & Je ATP/ CTP/ GTP $(\mathrm{je} 16 \mathrm{mM})$ \\
\hline- & $2,6 \mu \mathrm{l}$ & ATP, CTP, GTP $(\mathrm{je} 16 \mathrm{mM})$ \\
\hline $2,6 \mu \mathrm{l}$ & $2,6 \mu \mathrm{l}$ & Ethanol $(96 \%)$ \\
\hline $5,0 \mu \mathrm{l}(25 \mathrm{ng} / \mu \mathrm{l})$ & $0,5 \mu \mathrm{l}(250 \mathrm{ng} / \mu \mathrm{l})$ & Actinomycin D \\
\hline $3,0 \mu \mathrm{l}$ & $3,0 \mu \mathrm{l}$ & RNase-Inhibitor $(40 \mathrm{U} / \mu \mathrm{l})$ \\
\hline $10 \mu \mathrm{Ci}$ & $10 \mu \mathrm{Ci}$ & $\left(\alpha-{ }^{32} \mathrm{P}\right)-\mathrm{UTP}(800 \mathrm{Ci} / \mathrm{mmol})$ \\
\hline $21 \mu \mathrm{l}$ & $11,4 \mu \mathrm{l}$ &
\end{tabular}

Alle Nukleotide sind nach Aufnahme ihres Salzes in Wasser nicht neutralisiert worden, bevor sie in den Ansatz eingesetzt wurden.

Nach der Vereinigung aller drei Ansätze wurde für 1 Stunde bei $30^{\circ} \mathrm{C}$ inkubiert. Anschließend wurden $100 \mu \mathrm{H}_{2} \mathrm{O}$ und ein radioaktiv markiertes Referenzmolekül zugegeben, wenn dies nicht bereits nach der Aminoacylierung geschehen war. Jetzt wurde einmal mit Phenol/Chloroform $(1: 1)+1 \%$ SDS $+20 \mathrm{mM}$ EDTA und einmal mit Phenol/Chloroform (1:1) extrahiert. Dann wurde einmal mit Chloroform ausgeschüttelt. Anschließend wurde eine Fällung mit Zugabe von 1/10 NaAc (3M) und 3 Volumen des Ansatzes Ethanol für 30min. (oder über Nacht) bei $-20^{\circ} \mathrm{C}$ durchgeführt. Nun wurde $20 \mathrm{~min}$. bei 13000rpm (RT) abzentrifugiert und das Pellet an der Luft getrocknet.

Die RNA wurde in $5 \mu \mathrm{l} \mathrm{H}_{2} \mathrm{O}$ aufgenommen und mit der gleichen Menge RNAProbenpuffer (mit Formamid nach Sambrook, 1989 \#1552] vermischt.

Die Probe wurde dann auf ein 10\%iges Polyacrylamid-Gel $+8 \mathrm{M}$ Harnstoff gegeben. Nach etwa $2 / 3$ Durchlauf des dunkelblauen Farbmarkers Bromphenolblau (etwa nach 50min.) wurde die Gelelektrophorese gestoppt (Punkt 2.2.1.11.). Die Radioaktivität des Gels wurde daraufhin auf einer Photo-Platte (Imaging Plate, Fuji Photo Film Co., LTD, Kanagwa, Japan) aufgenommen und in einem Phosphor Imager (Fuji Photo Film Co., LTD) analysiert.

\subsubsection{Aufnahme des zeitlichen Verlaufs von Aminoacylierung und (-)-Strang- Synthese in einem Experiment}

Das Experiment wurde grundsätzlich wie in Punkt 2.2.3.1. beschrieben bis zum Ende der einstündigen Transkription (Tsk) durchgeführt. Allerdings wurden in der Aminoacylierung 
(1,5facher Ansatz) $43 \mu \mathrm{M}{ }^{3} \mathrm{H}-$ Valin und in der Transkription $\left[\alpha-{ }^{32} \mathrm{P}\right]-\mathrm{UTP}$ eingesetzt. Nach 0min. wurde 1/3 (10 $\mu$ l) vom Aminoacylierungsansatz abgenommen, auf ein Filterpapier pipettiert und in 5\% TCA gefällt. Nach 40min. (Tsk-Beginn) wurde wiederum 1/3 (31 $\mu \mathrm{l})$ des Ansatzes auf ein Filterpapier gegeben und in 5\% TCA gefällt. In gleicher Weise wurde nach 55min. (nach 15min. Tsk) und 100min. (nach 60min. Tsk) verfahren. Die Filterpapiere wurden nach Ablauf der 100min. wie unter Punkt 2.2.2.8. beschrieben mit 5\% TCA und Ethanol gewaschen, in $4 \mathrm{ml}$ Scintillations-Cocktail gegeben und die Radioaktivität ausgelesen. Die Messung jeder Probe erfolgte für $2 \mathrm{~min}$. in den Energiefenstern: 0-16 keV für ${ }^{3} \mathrm{H}$ und $16-1700 \mathrm{keV}$ für ${ }^{32} \mathrm{P}$.

\subsubsection{Versuche zur in vivo Replikation von TYMV-Varianten}

\subsubsection{In vitro Transkription von TYMV-TLS-Varianten im Gesamt-Genom- Kontext zur Transfektion von Pflanzenzellen}

Zur Synthese des (+)-TYMV-RNA-Genoms wurde der Vektor pACBL16 (Punkt 2.1.9.) benutzt. Nach Linearisierung mit Eco72I (durch Modifikation des Plasmids an Stelle von NdeI) und Aufreinigung über ein Agarose-Gel, wurde eine „Run-Off“-Transkription durchgeführt (Hellendoorn et al., 1997; ähnlich wie in Scotnicki et al., 1992 beschrieben):

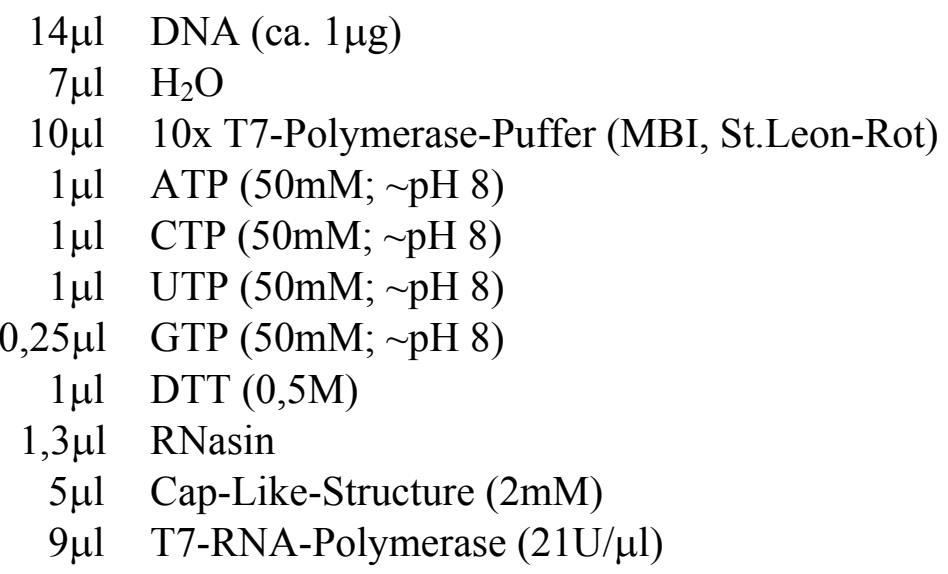

Nach einer Inkubation von $10 \mathrm{~min}$. bei $37^{\circ} \mathrm{C}$ wurden $0,2 \mu \mathrm{l}$ GTP $(50 \mathrm{mM})$ zugegeben. Nach weiteren $15 \mathrm{~min}$. Inkubation bei $37^{\circ} \mathrm{C}$ wurden $0,3 \mu \mathrm{l}$ GTP $(50 \mathrm{mM})$ zugegeben. Abschließend wurde für $2 \mathrm{~h} 30 \mathrm{~min}$. bei $37^{\circ} \mathrm{C}$ inkubiert. Der Ansatz wurde dann bis zur Verwendung auf Eis gelagert. Der Erfolg der Synthese wurde auf einem analytischen 1\%igen Agarose-Gel überprüft. 


\subsubsection{Unterhalt einer Flüssig-Zell-Kultur der Ackerschmalwand (Arabidopsis thaliana)}

Die Unterhaltung von Flüssigkulturen der Ackerschmalwand wurde wie von J. Schirawski beschrieben durchgeführt (Schirawski et al., 2000). Die hier verwendete Flüssigkultur von Arabidopsis thaliana L. (Heynh.) ssp. Columbia wurde 1992 etabliert (Axelos et al., 1992). Eine Flüssigkultur (150ml Volumen in $500 \mathrm{ml}$ Erlenmeyer-Kolben) wurden bei $25^{\circ} \mathrm{C}$ konstant mit 140rpm geschüttelt. Sie wurde pro Tag 16h künstlichem Tageslicht (12.000Lux) und 8h der Dunkelheit ausgesetzt. Einmal pro Woche wurden die Zellen in neues Zell-Medium (Punkt 2.1.6.) überführt. Dazu wurde die Kultur bei Raumtemperatur für 5min. ohne Schütteln stehen gelassen, um die Zellen zu sedimentieren. Der Überstand wurde dekantiert und die Zellen in der gleichen Menge sterilem Zell-Medium (150ml) resuspendiert. Nun wurden $15 \mathrm{ml}$ abgenommen und in $135 \mathrm{ml}$ sterilem, frischen ZellMedium verdünnt.

\subsubsection{Präparation von Protoplasten}

Zur Präparation von Protoplasten wurde eine Flüssig-Zell-Kultur (eine Woche alt) von Arabidopsis thaliana, wie unter Punkt 2.2.4.2. beschrieben, 1:10 verdünnt und über Nacht normal wachsen gelassen (Präparation nach Schirawski et al., 2000).

Am nächsten Tag wurden die Zellen für 5-10min. sedimentiert und der Überstand bis auf $20 \mathrm{ml}$ dekantiert. Die Zellen wurden dann möglichst vollständig in ein 50ml PlastikRöhrchen überführt. Nach 5min. Zentrifugation bei $80 \mathrm{~g}$ ( 600rpm, ohne Bremsen) und Raumtemperatur, wurde der Überstand vollständig abgenommen. Nun wurden $20 \mathrm{ml}$ Enzym-Lösung (Pectolyase, Cellulase) zugegeben, um die Zellen zu vereinzeln und die Zellwände abzubauen. Nach vorsichtigem Resuspendieren wurde im geschlossenen $50 \mathrm{ml}$ Plastik-Röhrchen bei $37^{\circ} \mathrm{C}$ für $30 \mathrm{~min}$. inkubiert. Nach vorsichtigem Vermischen der Zellen wurde für weitere $30 \mathrm{~min}$. bei $37^{\circ} \mathrm{C}$ inkubiert. Um Protoplasten von normalen Zellhaufen $\mathrm{zu}$ trennen, wurde die Suspension anschließend durch ein steriles $50 \mu \mathrm{m}$ Metall-Sieb (rostfrei) filtriert. Nun wurden $30 \mathrm{ml}$ Proto-Medium zugegeben und wieder für $5 \mathrm{~min}$. bei $80 \mathrm{~g}$ und Raumtemperatur zentrifugiert. Der Überstand wurde verworfen und die Zellen in $50 \mathrm{ml}$ frischem Proto-Medium aufgenommen. Nach erneuter Zentrifugation (unter den genannten Bedingungen) und Aufnahme der Protoplasten in 15ml Proto-Medium, wurde die Anzahl der Zellen in einer Mikro-Zählkammer bestimmt. Durch Zugabe von 35ml Proto-Medium und Zentrifugation wurden die Zellen erneut gewaschen. Der Überstand wurde verworfen und die Protoplasten in einem entsprechenden Volumen Proto-Medium aufgenommen, so daß eine Konzentration von etwa $16 \cdot 10^{6}$ Zellen/ml erreicht wurden. 


\subsubsection{Transfektion von Protoplasten}

Am gleichen Tag präparierte Protoplasten wurden nochmals in ihrer Konzentration bestimmt (Punkt 2.2.4.3.). Die eigentliche Transfektion wurde in Anlehnung an M. Axelos durchgeführt (Axelos et al., 1992). In einer sterilen Petrischale (Durchmesser $6 \mathrm{~cm}$ ) wurden $4 \cdot 10^{6}$ Zellen (ca. 250 $\mu 1$ Protoplasten-Suspension) vorgelegt. Dazu wurden $15 \mu 1$ Transkriptionsansatz vom gleichen Tag (Punkt 2.2.4.1.) und sofort danach ca. 250 $\mu 1$ PEGLösung (gleiche Menge wie Protoplasten-Suspension) zugegeben. Der gesamte Ansatz wurde sofort durch 3 maliges Pipettieren durchmischt. Nach ca. $15 \mathrm{~min}$. Inkubation in Ruhe bei Raumtemperatur, wurden $5 \mathrm{ml}$ Proto-Medium zugegeben. Nach einer weiteren Stunde in Ruhe bei Raumtemperatur, wurde der Ansatz dann für $42 \mathrm{~h}$ bei $25^{\circ} \mathrm{C}$ in Dunkelheit und unter leichtem Rühren (ca. 20rpm) inkubiert.

\subsubsection{Isolierung von TYMV aus transfizierten Arabidopsis-Protoplasten}

Das Experiment fand in Anlehnung an das Protokoll von R. Leberman (Leberman, 1966) statt. Eine 42 Stunden alte transfizierte Arabidopsis thaliana-Protoplasten-Suspension (Punkt 2.2.4.4.) wurde aus der Petrischale in ein 50ml Plastik-Röhrchen umgesetzt. Die festen Bestandteile wurden für 5min. bei $80 \mathrm{~g}$ ( $600 \mathrm{rpm}$, ohne Bremsen) und Raumtemperatur sedimentiert. Der Überstand wurde verworfen und der Bodensatz in $4 \mathrm{ml}$ $\mathrm{KCl}(3 \mathrm{M})$ resuspendiert. Die Lösung wurde nun in ein Zentrifugen-Röhrchen überführt und für $25 \mathrm{~min}$. bei $4^{\circ} \mathrm{C}$ und $10.000 \mathrm{rpm}$ in einem SS34-Rotor zentrifugiert. Der Überstand wurde abgenommen und auf Eis aufbewahrt. Der Bodensatz wurde nun nochmals in $4 \mathrm{ml}$ $\mathrm{KCl}(0,5 \mathrm{M})$ gelöst und im SS34-Rotor wie eben beschrieben zentrifugiert. Beide Überstände wurden in einem verschraubbaren Ultrazentrifugen-Röhrchen vereinigt und diese $8 \mathrm{ml}$ wurden dann für $2 \mathrm{~h}$ bei $4^{\circ} \mathrm{C}$ und 45.000rpm (Ti-60-Rotor) zentrifugiert. Der Überstand wurde verworfen und das Pellet in $2,5 \mathrm{ml}$ EDTA $(0,1 \mathrm{M}) \mathrm{pH} 7,5$ bei $4^{\circ} \mathrm{C}$ über Nacht resuspendiert.

Am nächsten Tag wurde nach Umfüllen des Ansatzes in ein geeignetes ZentrifugenRöhrchen für $25 \mathrm{~min}$. bei $4^{\circ} \mathrm{C}$ und $10.000 \mathrm{rpm}$ (SS34-Rotor) zentrifugiert. Der Überstand wurde in ein Ultrazentrifugen-Röhrchen umgefüllt. Danach wurde eine Ultrazentrifugation bei $45.000 \mathrm{rpm}$ und $4^{\circ} \mathrm{C}$ für $2 \mathrm{~h}$ durchgeführt. Das Pellet wurde nun in $400 \mu \mathrm{Tris} / \mathrm{HCl}$ $(10 \mathrm{mM}) \mathrm{pH} 7,5$ bei $4^{\circ} \mathrm{C}$ über Nacht resuspendiert.

Die Lösung wurde dann in ein 1,5ml Reaktionsgefäß überführt und abschließend für $25 \mathrm{~min}$. bei $4^{\circ} \mathrm{C}$ und $13.000 \mathrm{rpm}$ (Tischzentrifuge) zentrifugiert. Der Überstand wurde wiederum in ein neues $1,5 \mathrm{ml}$ Reaktionsgefäß umgefüllt.

Von der Lösung (Virionen) wurde der RNA-Gehalt bestimmt ( $\mathrm{OD}_{260}$-Messung). Da der durchschnittliche Ribonukleinsäure-Gehalt des TYMV bekannt ist, konnte ein spezifischer Extinktionskoeffizient (korrigierender Faktor) von $\mathrm{A}_{260}=86 \mathrm{ml} / \mathrm{mg}$ für die Meßwerte benutzt werden (Kaper and Litjens, 1966). Danach wurde das Volumen von $400 \mu 1$ auf ca. 
$50 \mu 1$ mittels einer Vacuumzentrifuge eingeengt. Der gesamte Ansatz konnte so auf ein denaturierendes Polyacrylamid-Gel gegeben werden und nachfolgend wurde ein Western Blot durchgeführt, um die Menge des Hüllproteins des Virus in der Präparation bestimmen zu können.

\subsubsection{Wachstumsbedingungen für Chinakohl-Pflanzen (Brassica pekinensis)}

Alle Infektionsversuche mit Chinakohl wurden im Labor von Professor C.W.A. Pleij (Leiden, Niederlande) durchgeführt.

Alle Pflanzen wurden aus Samen gezogen. Die Pflanzen wuchsen bei $16 \mathrm{~h}$ künstlichem Tageslicht (4.000Lux) und 8h Dunkelheit pro Tag. Die Temperatur betrug $24^{\circ} \mathrm{C}$ bei einer Luftfeuchtigkeit von etwa 70\%. Einmal pro Tag wurden die Pflanzen gegossen.

\subsubsection{Transfektion von Chinakohl}

Zur Transfektion wurden 3 Wochen alte Pflanzen benutzt. Einen Tag vor der Transfektion wurden sie durchgehend im Dunkeln gehalten, um Stärkekörner in den Zellen abzubauen.

Am folgenden Tag wurden jeweils die beiden jüngsten sekundären Blätter (also keine Keimblätter) durch Ausschneiden einer Ecke markiert. Diese Blätter wurden nun mit Carborundum-Pulver bepudert. Im weiteren wurden je $7 \mu l$ Transkriptionsansatz (Punkt 2.2.4.1.) auf die Blätter gegeben. Sofort danach wurde die Lösung mit einem sterilen GlasPlättchen-Spatel durch rührende Bewegungen auf dem Blatt verteilt und gleichzeitig das Blatt verletzt. Nach 10min. wurde das Carborundum-Pulver durch kurzes Besprühen mit Wasser von den Pflanzen gewaschen.

Die Pflanzen wurden für mindestens einen Monat jeden Tag auf die Entwicklung von Symptomen hin untersucht und die Ergebnisse notiert. Erste lokale Symptome traten nach etwa 4-6 Tagen auf. Erste systemische Symptome traten nach etwa 7-9 Tagen auf.

Nach etwa einem Monat wurden Homogenisate von symptomtragenden Blättern der Pflanzen hergestellt und die nächsten Pflanzen wurden damit infiziert.

Diese Methode ist dem Protokoll von Hellendoorn ähnlich (Hellendoorn et al., 1997).

\subsubsection{TYMV-Isolierung nach Dunn und Hitchborn (1965)}

Diese Methode wurde im Labor von Professor C.W.A. Pleij (Leiden, Niederlande) durchgeführt. Viren aus transfiziertem/infiziertem Chinakohl sollten isoliert werden, um Material für Infektionen und RNA für Sequenzierungen zu erhalten. Aus den zuletzt infizierten Pflanzen wurde TYMV allerdings mit dem Rneasy Plant Mini Kit (Qiagen) isoliert. Die folgende Methode orientiert sich an dem Protokoll von Dunn und Hitchborn (Dunn and Hitchborn, 1965). 
Vor Beginn des Experimentes wurde Magnesium-Bentonite hergestellt. Es soll Ribosomen und andere Proteine aus Pflanzen-Homogenisaten binden. Dazu wurden 100g BentonitePuder (ICN) in 10mM Na $2 \mathrm{HPO}_{4}, \mathrm{pH} 7,4$ (eingestellt mit $\mathrm{NaH}_{2} \mathrm{PO}_{4}$ ) / $10 \mathrm{M} \mathrm{MgSO}$ suspendiert. Die Lösung wurde dann bei Raumtemperatur 1min. mit 1500rpm (SS34Rotor) zentrifugiert. Der Überstand wurde nun nochmals für $15 \mathrm{~min}$. bei $10.000 \mathrm{rpm}$ (SS34Rotor) und gleicher Temperatur wie zuvor zentrifugiert und der Bodensatz wurde in 11 $1 \mathrm{mM} \mathrm{Na}_{2} \mathrm{HPO}_{4}$, pH 7,4 (eingestellt mit $\mathrm{NaH}_{2} \mathrm{PO}_{4}$ ) / $1 \mathrm{mM} \mathrm{MgSO} 4$ resuspendiert. Wieder wurde für $15 \mathrm{~min}$. bei $10.000 \mathrm{rpm}$ (SS34-Rotor) und Raumtemperatur zentrifugiert und die Pellets diesmal in 500ml des letzten Puffers aufgenommen. Die Lösung wurde gerührt, bis sie homogen war. Die Konzentration wurde so eingestellt, daß sie 50mg Trockengewicht pro $\mathrm{ml}$ ergab (Lagerung bei $4^{\circ} \mathrm{C}$ ).

Von den infizierten Pflanzen wurden die jüngsten Blätter mit systemischen Symptomen mit sterilen Rasiermesser-Klingen entfernt. Bei Fehlen einer systemischen Infektion wurden Blätter mit lokalen Symptomen abgenommen. Der Mittelnerv der Blätter wurde entfernt, die Blätter selbst wurden teilweise bei $4^{\circ} \mathrm{C}$ einige Tage gelagert. Ein Stück des Blattes $\left(\mathrm{ca} .7 \mathrm{~cm}^{2}\right)$ wurde in ein 1,5ml Eppendorf-Gefäß überführt. Das Blatt wurde nun mit einer zugeschmolzenen Pasteur-Pipettenspitze homogenisiert. Vom flüssigen Überstand wurde ein Teil abgenommen und bei $4^{\circ} \mathrm{C}$ gelagert, um neue Pflanzen infizieren zu können (Neuinfektion mit 10 1 l). Zum Homogenisat im Eppendorf-Gefäß wurden nun $200 \mu \mathrm{l}$ Magnesium-Bentonite gegeben und alles nochmals homogenisiert. Nach Mischen (Vortexer) und Zentrifugation für 15min. bei 13.000rpm und Raumtemperatur konnten 60$100 \mu \mathrm{l}$ Überstand in ein neues 1,5ml-Reaktionsgefäß überführt werden. Entsprechend dem Volumen wurden 0,6-1 $\mu \mathrm{l} 1 \mathrm{M}$ Tris/ $\mathrm{HCl} \mathrm{pH}$ 8,0 zugegeben, um die Virus-Kapside zu

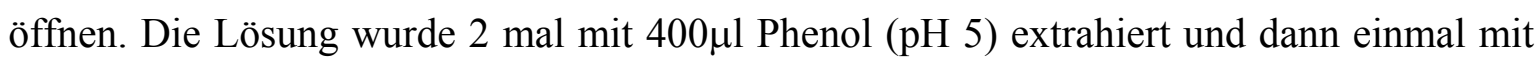
$400 \mu \mathrm{l}$ Chloroform/Isoamylalkohol ausgeschüttelt. 50-90 $\mu 1$ wurden danach in ein neues Eppendorf-Gefäß überführt und Ethanol-gefällt. Die Fällung wurde anschließend für $30 \mathrm{~min}$. bei $4^{\circ} \mathrm{C}$ und $13.000 \mathrm{rpm}$ zentrifugiert und das Pellet mit $70 \%$ Ethanol gewaschen. Das Pellet wurde zuletzt in $15 \mu 1 \mathrm{H}_{2} \mathrm{O}$ aufgenommen. Anschließend wurde eine gekoppelte Reverse Transkription und Polymerase-Kettenreaktion (PCR) durchgeführt (nach einem Protokoll aus dem Labor von Prof. Pleij). Als Oligonukleotide wurden TYMV7 oder TYshort-Val-3' und TD-PCR4 oder TY-pACBL-Rev (Punkt 2.1.10.) benutzt. 
$100 \mu 1$-Ansatz einer gekoppelten RT-PCR:

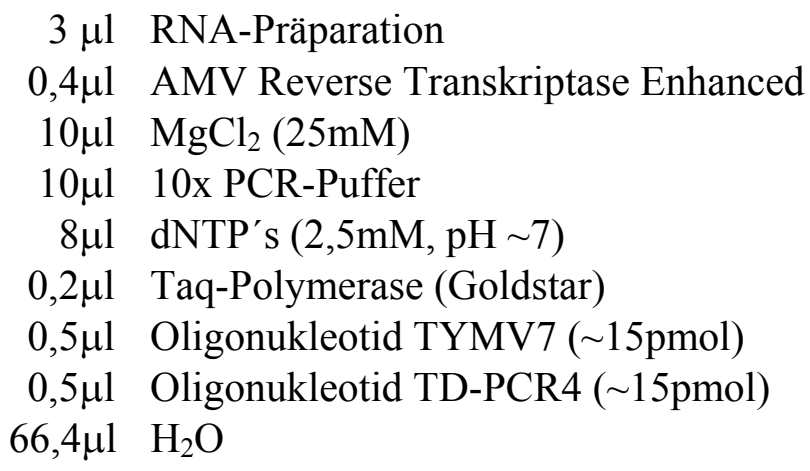

\begin{tabular}{|c|c|c|}
\hline Temperatur-Zyklen: & RT & 30sec. $42^{\circ} \mathrm{C}$ \\
\hline & $\Gamma$ & $1 \mathrm{~min} .94^{\circ} \mathrm{C}$ \\
\hline & & $1 \mathrm{~min} .94^{\circ} \mathrm{C}$ \\
\hline & PCR & $1 \mathrm{~min} .60^{\circ} \mathrm{C}$ \\
\hline & & 30 sec. $72^{\circ} \mathrm{C}$ \\
\hline & L & $7 \mathrm{~min} . \quad 72^{\circ} \mathrm{C}$ \\
\hline
\end{tabular}

Die Analyse der Produkte wurde über ein 12\%iges PAA-Gel durchgeführt.

\subsubsection{Präparation von viruseigener RNA-abhängiger RNA-Polymerase aus infizierten Chinakohl-Pflanzen (Brassica pekinensis)}

Für die vergleichenden in vitro Transkriptions-Experimente (Punkt 2.2.3.) mußte RNAabhängige RNA-Polymerase des TYMV aus infizierten Pflanzen präpariert werden. Die hier beschriebene Aufreinigung wurde nach einem Protokoll von Birgit Deiman durchgeführt (Deiman et al., 1997b), das großenteils auf der Methode von Quadt und Jaspars für BMV-RdRp basiert (Quadt and Jaspars, 1990).

3 Wochen alte Pflanzen wurden, wie bereits in Punkt 2.2.4.7. beschrieben, infiziert. 2 Wochen nach der Infektion (laut Protokoll nach 9 Tagen) wurden ca. 15g Blätter mit systemischen Symptomen abgenommen und die Mittelnerven entfernt. Die Blätter und 30ml Puffer A (Punkt 2.1.6.) wurden zusammen in einen Mörser gegeben. Nach mechanischer Homogenisierung wurden die verbliebenen festen Bestantteile durch ein grobes Plastiknetz abgetrennt. Die gefilterte Lösung wurde für $3 \mathrm{~min}$. bei $4^{\circ} \mathrm{C}$ und $5500 \mathrm{rpm}$ (SS34-Rotor) zentrifugiert. Je mit der Hälfte des Überstandes wurden zweimal $15 \mathrm{ml}$ Puffer $\mathrm{D}$ (Punkt 2.1.6.) überschichtet. Anschließend wurde für $1 \mathrm{~h}$ bei $4^{\circ} \mathrm{C}$ und $16.000 \mathrm{rpm}$ (SS34Rotor) zentrifugiert. Die entstandenen Pellets wurden mit insgesamt $3 \mathrm{ml}$ Puffer D + 0,5\% (w/v) LubrolW $+750 \mathrm{mM} \mathrm{KCl} \mathrm{resuspendiert.} \mathrm{Zum} \mathrm{vollständigen} \mathrm{Lösen} \mathrm{der} \mathrm{RdRp} \mathrm{wurde}$ nun für 30min. auf Eis gerührt. Dann wurde eine Ultrazentrifugation für $1 \mathrm{~h}$ bei $4^{\circ} \mathrm{C}$ und 
60.000rpm (SW-50.1-Rotor) durchgeführt. Danach wurde der Überstand abgenommen und mit Puffer D auf $8 \mathrm{ml}$ verdünnt. Je $4 \mathrm{ml}$ wurden nun auf $38 \mathrm{ml}$ eines Glycerin-Gradienten (25-55\%) in einem Ultrazentrifugenröhrchen gegeben.

Zwei Glycerin-Gradienten waren am Vortag angesetzt worden, indem 25, 40 und 55\%iges Glycerin in Puffer D + 0,5\% (w/v) Lubrol W langsam untereinander geschichtet wurden. Die so befüllten Röhrchen wurden bei $4^{\circ} \mathrm{C}$ über Nacht stehen gelassen, um den Gradienten ausbilden zu können.

Die mit RdRp-Lösung überschichteten Röhrchen wurden für $20 \mathrm{~h}$ bei $4^{\circ} \mathrm{C}$ und $22.000 \mathrm{rpm}$ (SS 28-Rotor) ultrazentrifugiert. Am nächsten Tag wurden vom Boden beginnend 1,5ml Aliquots mittels einer Peristaltik-Pumpe abgenommen. Einzelne Aliquots wurden durch Einsetzen von $20 \mu \mathrm{l}$ in eine in vitro Transkription (Punkt 2.2.3.1.) auf Enzymaktivität getestet. 


\section{$\underline{\text { 3. Ergebnisse }}$}

\subsection{Selektion funktionaler Varianten der tRNA-ähnlichen Struktur des TYMV}

\subsubsection{Aufgabenstellung}

Die tRNA-ähnliche Struktur (TLS) des TYMV kann in vitro mit verschiedenen ValyltRNA-Synthetasen interagieren (Pinck et al., 1970; Dreher et al., 1992; Florentz and Giegé, 1995) und wird auch in vivo aminoacyliert (Joshi et al., 1978; Joshi et al., 1982b). Mittels einer in vitro Selektionsmethode sollten teilrandomisierte TLS-Bibliotheken auf Valylierbarkeit optimiert werden. Einzelne Varianten sollten also bessere $\mathrm{k}_{\text {cat }}$ und im Idealfall auch $\mathrm{K}_{\mathrm{M}}$-Werte aufweisen.

Es sollte bestimmt werden, ob nach mehreren Selektionszyklen in den randomisierten Bereichen der TLS häufig ähnliche Sequenzen (Konsensus-Sequenzen) auftreten. Diese Konsensus-Sequenzen wären ein Hinweis auf eventuell vorhandene Identitäts- oder strukturerhaltende Elemente in den entsprechenden Regionen. Sollten sie von der WildtypSequenz abweichen, könnten so „Kandidaten-Regionen“ bestimmt werden, die im Wildtyp auch für andere Funktionen Bedeutung haben könnten. Außerdem sollten Ergebnisse aus vorangegangenen Experimenten überprüft werden und es sollten neue, unterschiedlich effizient valylierbare TLS-Varianten erhalten werden, die dann auf ihre Replikationsfähigkeit getestet werden könnten. Auf diese Art könnten neue Erkenntnisse über den Zusammenhang von Aminoacylierung und Replikation des TYMV erhalten werden.

\subsubsection{Die in vitro Selektionsmethode}

Mit der hier angewandten Methode wurden Moleküle einer teilrandomisierten TYMVTLS-Bibliothek nach ihrer Aminoacylierungseffektivität selektiert.

Da herkömmliche SELEX-Methoden (Tuerk and Gold, 1990; Peterson et al., 1993a; Gold, 1995; Ribeiro et al., 1995; Sampson and Saks, 1996) zumeist arbeitsaufwendig und technisch kompliziert sind, wurde ein Protokoll von J. Pütz et al. (Pütz et al., 1997) benutzt, das schnell und einfach durchzuführen ist und im Labor bereits etabliert war.

Durch in vitro Transkription eines DNA-Repertoires wird die Ausgangsbibliothek hergestellt (Abb.: 17). Nach Abtrennung von Nukleotiden, Proteinen und Salz wird der eigentlich selektive Schritt, die Aminoacylierung durchgeführt. Die Stringenz wird durch Dauer der Inkubation und Konzentration der Aminoacyl-tRNA-Synthetase im Ansatz bestimmt. Nun folgt die Abtrennung inaktiver Varianten. Wiederum nach Reinigung werden die aktiven RNA-Varianten an der $\alpha$-Aminogruppe ihrer 3'-terminal angekoppelten Aminosäure chemisch biotinyliert (mit Sulfo-N-hydroxy-succinimid- 
Biotin). Das freie Biotin wird abgetrennt und die RNA auf mit Streptavidin gekoppelte magnetische Kügelchen gegeben. Alle mit Biotin modifizierten, also mit Aminosäure beladenen RNA-Varianten, werden an den Kügelchen immobilisiert. Die inaktiven Varianten werden durch Waschen entfernt. Anschließend erfolgt die Amplifizierung der an den Kügelchen immobilisierten RNAs. Durch Reverse Transkription (RT) der immobilisierten RNA wird frei in Lösung vorliegende einzelsträngige DNA synthetisiert und die RNA abgebaut. Die cDNA wird mittels einer Polymerase-Kettenreaktion (PCR) zum Doppelstrang aufgefüllt und amplifiziert (,RT-PCR“). Über erneute in vitro Transkription wird wieder eine RNA-Bibliothek erstellt, die Basis einer weiteren Selektionsrunde ist. Von jeder neuen Bibliothek wird die Aminoacylierbarkeit bestimmt, indem mit 20nM ValRS für 15min. mit Tritium markiertem Valin aminoacyliert wird. Die in dieser Zeit maximal erreichte Radioaktivität (Plateau) weist auf den Anteil valylierbarer Moleküle im Pool hin.
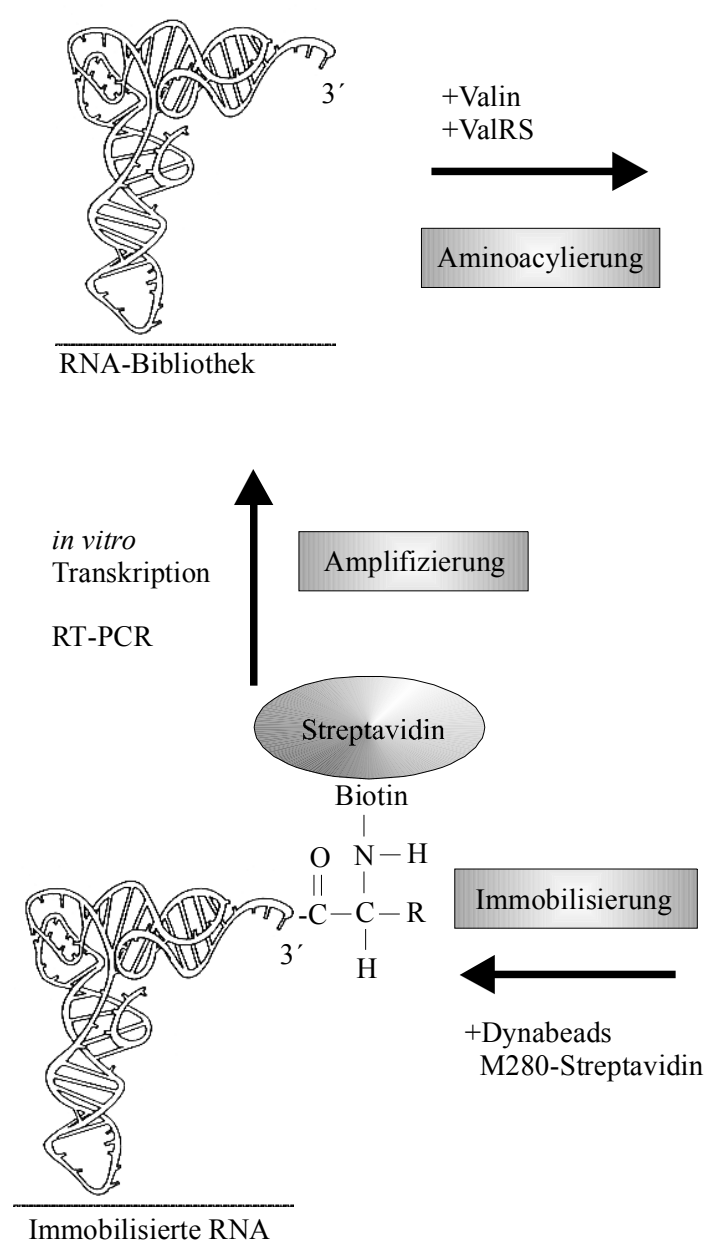
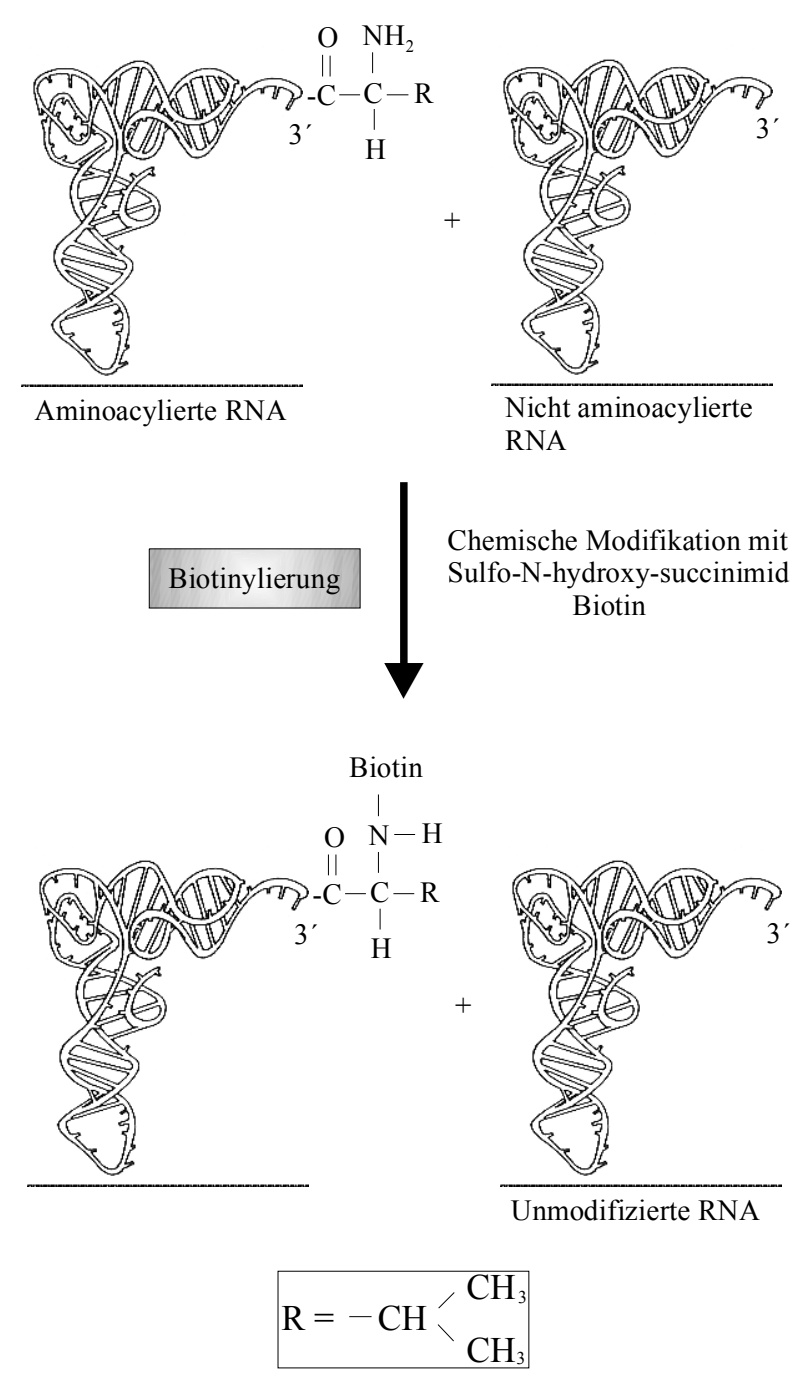

Abb.: 17,

Schema der in vitro Selektion auf Valylierbarkeit von Varianten der tRNA-ähnlichen Struktur des TYMV mittels der ValRS aus S. cerevisiae (Abbildung modifiziert aus Pütz J. et al., 1997; Abbildung der RNA aus Rietveld K. et al., 1983). 


\subsubsection{Grundlagen}

Mehrere in vitro Selektionen mit verschiedenen teilrandomisierten TYMV-TLSBibliotheken sind vor dieser Arbeit bereits durchgeführt worden. So hat J. Wientges mit einer TLS-Bibliothek eine Selektion über 9 Runden durchgeführt (Wientges et al., 2000). Innerhalb der tRNA-ähnlichen Struktur war die Sequenz der Anticodon-Schleife und die Sequenz und Länge der L1-Schleife (1-6 Nukleotide) randomisiert. Durch stufenweise Erhöhung der Stringenz (Valylierung bei 20nM ValRS für $15 \mathrm{~min}$. bis $0,5 \mathrm{nM}$ für $1 \mathrm{~min}$.) konnte die Aminoacylierbarkeit der Bibliothek bis auf das 1,7fache des Wildtyps gesteigert werden (Abb.:18). Während des Experimentes wurden zahlreiche, sehr unterschiedlich effizient valylierbare Varianten der TYMV-TLS-RNA kloniert und sequenziert (Wientges, 1998; Wientges et al., 2000). Aus den Sequenzdaten der Varianten konnten die folgenden Konsensus-Sequenzen bestimmt werden:

für die Anticodon-Schleife war dies U/A, N (ohne G), U/G, A, C, U/A, C, für die L1-Schleife war dies bei 4 nt's: $\mathrm{U} / \mathrm{A}, \mathrm{U}, \mathrm{N}$ (ohne G), C, und bei 3 nt's:

$$
\mathrm{U}, \mathrm{C} / \mathrm{U}, \mathrm{C}
$$

Das Auftreten von Konsensus-Sequenzen zeigte, bzw. bestätigte, daß sowohl AnticodonSchleife, als auch L1-Schleife Einfluß in der Aminoacylierung durch die Valin-tRNASynthetase aus Saccharomyces cerevisiae haben.

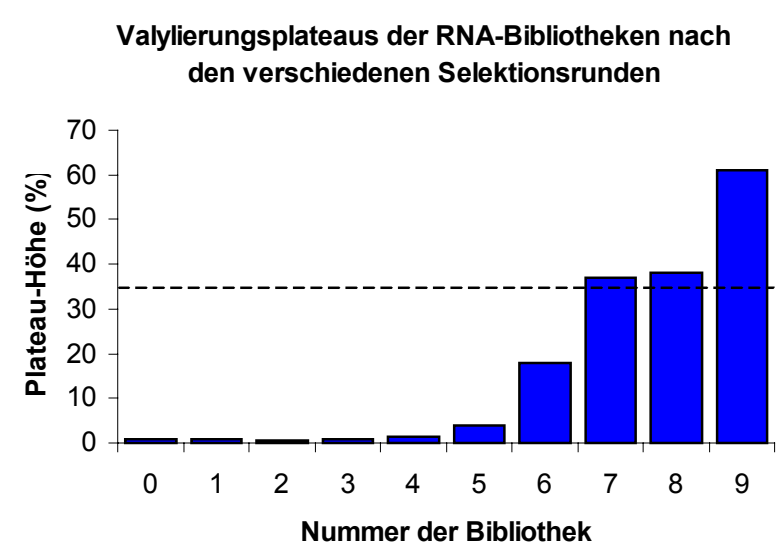

Abb.: 18,

Anteil der valylierten Moleküle in den TYMV-TLS-Bibliotheken nach den verschiedenen Selektionsrunden. Die X-Achse zeigt die Nummer der RNA-Bibliothek, bzw. die Anzahl der durchlaufenen Selektionsrunden. Die Y-Achse zeigt den Anteil valylierter Moleküle in der Population in Prozent, die gestrichelte Linie markiert diesen Anteil, wie er beim Wildtyp auftritt (Quelle: Wientges J., et al., 2000).

In eigenen Versuchen der Diplomarbeit, wurde nun die Bibliothek Lib C erstellt (Abb.: 19, A), um den Einfluß der Bereiche der Schleife der Haarnadel II (T-Schleifen Analogon), der Scharnier Region und der Anticodon-Schleife in der Valylierung aufzuklären (Klug, 2000). Im Fall der Anticodon-Schleife war bereits bekannt, daß sie, insbesondere an der Position 56 für die Aminoacylierung mit der ValRS aus Bäckerhefe, wichtige Interaktionen 
A

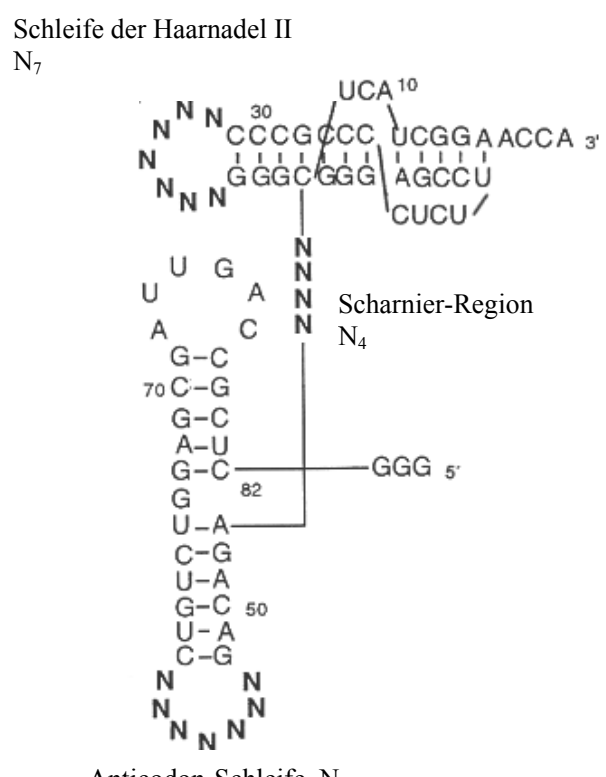

B

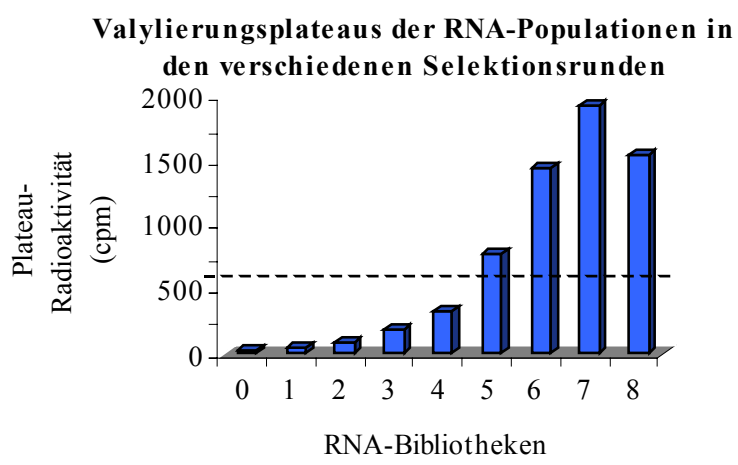

Abb.: 19, A, B:

A) RNA-Bibliothek Lib C (zum Ende der Selektion).Randomisiert wurden die Schleife der Haarnadel II, die Scharnier Region und die Anticodon-Schleife.

B) Zunahme der (unter gleichen Bedingungen) valylierbaren Moleküle in den Lib C-RNA-Bibliotheken nach den verschiedenen Selektionsrunden. Die X-Achse zeigt die Nummer der RNA-Bibliothek, bzw. die Anzahl der durchlaufenen Selektionsrunden. Die Y-Achse zeigt die Radioaktivität der Bibliothek nach Valylierung mit Tritium markiertem Valin. Die gestrichelte Linie markiert die Radioaktivität, die der Wildtyp unter den gegebenen Bedingungen erreicht.

mit dem Enzym eingeht (Florentz and Giegé, 1986; Van Belkum et al., 1987; Giegé et al., 1990; Florentz et al., 1991). Die Randomisierung dieses Bereiches diente zur Kontrolle der selektierten Sequenzen. Nach 7 Runden in vitro Selektion konnte die Radioaktivität der Bibliothek in der einheitlich durchgeführten Plateau-Valylierung auf das 2,6 fache des Wildtyps gesteigert werden (Abb.: 19, B). Die Sequenzierung der Bibliothek nach den Selektionsrunden ergab u.a. eine in der Initialbibliothek nicht vorhandene Variante (8-40;

Tab.: 1,

Selektierte Varianten der Bibliothek Lib C. Variante L18 entspricht der bisher am effizientesten valylierbaren Variante 8-40.

$\begin{array}{lccc}\text { Variante } & \text { Anticodon-Schleife } & \text { Scharnier-Region } & \text { Haarnadel II } \\ \text { WT } & \text { CCCACAC } & \text { UAAU } & \text { UGCAACU } \\ \text { L6 } & \text { UAGACUC } & \text { UAAU } & \text { UGCAACU } \\ \text { L14 } & \text { CCAAUUA } & \text { UAAU } & \text { UGUCGCG } \\ \text { L18 (8-40) } & \text { ACUACAC } & \text { UAAU } & \text { UGCAACU } \\ 9.16 & \text { ACCACAC } & \text { UAAU } & \text { CGCAACU }\end{array}$


Tab.: 1), die bereits im Selektionsexperiment von J. Wientges aufgetreten war (dort war sie allerdings Bestandteil der Ausgangsbibliothek). Sie ist zugleich die am effektivsten valylierbare TYMV-TLS-Variante, die bisher bekannt ist.

\subsubsection{Design der Initialbibliothek}

Aus der Literatur ist bekannt, daß das kleinste noch effektiv valylierbare Fragment des TYMV-Genoms aus den letzten $82 \pm 2$ Nukleotiden des 3'-Endes besteht (Joshi et al., 1982a; Rietveld et al., 1983; Dreher et al., 1988; Dreher et al., 1992). Sie umfassen ebenfalls die tRNA-ähnliche Struktur des TYMV (L-Struktur). Diese Struktur wurde auch wegen der Vergleichbarkeit mit früheren Versuchen, bei denen 83 Nukleotide (nt's) plus 2 Guanosine am 5'-Ende verwendet worden waren, ausgewählt. Da eine Region nahe am 5'Ende der TLS randomisiert werden sollte, wurden zu den 82nt's zusätzlich 9 viral-codierte Nukleotide angefügt, um eine ausreichende Länge der Oligonukleotide in den PCR's sicherstellen zu können. Zur Erhöhung der Transkriptionseffizienz bei Verwendung der T7-RNA-Polymerase wurden zusätzlich 2 Guanosin-Nukleotide am 5'-Ende angehängt, die nicht der viralen Sequenz entsprechen. Durch Arbeiten von J. Wientges wurden Hinweise darauf erhalten, daß diese Guanosin-Nukleotide keinen Einfluß auf die Aminoacylierbarkeit besitzen (Wientges, 1998).

Zur Funktion von Fragmentlängen der 3'-nicht translatierten Region (UTR, sie enthält die TLS) und insbesondere des Pseudoknotens wurden bereits einige Untersuchungen durchgeführt (Mans et al., 1990; Mans et al., 1992; Deiman et al., 1997a; Singh and Dreher, 1998). Funktionelle Eigenschaften begrenzter Regionen innerhalb der tRNAähnlichen Struktur aber außerhalb des Pseudoknotens wurden bisher dagegen kaum genauer untersucht. Im vorangegangenen Selektionsversuch mit der RNA-Bibliothek Lib C zeigten Sequenzierungen am Ende des Experimentes in den Bereichen des T-SchleifenAnalogons und der Scharnier-Region weitgehend die Wildtypsequenz. Durch Strukturaufklärungen verschiedener tRNA's ist bekannt, daß im Bereich von T-/D-Schleife und Variabler Schleife mehrere strukturerhaltende Interaktionen zwischen den Nukleotiden z. B. in Form von Watson-Crick-, aber auch Hoogsteen-Basenpaarungen (innerhalb sogenannter Basentripletts) auftreten können (Kim et al., 1974; Stout et al., 1978; Moras et al., 1980; Woo et al., 1980; Westhof et al., 1985). Auch in vivo Versuche mit TYMVVarianten weisen auf die Existenz von Interaktionen hin (de Smit et al., 2002). Es ist also wahrscheinlich, daß das T-Schleifen-Analogon und die Scharnier-Region der TYMV-TLS solche für die Struktur wichtigen Kontakte ausbilden. Dies könnte einen Grund für die Konservierung der Wildtypsequenz der beschriebenen Regionen in der in vitro Selektion darstellen.

Um nun das Ergebnis der Lib C-Selektion mit einer neuen Bibliothek vergleichen zu können und speziell den Bereich von T-/D-Schleife und variabler Schleife zu untersuchen, 
wurde in der neuen Bibliothek (Lib D) die Schleife der Haarnadel II und IV und die Scharnier-Region randomisiert (Abb.: 20). Die Scharnier-Region scheint speziell an der Position 43 einen Einfluß in der Aminoacylierbarkeit zu besitzen (Giegé et al., 1990). Ihre besondere Lage als winkelbestimmendes Verbindungselement zwischen Akzeptor-Helix und Anticodon-Schleife stellt eine besondere Eigenschaft dieser Region dar. Der Abstand der Determinanten auf Akzeptor-Helix und Anticodon-Schleife sind bei verschieden spezifischen tRNA's unterschiedlich und dürfte ein Ausschluß-Kriterium der ValRS für RNA-Varianten sein.

Die Haarnadel II stapelt auf die S1-Helix des Pseudoknotens und könnte so Auswirkungen auf die Stabilität des Pseudoknotens haben. Die Veränderung der Stabilität des Pseudoknotens wiederum könnte Einfluß auf die Aminoacylierungseffektivität haben (Mans et al., 1992). Direkte Wechselwirkungen mit der Valin-tRNA-Synthetase sind im Bereich von Schleife II und IV dagegen nicht zu erwarten (Favorova et al., 1981; Florentz and Giegé, 1986).

Abb.: 20,

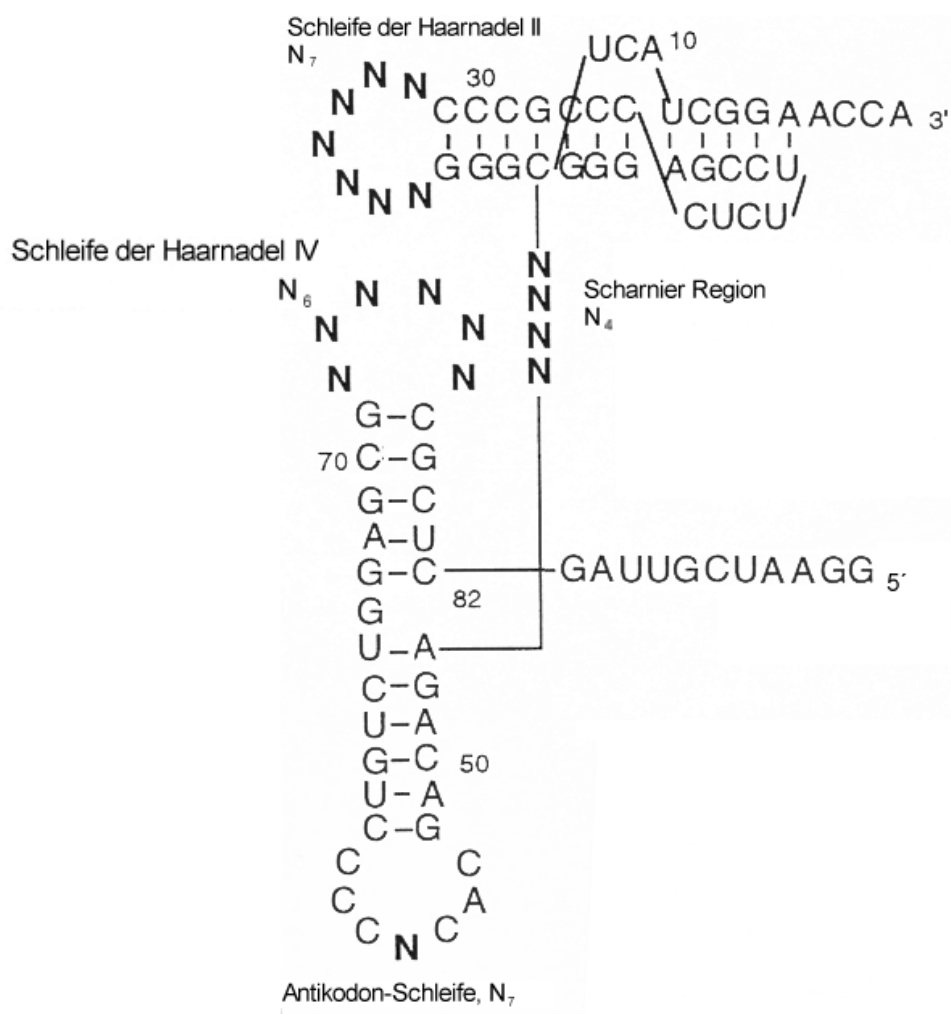

Zweidimensionale Darstellung der RNA-Bibliothek Lib D. Randomisiert sind die Schleifen der Haarnadel II und IV, die Scharnier-Region und die Position 56.

Da methodisch bedingt immer auch inaktive RNA-Varianten in den Bibliotheken vorhanden sind, sollte eine Möglichkeit geschaffen werden, um sequenzierte Moleküle noch vor weitergehenden Experimenten auf ihre Valylierungseffekivität hin abschätzen zu können. Zu diesem Zweck wurde die Position 56 zusätzlich randomisiert, weil sie in 
praktisch allen bekannten tRNA ${ }^{\text {Val }}$-Molekülen und tRNA-ähnlichen Strukturen, die valyliert werden, als Adenin konserviert ist (Ebel et al., 1973) und ihr Austausch nach G oder U vermutlich zu einer Effizienz-Verringerung um 4 Größenordnungen führt (Florentz et al., 1991).

\subsubsection{Konstruktion der Initialbibliothek}

Die Größe von Bibliotheken (Anzahl unterschiedlicher Varianten) ist durch Löslichkeit und handhabbares Volumen beschränkt. Mit den heutigen Labormaterialien ist eine maximale Größenordnung von ca. $10^{15}$ Varianten möglich. Im Fall einer Nukleinsäure liegt die Zahl der unterschiedlichen Moleküle für $\mathrm{N}$ randomisierte Positionen bei $4^{\mathrm{N}}$. Mit steigender Zahl der randomisierten Positionen steigt also die Menge der möglichen unterschiedlichen Moleküle exponentiell an. Für die in vitro Selektion sollten daher nicht mehr als 24 Positionen in der Bibliothek randomisiert werden, um sie vollständig herzustellen und einsetzen zu können.

Die zu selektierende Bibliothek Lib D sollte in der Schleife der Haarnadel II mit 7 Nukleotiden, in der Schleife der Haarnadel IV mit 6 Nukleotiden und in der ScharnierRegion mit 4 Nukleotiden randomisiert werden (Abb.: 20). Die Komplexität entspricht damit $4{ }^{18}$ und somit weniger als $10^{11}$ Molekülen.

Durch die Methode der chemischen Synthese (Phosphoramidit-Chemie) bedingt, nimmt die Anzahl von Sequenzfehlern und verkürzten Bruchstücken bei DNA-Oligonukleotiden von mehr als 100nt drastisch zu. Das Ausgangsmolekül für die Polymerase-KettenReaktion (PCR) wurde deshalb auf 98nt begrenzt.

Um die Lib D möglichst leicht synthetisieren zu können, wurde sie als Einzelstrang-DNAFragment mit der Sequenz des T7-Promotors am 5'-Ende (für die Transkription) in eine PCR eingesetzt. Die oben genannten Bereiche waren bereits randomisiert. Die zur Vervollständigung der Matrize notwendigen 14 Nukleotide und der restliche Gegenstrang zur Matrize wurden durch das Starter-Oligonukleotid („Primer“) TYMV-Rev (Punkt 2.1.10.) initiiert. Beide Primer der PCR banden außerhalb der randomisierten Regionen.

Das Produkt der Reaktion wurde anschließend direkt in eine in vitro Transkription eigesetzt, um die RNA-Bibliothek zu erzeugen. Ein kleinerer Teil wurde zur Klonierung und Sequenzanalyse verwendet. Als Kontrolle wurde ebenfalls die 91nt Wildtyp-Sequenz mittels T7-Transkription hergestellt.

Anzumerken ist, daß für die in vitro Selektion nicht der australische Blue Lake Stamm, sondern die Sequenz des Strasbourg-Stammes benutzt wurde. Der Unterschied für dieses Experiment liegt dabei lediglich in dem Austausch des $\mathrm{C}_{22}$ in der L1-Schleife nach U. Die Konsensus-Sequenzen der Selektion von J. Wientges zeigten an dieser Stelle die etwa gleichwertige Akzeptanz von $\mathrm{C}$ und $\mathrm{U}$ für die effiziente Valylierung. 


\subsubsection{Sequenzanalyse der Initialbibliothek}

Zur Kontrolle der Sequenz und der ausreichenden Randomisierung der entsprechenden Bereiche, wurde ein Teil der Eingangs-PCR kloniert und sequenziert. Zu diesem Zweck wurde ein Teil der PCR-Produkte in den Vektor pCR2.1 $1^{\mathrm{TM}}$ oder pCR4 ${ }^{\mathrm{TM}}$ ligiert. Das Ligationsprodukt wurde dann in den E. coli-Stamm XL1-Blue transformiert. Von 25 verschiedenen Klonen wurden die Insert-Bereiche der Vektoren sequenziert. Die konstanten Sequenzen der Varianten der Bibliothek zeigten in 3 Fällen Fehler (Basenaustausche, Insertionen, Deletionen). Die Bereiche der Schleife der Haarnadel II, IV, der Scharnier Region und der Position 56 wurden wegen ihrer zentralen Rolle im Experiment auf ihre Basenverteilungseigenschaften hin untersucht. In der Tabelle 2 sind die randomisierten Regionen der sequenzierten Varianten (22) aufgeführt, die keine unerwünschten Sequenzfehler aufwiesen. Nur diese Varianten wurden für die folgenden Berechnungen benutzt.

Tab.: 2,

Sequenzen der randomisierten Bereiche von 22 Varianten aus der Lib D-Initialbibliothek.

\begin{tabular}{c|c|c|c|c|}
$\begin{array}{c}\text { Variante } \\
\text { Nr. }\end{array}$ & $\begin{array}{c}\text { Schleife der } \\
\text { Haarnadel IV }\end{array}$ & $\begin{array}{c}\text { Anticodon- } \\
\text { Base, } \text { N }_{56}\end{array}$ & $\begin{array}{c}\text { Scharnier- } \\
\text { Region }\end{array}$ & $\begin{array}{c}\text { Schleife der } \\
\text { Haarnadel II }\end{array}$ \\
\hline WT & CAGTTA & A & TAAT & TGCAACT \\
\hline $0-1$ & TTGCAT & A & GACT & ATTTCTA \\
\hline $0-3$ & TCTAAA & C & AAAA & AGCCTTG \\
\hline $0-6$ & AATAGA & G & TACG & AGGGTGT \\
\hline $0-8$ & TTGGGG & A & AGGT & CTTAGGG \\
\hline $0-10$ & AATAGA & G & TACG & AGGGTGT \\
\hline $0-11$ & CATGGT & A & CCAA & ATCTGAT \\
\hline $0-13$ & TCGATT & T & GCTA & CCTAATC \\
\hline $0-14$ & TAAACT & G & TGTA & AATAATG \\
\hline $0-15$ & GTCTCA & G & AATA & GCTGACG \\
\hline $0-16$ & TGCGCA & A & ACAT & GCTGATT \\
\hline $0-17$ & TGCGGA & G & GATT & TCTAAGT \\
\hline $0-18$ & TGCCCA & C & TTAC & GGTAGAT \\
\hline $0-19$ & ATTAGA & A & CTAA & GTAATGT \\
\hline $0-20$ & GTATCT & A & GCGC & TCTAATG \\
\hline $0-21$ & TGGGCT & T & TATG & GGTGTGG \\
\hline $0-22$ & GTTAGT & T & TGAT & AGATTAA \\
\hline $0-23$ & TGACCT & G & TTTT & GGTAATG \\
\hline $0-25$ & AAGTAA & A & AAAA & TTAATAG \\
\hline $0-26$ & CGGCCG & T & AGAA & TATAATA \\
\hline $0-27$ & CAGATT & C & TCTT & TGCAAGG \\
\hline $0-28$ & TTAGGC & G & GCGA & CCTAAAC \\
\hline $0-29$ & AGCCGA & C & TTCC & GGTACTT \\
\hline
\end{tabular}

Die Basenverteilung in der Stichprobe zeigte, daß Cytosin etwas unterrepräsentiert war, dagegen waren Adenin und Tymin entsprechend stärker vertreten, als im Idealfall erwartet worden wäre. Im einzelnen war der prozentuale Anteil der Basen: A: 29,4\%; T: 29,4\%; C: 
16,1\%; G: 24,4\%. Der mittlere Paarabstand bestimmt, an wievielen Positionen zwei verschiedene Moleküle unterschiedliche Basen aufweisen. Der ermittelte mittlere Paarabstand betrug 12,9 Basen (von den 18 randomisierten). Bei idealen Zufallssequenzen mit 18 Nukleotiden wäre ein Wert von 13,5 Basen zu erwarten gewesen.

Die Lib D-Initialbibliothek konnte mit diesen Werten als ausreichend effizient randomisiert bezeichnet werden. Die Tabellen zur Berechnung der Werte sind im Anhang aufgeführt.

\subsubsection{Optimierung der Eingangs-PCR}

Das Einzelstrang-DNA-Oligonukleotid (ssDNA) der Lib D mußte, um als Matrize in der Transkription dienen zu können in einen Doppelstrang überführt und amplifiziert werden. Außerdem mußten die noch fehlenden 14 Nukleotide angehängt werden. In der PCR wurden dazu die Primer TYMV-Rev (Anhängen der Nukleotide) und TYMV-T7 benutzt (Punkt 2.1.10.).

In die PCR wurden $10 \mu \mathrm{g}$ ssDNA-Matrize (entspricht $0,1 \mathrm{ng} / \mu \mathrm{l}$ ) eingesetzt. Diese, im Gegensatz zu analytischen PCR's große Menge, soll eine große Komplexität der Initialbibliothek sicherstellen. Die hohe Konzentration an ssDNA kann dabei auch zu unspezifischem Hybridisieren untereinander (,Selbst-Priming“) führen und so auch zu große Produkte verursachen. Um das Auftreten solcher Nebenprodukte zu minimieren und die Ausbeute des Produktes gewünschter Länge (112nt's) zu optimieren, wurden PCRAnsätze jeweils einer verschiedenen Anzahl von Temperatur-Zyklen unterworfen.

Die Hybridisierungstemperatur $(\mathrm{T})$ der Oligonukleotide wurde dabei nach der Formel:

$\mathrm{T}=69,3+0,41 \cdot(\% \mathrm{GC})-(650 /$ Länge des Oligonukleotids $)$

bestimmt. Das Oligonukleotid TYMV-Rev würde demnach im ersten Hybridisierungsschritt $48^{\circ} \mathrm{C}$ benötigen, da Matrize und Primer nur über $16 \mathrm{nt}^{\prime} \mathrm{s}$ komplementär zu einander sind. In einem zweiten Schritt, wenn volle-Länge-Matrizen synthetisiert sind, ist die Temperatur des Primers TYMV-T7 mit $69^{\circ} \mathrm{C}$ geringer. Da mit niedrigeren Hybridisierungstemperaturen auch die Anzahl der Nebenprodukte ansteigt, wurde zunächst versucht, auch im ersten Schritt mit $69^{\circ} \mathrm{C}$ diese möglichst zu verhindern. Die Temperaturzyklen wurden wie folgt durchgeführt:

1. $94^{\circ} \mathrm{C} 3 \mathrm{~min} ., 69^{\circ} \mathrm{C} 2 \mathrm{~min} ., 72^{\circ} \mathrm{C} 2 \mathrm{~min}$., dann folgten

2. $94^{\circ} \mathrm{C} 30 \mathrm{sec} ., 69^{\circ} \mathrm{C} 45 \mathrm{sec} ., 72^{\circ} \mathrm{C} 45 \mathrm{sec}$. für 10,15 oder 20 Zyklen, dann folgten

3. $72^{\circ} \mathrm{C} 2 \min ., \infty 10^{\circ} \mathrm{C}$.

Die Reaktionsprodukte wurden über ein 12\%-Polyacrylamid Gel nach Größe aufgetrennt und analysiert (Abb.: 21). Eine Amplifizierung mit 10 Zyklen stellte sich als optimal heraus. Diese PCR zeigte im analytischen Gel die höchste Ausbeute des Produktes mit der richtigen Länge (112nt's) und dabei die wenigsten Nebenprodukte (Abb.: 21). Ein Teil dieser PCR wurde für eine anschließende Sequenzierung verwendet (siehe Punkt 3.1.6.). 


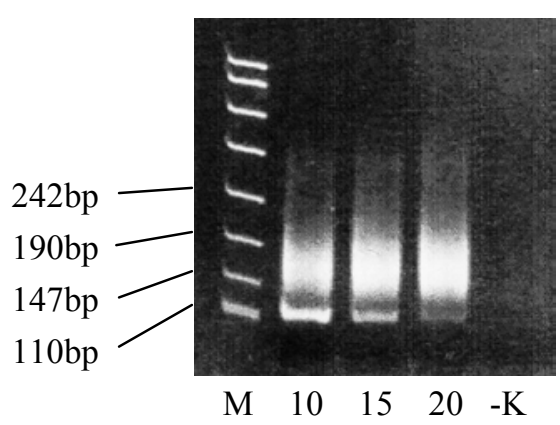

Abb.: 21,

12\%iges natives Polyacrylamid-Gel zur Analyse der Produkte der Eingangs-PCR (Lib D, 112nt). Aufgetragen wurden je $10 \mu \mathrm{l}$ Reaktionsprodukt nach 10, 15 oder 20 Zyklen (siehe Text: „2.“ der Temperaturzyklen). M ist der DNA-Längenstandard pUC19 (MspI), -K steht für die Negativ-Kontrolle (PCR-Ansatz ohne ssDNA-Matrize).

\subsubsection{In vitro Selektionsrunden der Bibliothek/Optimierungen der Bedingungen}

Alle Selektionsrunden folgten einem festgelegten Ablauf. Dieser soll hier kurz beschrieben werden.

Zur Gewinnung der RNA-Initialbibliothek wurde ein Teil des DNA-Produktes der ersten PCR $(40 \mu l)$ direkt als Matrize für einen in vitro Transkriptionsansatz verwendet und die Produkte der Reaktion 2 mal mit Phenol, mittels HPLC und Ethanolfällung aufgereinigt, bzw. konzentriert. Die RNA-Konzentration wurde dann mittels Messung der optischen Dichte bei $260 \mathrm{~nm}\left(\mathrm{OD}_{260}\right)$ bestimmt. 100pmol der gereinigten RNA wurden in der ersten Runde mit 20nM ValRS für 15min. aminoacyliert, dann sauer phenolisiert und mit Ethanol gefällt. Nun wurde biotinyliert und mittels HPLC und Ethanolfällung die RNA aufgereinigt. Zuletzt wurden aktive, biotinylierte Varianten auf Streptavidin-gekoppelten, magnetischen Kügelchen immobilisiert. Nach Abtrennung inaktiver Varianten durch verschiedene Waschschritte, wurde die RNA an den Kügelchen revers transkribiert. Die synthetisierte Einzelstrang-DNA diente dann als Matrize in einer weiteren PCR, deren Transkription (Tsk), bzw. RNA den Beginn einer weiteren Selektionsrunde darstellte.

Die folgende Darstellung soll den Ablauf des gesamten Selektions-Experimentes noch einmal verdeutlichen:
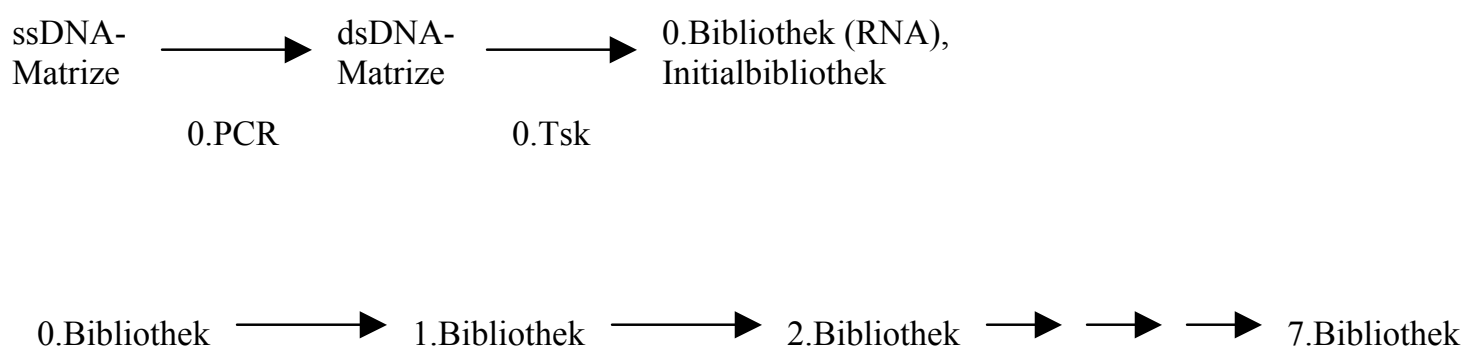

1.Selektionsrunde 2.Selektionsrunde 3.-7.Selektionsrunde 
Nach Eliminierung der Kontamination einer Lösung mit RNasen, die in der Transkription/Reversen Transkription eingesetzt wurde (rUTP, 50mM), konnte die erste Selektionsrunde mit einem korrekten PCR-Produkt abgeschlossen werden (Abb.: 22; 1. PCR, die Hybridisierungstemperatur des 1 . Zyklusses war auf $62^{\circ} \mathrm{C}$ herabgesetzt worden). In dieser ersten Selektionsrunde wurde eine relativ geringe Stringenz in der Valylierung mit 20nM Enzym und 15min. Inkubationszeit vorgegeben (siehe Tab.: 3). Die wenigen aktiven Moleküle der Initialbibliothek sollten nicht durch $\mathrm{zu}$ extreme Bedingungen vorzeitig verloren gehen. Zur Kontrolle, ob die Reverse Transkription und Amplifikation (PCR) mit den benutzten Lösungen nun grundsätzlich möglich war, wurde als PositivKontrolle Magnetkügelchen-gebundene RNA aus der 6. Selektionsrunde einer Vorgängerbibliothek (Lib C) ebenfalls revers transkribiert und amplifiziert. Auch dieser Versuch verlief erfolgreich (Abb.: 22; +K).

Tab.: 3,

Zusammenfassung des angelegten Selektionsdruckes (Stringenz) in den verschiedenen Selektionsrunden. Angegeben sind die Nummer der Selektionsrunde und die Konzentration der Valyl-tRNA-Synthetase aus $S$. cerevisiae im Valylierungsansatz und die Inkubationszeit des Enzyms mit der Bibliothek.

\begin{tabular}{|c|c|c|}
\hline Selektionsrunde & $\begin{array}{c}\text { ValRS-Konzentration } \\
\text { im Ansatz (nM) }\end{array}$ & $\begin{array}{c}\text { Inkubationszeit } \\
\text { (min.) }\end{array}$ \\
\hline 1 & 20 & 15 \\
\hline 2 & 20 & 5 \\
\hline 3 & 20 & 5 \\
\hline 4 & 20 & 3 \\
\hline 5 & 20 & 1 \\
\hline 6 & 2 & 1 \\
\hline 7 & 0,5 & \\
\hline
\end{tabular}

Für die 2. Selektionsrunde wurde eine „1.“ Transkription mit der 1. PCR als Matrize durchgeführt. Sie zeigte eine Produktbande im analytischen Gel mit einer korrekten Größe (Abb.: 22; 1. Tsk; Größenbestimmung der RNA nach Erfahrungen mit dem Laufverhalten einer Vorgängerbibliothek). In dieser Selektionsrunde wurde mit 20nM ValRS für 5min. valyliert. Die abschließende Amplifikation der selektierten, aufgereinigten Varianten (2. PCR; Abb.: 22) ergab im analytischen Gel eine Bande korrekter Größe und eine schwache unerwartete Bande von ca. 230bp. Da die unerwartete Bande auch in der Negativ-Kontrolle sichtbar war, konnte auf die Kontamination einer Lösung der PCR geschlossen werden. Grundsätzlich sollte diese Kontamination aber keinen bedeutenden Einfluß auf die Selektion haben, da nach der anschließenden Transkription zu große RNA's durch 
Größenausschluß-Chromatographie (HPLC) entfernt werden sollten und sie somit nicht in den eigentlich selektiven Schritt (Valylierung) gelangen.

Die aufgereinigte 2. Transkription (2. PCR als Matrize) ergab größtenteils Moleküle einer korrekten Größe (Abb.: 22; 2. Tsk), so daß direkt eine 3. Selektionsrunde durchgeführt wurde. Die Stringenz wurde diesmal nicht erhöht, um das Ergebnis der 3. PCR mit dem der

2. PCR vergleichen zu können. Die 3. PCR zeigte jetzt eine Produktbande der richtigen Länge und einen leichten Schmier in der Größe von ca. 180bp (Abb.: 22; 3. PCR). Bei der Negativ-Kontrolle traten keine unerwünschten Banden auf.
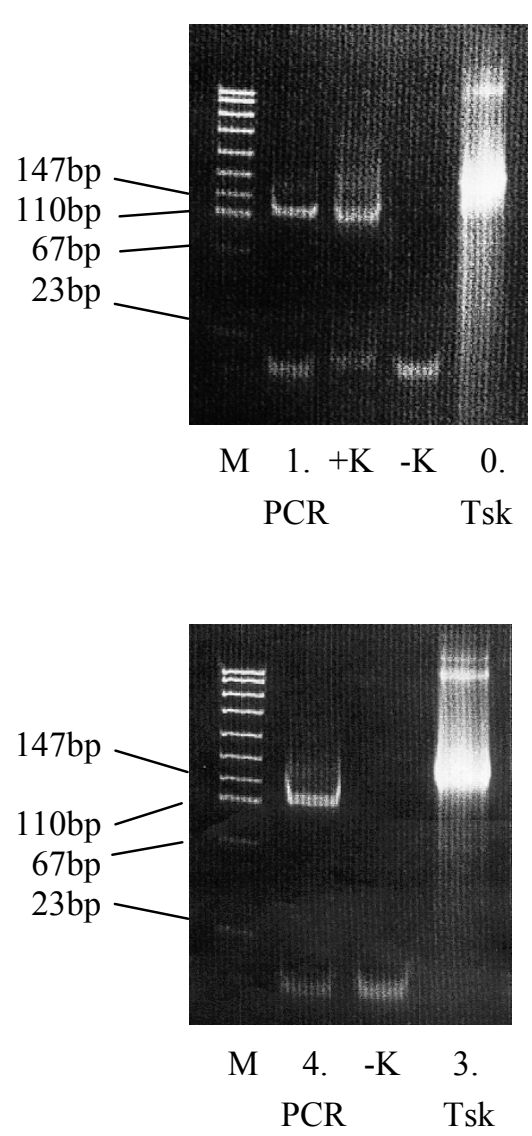

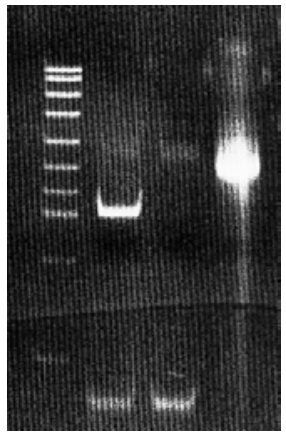

$$
\begin{array}{ccc}
\text { M } 2 . & -\mathrm{K} & 1 . \\
\text { PCR } & & \text { Tsk }
\end{array}
$$

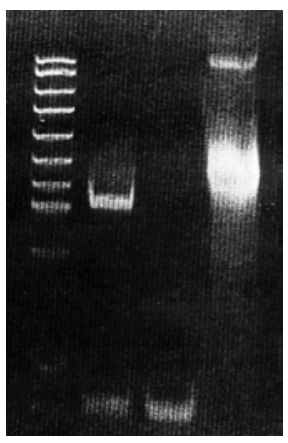

$$
\begin{array}{llll}
\text { M } & 5 . & -\mathrm{K} & 4 . \\
\text { PCR } & & \text { Tsk }
\end{array}
$$

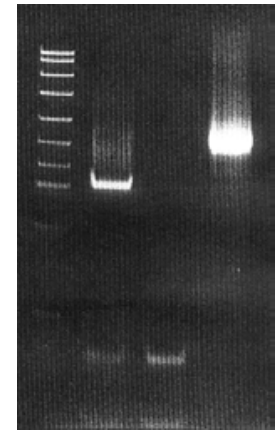

$$
\text { M 3. }-\mathrm{K} 2 .
$$$$
\text { PCR Tsk }
$$

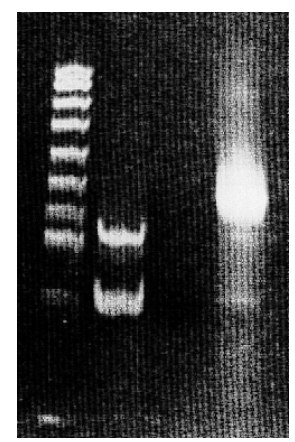

$$
\begin{array}{llll}
\text { M } & 6 . & -\mathrm{K} & 5 . \\
& \text { PCR } & & \text { Tsk }
\end{array}
$$

Abb.: 22,

Analytische, native 12\%ige Polyacrylamid-Gele der Polymerase-Kettenreaktionen (PCR's) und Transkriptionen (Tsk) der Selektionsrunden 1.-6. der Bibliothek Lib D. Die Nummern geben die bereits durchlaufenen Selektionsrunden an. $+\mathrm{K}$ steht für Positiv-Konrolle, -K für Negativ-Kontrolle. M bezeichnet den DNA-Marker pUC19 (MspI). Die Banden unterhalb von 23 Basenpaaren (am unteren Rand der Abbildungen) entsprechen dem Oligonukleotid TYMV-T7.

In der 4. Selektionsrunde wies das analytische Gel der 3. Transkription Produkte der richtigen Länge, aber auch zwei Banden einer geschätzten Länge von über 400 Nukleotiden (nt's) auf (Abb.: 22; 3. Tsk). Da die Transkription bereits durch Größenausschluß-HPLC von falschen Molekülgrößen getrennt worden sein sollte, könnten 
die zusätzlichen Banden durch Molekülaggregate, die bei hohen Konzentrationen vermehrt entstehen, verursacht sein. Nach der Selektionsrunde mit einer vorgegebenen Stringenz von 20nM ValRS und 3min. Inkubation, zeigte die 4. PCR ausschließlich Produkte der korrekten Länge. Aufgrund dieser Beobachtung wurde direkt die folgende Selektionsrunde durchgeführt.

Die 4. Transkription, die für die 5. Selektionsrunde benutzt wurde, zeigte im analytischen Gel die korrekte Produktbande. Zusätzlich zeigte sich, ähnlich wie in der 3. Tsk, wieder eine Bande bei ca. 420nt's (Abb.: 22; 4. Tsk). Die 5. PCR am Ende der Runde ergab wieder ausschließlich ein Produkt der korrekten Länge. In der Valylierung waren 20nM ValRS für 1min. mit der RNA-Bibliothek inkubiert worden.

Am Beginn der 6. Selektionsrunde wies die 5. Transkription außer dem Produkt der erwarteten Größe im Gel auch zwei schwache, kleinere Banden auf (Abb.: 22; 5. Tsk). Sie könnten entweder durch ungewöhnliches Laufverhalten der (zu) hoch konzentrierten korrekten RNA im Gel oder durch Abbau entstanden sein. Am Ende der Selektion mit einer hohen Stringenz von 2nM ValRS und 1min. Inkubation für die Valylierung, wurden in der 6. PCR zwei Produktbanden erhalten. Zu der erwarteten Produktbande in der Größe von 112 bp zeigte sich im analytischen Gel noch eine Bande von ca. 65bp Größe (Abb.: 22, 6. PCR). Die Moleküle unerwarteter Größe könnten entweder auf die zu kleinen Moleküle (Banden) der 5. Tsk, auf methodisch bedingt mitgeschleppte, inaktive „Hintergrundmoleküle“ oder auf spontane Mutationen in der PCR zurückzuführen sein.
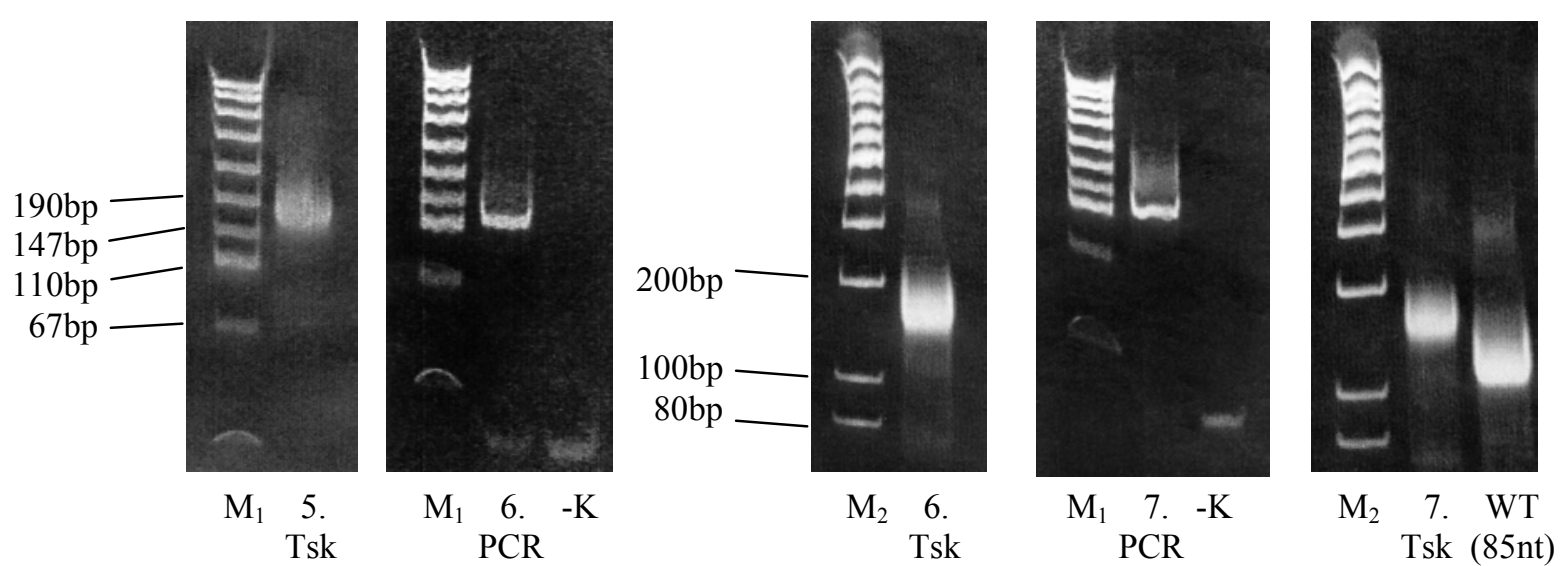

Abb.: 23,

Analytische, native 12\%ige Polyacrylamid-Gele der Polymerase-Kettenreaktionen (PCR's) und Transkription (Tsk) der neuen 6. und 7. Selektionsrunde der Bibliothek Lib D. Die Nummern geben die bereits durchlaufenen Selektionsrunden an, $-\mathrm{K}$ steht für den Ansatz der Negativ-Kontrolle. Marker $\mathrm{M}_{1}$ ist pUC19 (MspI), $\mathrm{M}_{2}$ ist Genruler 100bp-Leiter (MBI).

Die 6. Selektionsrunde sollte nun beginnend mit der 5. Tsk erneut durchgeführt werden. Die neue 5. Tsk (ausgehend von der 5. PCR) zeigte im analytischen Gel nun ausschließlich Produkte der korrekten Länge (Abb.: 23; 5.Tsk). Nach dem Ende der Selektion zeigte die 
neue 6. PCR nun ein Produkt der erwarteten Größe mit einem leichten Schmier bis nach ca. $160 b p$ (Abb.: 23, 6. PCR).

Nach einer weiteren 6. Transkription zeigte das Gel der 7. PCR nach der 7. Selektionsrunde wieder ein Produkt der korrekten Länge mit einem Schmier bis ca. 200bp. Dieser Schmier könnte durch eine zu hohe Menge an DNA-Molekülen pro Gel-Volumen („Überladen“ des Gels) verursacht sein oder es könnte eine weitere Produktbande darstellen. Eine abschließende Sequenzierung ergab allerdings keine größeren Moleküle, als die Ausgangsgröße von 112bp (Punkt 3.1.10.).

\subsubsection{Analyse der Aminoacylierungsaktivität der Bibliothek}

Ein Ziel des Selektionsexperimentes war die Verbesserung der Valylierungsaktivität der Bibliothek Lib D. Zur Analyse der Aktivität nach den verschiedenen Selektionsrunden wurden Plateau-Messungen (Punkt 2.2.2.8.) durchgeführt.

Eine erste Kontrollmessung der Aktivitätssteigerung der 2. und 4. Bibliothek zeigte die Zunahme der meßbaren Radioaktivität nach $15 \mathrm{~min}$. Reaktionszeit um etwa das Zweifache (auf 269,5cpm) für die 4. Bibliothek im Vergleich zur 2. und Ausgangsbibliothek (Abb.: 24). Im Diagramm wurde der Meßpunkt der 4. Bibliothek nach 6min. Reaktionszeit herausgenommen, da er zu einem frühen Zeitpunkt der Reaktion einen außergewöhnlich hohen Wert aufwies $(607 \mathrm{cpm})$.

\section{Plateau-Messung der Lib $D$ nach der 0./2./4.-Selektionsrunde}

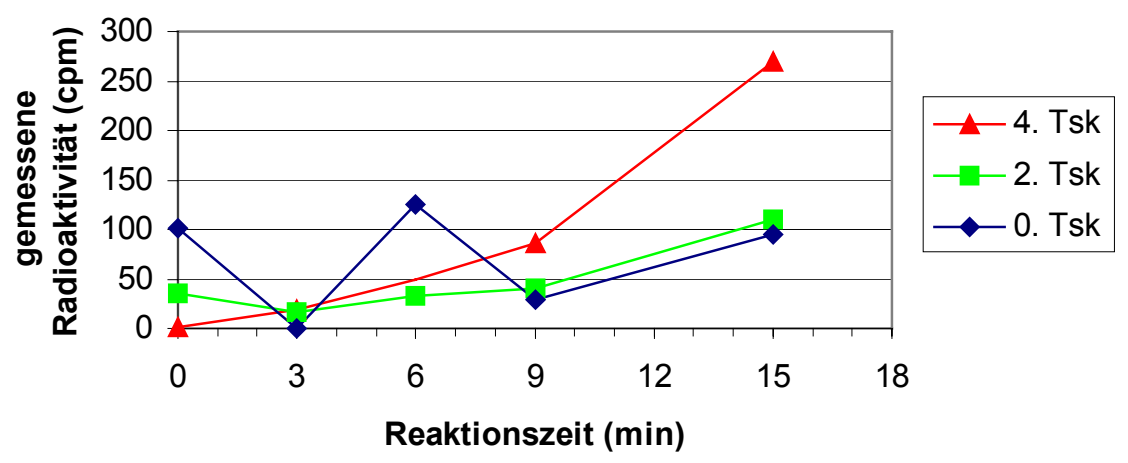

Abb.: 24,

Valylierungsplateaus der Ausgangsbibliothek Lib D und der Population nach der 2. und 4. Selektionsrunde (0., 2., 4.Tsk). Der Meßwert der Bibliothek nach der 4. Selektionsrunde, nach 6min. Reaktionszeit wurde nicht berücksichtigt (siehe Text).

Aufgrund dieser Meßwerte, die in etwa denen einer früheren Selektion (Lib C, Punkt 3.1.3.) entsprechen, wurden die weiteren Selektionsrunden (5.-7.) durchgeführt. Sie sollten $\mathrm{zu}$ einer möglichst hohen Effizienzsteigerung der Lib D in der Valylierungsreaktion 
führen. Die Stringenz der Selektion wurde zu diesem Zweck nun verschärft, indem die Bedingungen der Valylierung von 20nM ValRS und 3min. Reaktionszeit (4. Selektion) auf 2nM ValRS und 1min. Reaktionszeit (6. Selektion) geändert wurden.

Da anschließend die Werte des Valylierungsplateaus der 6. Runde niedriger waren, als die der 3./4. Runde, wurde noch eine 7. Selektionsrunde mit 0,5nM ValRS und $1 \mathrm{~min}$. Reaktionszeit in der Valylierung durchgeführt. Ein so hoher Selektionsdruck war bisher bei keiner, mit der hier verwendeten Methode selektierten, Bibliothek angelegt worden. Durch diese extremen Bedingungen bestand die Möglichkeit, daß die Zeit für die Valylierung auch „guter“ Varianten zu kurz ist und sie daher verloren gehen können. Die GesamtAktivität der Population könnte daher zurück gehen. In der Messung zeigte die Aktivität der Bibliothek Lib D nach der 7. Selektionsrunde allerdings keinen Abfall, sondern einen sehr leichten Anstieg der Valylierungseffizienz (Abb.: 25).

\section{Plateau-Messungen der Bibliothek Lib D aller Selektionsrunden}

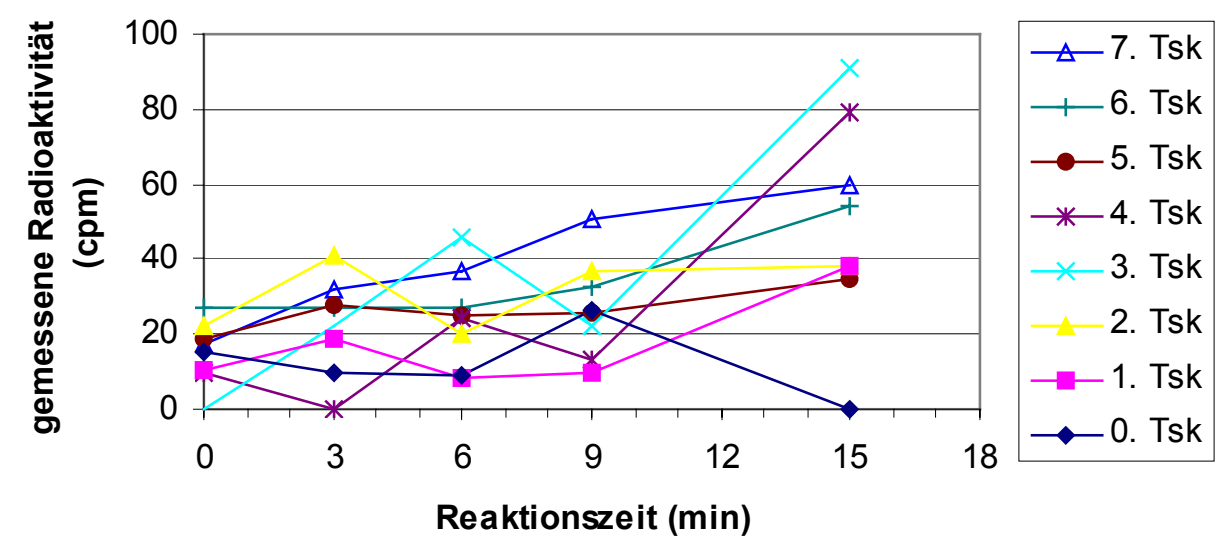

Abb.: 25,

Valylierungsplateaus der Bibliothek Lib D (1.-7. Tsk) nach jeder der 7 Selektionsrunden. Die höchsten Werte zeigen sich nach der 3. und 4. Runde. Allgemein sind aber nur geringe Veränderungen erkennbar. Die Werte nach 0 und 3min. der 3. Bibliothek (3.Tsk) wurden nicht berücksichtigt, da sie ungewöhnlich hohe Werte zeigten $(128,5 \mathrm{cpm} ; 107,5 \mathrm{cpm})$. Alle Werte wurden aus drei Messungen zusammengestellt, wobei die Kurven der 5. und 6. Transkription jeweils das Mittel aus zwei Messungen darstellen.

In der Zusammenstellung aller Plateau-Messungen in Abbildung 25 wurden die Werte der „1.-Messung“ der 0./2./4.-Selektionsrunde (Abb.: 24) nicht berücksichtigt, da diese z.T. sehr viel höher als in allen späteren Messungen waren und relativ stark um eine ideale Kurve schwankten. In der Übersicht der ausgewählten Plateau-Messungen der Bibliothek war ein Anstieg der Valylierungseffizienz um etwa das 3 fache von der 0. bis zur 3./4. Bibliothek erkennbar. Die 5. Bibliothek zeigte wieder geringe Werte und die anschließenden letzten Selektionsrunden $(6 ., 7$.$) ergaben wiederum eine gesteigerte$ 
Aktivität um etwa das 2fache. Zur besseren Übersicht zeigt Abbildung 26 die höchsten Werte der Plateau-Valylierungen aus Abbildung 25 im Vergleich.

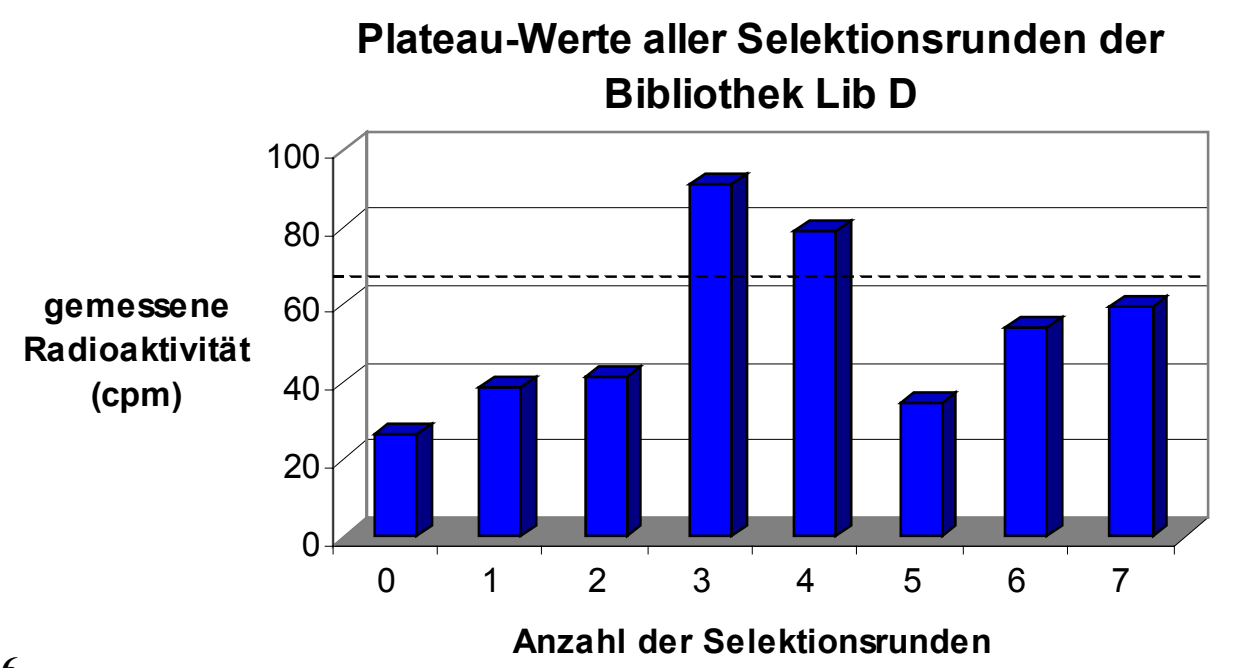

Abb.: 26,

Balkendiagramm der Plateau-Werte der Valylierung der Bibliothek Lib D nach den angegebenen Selektionsrunden. Nach 3 Selektionsrunden wurde etwa das 3fache, nach 7 Selektionsrunden etwa das 2 fache der Radioaktivität der Ausgangsbibliothek gemessen. Damit wurde das Valylierungsplateau des Wildtyps erreicht, das durch die gestrichelte Linie gekennzeichnet ist.

Das Valylierungsplateau des WT (in der Länge der Lib D mit 93nt) konnte mit der selektierten Bibliothek erreicht werden. Allerdings blieben alle radioaktiven Werte relativ dicht am Hintergrund. Ursache hierfür könnte eine zu hohe Stringenz in der Selektion sein, die dazu führen würde, daß bereits in sehr frühen Selektionsrunden nur noch wenige aktive Varianten valyliert und damit selektiert werden. Dadurch würde das Verhältnis von aktiven Varianten zu inaktivem Hintergrund negativ beeinflußt werden (Ellington and Conrad, 1995).

Eine weitere Ursache könnte ein (fast) inaktives Enzym im selektiven Schritt (ValRS in der Valylierung) darstellen, wodurch die Valylierung und Selektion von aktiven Varianten fast vollständig verhindert würde. Ebenfalls möglich ist aber auch, daß die gewählte Moleküllänge von $91 \mathrm{nt}+2 \mathrm{G}^{\prime}$ s in der Valylierung ein fast inaktives Substrat für die ValRS darstellt. Um diese Möglichkeiten zu untersuchen, wurden zwei unterschiedlich lange Fragmente des 3'-Endes des TYMV miteinander verglichen. Die Wildtyp-Sequenz der Länge der Lib D $(91+2 n t)$ wurde mit der bekannt aktiven Wildtyp-Sequenz der Länge der Lib C (83+2nt; siehe Punkt 3.1.3.) in der Valylierungseffizienz verglichen (Abb.: 27).

In dieser Vergleichsmessung wurde beobachtet, daß die Radioaktivität im Plateau des Wildtyps mit 93nt (WT 93nt) nur ca. 1/4 von der des Wildtyps mit 85nt (WT 85nt) erreicht. Die Werte des WT (93nt) sind dabei nur 2,5mal so hoch wie der Hintergrund, die des WT (85nt) sind dagegen gut 7 mal so hoch. 
In diesem Experiment konnte außerdem anhand des WT (85nt) gezeigt werden, daß die Aktivität des Enzyms Valyl-tRNA-Synthetase unter den gegebenen Bedingungen vorhanden ist.

\section{Vergleich der Plateau-Valylierbarkeit der WT-TLS der Länge 85nt (Lib C) und 93nt (Lib D)}

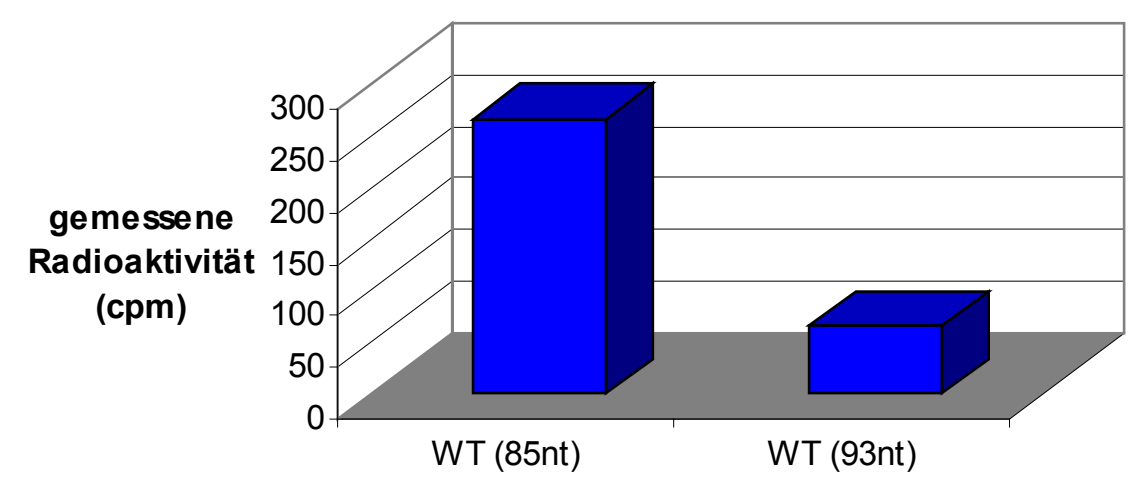

Abb.: 27,

WT-TLS-RNA

Balkendiagramm der Valylierungsplateaus zweier unterschiedlich langer Wildtyp-Fragmente des 3'-Endes des TYMV-Genoms. Beide schließen die sogenannte tRNA-ähnliche Struktur mit ein. Ein Fragment umfaßt die 83 letzten Nukleotide plus 2 G's (WT (85nt)), das zweite Fragment besteht aus den 91 letzten Nukleotiden plus 2 G's (WT (93nt)).

Die Tatsache, daß der WT (93nt) nur geringe Valylierungseffizienz besitzt, verringert die Wahrscheinlichkeit der Selektion von sehr effizienten Varianten bei hohen Selektionsdrücken. Diese Varianten bleiben, auch wenn sie „besser“ als der Wildtyp sind, relativ dicht an der Hintergrund-Aktivität. Daher können sie methodisch bedingt relativ leicht verloren gehen.

Die Entwicklung der Valylierungsplateaus im Experiment (Abb.: 26) zeigte, daß eine Selektion der Bibliothek bis zur WT-Effizienz stattgefunden hatte. Um zu prüfen, ob die selektierten Varianten der WT-Sequenz ähneln, wurden Varianten aus der 4. und 7. Bibliothek stichprobenartig sequenziert.

\subsubsection{Sequenzanalyse ausgewählter Selektionsrunden}

In dem hier durchgeführten Experiment der in vitro Selektion sollte u.a. gezeigt werden, ob ein Teilergebnis einer früheren Selektion (Bibliothek Lib C, siehe Punkt 3.1.3.) reproduziert werden kann. Im Bereich des T-Schleifen-Analogons und der ScharnierRegion war im Wesentlichen die Wildtyp-Sequenz erhalten worden. Dies war ein Hinweis darauf, daß in diesen Bereichen intramolekulare Interaktionen stattfinden, die für die Tertiär-Struktur des Moleküls wichtig sind. Die Interaktion mit der Valyl-tRNASynthetase erscheint nach Literaturangaben weniger wahrscheinlich (Florentz and Giegé, 1986). 
Die Valylierungsplateaus im in vitro Selektionsexperiment mit der Bibliothek Lib D zeigten eine Steigerung der Effizienz bis etwa zum Niveau des Wildtyps.

Um zu analysieren, ob tatsächlich Wildtyp-Sequenzen in den randomisierten Bereichen selektiert wurden, wurden Varianten aus den Bibliotheken 4. und 7. stichprobenartig sequenziert. Die Tabelle 4 zeigt die Varianten der ersten Sequenzierungen nach den Selektionsrunden der Bibliothek getrennt.

Tab.: 4, A, B,

Tabelle der sequenzierten Varianten aus der Bibliothek Lib D nach der (A) 4. und (B) 7. Selektionsrunde. Es ist die DNA-Sequenz angegeben. Die randomisierten Bereiche der Lib D Ausgangsbibliothek sind fett gedruckt, die Determinante $\mathrm{A}_{56}$ ist zusätzlich unterstrichen. Zusätzliche Mutationen sind bei Basenaustausch hellblau, bei Deletionen und Insertionen rot markiert.

A

\begin{tabular}{|c|c|c|}
\hline $\begin{array}{c}\text { Runde/ } \\
\text { Nummer }\end{array}$ & \multicolumn{1}{|c|}{ Sequenz (5' -3') $^{\prime}$} & $\begin{array}{c}\text { Anzahl der } \\
\text { Mutationen }\end{array}$ \\
\hline WT & $\begin{array}{l}\text { GGAATCGTTAGCTCGCCAGTTAGCGAGGTCTGTCCCCACACGACAGATAATCGG } \\
\text { GTGCAACTCCCGCCCCTCTTCCGAGGGTCATCGGAACCA }\end{array}$ & - \\
\hline \hline $4-17$ & $\begin{array}{l}\text { GGAATCGTTAGCTCGCGACAGAGCGAGGTCTGTCCCCACACGACAGATCCTCGG } \\
\text { GTGCTAACCCCGCCCCTCTTCCGAGGGTCATCGGAACAA }\end{array}$ & - \\
\hline $4-18$ & $\begin{array}{l}\text { GGAATCGTTAGCTCGCGACAGAGCGAGGTCTGTCCCCACACGACAGATCCTCGG } \\
\text { GTGCTAACCCCGCCCCTCTTCCGAGGGTCATCGGAACCA }\end{array}$ & - \\
\hline $4-20$ & $\begin{array}{l}\text { GGAATCGTTAGCTCGCCAACGCGCGAGGTCTGTCCCCGCACGACAGACACGCGG } \\
\text { GAAAGGAACCCGCCCCTCTTCCGAGGGTCATCGGAACCA }\end{array}$ & - \\
\hline $4-21$ & $\begin{array}{l}\text { GGAATCGTTAGCTCGCAGGACAGCGAGGTCTGTCCCCTCACAACAGAAATTCGG } \\
\text { GGATGGTGCCCGCCCCTCTTCCGAGGGTCATCGGAACCA }\end{array}$ & $\begin{array}{c}\text { GGATCGTTAGCTCGCTAGTGCGCGAGGTCTGTCCCCGCACGACAGACTACCGG } \\
\text { GGTAAACCCCCGCCCCTCTTCCGAGGGTCATCGGAACCA }\end{array}$ \\
\hline
\end{tabular}

B

\begin{tabular}{|c|c|c|}
\hline $\begin{array}{l}\text { Nummer/ } \\
\text { Runde }\end{array}$ & Sequenz $\left(5^{\prime}-3^{\prime}\right)$ & $\begin{array}{l}\text { Anzahl der } \\
\text { Mutationen }\end{array}$ \\
\hline WT & $\begin{array}{l}\text { GGAATCGTTAGCTCGCCAGTTAGCGAGGTCTGTCCCCACACGACAGATAATCGG } \\
\text { GTGCAACTCCCGCCCCTCTTCCGAGGGTCATCGGAACCA }\end{array}$ & - \\
\hline $7-5$ & $\begin{array}{l}\text { GGAATCGTTAGCTCGCTAAACCGCGAGGTCTGTCCCCXACCGACAGACGACCGG } \\
\text { GTAGTGGGCCCGCCCCTCTTCCGAGGGTCATCGGAACCA }\end{array}$ & 3 \\
\hline $7-7$ & $\begin{array}{l}\text { GGAATCGTTAGCTCGGTGCGTCGCGAGGTCTGTCCCCTCACGACAGAGTTACTG } \\
\text { GGXXTTCCACCCGCCCCTCTTCCGAGGGTCATCGGAACCA }\end{array}$ & 4 \\
\hline $7-8$ & $\begin{array}{l}\text { GGAATCGTTAGCTCGCGGTTATTCGAGGTCTGTCCCCACACGACAGAATTCCGG } \\
\text { GTTAGCTGCCCGCCCCTCTTCCGAGGGTCCCCGGAACCA }\end{array}$ & 3 \\
\hline $7-10$ & 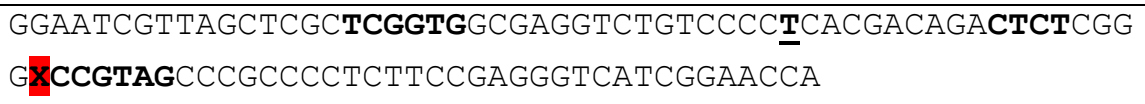 & 1 \\
\hline $7-15$ & $\begin{array}{l}\text { GGAATCGTTAGCTCGCGTTACTGTGAGGTCTGTCCTCACACGACAGATATTCGG } \\
\text { GTCCAGTACCCGCCCCTCTTCCGAGGGTCATCGGAACCA }\end{array}$ & 2 \\
\hline
\end{tabular}


Unter den 5 Sequenzen der 4. Bibliothek befand sich zweimal die gleiche Variante (4-17, 4-18). Aufgrund des Adenins an der Position 56 könnten sie zu den tatsächlich selektierten aktiven Varianten gehören. Das Auftreten von zwei gleichen Sequenzen könnte dabei auch durch die nach dem selektiven Schritt durchgeführte PCR entstanden sein. Die randomisierten Bereiche der Varianten 4-17 und 4-18 ähneln der Wildtyp-Sequenz in den 9 Positionen A34, C36, G37, T38 (,T-Schleife“), bei T43, T46 (Scharnier-Region), bei A56, und bei A72, A76 (,D-Schleife“).

Mehr als die Hälfte der Stichprobe (3 Varianten, 4-20, 4-21, 4-22) scheint zum inaktiven Hintergrund zu zählen, da sie an der Position 56 statt des Adenins entweder Guanin oder Thymin, bzw. als RNA-Molekül Uracil aufweisen. Die Variante 4-21 zeigte zudem eine unerwünschte Mutation in einer konstant gehaltenen Molekülregion. Solche Mutationen wirken sich häufig negativ auf intra- oder intermolekulare Interaktionen aus und verringern so die Aktivität.

\section{Tab.: 5,}

Sequenzierte Varianten aus der Bibliothek Lib D nach der 7. Selektionsrunde. Es ist die DNA-Sequenz der randomisierten Bereiche angegeben. Außerdem wurde die gesamte Anzahl von unerwünschten Mutationen angegeben. Deletionen in den randomisierten Bereichen wurden mit einem rot unterlegten „X“ markiert.

\begin{tabular}{|c|l|l|l|l|c|}
\hline \multirow{2}{*}{$\begin{array}{l}\text { Runde/ } \\
\text { Nummer }\end{array}$} & \multicolumn{4}{|c|}{ „D-Schleife“ } & \multicolumn{2}{c|}{ Position 56 } & \multicolumn{2}{c|}{ Scharnier-Region } & Anz-Schleife“ & Mutationen der \\
\hline WT & CAGTTA & A & TAAT & TGCAACT & - \\
\hline \hline $7-1$ & TACAGG & A & CCTA & ATGTAGT & - \\
\hline $7-3$ & AGGTGT & A & AAGT & GTTTTAG & 1 \\
\hline $7-5$ & CGAGAA & T & TTTC & AAACCGT & 1 \\
\hline $7-6$ & GTTCXX & T & CTAT & TAGACGA & 4 \\
\hline $7-8$ & TGAGGG & T & AAAC & TGAGCAG & - \\
\hline $7-9$ & ATATAA & T & TCAT & TTTTCGT & - \\
\hline $7-10$ & TACGGT & G & TAAT & TATCTGT & - \\
\hline $7-11$ & TAATAG & G & AGAC & CAATAAG & 1 \\
\hline $7-13$ & TTGAGG & G & TAAT & CATGGGA & - \\
\hline $7-14$ & CAATGA & A & AACA & AACGGAA & 2 \\
\hline $7-15$ & TATATT & T & AGTA & TTTTTAC & 1 \\
\hline $7-17$ & GGGAAT & A & CTCG & XAGCTCC & 2 \\
\hline $7-18$ & CAAACC & G & CACG & CTTTGTT & - \\
\hline $7-19$ & TTTTGX & A & ATAT & TGTGTGT & 2 \\
\hline $7-20$ & ATGGTA & A & CACA & ATTTGCA & - \\
\hline $7-21$ & GATGAA & A & CCAT & AAATGTG & - \\
\hline $7-22$ & ATATAA & T & TCAT & TTTTCGT & - \\
\hline $7-23$ & GTGTAG & T & CTTA & TTTATAG & - \\
\hline $7-24$ & GGGTAT & A & ATGA & TCGAGGG & - \\
\hline
\end{tabular}

Die Varianten der 7. Bibliothek, die aus der ersten (Tab.: 4, B) und einer späteren zweiten Sequenzierung (Tab.: 5) erhalten wurden, zeigten in den randomisierten Bereichen eine 
annähernd statistische Basenverteilung. Über die Hälfte (13 von 24; 54\%) der Moleküle weist außerdem Mutationen in den konstant gehaltenen Regionen auf.

Die aus Valylierungsmessungen (Punkt 3.1.9.) und Sequenzierungen der Bibliotheken erhaltenen Ergebnisse deuten darauf hin, daß eine Selektion bis zur 3./4. Runde stattgefunden hat. In den weiteren Runden könnte eine zu hohe Stringenz dazu geführt haben, daß aktive Varianten verloren gingen. Aufgrund der niedrigen Aktivität des Wildtyps (93nt) und des somit geringen Aktivitätspotentials der Bibliothek konnten selektierte aktive Varianten nicht ausreichend deutlich vor dem Hintergrund angereichert werden.

Die Frage nach der Reproduzierbarkeit der Ergebnisse des Selektionsexperimentes mit der Bibliothek Lib D konnte so nicht beantwortet werden. Außerdem konnten in diesem Experiment keine Varianten selektiert werden, die in ihrer Valylierungseffizienz deutlich gesteigert waren.

Varianten, die für die nachfolgenden Versuche benötigt wurden, wurden daher aufgrund bereits vorhandener Daten z.T. neu konstruiert.

\subsection{Versuche zur in vitro Replikation des TYMV}

\subsubsection{Aufgabenstellung}

Mittels der durchgeführten in vitro Experimente sollte die Interaktion der Replikase des TYMV mit (verschieden effektiv valylierbaren) Varianten der TLS des Virus untersucht werden. Da die Gesamtanzahl der in vivo vorhandenen Proteine/Enzyme der Replikase nicht bekannt ist, wurde nur die viral codierte RNA-abhängige RNA-Polymerase (RdRp) nach einem Protokoll von Birgit A. Deiman aus infizierten Chinakohlblättern grob aufgereinigt (Tsai and Dreher, 1991; Deiman et al., 1997b; Punkt 2.2.4.9.).

Von Theo W. Dreher wurden 1991 in vivo-Daten veröffentlicht, die darauf schließen ließen, daß die Aminoacylierungseffizienz Einfluß auf die Replikationseffizienz hat (siehe Abb.: 8). Ineffizient valylierbare Varianten waren demnach in der Regel auch „schlecht“ amplifizierbar.

Da die effizientest valylierbare Variante im Experiment der Wildtyp war, stellte sich die Frage, ob „,besser“ valylierbare Varianten auch „,besser“ als der Wildtyp replizieren.

Mit den hier durchgeführten in vitro Transkriptionsversuchen sollte daher vor allem untersucht werden, ob, effizienter als der Wildtyp valylierbare TLS-Varianten auch effizienter durch die virale RdRp transkribiert werden ((-)-Strang-Synthese).

Damit sollte gleichzeitig beobachtet werden, wie die „Verbesserung“, bzw. „Verschlechterung“ einer Funktion der TLS (hier die Interaktionsfähigkeit mit ValyltRNA-Synthetase) eine zweite Funktion (Interaktionsfähigkeit mit der RdRp) beeinflußt. 
Außerdem waren in vorangegangenen Experimenten Ergebnisse erhalten worden, die auf einen Einfluß der Länge der L1-Schleife und der Sequenz der Anticodon-Schleife auf die Replizierbarkeit hinwiesen. Mit speziell hierfür konstruierten Varianten sollten diese Ergebnisse überprüft werden.

\subsubsection{Design der Varianten}

In den Replikationsversuchen sollten u.a. Varianten eingesetzt werden, die auf effiziente Valylierung selektiert worden sind. Da durch die vorangegangene in vitro Selektion der Bibliothek Lib D keine geeigneten Moleküle isoliert werden konnten, mußte auf Varianten früherer Selektionen zurückgegriffen werden.

Die Varianten sollten aufgrund der Erkenntnisse aus der Lib D-Selektion aus den 83nt der TLS und den zusätzlichen zwei G's für die T7-Transkription bestehen.

Die verwendeten Varianten wurden z.T. der Publikation der Selektion der Lib B (Wientges, 1998; Wientges et al., 2000) entnommen oder aus den Ergebnissen neu konstruiert. So waren Varianten bekannt, die effizienter oder ineffizienter valylierbar sind, als der Wildtyp. Außerdem konnten Konsensus-Sequenzen für optimale Valylierbarkeit aus den dort aufgetretenen Varianten zur Konstruktion neuer Varianten genutzt werden.

Die ausgewählten, bzw. neu konstruierten Varianten unterschieden sich vom Wildtyp in der Sequenz der L1-Schleife und der Anticodon-Schleife (siehe Punkt 3.1.3.; Abb.: 19, A). Die 83nt des Wildtyps entsprechen der Sequenz des Blue-Lake Stammes, wodurch die L1Schleife hier nicht aus CUCU, sondern aus der Sequenz CUUU besteht (Blok et al., 1987; Morch et al., 1988).

Im Einzelnen wurden 25 verschiedene Varianten nach folgenden Fragen ausgewählt, bzw. neu konstruiert:

\section{Abhängigkeit der Replikation von der Valylierungseffizienz}

Es sollen effizient und ineffizient valylierbare Varianten verglichen werden (selektierte Moleküle der Lib B/Lib C).

In der Valylierbarkeit optimierte Varianten:

\begin{tabular}{lcc} 
Nr. & Anticodon-Schleife & L1-Schleife \\
$8-40$ & ACUACAC & UUUC \\
$8-39$ & ACGACUC & UCG \\
$8-7$ & UCGACUU & UCG \\
\multicolumn{2}{l}{ Varianten mit } & geringerer Valylierbarkeit, als der Wildtyp: \\
Nr. & Anticodon-Schleife & L1-Schleife \\
WT (C) & CCCACAC & C \\
$8-39($ C $)$ & ACGACUC & C \\
$8-13$ & GUGAUUU & AUCC \\
$8-16$ & CUUAGUG & UCUG
\end{tabular}




\section{Vergleich der Replikationseffizienz von Varianten mit Konsensussequenzen und} Anti-Konsensussequenzen

Varianten mit Konsensussequenzen für optimale Valylierung (nach Daten in Selektionsexperimenten gefundener Moleküle) sollen mit solchen mit funktionell entgegengesetzten Sequenzen verglichen werden.

$\begin{array}{lcc}\text { Nr. } & \text { Anticodon-Schleife } & \text { L1-Schleife } \\ \text { Konsensus } & \text { UCUACAC } & \text { UUAC } \\ \text { Anti-Kon. } & \text { GGACACU } & \text { GCGA } \\ \text { Kon./Anti } & \text { UCUACAC } & \text { GCGA } \\ \text { Anti/Kon. } & \text { GGACACU } & \text { UUAC }\end{array}$

\section{L1-Längenabhängigkeit der Replikation}

Bei konstanten Anticodon-Schleifen sollen die L1-Schleifen variiert werden.

$\begin{array}{lcl}\text { Nr. } & \text { Anticodon-Schleife } & \text { L1-Schleife } \\ \text { WT (C5U) } & \text { CCCACAC } & \text { CUUUUU } \\ \text { WT (C4U) } & \text { CCCACAC } & \text { CUUUU } \\ \text { WT } & \text { CCCACAC } & \text { CUUU } \\ \text { WT (C2U) } & \text { CCCACAC } & \text { CUU } \\ \text { WT (C1U) } & \text { CCCACAC } & \text { CU } \\ \text { WT (C) } & \text { CCCACAC } & \text { C } \\ & & \\ 8-40(4 U C C) & \text { ACUACAC } & \text { UUUUCC } \\ 8-40 & \text { ACUACAC } & \text { UUUC } \\ 8-40(\mathrm{UCG}) & \text { ACUACAC } & \text { UCG } \\ 8-3 & & \\ 8-3(\text { ACC }) & \text { AAAACGC } & \text { AUUC } \\ 8-3(\mathrm{C}) & \text { AAAACGC } & \text { ACC } \\ & & \text { C }\end{array}$

\section{Einfluß der Anticodon-Schleife auf die Replikation}

Bei konstanten L1-Schleifen sollen die Anticodon-Schleifen variiert werden.

$\begin{array}{lcc}\text { Nr. } & \text { Anticodon-Schleife } & \text { L1-Schleife } \\ \text { WT (UCG) } & \text { CCCACAC } & \text { UCG } \\ 8-39 & \text { ACGACUC } & \text { UCG } \\ 8-40 \text { (UCG) } & \text { ACUACAC } & \text { UCG } \\ & & \\ \text { WT (UUUC) } & \text { CCCACAC } & \text { UUUC } \\ 8-39 \text { (UUUC) } & \text { ACGACUC } & \text { UUUC } \\ 8-40 & \text { ACUACAC } & \text { UUUC } \\ & & \\ \text { WT (C) } & \text { CCCACAC } & \text { C } \\ 8-39(\mathrm{C}) & \text { ACGACUC } & \text { C } \\ 8-40(\mathrm{C}) & \text { ACUACAC } & \text { C }\end{array}$


Von den Varianten sind hier nur die Bezeichnung („Nr.“), Sequenz der Anticodon- und L1-Schleife aufgelistet. Die übrige Sequenz der Moleküle entspricht dem Wildtyp. Die Bezeichnung bezieht sich zuerst auf die Sequenz der Anticodon-Schleife (z.B. ,8-40“) und auf die der L1-Schleife (z.B. ,(UCG)“").

\subsubsection{Methode der in vitro Transkription}

Für die ersten Versuche zur in vitro Replikation wurde folgend beschriebene Methode angewendet (für Details siehe Punkt 2.2.3.1.). Diese Experimente wurden modifiziert nach einem Protokoll von Birgit A. Deiman im Labor von Prof. C.W.A. Pleij in Leiden (Niederlande) durchgeführt (Deiman et al., 1997a). Da es sich in diesen Experimenten nur um eine (-)-Strang-Synthese handelt, muß statt von in vitro Replikation von Transkription gesprochen werden.

Die aus infizierten Chinakohlblättern aufgereinigte RNA-abhängige RNA-Polymerase (RdRp) wurde mit Mikrococcen-Nuklease behandelt, um noch vorhandene intrinsische (virale) RNA abzubauen. Die Funktion der Nuklease wurde durch Zugabe von EGTA (komplexiert spezifisch $\mathrm{Ca}^{2+}$, ein Cofaktor der Nuklease) gestoppt und Restaktivitäten wurden durch RNase-Inhibitor unterbunden. Anschließend wurden das RNA-Fragment und ein Polymerisationsansatz zugegeben. Dieser Ansatz enthielt zur spezifischen Inhibition von RNA-Polymerasen aus der Pflanze Actinomycin D (Mamoun and Bové, 1976) und für die spätere Detektion des Polymerisationsproduktes $\left[\alpha-{ }^{32} \mathrm{P}\right]-\mathrm{UTP}$. Die Replikation fand bei $30^{\circ} \mathrm{C}$ für eine Stunde statt.

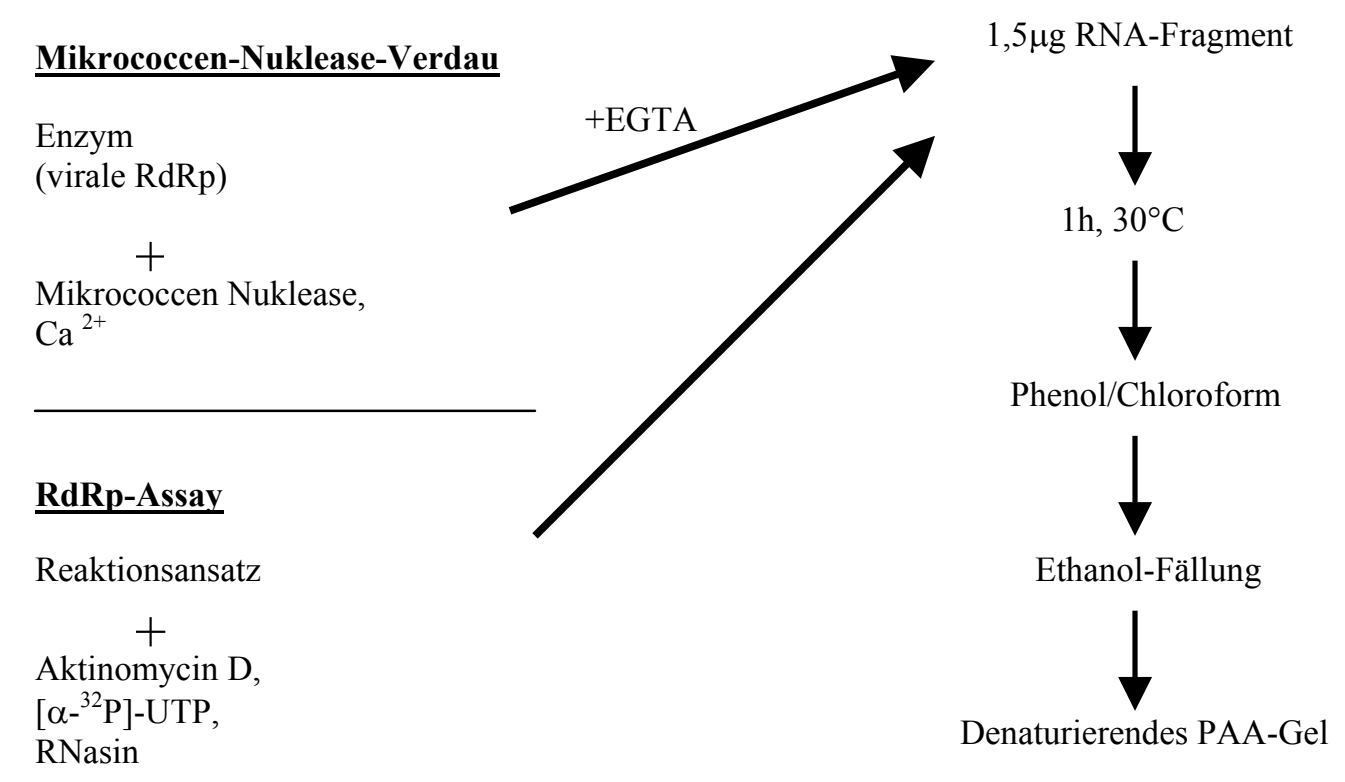

Abb.: 28,

Systematischer Überblick zur Vorgehensweise in der in vitro Transkription (Details siehe Punkt 2.2.3.1.). 
Direkt im Anschluß wurde zweimal mit Phenol/Chlorophorm das Protein extrahiert, wobei beim ersten Ausschütteln 1\%SDS und 20mM EDTA zugegeben wurde. Nach einer Ethanolfällung wurde die RNA dann auf ein denaturierendes 20\%iges Polyacrylamid Gel gegeben. Durch Aufnahme der Radioaktivität auf eine sogenannte Bildplatte („Imaging Plate") und dessen Auswertung mittels eines Phosphor Imagers (Fuji Photo Film Co., LTD, Japan) wurde die relative Replikationseffizienz bestimmt (eine systematische Übersicht gibt Abbildung 28).

\subsubsection{Herstellung der 25 TLS-Varianten}

Für die Synthese der RNA-Varianten mußte jeweils eine entsprechende Matrize als DNAMolekül mit korrekt angefügtem T7-RNA-Polymerase-Promotor hergestellt werden.

Dies sollte über die gängigen Methoden der PCR (z.T. mit mutagenisierten StarterOligonukleotiden), Restriktionsverdau, Ligation, Transformation, Klonierung und Sequenzierung durchgeführt werden.

Anfangs wurde als Matrize in den PCR's ein Vektor/PCR-Produkt-Gemisch (PCRReaktionen von Varianten aus früheren Selektionen der Lib B/Lib C) verwendet. Zur gezielten Einführung von Mutationen wurden entsprechend konstruierte Oligonukleotide (,Primer“) eingesetzt. Auf diese Weise wurden fast ausschließlich Varianten erhalten, die entweder keine der einzuführenden Mutationen oder Mutationen nur in unerwarteten Regionen aufwiesen. Auch die Erneuerung von Enzymen nachfolgender Experimente (Austausch des TOPO-TA-Cloning ${ }^{\circledR}$ Kits, Invitrogen) oder Modifikationen von Reaktionsbedingungen führte nicht zum erwünschten Ergebnis.

Auch die Direktsequenzierung der PCR-Produkte blieb erfolglos, da die Moleküle mit ca. 100nt Länge zu kurz waren, um ausreichend genaue Informationen über die gesamte Sequenz erhalten zu können. Das analytische Gel der angewendeten Sequenzierungsmethode (Sanger et al., 1977) hat im Bereich von 1-80nt nur ein sehr ungenaues Auflösungsvermögen.

Die PCR's wurden anschließend mit 2 Oligonukleotiden durchgeführt, die mittig über 7 Nukleotide komplementär zu einander konstruiert waren (Hybridisierungstemperatur: $17^{\circ} \mathrm{C}$ ) und je entweder eine spezifische Anticodon- oder L1-Schleifen-Sequenz codierten. Auch über diesen Ansatz wurden anfänglich fast keine korrekten Varianten erhalten.

Es wurden mehrere verschiedene Klonierungsschemata verfolgt und entsprechend der vermuteten Fehler-Ursache wurden einzelne oder mehrere Parameter der durchgeführten Versuche variiert. Zusammenfassend wurden die folgenden Bedingungen der entsprechenden Methoden modifiziert:

PCR:

- Matrizen (Plasmide; PCR-Produkte, chemisch synthetisierte Oligonukleotide)

- Primer (Phosphorylierung, verschiedene Bezugsquellen) 
Ligation:

Transformation:
- Enzyme (Ampli-Taq, Vent)

- Dauer

- Temperatur $\left(14^{\circ} \mathrm{C}, \mathrm{RT}\right.$, Kühlschranktür $\left.\sim 8^{\circ} \mathrm{C}\right)$

- Enzym (Topoisomerase, T4-Ligase)

- Konzentration Vektor : Insert

- Konzentration T4-Ligase

- Klebrige-/Stumpfe-Enden der DNA

- Zugabe von PEG 8000

- Vektor (pCR2.1, pCR4, pUC19, pDrive)

- Hitzeschock/Elektroporation

- verschiedene Präparationen von XL1-Blue kompetenten

Zellen, verschiedene kommerziell erhaltene TOP10

kompetenten Zellen

Die Suche nach geeigneten Reaktionsbedingungen führte zu einem Klonierungsschema, das in Abbildung 29 dargestellt ist. Die erste Polymerase-Kettenreaktion wurde mit je 2 Oligonukleotiden durchgeführt, die miteinander über die Sequenz 5' -CCCGCCC-3'
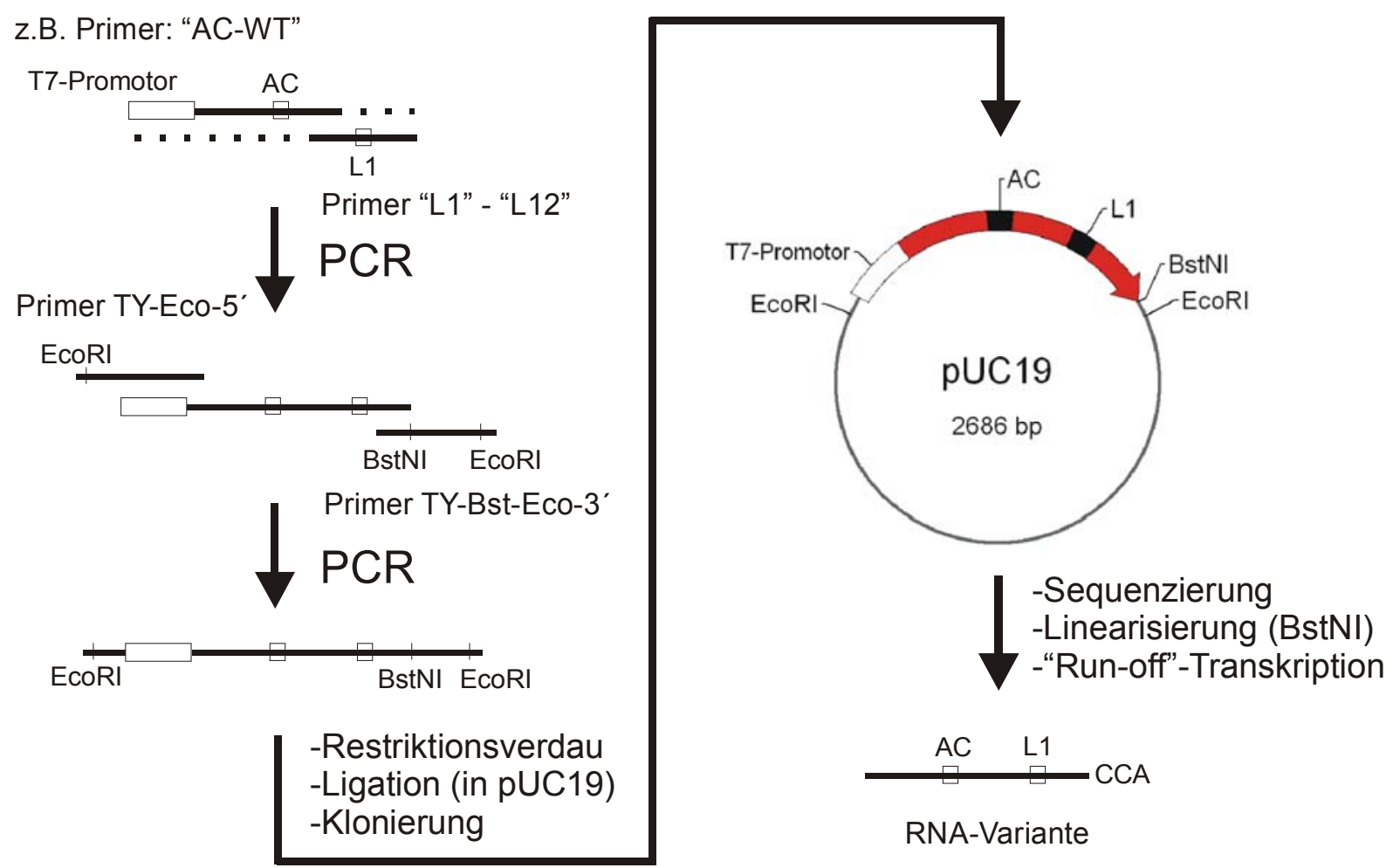

Abb.: 29,

Klonierungsschema der Varianten für die in vitro Transkriptionen. „AC“ markiert die Region der AnticodonSchleife, „L1“ markiert die Region der L1-Schleife, die bei verschiedenen Startermolekülen („Primer“) verschiedene Sequenzen darstellen. Das Plasmid pUC19 und das eingesetzte PCR-Produkt (Pfeil im Plasmid) sind nicht maßstabsgetreu dargestellt. 
hybridisieren konnten und zusammen die gesamte Länge der Variante und einen T7Promotor umfaßten. Ein Molekül legte dabei die Sequenz der Anticodon-Schleife fest (6 „AC-..."-Primer, Punkt 2.1.10.) und enthielt außerdem den T7-Promotor, das zweite codierte je eine bestimmte L1-Schleife (12 „L..“-Primer). Die PCR wurde im allgemeinen wie unter Punkt 2.2.2.1. beschrieben durchgeführt, allerdings wurde Vent-Polymerase und entsprechender 10x Puffer benutzt, um die Korrekturlese-Aktivität des Enzyms zu nutzen. Die Temperaturzyklen entsprechen ebenfalls der Beschreibung mit den folgenden Spezifikationen. 2 Vorzyklen mit der Hybridisierungstemperatur von $17^{\circ} \mathrm{C}$ folgten 20 Zyklen mit einer Hybridisierungstemperatur von $72^{\circ} \mathrm{C}$.

In der zweiten PCR dienten $0,5 \mu 1$ der ersten PCR als Matrize. Die Oligonukleotide TYEco-5' und TY-Bst-Eco-3' (Punkt 2.1.10.) wurden eingesetzt, um die Restriktionsschnittstellen BstNI und EcoRI anzufügen. Ansonsten entspricht der Ansatz dem der vorhergehenden PCR. Die Temperaturzyklen fanden ebenfalls wie in der ersten PCR statt, außer das die Hybridisierungstemperatur in den 2 Vorzyklen bei $61^{\circ} \mathrm{C}$ und in den 20 folgenden Zyklen bei $69^{\circ} \mathrm{C}$ lag.

Je 3 PCR-Ansätze wurden vereinigt und 2x 150 $\mu$ l wurden mittels PCR-Purification-Kit ${ }^{\mathrm{TM}}$

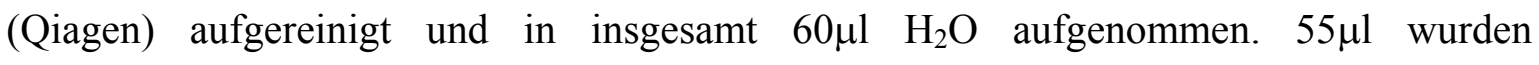
anschließend in einem 100 $\mu \mathrm{l}$ Standard-Ansatz (Punkt 2.2.1.19.) mit $2 \mu \mathrm{l}$ EcoRI über Nacht verdaut. Nach Hitzeinaktivierung des Enzyms $\left(65^{\circ} \mathrm{C}, 15 \mathrm{~min}\right.$.) wurde der Ansatz wiederum mittels PCR-Purification-Kit ${ }^{\mathrm{TM}}$ (Qiagen) aufgereinigt und in $50 \mu 1 \mathrm{H}_{2} \mathrm{O}$ aufgenommen.

Der Vektor pUC19 wurde für die Ligation mit EcoRI linearisiert und über ein 1\% AgaroseGel mittels Qiaquick-Gel-Extraction-Kit ${ }^{\top M}$ (Qiagen) aufgereinigt. Nach Dephosphorylierung der 5'-Enden des Vektors durch Krabben-Alkalische-Phosphatase (SAP) und Inaktivierung des Enzyms $\left(65^{\circ} \mathrm{C}, 15 \mathrm{~min}\right.$.) wurde der Ansatz mit Ethanol gefällt. Für die Ligation wurde das Insert in sehr hohem Überschuß über das Plasmid eingesetzt und die Reaktion fand bei $15^{\circ} \mathrm{C}$ über Nacht statt. $2 \mu 1$ des $10 \mu 1$ Ligationsansatzes wurden zu $50 \mu 1$ XL1-Blue kompetente Zellen gegeben. Die Transformation der ligierten DNA fand dann über eine Elektroporation statt.

Für verschiedene Varianten wurde dieses Protokoll leicht variiert.

\subsubsection{Grundlagen und erste Ergebnisse}

In einem früheren Versuch zur Replikation der TYMV-TLS mit viraler RdRp zeigten unterschiedliche TLS-Varianten relativ deutliche Effizienzunterschiede bei der (-)-Strang Synthese (Klug, 2000). Diese Varianten waren z.T. in Anticodon- und/oder L1-Schleife von der Sequenz des Wildtyps verschieden. Auffällig war vor allem eine scheinbare Abhängigkeit der Transkriptionseffizienz von der Länge der L1-Schleife (weniger von der Sequenz, Abb.: 30, A). Ebenso schien die Sequenz der Anticodon-Schleife unter 
bestimmten Sequenzbedingungen Einfluß auf die Transkriptionseffizienz besitzen zu können (Abb.: 30, B). Beide Eigenschaften sind bisher nicht beobachtet worden und sind nicht in der Literatur beschrieben. Allerdings würde dafür sprechen, daß eine verringerte Stabilität des Pseudoknotens effizienzsteigernd in der in vitro (-)-Strang Synthese wirken kann (Deiman et al., 1998). Dem stehen die bekannten Eigenschaften der TYMV-RdRp entgegen, wonach dieses Enzym zur Initiation nur ein ungepaartes 3'-CCA-Ende benötigt und keine spezifischen Kontakte zur L1-Schleife eingeht (Deiman et al., 1997a; Deiman et al., 1998).

A

\section{Vergleich von Varianten nach Länge der L1-Schleife}

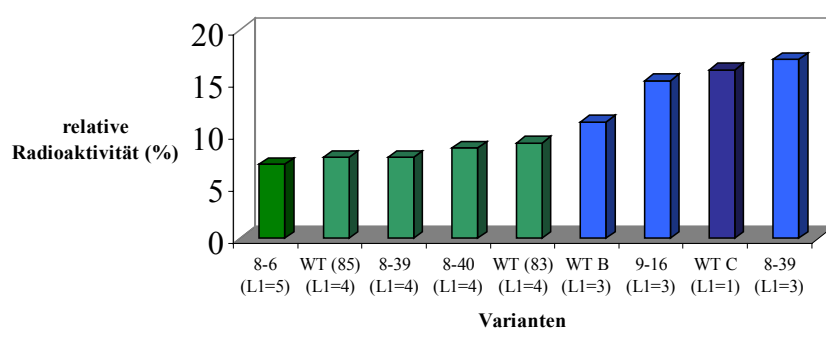

B
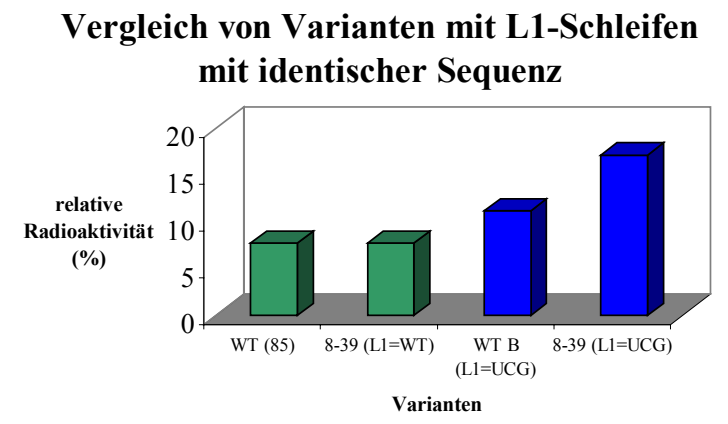

Abb.: 30,

Vergleich der Radioaktivität der RNA-Produkte von 9 TLS-Varianten aus einer in vitro (-)-Strang Synthese mit viraler RdRp. Es ist jeweils der Anteil einer Variante an der Gesamt-Radioaktivität in Prozent dargestellt. Die Farben unterscheiden die Länge der L1-Schleife.

A) Vergleich der Radioaktivität der Varianten nach der Länge der L1-Schleife („L1-Anzahl der Nukleotide“).

B) Vergleich der Radioaktivität von Varianten mit sequenzidentischen L1-Schleifen.

Um diese Ergebnisse zu überprüfen, wurden die in Punkt 3.2.2. genannten 25 Varianten in die in vitro Transkription eingesetzt und die Radioaktivität der RNA-Produkte miteinander verglichen (Abb.: 31).

Bei einzelnen Versuchen (3 Wiederholungen) konnten relative Unterschiede der Effizienz der Varianten von bis $\mathrm{zu}$ ca. $15 \%$ ermittelt werden (gemessen an der relativen Radioaktivität der Produktbanden im Gel). Bei dem Vergleich der durchgeführten Versuche zeigte sich allerdings eine große Variabilität in den Ergebnissen. Einzelne Varianten waren dabei zwar immer weniger effizient transkribierbar, als andere, aber auf unterschiedlich hohem Niveau.

Nur bei einigen Varianten konnte ein relatives Verhältnis zu einander vermutet werden (Abb.: 31, mittelblaue Balken). Interessant erschienen hier die Varianten Konsensus („Kon.“) und Anti/Kon. (,A/K“), die immer relativ besser transkribierbar waren, als AntiKonsensus und Kon./Anti (,K/A“). Dies könnte ein Hinweis dazu sein, daß die KonsensusSequenz für optimale Valylierbarkeit in der L1-Schleife auch zu einer verbesserten Replikation führt. Die Ursache in diesen Experimenten liegt dabei vermutlich nicht an der Valylierbarkeit an sich, sondern an verbesserten Faltungseigenschaften des Moleküls. 
Ebenfalls von Interesse waren die Werte der Varianten 8-40, 8-40 (4UCC) und WT (C), da diese im Gesamt-Genom-Kontext auch in in vivo Experimenten mit Pflanzenzellen eingesetzt wurden. Die Werte der beiden 8-40iger Varianten wiesen in jedem Experiment auf sehr ähnliche Transkriptionsaktivität hin, während WT (C) im gleichen Experiment immer die geringere Aktivität zeigte.

\section{In vitro Transkription der 25 TYMV-TLS-Varianten}

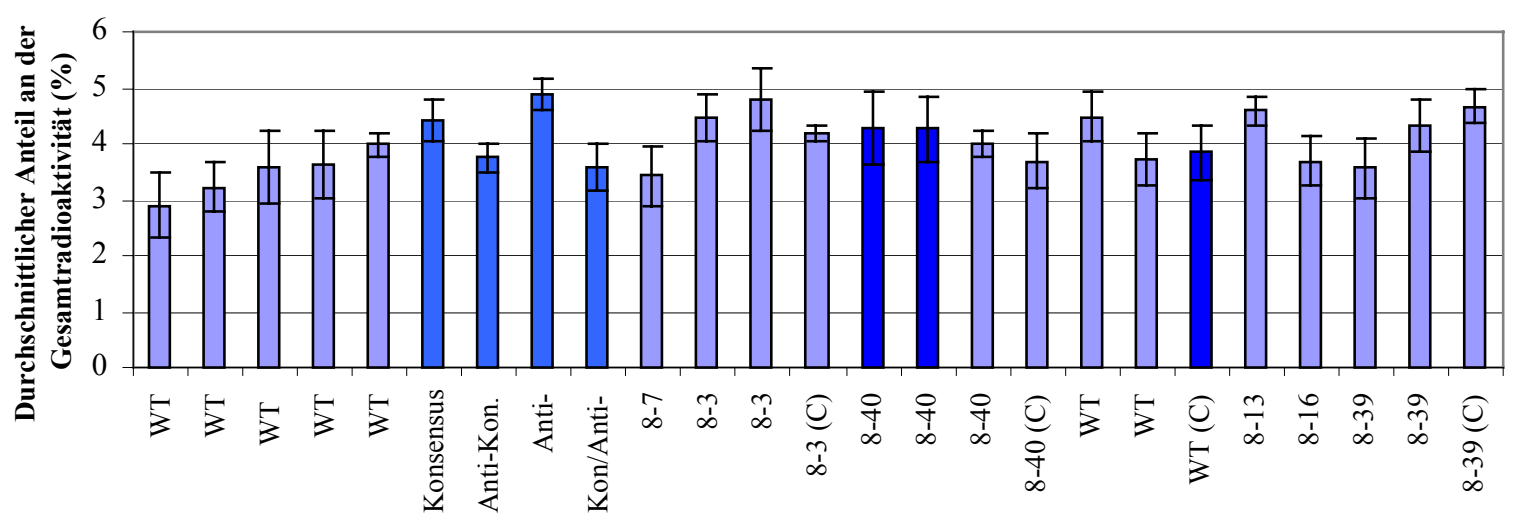

\section{Varianten}

Abb.: 31,

Balkendiagramm der RNA-Produktradioaktivität der 25 TLS-Varianten in den ersten in vitro (-)-Strang Synthesen. Die Werte sind aus drei unabhängigen Experimenten erhalten worden. Die mittelblauen Balken kennzeichnen Varianten, deren radioaktive Werte bei allen Versuchen in der gleichen Relation zueinander waren. Die dunkelblauen Balken markieren Varianten, die später im Gesamt-Genom-Kontext auch in in vivo Experimente eingesetzt wurden.

Nach den Ergebnissen der 3 in vitro Transkriptionen ist anzunehmen, daß Unterschiede, die eventuell im Zusammenhang mit der Valylierungsaktivität der Varianten auftreten, vorhanden sind. Diese sind aber so gering, daß sie mit den momentan zur Verfügung stehenden Methoden nicht exakt erfaßt werden können.

Die anfänglich gestellte Frage nach dem Einfluß der Länge der L1-Schleife und Sequenz der Anticodon-Schleife kann hier nur negativ beantwortet werden. Es scheint, übereinstimmend mit Daten aus der Literatur, keinen deutlichen Einfluß der beiden Sequenz-Regionen auf die Transkriptionseffizienz zu geben.

\subsubsection{Ergebnisse der in vitro (-)-Strang-Synthesen mit/ohne Valylierung und zusätzlichen Kompetitoren}

In den ersten in vitro Transkriptionen konnten kaum Unterschiede in der Effizienz der Varianten erkannt werden. Daher sollte nun genauer untersucht werden, ob die Valylierungseffizienz der Varianten oder die Aminosäure selbst die Transkriptionseffizienz (mit RdRp) beeinflußt. In der Literatur sind nur in vivo-Daten vorhanden, die zeigen, daß 
weniger effizient als der Wildtyp valylierbare Varianten sich meist auch schlechter in Pflanzenzellen amplifizieren (Tsai and Dreher, 1991).

Um die beschriebene Frage näher zu untersuchen, wurden die TLS-Varianten erst jeweils in einem $20 \mu \mathrm{l}$ Ansatz valyliert (ValRS aus E. coli), der dann direkt in einen so modifizierten Transkriptionsansatz gegeben wurde, daß dessen Endvolumen (100 $\mu 1)$ nicht geändert wurde (Details der Ansätze siehe Punkt 2.2.3.1.).

Da die Valylierung unter bestimmten Volumenbedingungen stattfinden mußte, wurden Vorversuche mit dem Wildtyp $(1,5 \mu \mathrm{g})$ durchgeführt, die zeigen sollten, daß eine Aminoacylierung im 20 $\mu$ l Ansatz erfolgte und die Esterbindung zwischen Aminosäure und RNA während der anschließenden Transkription auch stabil erhalten blieb. Dazu wurden die Valylierungen mit Tritium $\left({ }^{3} \mathrm{H}\right)$ markierter Aminosäure durchgeführt. Von drei Ansätzen wurden Endpunktbestimmungen (wie in Punkt 2.2.2.8.) der akkumulierten Radioaktivität entweder nach 40min. Valylierung, nach Valylierung und Zugabe des Transkriptionsansatzes (30min. Reaktion) und nach Valylierung und 60min. Transkriptionsreaktion durchgeführt (Abb.: 32, A). Die Ergebnisse zeigten, daß eine Aminoacylierung in den ersten 40min. stattfand und während der Transkriptionsreaktion sogar noch weiter lief.

A

Valylierung / Valylierung + Replikation der WT-TLS-Variante

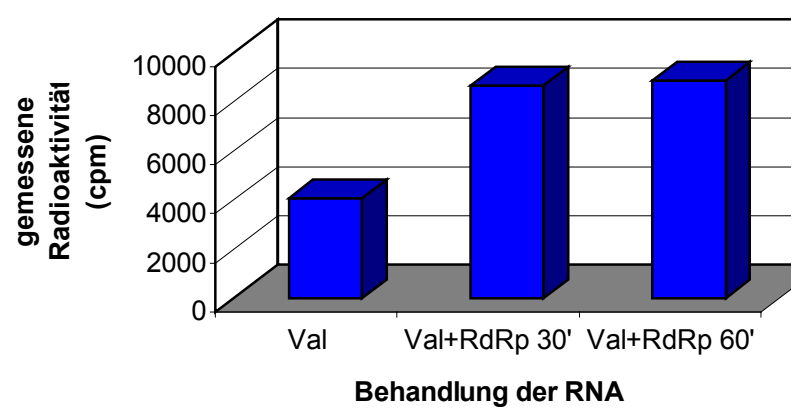

B

Valylierungen des 85nt-TYMV-WTFragmentes

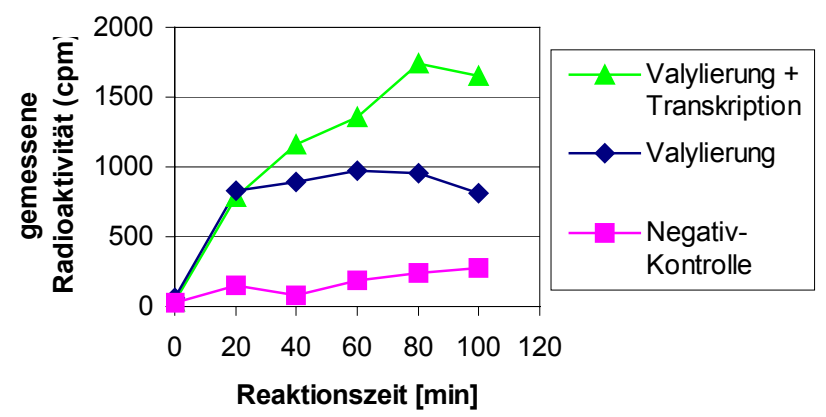

Abb.: 32,

Messungen der Radioaktivität der mit ${ }^{3} \mathrm{H}$-Valin aminoacylierten WT-TLS-RNA (85nt; 1,5 $\mu \mathrm{g}$ ) aus zwei

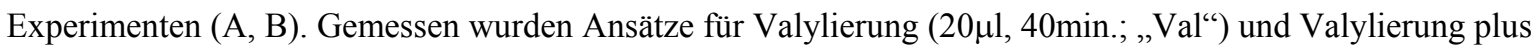

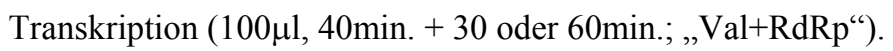

A) Endpunktbestimmungen von drei Reaktionen (Transkriptionsansätze nach 40min. zugegeben),

B) Bestimmung des zeitlichen Verlaufs (Transkriptionsansätze bei 0min. zugegeben).

Um diese ersten Ergebnisse zu bestätigen und den zeitlichen Verlauf der Valylierung der TLS-RNA nachvollziehen zu können, wurden in einem weiteren Experiment Aliquots nach 0, 20, 40, 60, 80 und 100min. von den Reaktionsansätzen genommen (Abb.: 32, B). Um das Abnehmen immer gleicher Volumina zu ermöglichen, wurden für die Valylierung plus 
Transkription beide Ansätze bereits bei 0min. zusammengegeben. Außerdem wurde eine Negativ-Kontrolle mit vermessen. Diese bestand aus dem Ansatz der Valylierung plus Transkription, wobei nur das Enzym ValRS weggelassen worden war.

Auch diese Ergebnisse zeigten, daß die Radioaktivität im Valylierungs- plus Transkriptionsansatz höher stieg, als im Valylierungsansatz allein. Das Plateau wurde später, als im Valylierungsansatz erreicht, lag aber deutlich höher. Da der Anstieg der Radioaktivität in den ersten 20min. dem des Valylierungsansatzes entsprach, wurden vermutlich entweder valylierte Moleküle stabilisiert oder die Anzahl valylierbarer Moleküle vergrößert. Letzteres könnte durch (+)-Strang Synthese der RdRp(-Präparation) erreicht werden, dies wird durch Literaturdaten aber eher ausgeschlossen (Deiman et al., 1997b). Eine Stabilisierung der Esterbindung, eventuell durch die RdRp erscheint daher eher wahrscheinlich.

Insgesamt liegen die vergleichbaren radioaktiven Werte (gleicher Ansatz und Zeitpunkt) des ersten Versuches (Abb.: 32, A) um etwa 11-24\% niedriger, als beim zweiten Versuch (Abb.: 32, B).

Die Radioaktivität der Negativ-Kontrolle des Versuchs blieb auf niedrigem Niveau. Der erkennbare leichte Anstieg zum Ende der Reaktionszeit könnte auf geringe Verunreinigung der RdRp-Präparation mit pflanzlicher tRNA-Synthetase hinweisen.

Ein weiteres Experiment, durch das untersucht werden sollte, in wie weit die RdRpPräparation Einfluß auf die Valylierung nimmt oder eine (+)-Strang Synthese stattfindet, zeigte starke Schwankungen und Kontaminationen. Die Ergebnisse konnten nur bestätigen, daß die RNA valyliert wurde und während der Transkription stabil valyliert blieb.

In einem ersten Versuch (Endpunktbestimmung nach Punkt 2.2.3.1.) wurde die Transkriptionseffizienz einer valylierten mit einer nicht valylierten Variante (WT (UUUC)) verglichen. Dabei wurde beobachtet, daß die valylierte Variante ein ca. 4fach höheres radioaktives Signal aufwies. Dieses Ergebnis konnte mit der hier angewandten Methode aber nicht reproduziert werden.

Die bisher beschriebenen Experimente wurden im Labor von Professor Pleij in Leiden (Niederlande) durchgeführt, die weiteren in vitro Versuche fanden dann am Institut für Mikrobiologie und molekulare Genetik in Göttingen statt.

Um das vorläufige Ergebnis aus den Niederlanden zu überprüfen, sollten nun bestimmte Varianten, die ebenfalls für in vivo Experimente verwendet wurden, getestet werden. Diese waren WT, 8-40, WT (C) und 8-40 (4UCC).

Damit der zeitliche Verlauf der Valylierung und (-)-Strang Synthese verfolgt werden konnte, wurde das Experiment sowohl mit ${ }^{3} \mathrm{H}-$ Valin, als auch mit $\left[\alpha-{ }^{32} \mathrm{P}\right]-\mathrm{UTP}$ durchgeführt (siehe Punkt 2.2.3.2.). Vom Ansatz valylierter Varianten wurden bei 0 und 40min. (Valylierung) und bei 55 und 100min. ((-)-Strang Synthese) Aliquots abgenommen und die Radioaktivität nach Strahlungsenergie der Isotope getrennt bestimmt $(0-16 \mathrm{keV}$ für ${ }^{3} \mathrm{H} ; 16-1700 \mathrm{keV}$ für $\left.{ }^{32} \mathrm{P}\right)$. In der Valylierung wurde wieder E. coli-ValRS benutzt. Vom 
Ansatz nicht valylierter Varianten wurden bei 0, 15 und 60min. Reaktionszeit (entspricht den Zeitpunkten 40, 55, 100min. des valylierten Ansatzes) Aliquots genommen und ihre Radioaktivität bestimmt.

\section{Zeitliche Verläufe der WT-TLS Valylierung und (-)-Strang Synthese}

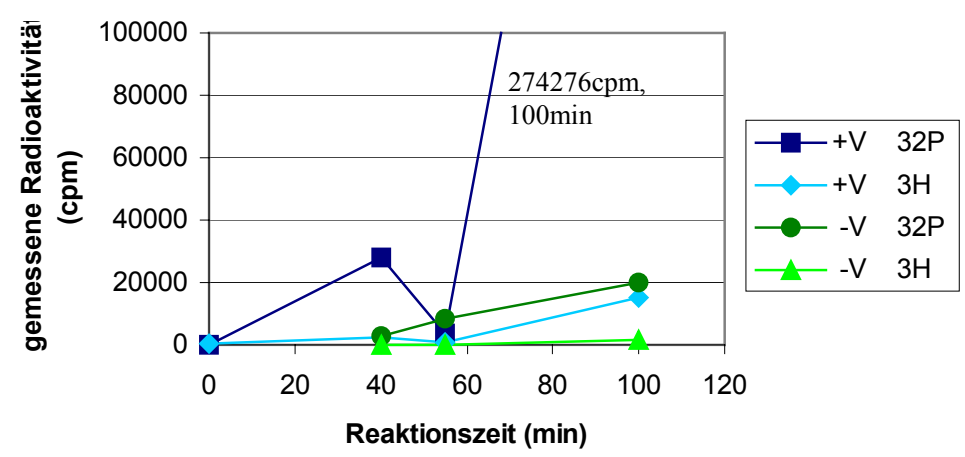

Abb.: 33,

Vergleich des Verlaufs der hoch- und niederenergetischen Radioaktivität während der in vitro Valylierung und/oder (-)-Strang Synthese der WT-TLS (85nt). Blau zeigt die Meßwerte des Ansatzes mit Valylierung und (-)-Strang Synthese (+V; Hellblau für ${ }^{3} \mathrm{H}-$ Valin, Dunkelblau für $\left.{ }^{32} \mathrm{P}-\mathrm{UTP}\right)$. Grün zeigt Meßwerte des Ansatzes nur mit (-)-Strang Synthese (-V; Hellgrün für ${ }^{3} \mathrm{H}-$ Valin, Dunkelgrün für $\left.{ }^{32} \mathrm{P}-\mathrm{UTP}\right)$.

Im ersten Experiment (Abb.: 33) war zu beobachten, daß für den Ansatz der (-)-Strang Synthese (Grün) die Tritium-Werte (Valylierung) niedrig blieben und auch die ${ }^{32}$ P-UTPWerte (Transkription) nur langsam anstiegen. Für den Ansatz mit Valylierung und (-)Strang Synthese wurde eine deutliche Erhöhung der Tritium-Werte und ein überraschend hoher Endwert ${ }^{32} \mathrm{P}$ ermittelt. Bei ca. 12 fach über den Hintergrundwert gesteigerter TritiumValin-Radioaktivität, hat sich der Wert für ${ }^{32}$ P-UTP auf ca. das 13,5fache des Wertes für den unvalylierten Ansatz gesteigert (14fach über den Hintergrundwert).

Nach diesem Ergebnissen würde die Valylierung der WT-TLS (85nt) eine enorme Verbesserung der Transkriptionseffizienz bedeuten. Es würde das Ergebnis des letzten Versuches aus den Niederlanden bestätigen. Auffällig im Versuch war, daß die TritiumWerte bei 40 und 55min. trotz des Valylierungsansatzes relativ niedrig bleiben. Der gleiche Ansatz zeigt bei 40min., also dem Beginn der (-)-Strang Synthese, einen relativ hohen Wert. Einflüsse von Kontaminationen im Versuch konnten daher nicht ausgeschlossen werden.

Anschließend wurden nun nochmals der WT und die oben genannten drei weiteren Varianten untersucht (Abb.: 34). Das Ergebnis des ersten Versuchs konnte dabei nicht reproduziert werden.

Die Versuche zeigten eher einen gegenteiligen Effekt. Die Ansätze der Varianten, in denen Valylierung und (-)-Strang Synthese (grüne Kurven) ablief, zeigten bei fast jeder Variante einen höheren Endwert für ${ }^{32}$ P-UTP (RNA-Synthese), als in den Ansätzen in denen nur (-)Strang Synthese stattfand (schwarze Kurven). In allen Ansätzen mit Aminoacylierung 

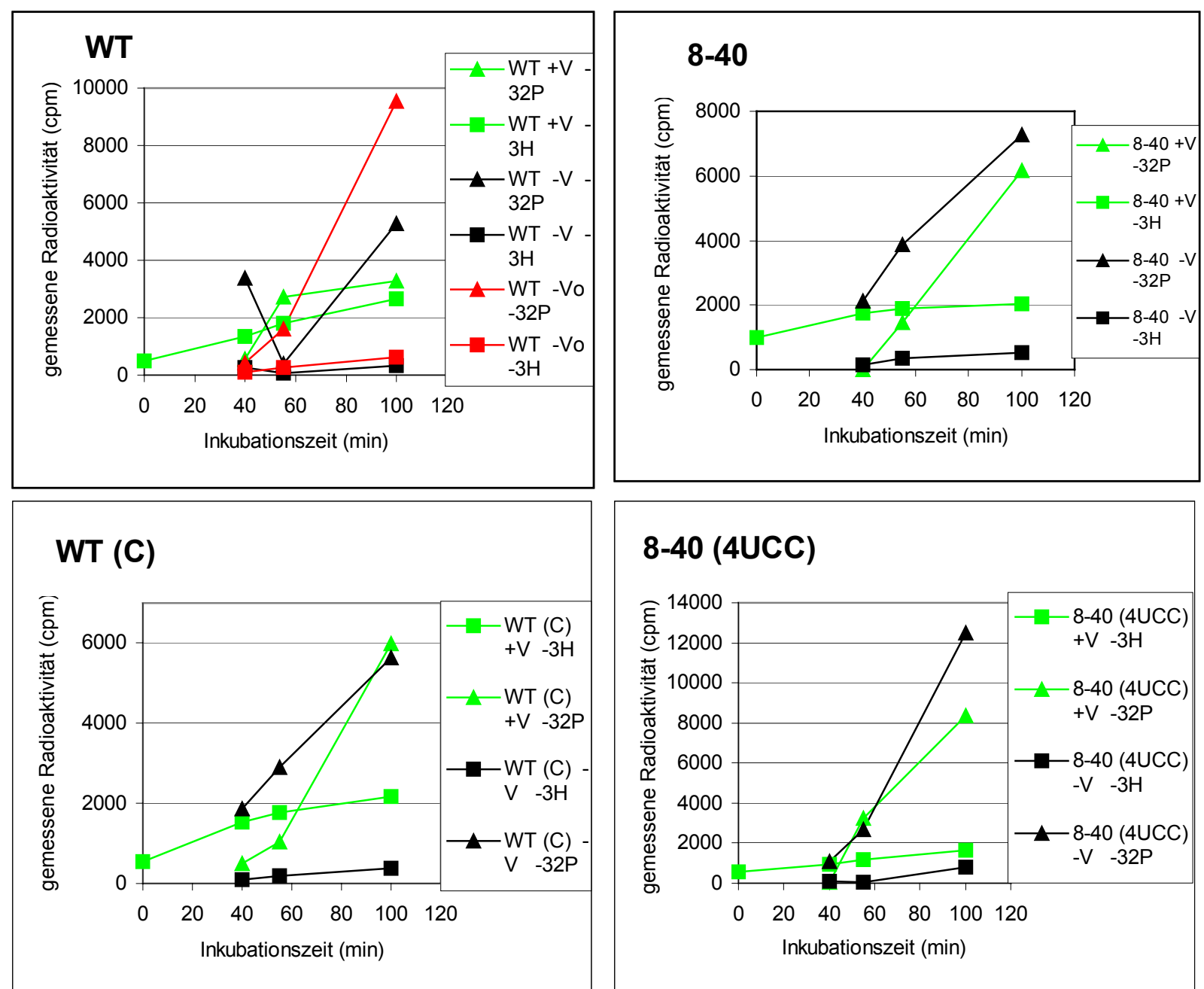

\section{8-40 (4UCC)}

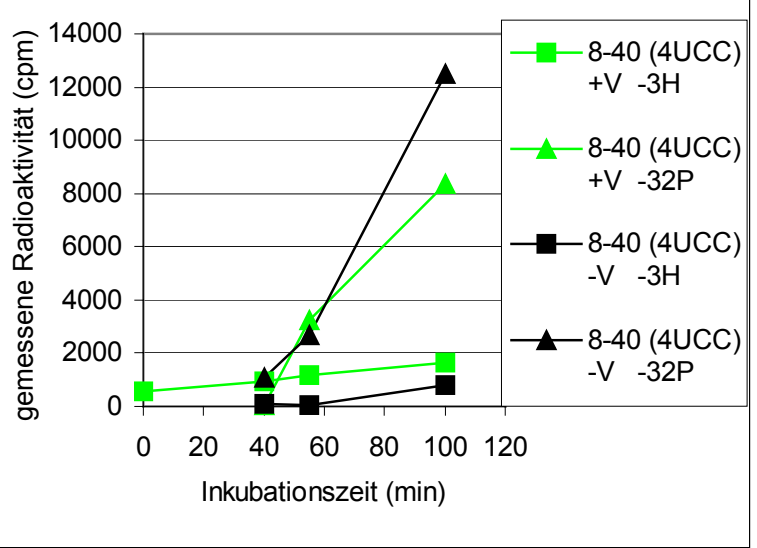

Abb.: 34,

Zeitlicher Verlauf der Radioaktivität von je 2 Ansätzen einer TLS-Variante (85nt): 1. in vitro Valylierung und (-)-Strang Synthese (Grün) und 2. in vitro (-)-Strang Synthese ohne Valylierung (Schwarz). Je Ansatz wurde die energiearme radioaktive Strahlung von ${ }^{3} \mathrm{H}-$ Valin (Valylierung) und die energiereiche Strahlung von $\left[\alpha_{-}^{32}\right.$ P]-UTP ((-)-Strang Synthese) getrennt aufgetragen. In Rot ist eine in vitro (-)-Strang Synthese des Wildtyps aufgetragen, dessen „Valylierungsansatz“ ausschließlich aus $\mathrm{H}_{2} \mathrm{O}$ und RNA bestand (siehe Text).

konnte eine erfolgreiche Valylierung nachgewiesen werden, sie lag immer bei ca. 2000cpm. Sie war jeweils durch die Werte der energiearmen Radioaktivität im valylierten Ansatz $\left(,,+\mathrm{V}-3 \mathrm{H}^{\circ *}\right)$ zu verfolgen.

In der (2fach) Messung des Wildtyps zeigte sich, daß die Radioaktiv-Werte (resultierend aus ${ }^{32} \mathrm{P}$-UTP- und ${ }^{3} \mathrm{H}$-Valin-Einbau), die der Transkription mit Valylierung entsprechen (grün, $+\mathrm{V}-32 \mathrm{P}$ ), ihr Maximum bereits fast nach den ersten 15min. erreichten. Der Endwert (bei 100min.) erreichte dann nur das 0,6fache des Ansatzes ohne Valylierung (schwarz, -V -32P). Umgekehrt erreichte der nicht valylierte Ansatz das 1,6fache.

Ungewöhnlich schien hier der in zwei Messungen aufgetretene hohe „Null“-Wert (bei 40min. Inkubation) der nicht valylierten Transkription (schwarz, -V -32P). 
Auch bei den anderen Varianten schien dieser Wert (zwischen 1000 und 3400cpm) relativ hoch zu liegen. Es könnte sich hier um eine methodisch verursachte Kontamination gehandelt haben, die allerdings nicht einfach zu erklären ist. Dagegen sprechen die Werte der valylierten Ansätze, die zu dem Zeitpunkt 40min. relativ gut bei Null lagen. Dabei wurden immer dieselben Lösungen zur RNA pipettiert und dabei auch dieselben Hilfsmittel benutzt. Eine mögliche Erklärung könnte die Bindung von Triphosphaten der NTP's (z.B. ${ }^{32}$ P-UTP) während der TCA-Fällung an das benutzte Filterpapier sein. Im Ansatz mit vorheriger Aminoacylierung wurde zum Zeitpunkt 40min. bereits viel ATP zu AMP und Pyrophosphat (PPi) umgesetzt. Das AMP wurde außerdem durch PyruvatKinase wieder zu ATP regeneriert. In diesem Ansatz wäre die nicht radioaktive bindungsfähige „Phosphatmenge“ also deutlich gesteigert und würde wegen höherer Konzentration und z.T. geringerem Volumen des Moleküls (PPi) verstärkt mit dem ${ }^{32} \mathrm{P}-$ UTP konkurrieren.

Der radioaktive Wert bei 100min. des valylierten Ansatzes der Variante 8-40 liegt beim 0,85fachen des nicht valylierten Ansatzes (umgekehrt: 1,2fach). Bei der Variante WT (C) liegt dieser Wert beim 1,1fachen (umgekehrt: 0,9fach). Die Messung dieser Variante zeigte die geringsten Unterschiede zwischen valylierter und nicht valylierter RNA-Matrize. Die Variante 8-40 (4UCC) hatte als Endwert des valylierten Ansatzes das 0,7fache des nicht valylierten Ansatzes (umgekehrt: 1,5fach).

Wenn man die Höhe der Endwerte der nicht valylierten Ansätze miteinander vergleicht, so wird erkennbar, daß bei WT, 8-40 und WT (C) dieser etwa bei $6000 \mathrm{cpm}$ liegt, während er bei 8-40 (4UCC) mit etwa 12000cpm doppelt so hoch ist. Vergleicht man die Endwerte der valylierten Ansätze miteinander, so liegen diese bei 8-40 und WT (C) bei ca. $6000 \mathrm{cpm}$. Der WT ist mit etwa $3000 \mathrm{cpm}$ nur halb so effektiv und 8-40 (4UCC) mit ca. $8000 \mathrm{cpm}$ 1,3fach effektiver, als die Varianten 8-40 und WT (C).

Abschließend betrachtet ist der Unterschied in der Transkriptionseffizienz (Werte der energiereichen Radioaktivität) zwischen einer valylierten und nicht valylierten Variante relativ gering (höchstens 1,6facher Unterschied). Vergleicht man die Transkriptionseffizienz verschiedener Varianten, so erscheint der WT in etwa so effizient wie 8-40 und WT (C), die Variante 8-40 (4UCC) erreicht dagegen deutlich höhere Werte. Dieses Ergebnis ist vermutlich nicht durch effiziente Valylierbarkeit erklärbar, da die Zeit zur Valylierung jeder Variante ausreichend lang gewählt war, um das Plateau erreichen zu können (die entsprechenden Werte sind etwa auf dem gleichen Niveau).

Der geringe Unterschied innerhalb einer Variante könnte dadurch erklärt werden, daß die Aminosäure die Erkennung der Initiationsregion durch die RdRp sterisch bedingt behindert. 
Der Unterschied zwischen Varianten könnte durch geänderte Sequenz- und Faltungseigenschaften bedingt sein. Die verlängerte L1-Schleife könnte dabei (unspezifische) Wechselwirkungen mit der RdRp eingehen, die die Erkennung der Initiationsregion begünstigen. Auch die Schwächung der Stabilität des Pseudoknotens könnte eine Verbesserung der Transkriptionseffizienz bewirken (Deiman et al., 1998). Danach wären nicht nur für 8-40 (4UCC), sondern auch für WT (C) bessere Werte zu erwarten.

In einem abschließenden Experiment sollte getestet werden, ob Bestandteile des Valylierungsansatzes die Transkriptionseffizienz beeinflussen (Abb.: 34, WT, rot). Dieser Ansatz ohne Valylierung der RNA enthielt im „Valylierungsansatz“, anders als sonst, nur $\mathrm{H}_{2} \mathrm{O}$ und RNA. Tu-Puffer, ATP und Phosphoenolpyrovat fehlten. Die Radioaktivität für ${ }^{32} \mathrm{P}$ stieg mit ca. $9500 \mathrm{cpm}$ etwa $1,8 \mathrm{mal}$ so hoch wie der vergleichbare unvalylierte Ansatz. Dieses Ergebnis ließ darauf schließen, daß einer der weggelassenen Bestandteile, vermutlich der Tu-Puffer, die (-)-Strang Synthese negativ beeinflußt. Da diese Bestandteile aber in jedem der besprochenen Ansätze vorhanden war, dürften die Ergebnisse entsprechend aussagekräftig sein.

$\mathrm{Zu}$ den beschriebenen Experimenten ist anzumerken, daß die Radioaktivität insgesamt niedriger lag, als im ersten Experiment (Abb.: 33). Die Verwendung nicht ausreichend dekontaminierter Gefäße für den Versuch könnte eine Erklärung hierfür sein.

Außerdem stiegen die Tritium-Werte der nicht valylierten Ansätze mit der Zeit leicht an, obwohl kein ${ }^{3} \mathrm{H}$-Valin zugesetzt wurde. Da die radioaktive Strahlung von ${ }^{32} \mathrm{P}$ auch geringe energiearme Anteile umfaßt, werden bei hoher Strahlungsintensität auch die Tritium-Werte beeinflußt. Dieser Effekt kann in den Versuchen aber von Werten unterschieden werden, die ursächlich von ${ }^{3} \mathrm{H}$-Valin-RNA stammen; sie liegen 2 bis 7,5fach höher.

Ein Nachteil der angewandten Methode bestand in den hohen Hintergrundwerten besonders für ${ }^{32} \mathrm{P}$, die die Aussagekraft der Ergebnisse verringern.

Die erhaltenen Ergebnisse sollten noch einmal in einer Endpunktbestimmung (nach Punkt 2.2.3.1.) überprüft werden. Um den Mechanismus der (-)-Strang Synthese besser verstehen zu können, sollten verschiedene Substanzen getestet werden, die potentiell einen Einfluß auf die (-)-Strang Synthese ausüben können. Eingesetzt wurden folgende Substanzen:

\section{EF-Tu}

Im Folgenden noch beschriebene in vivo Experimente zur Amplifikationseffizienz von TYMV-TLS-Varianten (Punkt 3.3.), hatten Hinweise ergeben, daß, effizienter als der Wildtyp, valylierbare Varianten auch effizienter replizieren könnten. Aus der Literatur ist bekannt, daß die Identität der Aminosäure am 3'-Ende des Genoms für die erfolgreiche 
Infektion von Wirtspflanzen nicht entscheidend zu sein scheint (Dreher et al., 1996). Wenn verschiedene Aminosäuren zu effizienter Replikation führen können, dann müßte die Aminosäure relativ unspezifisch erkannt werden, eventuell durch ein Adaptermolekül. Ein solches Molekül könnte eEF1A (vormals EF-1 $\alpha$ ) sein (Florentz et al., 1984; Dreher, 1999). Elongationsfaktoren als Bestandteil der RNA-Replikase ist für verschiedene Bakteriophagen (Q $\beta$, f2) bereits beschrieben worden (z.B. Blumenthal et al., 1972; Blumenthal, 1982).

Aus technischen Gründen konnte eEF1A nicht verwendet werden. Es ist aber bekannt, daß Elongationsfaktoren in Mitochondrien/Chloroplasten von Pflanzenzellen (in letzteren findet vermutlich die Synthese von TYMV-RNA statt (Mouchès et al., 1974; Prod'homme et al., 2001)) Ähnlichkeiten mit prokariotischem EF-Tu haben (der EndosymbiontenTheorie folgend; Hoober, 1984; Rochaix, 1987).

Aus diesen Gründen wurde EF-Tu aus E. coli benutzt. Dieses Enzym kann in vitro die aminoacylierte TYMV-TLS binden (Litvak et al., 1973a). Der Elongationsfaktor könnte effizienzsteigernd in der (-)-Strang Synthese wirken, wenn er zur Erkennung der TLS beiträgt. Er könnte aber ebenfalls die Effizienz erniedrigen, falls er ohne Kooperation mit der RdRp mit dieser um die RNA kompetitieren würde.

\section{Puromycin}

Es ist ebenfalls denkbar, daß die Erkennung von aminoacylierter RNA direkt durch die virale RdRp geschieht. In diesem Fall könnte die (-)-Strang Synthese vielleicht durch ein Antibiotikum gehemmt werden. Eine Voraussetzung ist dabei die Interaktion des Antibiotikums mit EF-Tu•GTP möglichst im Bereich der aminoacyl-tRNA (aa-tRNA) Bindungsregion. Pulvomycin und GE2270 A behindern beide die Bindung von aa-tRNA an den Komplex EF-Tu•GTP (Wolf et al., 1978; Anborgh and Parmeggiani, 1991), sind aber beide nicht kommerziell erhältlich. Kirromycin vermindert die Affinität der aa-tRNA zu EF-Tu•GTP, behindert aber nicht die Assoziation (Abrahams et al., 1991). Geeignet, um direkt die Bindung von aa-tRNA in eine Bindungstasche zu verhindern, erschien Puromycin. Es imitiert das aminoacylierte 3'-Ende einer tRNA (Kawakami et al., 1975) und ist durch seine geringe Größe vermutlich in der Lage, auch von aa-tRNABindungstaschen erkannt zu werden, die der von EF-Tu nur ähnlich ist.

Puromycin könnte in der (-)-Strang Synthese eine Effizienzerniedrigung bewirken.

\section{3. tRNA}

Wenn die virale RdRp valylierte und nicht valylierte RNA unterschiedlich effizient erkennt, dann könnte es möglich sein, daß valylierte/nicht valylierte tRNA durch Kompetition mit der TYMV-TLS die (-)-Strang Synthese entsprechend beeinflußt. Für den

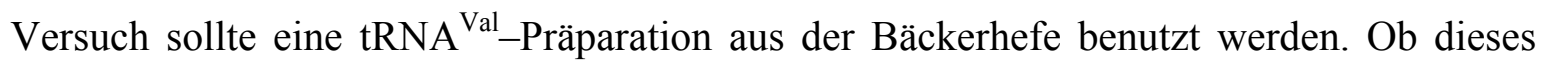


Molekül durch die RdRp überhaupt erkannt wird, wird durch die Literatur nicht ganz eindeutig geklärt. Obwohl bisher keine Nukleotid-modifizierten TYMV-RNA's aus Pflanzen isoliert wurden (Silberklang et al., 1977), kann diese aber potentiell doch modifiziert werden (Becker et al., 1998). Vermutlich wird tRNA ${ }^{\text {Val }}$ ähnlich wie tRNA ${ }^{\text {Phe }}$ und tRNA ${ }^{\text {His }} /$ tRNA $^{\text {Thr }}$ aus S. cerevisiae von der RdRp als Substrat erkannt, aber praktisch nicht als Matrize benutzt (Deiman et al., 1997a; Ravindra et al., 1997; Deiman et al., 1998). Pflanzliche tRNA kann dagegen sowohl modifiziert, als auch unmodifiziert als Matrize dienen.

Die Wirkung der tRNA aus Bäckerhefe, sollte eventuell nach valyliertem/nicht valyliertem Zustand der Moleküle verschieden sein.

Für die Versuche wurde der Wildtyp immer jeweils valyliert/nicht valyliert eingesetzt. Im einzelnen wurde jeweils zu Beginn der 60min. (-)-Strang Synthese zugegeben:

I) Kein Zusatz

II) $0,2 \mu 1$ einer EF-Tu-Präparation aus E. coli (erhalten durch Prof. Mayer). Die Menge

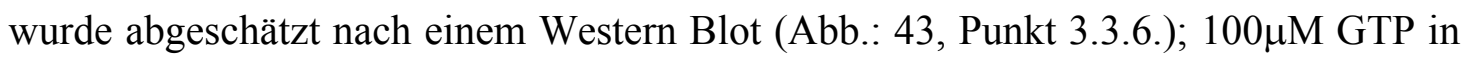
der zugesetzten Lösung.

III) $0,75 \mu$ g Puromycin (ca. $1,38 \mathrm{nmol}$ ) in $\mathrm{H}_{2} \mathrm{O}$

IV) ca. $70 \mu \mathrm{g}$ valylierter Gesamt-tRNA aus $S$. cerevisiae. Es wurde davon ausgegangen, daß nur etwa $1 / 15$ der Moleküle aus tRNA ${ }^{\text {Val }}$ besteht. Unter dieser Bedingung wurde ein etwa 3 facher Überschuß gegenüber der TLS-RNA eingesetzt. Separat valyliert wurde die tRNA für 30min. nach der in Punkt 2.2.2.4. beschriebenen Methode. Anschließend Phenol-, Ether- und Ethanol-Behandlung.

V) ca. $70 \mu \mathrm{g}$ nicht valylierter Gesamt-tRNA aus $S$. cerevisiae. Behandlung wie in D) nur wurde Valin und ValRS durch $\mathrm{H}_{2} \mathrm{O}$ ersetzt.

In Abbildung 35, A) ist ein radioaktives 10\%iges PAA-Gel mit den Produktbanden der einzelnen Ansätze dargestellt (Methode und Auswertung ansonsten nach Punkt 2.2.3.1.). Die Werte der Doppelbestimmung sind als Balkendiagramm ebenfalls gezeigt (Abb.: 35, B)). Hier wurde aus Gründen der Vergleichbarkeit der valylierte $\left(,+^{“}\right)$ WT ohne Zusätze auf 10 normiert. Im Ergebnis ließ sich die leicht ineffizientere in vitro (-)-Strang Synthese von valyierten TLS-RNA's reproduzieren (ähnlich den Zeitverlaufsmessungen). Die Zugabe von EF-Tu hatte keinen größeren Einfluß, die geringeren Werte mit der nicht valylierten TLS-RNA erscheinen (auch im optischen Vergleich mit dem Gelfoto) nicht deutlich erniedrigt. Der fehlende Einfluß von EF-Tu im Ansatz mit valylierter TLS-RNA ist überraschend, da eine Interaktion grundsätzlich möglich sein sollte (Joshi et al., 1984). Die Zugabe von Puromycin hatte ebenfalls kaum einen Effekt, durch die hohen Schwankungen der Werte ist keine andere Aussage zu rechtfertigen. Die Zugabe von tRNA, sowohl in valylierter, als auch nicht valylierter Form, hatte dagegen einen deutlich 
inhibitorischen Effekt. Die Effizienz der TLS-RNA in der (-)-Strang Synthese ist etwa auf die Hälfte reduziert, wenn man am Gelfoto die Werte optisch vergleicht, erscheint der Unterschied noch deutlicher. Da die radioaktive Produktintensität der Ansätze mit valylierter und nicht valylierter tRNA gering war und auch keine deutlichen Unterschiede sichtbar waren, sind beide tRNA-Spezies vermutlich durch die RdRp erkannt, aber nicht als Matrize für RNA-Synthese genutzt worden. Die tRNA hätte so als kompetitierender Inhibitor gewirkt.

A

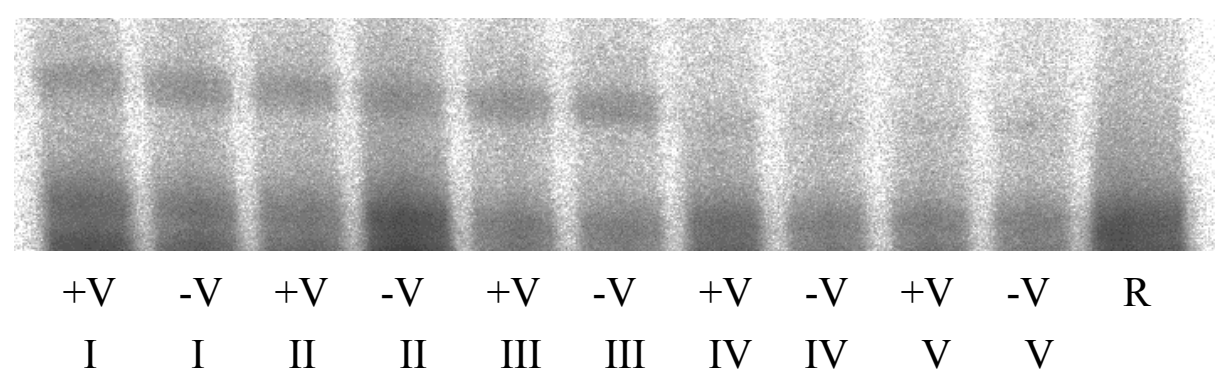

B

\section{(-)-Strang-Synthese der WT-TLS (85nt) durch TYMV-RdRp mit verschiedenen Kompetitoren}

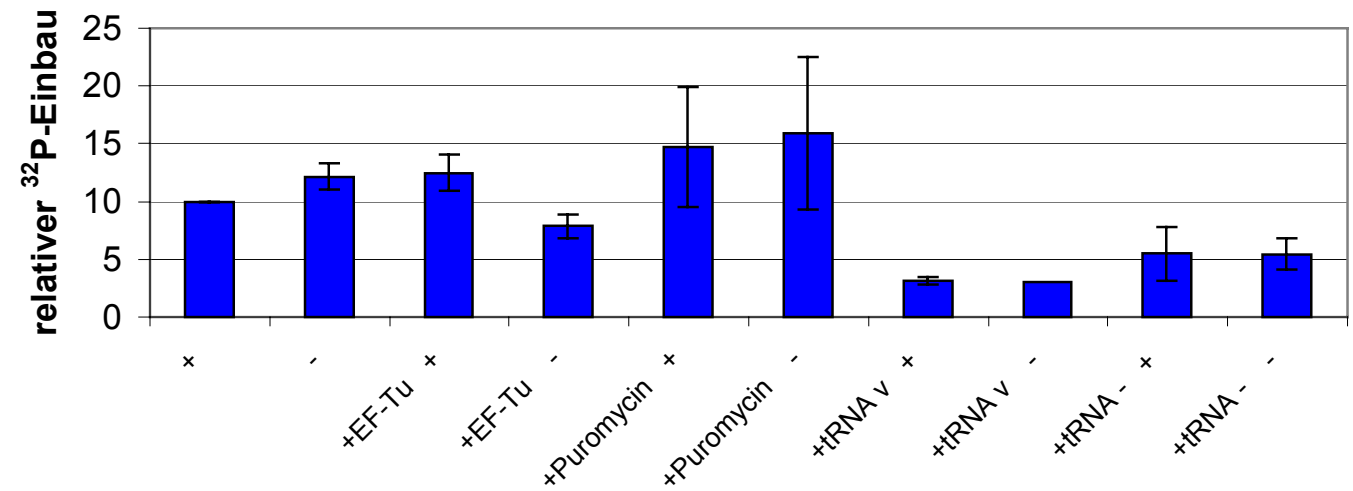

Abb.: 35,

\section{Valylierungszustand der WT-TLS und Kompetitor}

Produktradioaktivität der (-)-Strang Synthesen der WT-TLS (85nt) mittels RdRp. Zu valylierter (+, +V) und nicht valylierter (-, -V) TLS-RNA wurden jeweils zur RNA-Synthese die angegebenen Substanzen gegeben (I: kein Zusatz, II: EF-Tu, III: Puromycin, IV: tRNA valyliert, V: tRNA nicht valyliert). R bezeichnet die Referenz.

A) $10 \%$ PAA-Gel +8M Harnstoff, analysiert mittels Phosphor Imager (Zählung der Schwärzung pro Fläche)

B) Auf 10 normierte Mittelwerte der Zählungen zweier Experimente.

Die insgesamt durchgeführten in vitro (-)-Strang Synthesen deuten darauf hin, daß die Valylierung der TYMV-TLS-RNA (85nt), wenn überhaupt, eher einen negativen Effekt in der Effizienz des Moleküls erzeugt. Die Valylierungseffizienz einer TLS-Variante scheint kaum Einfluß zu haben. Unterschiede zeigen sich nur bei Valylierung der Variante und könnten auch auf Faltungseigenschaften zurückzuführen sein. EF-Tu erkennt anscheinend nicht die TLS-RNA und auch nicht die RdRp in einem für die RNA-Erkennung kritischen Bereich. Puromycin wird ebenfalls nicht durch die RNA-Bindungsregion der TYMV- 
RdRp erkannt. Die RNA-Bindungsregion ist vermutlich von der von EF-Tu deutlich verschieden. Modifizierte Hefe-tRNA bindet und inhibiert virale RdRp vermutlich auch in nicht valylierter Form.

\subsection{Experimente zur in vivo Amplifikation von TYMV-TLS-Varianten}

\subsubsection{Aufgabenstellung}

Da die Bestandteile der TYMV-Replikase (virale und eventuell Wirtsproteine; Hall, 1979) bisher nicht vollständig bekannt sind, können die bisher beschriebenen in vitro Experimente bestenfalls Näherungen zu den in der Natur ablaufenden Mechanismen der Replikation darstellen. Die Infektion von ganzen Pflanzen ist also zur Zeit die einzige Möglichkeit, alle Abläufe der Replikation im Wirtsorganismus in einen Versuch mit einzuschließen. Hier sollte der für TYMV-Experimente häufig genutzte Chinakohl (Brassica pekinensis) verwendet werden.

Die Verwendung ganzer Pflanzen hat allerdings auch verschiedene Nachteile. So kann das „Verhalten“ von TYMV-Varianten im Wirtsorganismus nur phänotypisch anhand äußerer Symptome (lokal/systemisch; früher/später) oder durch die nachträgliche Isolation von Revertanten indirekt betrachtet werden. Von den beobachteten Symptomen der Pflanze kann also nicht zwangsläufig auf die Replikation des Virus geschlossen werden, da andere Abläufe, wie z.B. die Hüllprotein-Verpackung oder die Translation der viralen RNA, ebenfalls beeinflußt sein können. Ein Zusammenhang zwischen der Intensität der Symptome und der Replikation erscheint aber deshalb wahrscheinlich, da z.B. frühe, starke Symptomausprägung an der Pflanze auch mit schneller, hoher Syntheseleistung von TYMV-RNA gekoppelt sein sollte. Aus den eben besprochenen Gründen wird im Folgenden nicht von Replikation, sondern von Amplifikation des TYMV gesprochen. Ein weiterer Nachteil der Infektion von ganzen Pflanzen liegt darin, daß das Verhältnis von TYMV-RNA und transfizierten Zellen in separaten Experimenten praktisch nicht abgeschätzt werden kann.

Revertanten, die im Verlauf des Experimentes isoliert werden, könnten durch die neu eingeführten Mutationen Hinweise liefern, welche Nukleotid-Positionen für die Replikation wichtig sein könnten.

Die Transfektion von Protoplasten stellt ein vereinfachtes ,in vivo“-System dar. Es ermöglicht in verschiedenen Versuchen ein in etwa konstantes Verhältnis von Virus-RNA zu Pflanzenzellen. Die Fähigkeit der eingesetzten TYMV-Varianten zur Amplifikation in einzelnen Zellen ist in diesem System prinzipiell genauer zu quantifizieren, als in ganzen Pflanzen.

Aus technischen, bzw. zeitlichen Gründen konnte für die in vivo Versuche nur eine eingeschränkte Anzahl von TYMV-TLS-Varianten ausgewählt werden. Sie wurden nach 
drei Fragestellungen bestimmt. Die TYMV-TLS stellt in Sequenz und Struktur einen Effektivitäts-Kompromiß zwischen vielen Funktionen (Interaktionen mit Proteinen; siehe Punkt 1.2.2.) dar. Varianten, die in der Funktion der Valylierbarkeit optimiert sind, sollten untersucht werden, wie ihre weiteren Funktionen (z.B. Interaktion mit viraler RdRp oder eEF1A) in der Pflanzenzelle beeinflußt werden.

Daran angelehnt ist die Fragestellung, ob effizient oder ineffizient valylierbare TLSVarianten (im Gesamt-Genom-Kontext) ebenfalls in dieser Weise amplifizieren. Es sollte also ein möglicher Zusammenhang zwischen Valylierbarkeit und Replikation weiter untersucht werden, wie er bereits für bestimmte ineffizient valylierbare Varianten beschrieben wurde (Tsai and Dreher, 1991).

Außerdem sollten Ergebnisse früherer in vitro Experimente, nach denen die Länge der L1Schleife der TYMV-TLS Einfluß in der Replikation haben könnte, auch in vivo untersucht werden.

Abschließend sollte, soweit möglich, das Verhalten der Varianten in vitro und in vivo miteinander verglichen werden.

\subsubsection{Auswahl der Varianten}

Die in vivo Experimente sollten möglichst vergleichbar mit den in vitro Versuchen bleiben. Daher wurden nur Varianten ausgewählt, die bereits in den entsprechenden Experimenten eingesetzt worden waren (siehe Punkt 3.2.2.). Die TLS-Varianten wurden für die in vivo Versuche in den Gesamt-Genom-Kontext gebracht (Punkt 3.3.3.). Es wurden Varianten genommen, die bekanntermaßen effizient oder ineffizient valylierbar waren oder nach Literaturdaten eine einschätzbar hohe Effizienz besitzen sollten (Wientges, 1998; Wientges et al., 2000). Außerdem wurden sie nach Länge der L1-Schleife und Sequenz der Anticodon-Schleife ausgewählt.

Um die Anzahl der Pflanzen und Protoplastenkulturen in den Experimenten zeitlich und technisch handhabbar zu halten, wurde die Anzahl der Varianten auf 4 beschränkt:

\begin{tabular}{lc|c|c} 
& Anticodon-Schleife & L1-Schleife & Relative Valylierungseffizienz (x-fach) \\
WT & CCCACAC & CUUU & 1 \\
WT (C) & CCCACAC & C & 0,005 \\
$8-40$ & ACUACAC & UUUC & 53 \\
$8-40$ (4UCC) & ACUACAC & UUUUCC & 5
\end{tabular}

Die relative Valylierungseffizienz bestimmt sich aus dem Quotienten $\mathrm{k}_{\mathrm{cat}} / \mathrm{K}_{\mathrm{M}}$, der für den Wildtyp $0,24 \mathrm{sec}^{-1} / 2,44 \mu \mathrm{M}=0,098 \mathrm{sec}^{-1} \mu \mathrm{M}^{-1}$ beträgt und als, $1^{\text {“ }}$ gesetzt wird. Die kinetischen Parameter für WT (C) lauten $0,002 \mathrm{sec}^{-1} / 4,13 \mu \mathrm{M}^{-1}=0,0005 \mathrm{sec}^{-1} \mu \mathrm{M}^{-1}$, für $8-40$ sind sie $4,18 \sec ^{-1} / 0,81 \mu \mathrm{M}=5,16 \sec ^{-1} \mu \mathrm{M}^{-1}$. Die Valylierungseffizienz der Variante $8-40$ 
(4UCC) wurde anfänglich nach Literaturangaben auf eine relative Valylierungseffizienz zwischen 10 und 30fach geschätzt, später wurden folgende Werte gemessen: $3,24 \mathrm{sec}^{-1} / 6,24 \mu \mathrm{M}=0,519 \mathrm{sec}^{-1} \mu \mathrm{M}^{-1}$.

\subsubsection{Herstellung von 4 TLS-Varianten im Gesamt-Genom-Kontext}

Die 4 TLS-Varianten WT, 8-40, WT (C) und 8-40 (4UCC) sollten in den Kontext des TYMV-Genoms gebracht werden. Damit eine entsprechende DNA-Matrize für T7Transkription erhalten werden konnte, wurde das Plasmid pACBL16 (Produkt aus pACYC184 und pBL16 (Skotnicki et al., 1992); Punkt 2.1.9.) verwendet. Es enthält das Wildtyp-Genom des TYMV mit einem T7-Promotor am 5'-Ende und einer NdeIRestriktionsschnittstelle am 3'-Ende. Das Plasmid wurde mir freundlicherweise von Prof. C.W.A. Pleij (Leiden, Niederlande) überlassen.

Die Herstellung der Varianten als DNA-Matrize im pACBL16 war nicht trivial. Zu beachten war, daß die bisher vorhandenen TLS-Varianten (85nt) im Plasmid pUC19 bereits einen T7-Promotor besaßen und außerdem 2 nicht virale G's am 5'-Ende aufwiesen. Zusätzlich sollte die NdeI-Restriktionsschnittstelle zur Linearisierung des pACBL16 zu Eco72I geändert werden. Die am 3'-Ende des RNA-Transkriptes überhängenden Nukleotide können so von zwei auf eines verringert werden. Diese zusätzlichen Nukleotide scheinen für die Infektiösität der RNA ohne Belang zu sein (persönliche Mitteilung des Labors Pleij).

Drei verschiedene Klonierungsschemata, in denen z.T. verschiedene PCR-Techniken, wie z.B. die Herstellung eines Megaprimers oder SOE (Splicing by Overlap Extension)-PCR (Horton et al., 1989), angewandt wurden, führten nicht zum Erfolg.

Die DNA-Varianten mit Genom-Länge wurden schließlich über die in Abbildung 36 dargestellte Vorgehensweise erhalten. Die erste Polymerase-Kettenreaktion wurde methodisch nach Punkt 2.2.2.1. durchgeführt, außer das Vent-Polymerase $(0,7 \mu 1)$ und PCR-Puffer verwendet wurde. Als Matrize diente der unbehandelte pACBL16, mittels des Starteroligonukleotids „TY-60-Repl-Variante“ wurden die Sequenzen der Anticodon- und L1-Schleifen-Region bestimmt. Das zweite Starteroligonukleotid war TY-Repl-3 (Punkt 2.1.10) und enthielt die Restriktionsschnittstelle $X m a \mathrm{I}$, über die später in pACBL16 ligiert wurde. Die PCR wurde mit 2 Start-Temperaturzyklen mit $3 \mathrm{~min} .94^{\circ} \mathrm{C}, 2 \mathrm{~min} .34^{\circ} \mathrm{C}, 2 \mathrm{~min}$. $72^{\circ} \mathrm{C}$ und 40 weiteren Temperaturzyklen mit $30 \mathrm{sec} .94^{\circ} \mathrm{C}, 45 \mathrm{sec} .63^{\circ} \mathrm{C}$ und $1 \mathrm{~min} .72^{\circ} \mathrm{C}$ durchgeführt. Das PCR-Produkt wurde über ein Agarose-Gel aufgereinigt (Nucleospin Extract $^{\mathrm{TM}}$-Kit, Macherey\&Nagel) und ein kleiner Teil wurde in eine zweite PCR als Matrize eingesetzt. In dieser 2. PCR wurden durch das Oligonukleotid TY-Repl-1 die Schnittstellen Eco72I und XbaI angefügt, das zweite Oligonukleotid war wieder TY-Repl3. Für die DNA-Synthese wurde hier $1 \mu$ l Ampli-Taq-Polymerase (Perkin Elmer, USA) wie in Punkt 2.2.2.1. benutzt, um einzelne ungepaarte Adenin-Nukleotide an den 3'-Enden der 


\section{Klonierungsschema der Varianten zu den in vivo Experimenten}
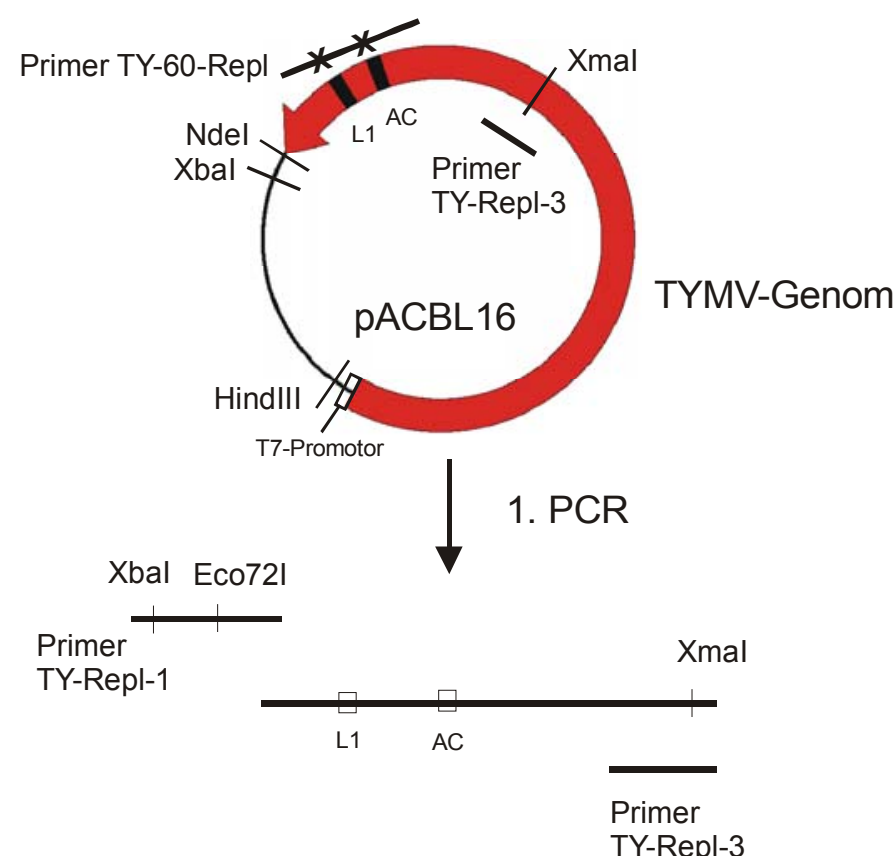

2. $P C R$
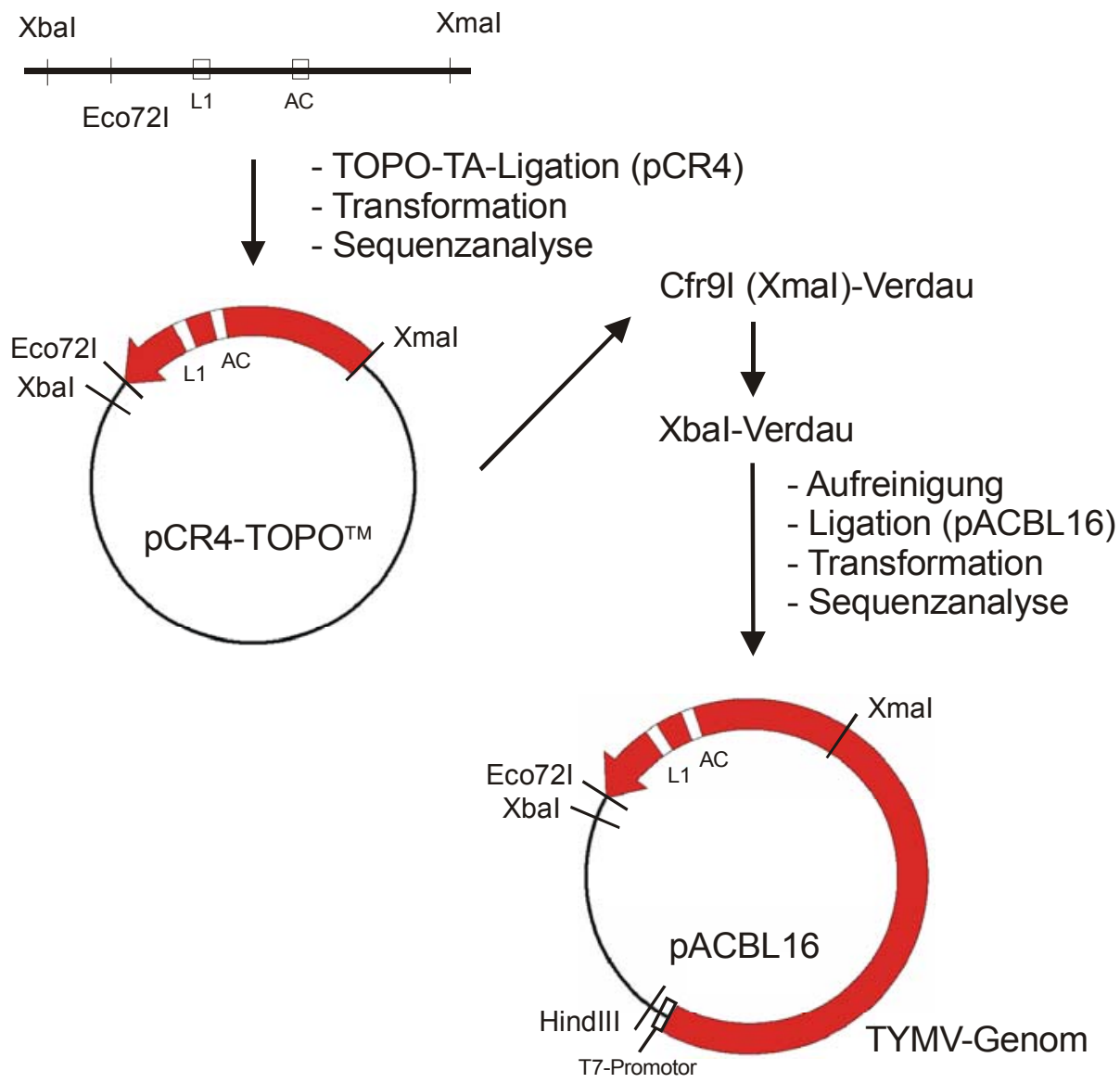

Abb.: 36,

Klonierungsschema der 4 Varianten zu den in vivo Amplifikationsexperimenten. „AC“ markiert die Region der Anticodon-Schleife, „L1“ markiert die Region der L1-Schleife, die bei verschiedenen TY-60-Repl Startermolekülen (,Primer“) verschiedene Sequenzen darstellen. 
DNA's zu bekommen. Die Temperaturzyklen entsprachen denen der 1.PCR, bis auf die Hybridisierungstemperatur in den ersten 2 Start-Temperaturzyklen, sie lag hier bei $30^{\circ} \mathrm{C}$. Das PCR-Produkt konnte nun unter Verwendung eines TOPO-TA-Cloning ${ }^{\circledR}$ Kits (Invitrogen) mittels Topoisomerasen in den vorgeschnittenen Vektor pCR4 ${ }^{\mathrm{TM}}$ (Invitrogen, Punkt 2.1.9.) ligiert werden. Das Plasmid wurde durch Elektroporation in XL1-Blue kompetente Zellen transformiert. Nach Präparation und Sequenzierung folgte eine Umklonierung. Das Plasmid $\mathrm{pCR}^{\mathrm{TM}}$ mit dem eingefügten PCR-Produkt wurde nacheinander mit $C f r 9 \mathrm{I}$ (=XmaI) und $X b a \mathrm{I}$ verdaut. Nach jedem Verdau wurde das Enzym hitzeinaktiviert und die DNA mit Ethanol gefällt. Das ausgeschnittene DNA-Fragment wurde vom Plasmid über Agarose-Gel Extraktion getrennt (Nucleospin Extract ${ }^{\mathrm{TM}}{ }^{\mathrm{K}} \mathrm{Kit}$, Macherey\&Nagel). Das DNA-Fragment wurde anschließend in das entsprechend geschnittene Plasmid pACBL16 ligiert (Punkt 2.2.1.16.). Das resultierende Plasmid wurde dann wieder mittels Elektroporation in XL1-Blue kompetente Zellen transformiert. Korrekte Klonierungen wurden mittels Sequenzanalyse identifiziert.

\subsubsection{Ergebnisse der Transfektion/Infektion von Brassica pekinensis mit TYMV- Varianten}

Alle hier aufgeführten Transfektionen und Infektionen und die Aufreinigung der VirusRNA aus Chinakohl der 1. und 2. Generation wurden im Labor von Prof. C.W.A. Pleij in Leiden (Niederlande) durchgeführt.

Alle Pflanzen wurden aus Samen gezogen und waren aufgrund der natürlichen Diversität in Populationen einer Spezies genetisch verschieden (Eigen, 1987). Nach dem Keimen ließ man die Pflanzen in der Regel 3 Wochen wachsen, bevor sie für die Experimente verwendet wurden. Sie wuchsen, wie in Punkt 2.2.4.6. beschrieben für 16h am Tag unter künstlichem Sonnenlicht und für $8 \mathrm{~h}$ in der Dunkelheit, immer bei $24^{\circ} \mathrm{C}$. Für die Transfektion der Pflanzen der 1. Generation (Generation ist hier nicht im botanischen Sinn gemeint; Punkt 2.2.4.7.) wurden T7-Transkripte verwendet (Punkt 2.2.4.1.), die am 5'Ende eine Cap-Struktur besaßen und am 3'-Ende technisch bedingt ein nicht virales, zusätzliches Guanin-Nukleotid aufwiesen (das Nukleotid ist ohne Effekt für die grundsätzliche Infektionsfähigkeit, persönliche Mitteilung Labor Pleij). Die anschließende Infektion der 2. und 3. Pflanzengeneration wurde mit Viren, die aus der Vorgängergeneration isoliert worden waren, durchgeführt (Punkt 2.2.4.8.). Nach der Infektion der Pflanzen wurden diese einmal täglich für knapp 4 Wochen auf Krankheitssymptome hin untersucht.

Im Fall des Wildtyps entwickeln direkt infizierte Blätter normalerweise nach 4-7 Tagen lokale Symptome in Form von einzelnen gelben Flecken, die im gesamten Verlauf der Infektion kaum zunehmen (Abb.: 37). Systemische Symptome treten nach 7-9 Tagen auf. 


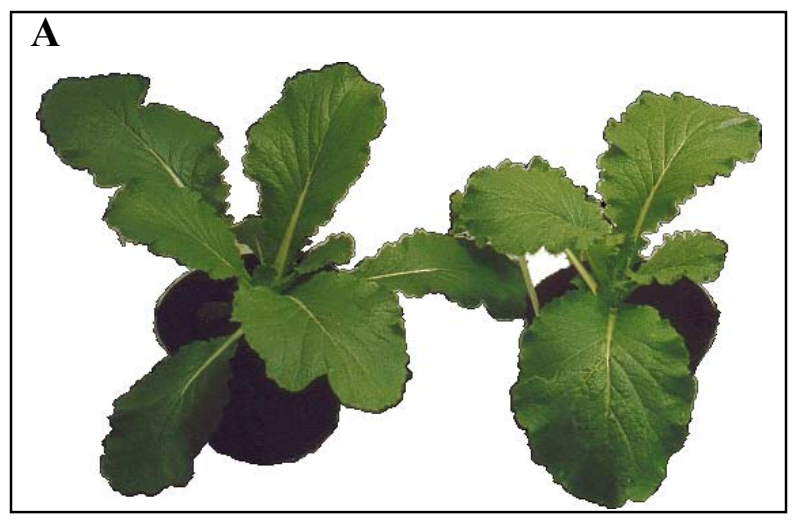

B
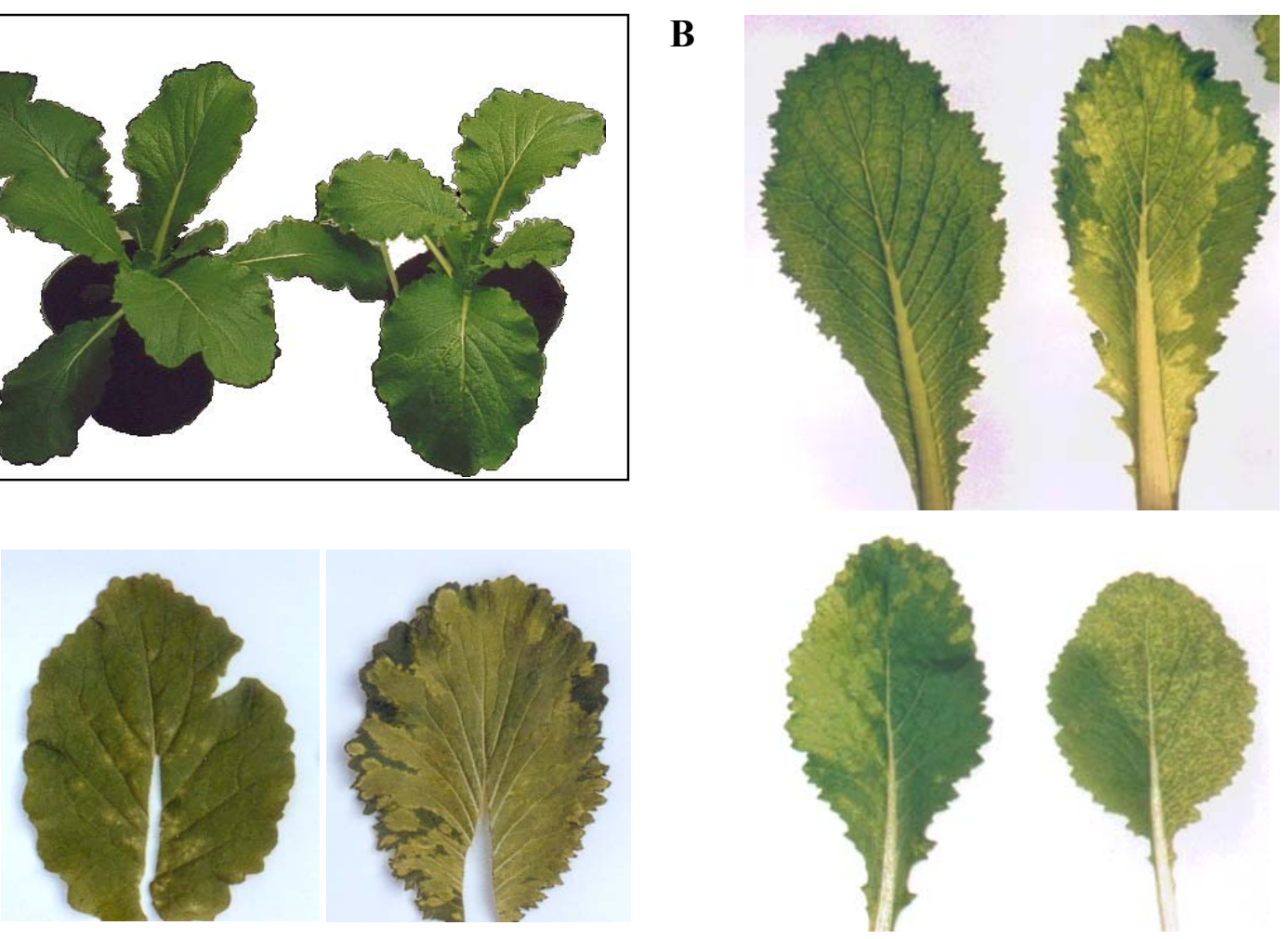

Abb.: 37,

A) Chinakohl Pflanzen (Brassica pekinensis), ca. 4,5 Wochen alt.

B) Sekundäre Blätter des Chinakohls. Oben links, nicht infiziertes Blatt; unten links, direkt infiziertes Blatt mit lokalen Symptomen in Form von gelben Flecken. Die anderen Blätter zeigen systemische Symptome, hervorgerufen durch die Ausbreitung des Virus in der Pflanze, in verschiedenen Stadien.

Sie zeigen sich auf nicht direkt infizierten Blättern anfangs als große Menge kleiner gelber Flecken und kleiner gelber Areale an den Blattnerven. Im Verlauf der Infektion verschmelzen die Läsionen später zu unterschiedlich gelb gefärbten, das ganze Blatt umfassenden, Arealen. Mit fortdauernder Infektion wird zusätzlich eine Einschränkung des Pflanzenwachstums sichtbar.

Die RNA-Aufreinigung aus den Pflanzen wurde für die 1. und 2. Generation in den Niederlanden mit der in Punkt 2.2.4.8. beschriebenen Methode durchgeführt (Dunn and Hitchborn, 1965). Die RNA der 3. Pflanzengeneration wurde mittels des schonenderen RNeasy Plant Mini Kit ${ }^{T M}$ (Qiagen) aufgereinigt. TYMV-RNA wurde durch das spezifische Oligonukleotid TY-pACBL-Rev revers transkribiert und die einzelsträngige DNA in einer PCR mittels des zusätzlichen Oligonukleotids TY-Val-3'oder TY-short-Val-3' (Punkt 2.1.10.) amplifiziert. Die nun doppelsträngige DNA wurde dann direkt oder nach Ligation in pCR $^{\mathrm{TM}}$ (Invitrogen) sequenziert, so daß in etwa die letzten 330 Nukleotide vom $3^{\prime}$-Ende des Virus-Genoms analysiert werden konnten.

Für jede Variante (nicht WT) wurden 30 Pflanzen infiziert (1.-3. Generation, je 10 Pflanzen), unabhängig davon wurden später nocheinmal je 8 Pflanzen (1. und 2. Generation, je 4 Pflanzen) infiziert. Die Generationen umfassen also potentiell 14, 14 und 10 Pflanzen. In der 2./3. Generation wurde eine Pflanze aber nur dann infiziert, wenn die 


\section{Symptomentwicklung von Chinakohl nach Infektion mit TYMV-Varianten}
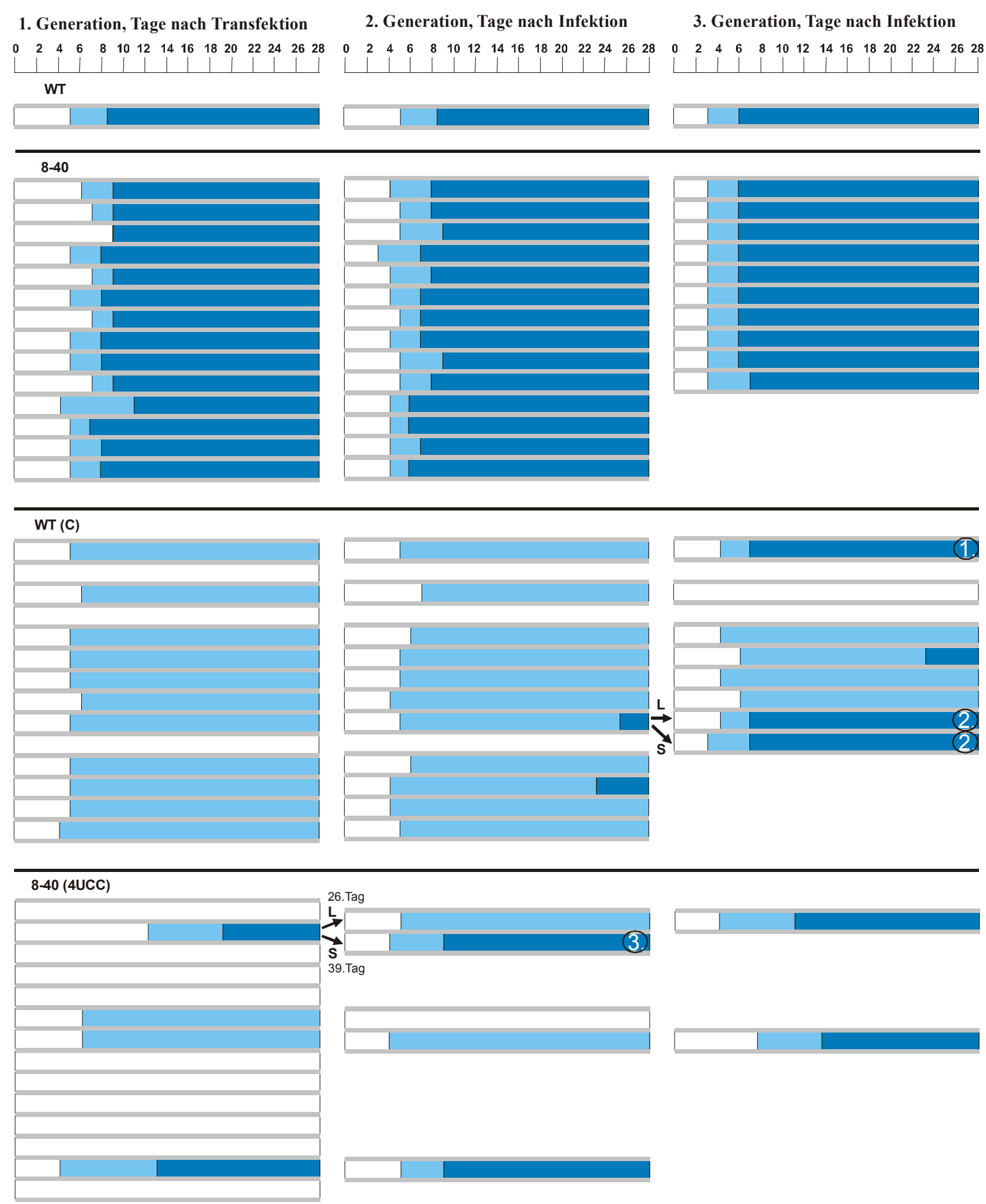

Abb.: 38,

Übersicht zur Symptomentwicklung bei Chinakohlpflanzen, die mit TYMV-Varianten infiziert wurden. Jeder Balken steht für die Symptomentwicklung einer Pflanze über knapp 4Wochen (Weiß = keine Symptome; Hellblau = lokale Symptome; Dunkelblau = systemische Symptome). „L“ = Viren für die Infektion wurden aus Blättern aufgereinigt, die lokale Symptome trugen; „S“ = Viren für die Infektion wurden aus Blättern aufgereinigt, die systemische Symptome trugen. Die nummerierten Balken weisen auf gefundene Revertanten hin (siehe Text). 
„Vorgängerpflanze“ Symptome aufwies. Die beobachtete Symptomentwicklung der Pflanzen nach Transfektion (1. Generation) und Infektion (2., 3. Generation) zeigt Abbildung 38. Der Wildtyp wurde als Positiv-Kontrolle mitgezogen.

Die Symptome, die durch Variante 8-40 verursacht wurden, entsprachen im zeitlichen Verlauf denen, die durch den Wildtyp verursacht wurden. Transfektion und Infektion unterschieden sich nicht. Lokale Symptome wurden in der Regel zwischen dem 4. und 7. Tag entwickelt. Systemische Symptome zeigten sich meist zwischen dem 7. und 9. Tag. Die Symptome der 3. Generation entwickelten sich abweichend von den ersten beiden Generationen bereits am 3. (lokal) und 6./7. Tag (systemisch). Diese frühe und regelmäßige Symptomentwicklung ist vermutlich darauf zurückzuführen, daß die Pflanzen dieser Generation etwa eine halbe Woche jünger waren, als sonst üblich. Der Wildtyp entwickelte in der 3. Generation ebenfalls derartig frühe Symptome. Die Intensität (Anzahl/Größe) der Läsionen waren dabei aber trotzdem sehr unterschiedlich. Insgesamt 38 von 38 infizierten Pflanzen zeigten Symptome.

Die durch WT (C) verursachten Symptome entwickelten sich anders, als bei 8-40. Lokale Symptome zeigten sich nach etwa 4-6 Tagen, aber systemische entwickelten sich meist gar nicht, selten nach über 3 Wochen. In den Pflanzen mit wildtypähnlichem Symptomverlauf wurden Revertanten gefunden (Abb.: 38; mit 1., 2. markierte Balken). Einige Pflanzen zeigten keine Symptome für die Dauer von mindestens 4 Wochen. Insgesamt entwickelten 28 von 38 potentiell möglichen Pflanzen Symptome.

Die Variante 8-40 (4UCC) verursachte wiederum eine andere Symptomentwicklung. Die meisten transfizierten Pflanzen der 1. Generation zeigten über 4 Wochen keine Symptome. 4 Pflanzen entwickelten nach 4 bis 12 Tagen lokale Symptome und 2 von diesen zeigten nach 13, bzw. 19 Tagen auch systemische. Die Infektion der folgenden Pflanzengenerationen verlief relativ stabil, mit Symptomentwicklungen, die dem des Wildtyps etwa in der Hälfte der Fälle (4 von 7) ähnelten. Eine Pflanze der 2. Generation zeigte keine Symptome, zwei nur lokale. Die zwei infizierten Pflanzen der 3. Generation zeigten beide lokale und systemische Symptome. Trotz der beobachteten systemischen Infektionen wurde nur in einer Pflanze eine Reversion gefunden (Abb.: 38; mit 3. markierter Balken). Insgesamt entwickelten 9 von 38 potentiell möglichen Pflanzen Symptome.

Zusätzlich konnte beobachtet werden, daß Viren (WT (C), isoliert aus einer systemisch infizierten Pflanze) die gleichen Symptome in der jeweiligen „Folgepflanze“ verursachen, unabhängig davon, ob sie aus „lokalen“ („L“)- oder ,systemischen“(,,S“)-Blättern stammen (Abb.: 38). Die Reversion der Variante WT (C) ist also im lokal infizierten Blatt entstanden oder konnte aus der restlichen Pflanze auch dorthin einwandern. Lokal infizierte Blätter sind daher vermutlich auch in der späteren Infektion nicht statisch. 
Eine mit Variante 8-40 (4UCC) transfizierte Pflanze zeigte nach 19 Tagen vermutlich systemische Symptome (Abb.: 38). Diese waren allerdings lange Zeit sehr kleinflächig und sehr schwach. Am 26. Tag wurden Viren aus einem lokal infizierten Blatt isoliert (die Sequenzierung der Virus-RNA zu diesem Zeitpunkt ergab keine Reversionen). Die anschließend infizierte Pflanze entwickelte nur lokale Symptome. Nachdem sich in der ersten Pflanze auch deutliche systemische Symptome zeigten, wurden Viren nun aus diesen Blättern isoliert (am 39. Tag). Diesmal zeigte die folgend infizierte Pflanze sofort einen Symptomverlauf wie bei der Infektion durch den Wildtyp (die Virus-RNA zeigte hier die Revertante 8-40 (UUU)).

Nach diesen Beobachtungen kann vermutet werden, daß hier eine Evolution statt einer Selektion stattfand. Die Revertante der Variante 8-40 (4UCC) scheint spontan entstanden zu sein.

Die gefundenen Revertanten (Abb.: 38; 1., 2., 3.) wiesen Mutationen nur in der L1Schleife auf:
1. WT (C)
$1: \mathrm{L} 1=\mathrm{C} \rightarrow \mathrm{CC}$
2. WT (C)
9L/9S : $\mathrm{L} 1=\mathrm{C} \rightarrow \mathrm{CC}$
3. $\quad 8-40(4 \mathrm{UCC}) 2 \mathrm{~S}$
$\mathrm{L} 1=\mathrm{UUUUCC} \rightarrow \mathrm{UUU}$

\subsubsection{In vivo Experimente mit Arabidopsis thaliana-Flüssigkulturen}

Ziel des Experimentes war u.a. exaktere Aussagen zum Verhältnis von Zellzahl und Virusproduktion zu erhalten. Bei konstanter Zellzahl (ca. 4·10 ${ }^{6}$ ) läßt sich die relative Virusproduktion unter den Varianten vergleichen. Dies ist in dem weniger komplexen System, der Flüssigkultur, möglich (Abb.: 39).
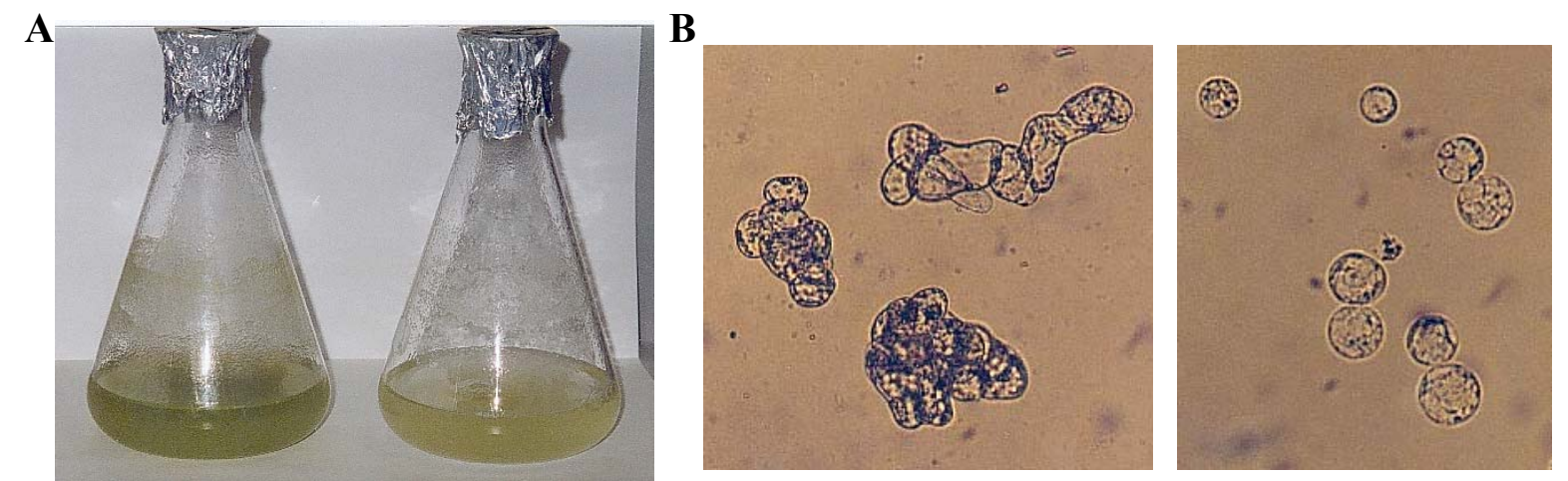

Abb.: 39,

A) Arabidopsis thaliana Flüssigkulturen. Links nach einer Woche Wachstum, rechts nach frischem Animpfen des Mediums.

B) Arabidopsis thaliana Flüssigkultur bei 400facher Vergrößerung. Man erkennt ungeordnete Zellhaufen (links). Nach Protoplastierung sind die Zellen ohne Zellwand vereinzelt und kugelförmig (rechts). 
Die Suspensionskultur der Ackerschmalwand (Arabidopsis thaliana) wurde aus technischen Gründen benutzt. Protoplasten sind schneller und mit besserer Qualität herzustellen, als mit Protokollen für andere Wirtspflanzen des TYMV (Boyer et al., 1993; Weiland and Dreher, 1993; Schirawski et al., 2000). Die Kultur wurde mir vom Labor von Prof. Pleij überlassen. Die Experimente wurden am Albrecht-von-Haller-Institut in der Abteilung von Prof. Gatz und am Institut für Mikrobiologie und molekulare Genetik (beide Universität Göttingen) durchgeführt.

Haltung der Kulturen, Protoplastierung und Transfektion der Zellen und Aufreinigung der Viren sind unter Punkt 2.2.4.1. bis 2.2.4.5. beschrieben.

Die Protoplastierung, die die Aufnahme der RNA erst ermöglicht, und die Zählung der Zellen wurde optisch mittels eines Mikroskops überprüft, bzw. durchgeführt. Der morphologische Unterschied zwischen unbehandelter Flüssigkultur und protoplastierten Zellen ist deutlich sichtbar. Bei ersterem handelt es sich um Zellhaufen unterschiedlich geformter Zellen, nach Auflösung der Zellwand sind nur noch vereinzelte, durch den Turgor kugelförmig ,aufgeblasene“ Zellen sichtbar (Abb.: 39, B). Pektolyase wird dabei vor allem für die Trennung der Zellen, Cellulase für die endgültige Auflösung der Zellwände eingesetzt.

Nach $42 \mathrm{~h}$ Inkubation der transfizierten Zellen wurden die produzierten Viren der Varianten in Anlehnung an das Protokoll von Leberman isoliert (Leberman, 1966; Schirawski et al., 2000). Die Extinktion der TYMV-Präparation wurde dann bei einer Wellenlänge von 260nm bestimmt. J. Kaper und E. Litjens konnten bereits 1966 einen spezifischen Extinktionskoeffizienten für TYMV errechnen (Kaper and Litjens, 1966). Sie bestimmten außerdem den RNA-Anteil des Virus mit 33,5\%. Daher konnte die Konzentration des Virus in der Präparation berechnet werden.

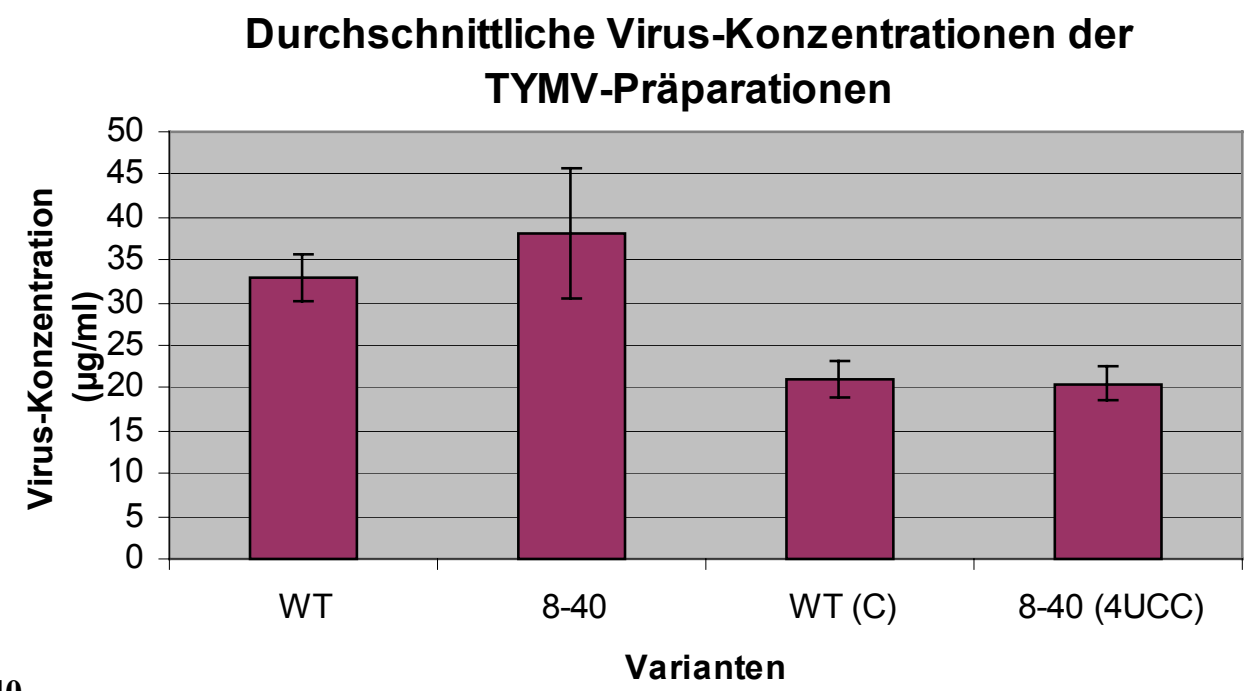

Abb.: 40,

\section{Varianten}

Vergleich der TYMV-Konzentrationen von Virus-Präparationen verschiedener Varianten. Die Werte wurden aus den optischen Dichten (260nm) der Suspensionen errechnet (Schirawski et al., 2000). 
In 3 zeitlich verschiedenen Experimenten wurde die optische Dichte von jeweils 2 oder 3 voneinander unabhängigen Präparationen bestimmt. Die $\mathrm{OD}_{260}$-Werte lagen zwischen 0,408 und 0,09. Alle Präparationen mit einem $\mathrm{OD}_{260}$-Wert unter 0,13, die auch in den anschließenden Western Blots niemals Signale zeigten, wurden als nicht transfiziert eingestuft und nicht gewertet.

Der Wildtyp (WT) zeigte eine durchschnittliche Virus-Konzentration von ca. $33 \mu \mathrm{g} / \mathrm{ml}$ (Abb.: 40). Die Standard-Abweichung der drei gemessenen Werte beträgt 2,85. Wenn man das Molekulargewicht eines Virus auf $5,6 \cdot 10^{6} \mathrm{~g} / \mathrm{mol}$ festlegt (Canady et al., 1996), hätte man ca. $2,4 \mathrm{fmol}$ aufgereinigt. Eine Wirtszelle hätte dann etwa $1,42 \cdot 10^{12}$ Viren $/ 4 \cdot 10^{6}$ Zellen $=355000$ Viren in $42 \mathrm{~h}$ produziert.

Die Virus-Präparationen der Variante 8-40 hatten durchschnittlich eine Konzentration von $38,1 \mu \mathrm{g} / \mathrm{ml}$. Die Standardabweichung der vier gemessenen Werte beträgt 7,56. Für die Variante WT (C) betrug die durchschnittliche Konzentration $21 \mu \mathrm{g} / \mathrm{ml}$ und die Standardabweichung der fünf gemessenen Werte ist 2,04. Die Präparationen der Variante 8-40 (4UCC) ergab eine durchschnittliche Konzentration von 20,6 $\mathrm{g} / \mathrm{ml}$. Die Standardabweichung der fünf gemessenen Werte beträgt 1,91.

Im Vergleich der Varianten ist erkennbar, daß WT und 8-40 mindestens 1/3 höhere Konzentrationen erreichen, als WT (C) und 8-40 (4UCC). Tendenziell zeigt die Variante 840 die höchsten Konzentrationswerte.

Von zwei Experimenten wurde je die gesamte Präparation einer Variante auf ein denaturierendes Proteingel aufgetragen und anschließend wurde ein Western Blot durchgeführt (Punkt 2.2.1.13.). Der erste Antikörper war gegen das Hüllprotein des TYMV gerichtet $(20 \mathrm{kDa})$, der zweite Antikörper war gegen Maus-Antikörper gerichtet und mit alkalischer Phosphatase fusioniert (Punkt 2.1.4.). Abbildung 41 zeigt, daß der WT und 840 deutlich die stärksten Signale ergaben. WT (C) und 8-40 (4UCC) entwickelten im Western Blot geringe bis keine Signale. In Blot A ist 8-40 deutlich intensiver als der WT, während in Blot B 8-40 und der WT sehr ähnlich intensive Signale ergeben. WT (C) zeigte einmal ein deutliches Signal (Abb.: 41, A), während es im zweiten Blot kein deutlich erkennbares Signal ergibt (Abb.: 41, B). 8-40 (4UCC) zeigt in beiden Blots ein schwaches aber erkennbares Signal (in Blot B durch einen Pfeil markiert). Die Präparation aus nicht infizierten Protoplasten (,--K“) zeigt kein Signal.

Alle sichtbaren Signale stimmen in ihrem Laufverhalten mit der positiv-Kontrolle $\left(,+\mathrm{K}^{\text {“ }}\right.$; pulverisiertes, infiziertes Pflanzenmaterial, von DSMZ, Braunschweig) überein. Der Unterschied bei der Intensität der Signale zwischen den Blots und das Fehlen von Signalen innerhalb eines Blots könnte darauf zurückzuführen sein, daß die Präparationen für Blot B wenige Tage bei ca. $+6^{\circ} \mathrm{C}$, die für Blot $\mathrm{A}$ dagegen bei $-20^{\circ} \mathrm{C}$ aufbewahrt wurden (zwischen $\mathrm{OD}_{260}$-Messung und Gel-Auftrag). Kontaminationen mit Proteinasen oder 
Abbau durch Milieu-Bedingungen könnten bei $+6^{\circ} \mathrm{C}$ geringe Protein-Mengen abgebaut haben.

Blot A weist zwei Banden (in Übereinstimmung mit der Positiv-Kontrolle) und einen „Schmier“ zwischen ihnen auf. Blot B zeigt jeweils nur eine Bande, die der oberen in Blot A entspricht. Auch hier ist der Grund vermutlich die unterschiedliche Lagerungstemperatur der Proben. Da es sich um definierte Banden handelt, von der die niedrigere genau den $20 \mathrm{kDa}$ des Hüllproteins $\mathrm{zu}$ entsprechen scheint, findet hier wahrscheinlich kein ungerichteter Abbau statt. Vermutlich wird durch das Gefrieren eine Substanz (Spermidin?) vom Hüllprotein gelöst.

Die Ergebnisse der Protein-Anfärbungen wurden zusätzlich mittels eines Scanprogrammes quantifiziert (Abb.: 41, C).

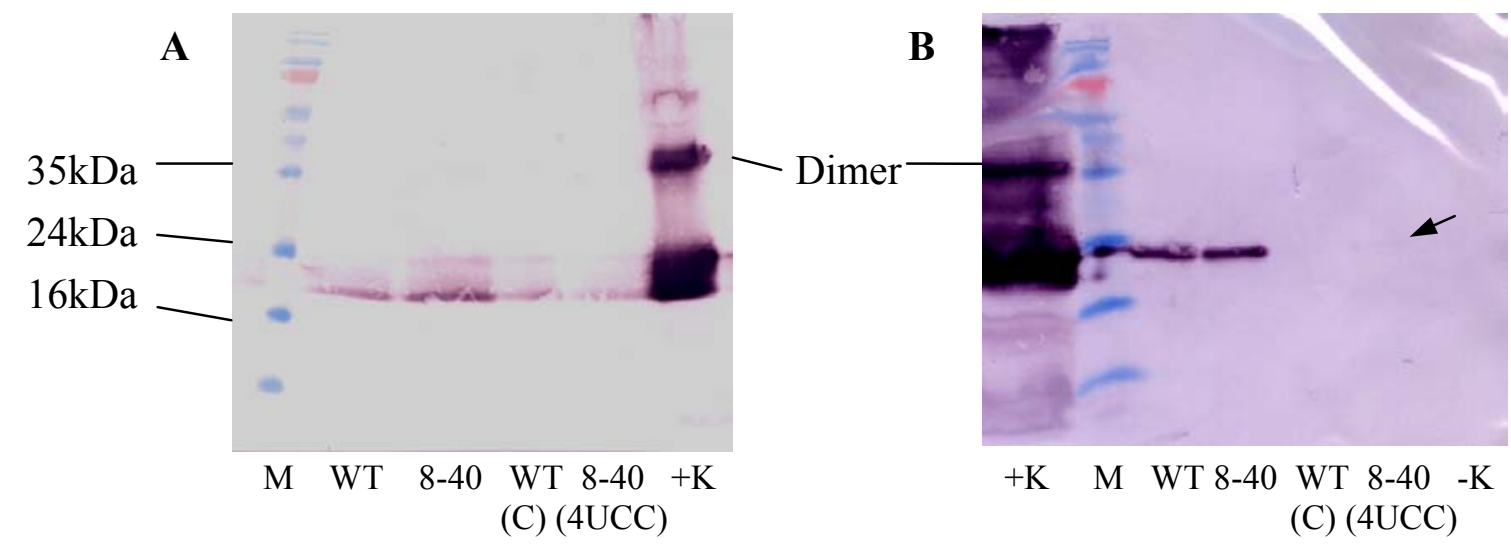

C

TYMV-Hüllprotein-Mengen in Präparationen aus Transfizie rten Protoplasten

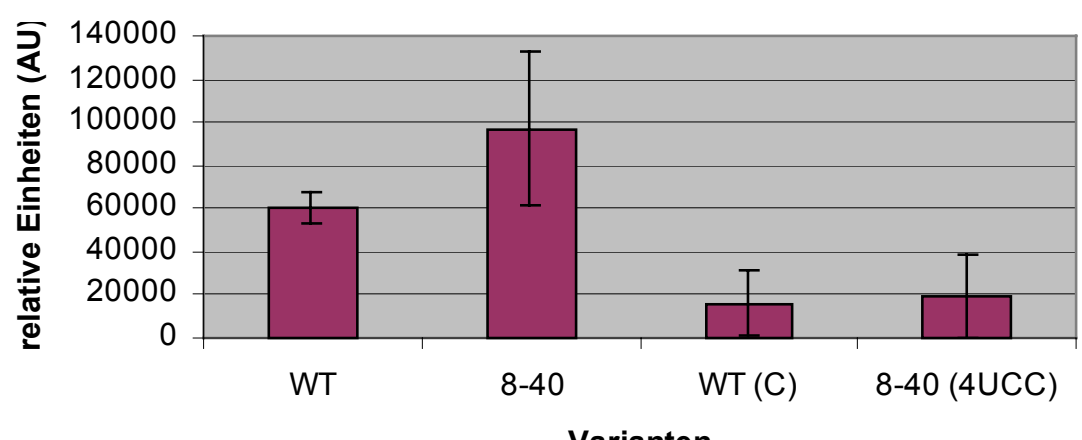

Abb.: 41,

Varianten

A), B) Hüllprotein-Anfärbungen (Western Blot) von TYMV-Präparationen verschiedener Varianten. Präpariert wurden sie 42h nach Transfektion von Arabidopsis thaliana-Protoplasten. Der Pfeil in B) markiert eine schwache Bande der Präparation der Variante 8-40 (4UCC). M: Protein-Marker (MBI); +K: PositivKontrolle (TYMV-Hüllprotein); -K: Negativ-Kontrolle; Die Beschriftung zeigt die TYMV-Varianten der Präparationen.

C) Zusammenfassung und Normierung von A) und B). Normiert wurden die Werte jeweils gegen den Hintergrund. 
Die Ergebnisse zu den relativen Hüllprotein-Mengen decken sich in etwa mit den ermittelten Werten der optischen Dichte und den Beobachtungen $\mathrm{zu}$ den Symptomentwicklungen von infizierten Chinakohl-Pflanzen.

Abschließend können die Eingangs gestellten Fragen dahingehend beantwortet werden, daß die Effizienzänderung einer Funktion der TYMV-TLS in vivo auch zu Änderungen bei anderen Funktionen (sichtbar an der Amplifikationsfähigkeit) führt. Die Valylierungseffizienz der TLS scheint in vivo tatsächlich Einfluß auf die Amplifikation des Virus zu haben. Geringere Valylierungseffizienz als die des Wildtyps führt zu geringer Amplifikation, höhere Valylierungseffizienz führt in Protoplasten durchschnittlich zu höherer Amplifikation, in Pflanzen dagegen zu wildtyp-artigen Symptomen.

Ein Einfluß der L1-Schleife könnte davon abhängig sein, daß jede Änderung der Länge (nicht der Sequenz, die L1-Schleife des WT und der 8-40 ist 3'-CUUU-5' und 3'-UUUC5 ' und verursachen trotzdem beide in vivo ähnliche Symptome) zu einer verringerten Amplifikationseffizienz führt. Die ermittelten in vitro Daten zeigten dagegen keine entscheidenden Unterschiede der (-)-Strang Synthese für unterschiedlich lange L1Schleifen.

\subsubsection{Präparation von viraler RNA-abhängiger RNA-Polymerase aus transfiziertem Chinakohl}

Für alle in vitro (-)-Strang Synthesen (Punkt 3.2.4./5.) mußte TYMV-RdRp isoliert werden. Die schnellste und einfachste Methode, spezifisches Matrizen-abhängiges Enzym $\mathrm{zu}$ erhalten, stellte die Präparation aus transfizierten Chinakohl-Pflanzen dar (Punkt 2.2.4.9.). Diese Methode der teilweisen Aufreinigung wurde im Labor von Prof. Pleij in Anlehnung an das Protokoll von Quadt und Jaspars entwickelt (Quadt and Jaspars, 1990; Deiman et al., 1997b).

Die RdRp wurde abschließend in 1,5ml Fraktionen (25) einer Glyzerin-DichtegradientenZentrifugation erhalten. Die Fraktionen wurden auf Aktivität in einer in vitro (-)-Strang Synthese (Punkt 2.2.3.1.) mit WT-TLS-RNA als Matrize getestet (Abb.: 42). Die Fraktionen 15, 16, 17 und 18 wurden als aktiv eingestuft und zur Sicherheit ein zweites mal getestet. In den in vitro Experimenten mit TYMV-TLS-Varianten wurden die Fraktionen 16 und 17 benutzt. Zusätzlich sollte geprüft werden, ob und in welcher Menge

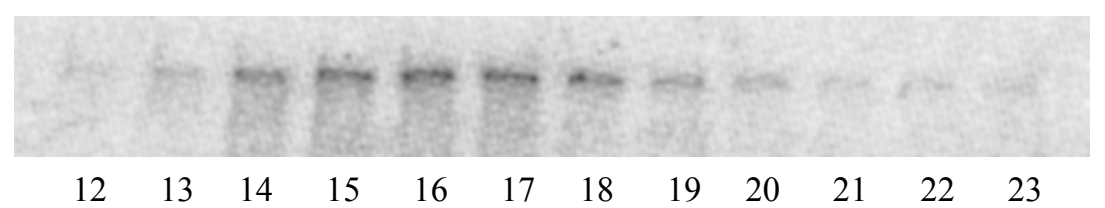

Abb.: 42,

Radioaktive Produktbanden der (-)-Strang Synthesen verschiedener RdRp-Fraktionen mit WT-TLS-RNA als Matrize. Die Zahlen geben die Nummern der getesteten Fraktionen wieder. 
weitere Proteine in den Fraktionen vorhanden waren. Außerdem wurde getestet, ob eventuell eEF1A in den Fraktionen mit enthalten sein könnte, da Hinweise bestanden, daß es ein Bestandteil der viralen Replikase sein könnte (siehe Punkt 3.2.6.). Dazu wurde aus technischen Gründen EF-Tu aus E. coli zusammen mit der RdRp-Fraktion auf ein denaturierendes 12\%iges Proteingel aufgetragen (Abb.: 43). Von zwei angefertigten Gelen wurde eines mit Coomassie angefärbt (Sambrook et al., 1989), das zweite wurde für einen Western Blot mit Anti-EF-Tu-Antikörper (polyklonal; Punkt 2.1.4.) benutzt. Gleichzeitig wurde ein Arabidopsis-Zelllysat auf beide Gele mit aufgetragen, um zu testen, ob der Antikörper auch pflanzliches eEF1A der Chloroplasten erkennt. Auf die Gele wurden 0,2, 0,1 und $0,05 \mu 1$ einer EF-Tu-Präparation aus E. coli (erhalten von Prof. Mayer, Universität Göttingen) gegeben, zusätzlich noch $40 \mu \mathrm{l}$ aktive RdRp-Fraktion und $9 \mu 1$ eines Arabidopsis-Pflanzenzelllysates (erhalten aus der Abteilung von Prof. Gatz).
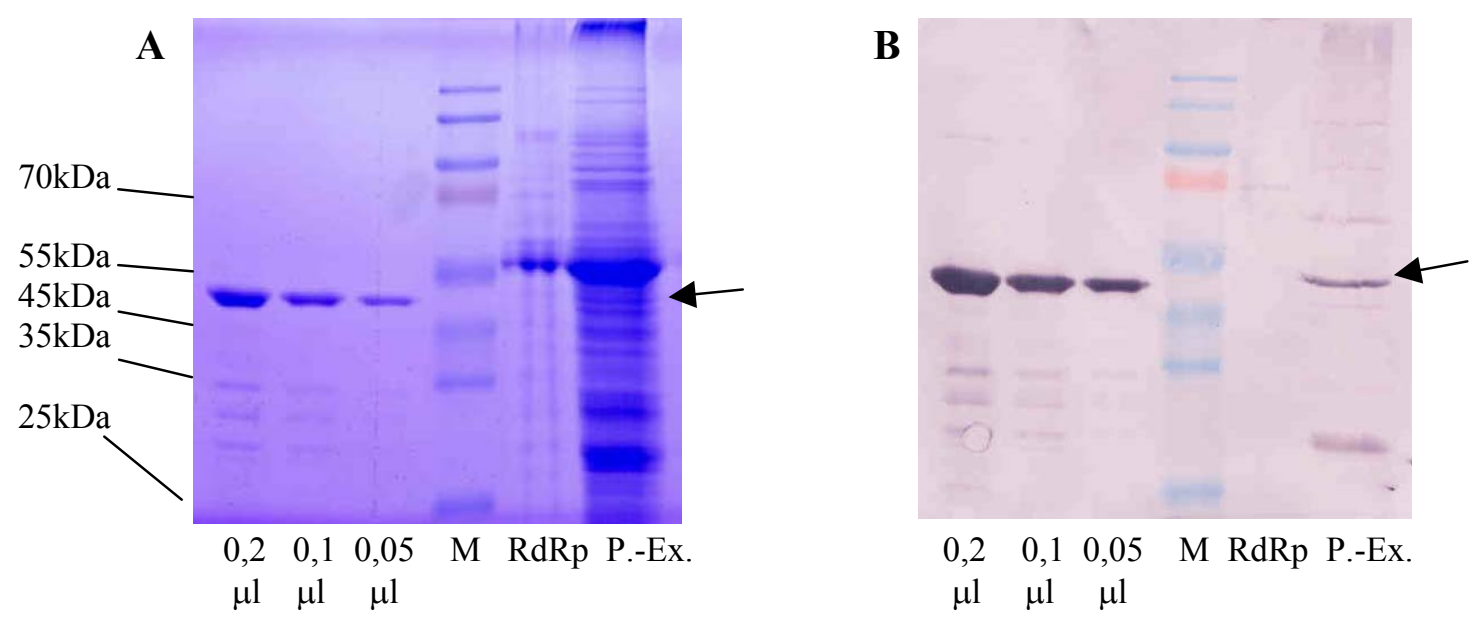

Abb.: 43,

A) Denaturierendes 12\%iges PAA-Gel mit Auftragungen verschiedener Protein-Präparationen (CoomassieFärbung). Mit „, $\mathrm{l}^{\text {“ }}$ sind die Auftragungen entsprechend angegebener Mengen einer E. coli-EF-TuPräparation markiert. „RdRp“ steht für den Auftrag von $40 \mu$ l einer RdRp-Glyzerin-Fraktion und „P.Ex." bezeichnet den Auftrag von $9 \mu 1$ eines Arabidopsis thaliana-Zelllysats.

B) Western Blot des gleichen Gels wie unter A). Die Anfärbung fand mittels eines polyklonalen EF-TuAntikörpers satt. Man erkennt die Anfärbung von eEF1A im Pflanzenzelllysat (Pfeil).

Wie in Abbildung $43 \mathrm{zu}$ sehen, wurde mit dem Anti-EF-Tu-Antikörper auch ein Protein (vermutlich eEF1A, 49kDa (Axelos et al., 1989; Ransom et al., 1998)) im Pflanzenzelllysat angefärbt (Pfeile). In der RdRp-Präparation ist auf der gleichen Höhe dagegen keine Bande sichtbar. Dort scheint kein eEF1A enhalten zu sein. Eine schwache Bande zeigt sich dagegen bei etwa $70 \mathrm{kDa}$. Sie läuft aber nicht auf der Höhe der 66kDa-RdRp oder eines anderen Proteins (115 oder $140 \mathrm{kDa})$, daß potentiell virale Transkriptionsaktivität besitzen könnte (Candresse et al., 1986; Morch et al., 1989; Bransom et al., 1991). Vermutlich wurde hier ein Protein mit aufgereinigt, daß unspezifisch einen Teil der eingesetzten Antikörper binden kann. Die Bande der 66kDa-RdRp ist nur schwach im Coomassie-Gel 
direkt oberhalb der deutlich erkennbaren Doppelbande bei ca. $58 \mathrm{kDa}$ sichtbar (Deiman et al., 1997b). Die zusätzlichen Banden des Pflanzenzelllysates (im Western Blot) könnten durch Abbau oder Proteinkomplexe von eEF1A mit anderen Proteinen (oder mit RNA) entstanden sein. Die Banden der EF-Tu-Auftragungen (Massengewicht: 47kDa (Arai et al., 1972; Arai et al., 1973)) unterhalb von 45kDa sind durch Abbau oder im Fall der bei $100 \mathrm{kDa}$ liegenden Bande durch Dimerisierung entstanden.

\subsection{Messung der kinetischen Parameter der Valylierung einzelner TYMV-TLS- Varianten}

Die kinetischen Parameter $\mathrm{k}_{\mathrm{cat}}$ und $\mathrm{K}_{\mathrm{M}}$ der TYMV-TLS-Variante (85nt) 8-40 (4UCC) in der Valylierung sollten bestimmt werden. Außerdem sollte untersucht werden, ob die in den in vivo Experimenten erhaltenen Revertanten WT (CC) und 8-40 (UUU) ihre Valylierungseffizienz gegenüber dem jeweiligen Ausgangsmolekül (WT (C), 8-40 (4UCC)) verändert haben.

Die Messungen wurden ähnlich wie in Punkt 2.2.2.8. beschrieben durchgeführt. Allerdings mußte die Probennahme aus dem Reaktionsansatz in einem Zeitraum erfolgen, in dem die Anfangsgeschwindigkeit des Substratumsatzes durch das Enzym (ValRS) noch annähernd linear verlief. Daher wurden $20 \mu$ l Aliquots nach 0, 1, 2, 3 und 4min. genommen und die TCA-fällbare Radioaktivität (entspricht der aminoacylierten RNA) gemessen. Zusätzlich wurde die Anfangsgeschwindigkeit für verschiedene RNA-Konzentrationen bestimmt. Dazu wurde die Zunahme der Radioaktivität in 5 parallelen Reaktionsansätzen (je $100 \mu 1$ ) mit $0,25,0,5,1,2$ und $3 \mu \mathrm{M}$ RNA (das sind 25-300pmol) verfolgt.

Um die Ergebnisse mit früheren Messungen anderer Varianten (Wientges et al., 2000) vergleichen zu können, wurden die Werte des Wildtyps exemplarisch bestimmt. Dabei stellte sich heraus, daß sich sowohl in der Valyl-tRNA-Synthetase-Präparation (aus $S$. cerevisiae), als auch in der ${ }^{3} \mathrm{H}$-Valin-Lösung die Anzahl intakter Moleküle verringert haben mußte. Beide waren auch für die Messungen von J. Wientges benutzt worden. Die Aktivität der ValRS war im Vergleich zu den älteren Messungen deutlich verringert und der Zerfall des Tritiums mit einer Halbwertszeit von 12,43 Jahren verursacht zwangsläufig auch die Zerstörung eines Teils des Valins. Durch die Benutzung einer anderen ValRSPräparation und Einsetzen eines geeigneten Volumens und zusätzlicher Erhöhung der ${ }^{3} \mathrm{H}$ Valin-Menge auf das 1,6fache, konnten akzeptable Werte erhalten werden.

Der erhaltenen Werte für den WT $(\mathrm{L} 1=\mathrm{CUUU})$ waren: $\mathrm{k}_{\mathrm{cat}}=0,318 \mathrm{sec}^{-1}, \mathrm{~K}_{\mathrm{M}}=2,74 \mu \mathrm{M}$, die relative Valylierungseffizienz war $\mathrm{k}_{\mathrm{cat}} / \mathrm{K}_{\mathrm{M}}=0,116$. Dem gegenüber lagen die Werte der Messung von J. Wientges (für den WT mit L1 $=$ CUCU) bei: $\mathrm{k}_{\text {cat }}=0,24 \mathrm{sec}^{-1}, \mathrm{~K}_{\mathrm{M}}=$ $2,44 \mu \mathrm{M}$, die relative Valylierungseffizienz war $\mathrm{k}_{\mathrm{cat}} / \mathrm{K}_{\mathrm{M}}=0,098$. Damit liegt die selbst bestimmte relative Valylierungseffizienz etwa $18,3 \%$ über dem älteren Wert. Da 
Valylierungseffizienzen sehr stark von den Reaktionsbedingungen abhängig sind (Dreher and Goodwin, 1998), ist hier eine gute Näherung erhalten worden.

In einer ersten analytischen Messung wurden alle Varianten (auch Revertanten) der in vivo Experimente unter gleichen Bedingungen aminoacyliert. Jeweils $1 \mu \mathrm{M}$ RNA im Reaktionsansatz wurde mit ca. $25 \mathrm{nM}$ ValRS für $4 \mathrm{~min}$. valyliert, die ${ }^{3} \mathrm{H}-$ Valin Konzentration war dabei noch nicht erhöht worden (Abb.: 44). Erkennbar ist, daß die Variante 8-40 (4UCC) vermutlich etwas effizienter valyliert wird, als der Wildtyp. Auffällig ist die Effizienzsteigerung der Revertanten WT (CC) und 8-40 (UUU) gegenüber ihren Ausgangsmolekülen WT (C) und 8-40 (4UCC). Die Valylierungseffizienzen der Varianten WT, WT (C) und 8-40 scheinen in ihrer Tendenz den bekannten Werten zu folgen.

Anschließend wurden die Experimente zur Ermittlung der kinetischen Parameter der Valylierung der Varianten 8-40 (4UCC), WT (CC) und 8-40 (UUU) durchgeführt.

\section{Valylierungsplateaus von 6 TYMV-Varianten}

(85nt-TLS)

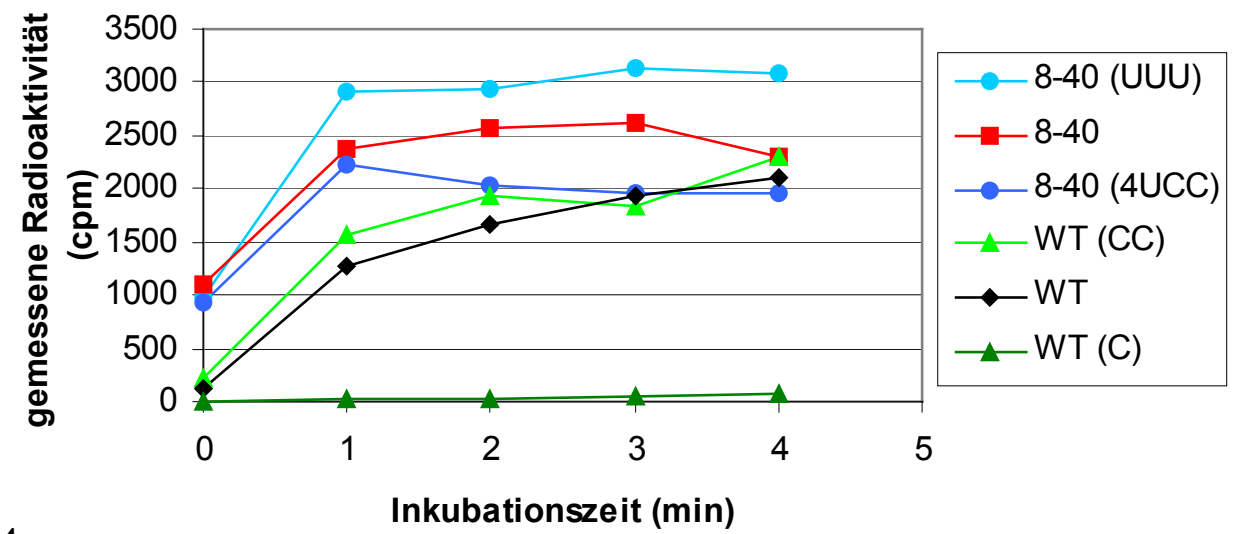

Abb.: 44,

Inkubationszeit (min)

Messung der Valylierungsplateaus von 6 TYMV-TLS-Varianten. $1 \mu \mathrm{M}$ RNA im Reaktionsansatz wurde mit ca. $25 \mathrm{nM}$ ValRS aminoacyliert. Die Varianten (85nt) sind in der Legende des Diagramms bezeichnet. Fast alle Varianten erreichen ihr Plateau nach 1-2min. (außer WT(C) und WT).

Die Ergebnisse der 3 Varianten sind:

8-40 (4UCC) $\mathrm{k}_{\text {cat }}=3,24 \mathrm{sec}^{-1}, \quad \mathrm{~K}_{\mathrm{M}}=6,24 \mu \mathrm{M}, \mathrm{k}_{\mathrm{cat}} / \mathrm{K}_{\mathrm{M}}=0,519 \rightarrow 5,3 \mathrm{x}$ besser als WT

WT $(C C) \quad \mathrm{k}_{\text {cat }}=0,896 \mathrm{sec}^{-1}, \quad \mathrm{~K}_{\mathrm{M}}=7,36 \mu \mathrm{M}, \mathrm{k}_{\text {cat }} / \mathrm{K}_{\mathrm{M}}=0,122 \rightarrow 1,2 \mathrm{x}$ besser als WT

8-40 (UUU) $\quad \mathrm{k}_{\text {cat }}=1,36 \mathrm{sec}^{-1}, \quad \mathrm{~K}_{\mathrm{M}}=1,59 \mu \mathrm{M}, \mathrm{k}_{\text {cat }} / \mathrm{K}_{\mathrm{M}}=0,854 \rightarrow 8,7 \mathrm{x}$ besser als WT

Die Valylierungen von 8-40 (4UCC) und 8-40 (UUU) wurden mit ca. 1,25nM ValRS, die von WT (CC) mit ca. 10nM ValRS durchgeführt.

Die Werte bestätigen, daß die Revertanten aus den Pflanzen-Infektionen mit ihrer verbesserten Amplifikationseffizienz (Symptomentwicklung) auch ihre relative 
Valylierungseffizienz $\left(\mathrm{k}_{\mathrm{cat}} / \mathrm{K}_{\mathrm{M}}\right)$ verbessert haben. Der WT (CC) hat eine $244 \mathrm{fach}$ gesteigerte Effizienz im Vergleich zu WT (C), dabei ist die Umsatzgeschwindigkeit ( $\mathrm{k}_{\text {cat }}$ ) von $0,002 \mathrm{sec}^{-1}$ auf $0,896 \mathrm{sec}^{-1}$ (448fach) gestiegen, während sich die Affinität zur ValRS $\left(\mathrm{K}_{\mathrm{M}}\right)$ nur wenig von $4,13 \mu \mathrm{M}$ auf 7,36 $\mu \mathrm{M}$ (1,8fach) verringerte. Die Variante 8-40 (UUU) hat eine um die Hälfte (1,6fach) gesteigerte relative Valylierungseffizienz im Vergleich zu 8-40 (4UCC). Hier ist die Umsatzgeschwindigkeit ( $\mathrm{k}_{\mathrm{cat}}$ ) gering von $3,24 \mathrm{sec}^{-1}$ auf $1,36 \mathrm{sec}^{-1}$ (2,4fach) verringert, die Affinität zum Enzym $\left(\mathrm{K}_{\mathrm{M}}\right)$ ist von $6,24 \mu \mathrm{M}$ auf $1,59 \mu \mathrm{M}$ (ca. 4 fach) verbessert. Eventuell war die Reaktionsgeschwindigkeit für eine effizientere Amplifizierbarkeit nicht so entscheident, da der $\mathrm{k}_{\text {cat }}$ von 8-40 (4UCC) mit 3,24 $\mathrm{sec}^{-1}$ bereits etwa 10 fach besser als der des WT $\left(0,318 \mathrm{sec}^{-1}\right)$ war. Die Affinität $\left(\mathrm{K}_{\mathrm{M}}\right)$ war dagegen mit $6,24 \mu \mathrm{M} 2,3$ fach schlechter als beim WT $\left(\mathrm{K}_{\mathrm{M}}=2,74 \mu \mathrm{M}\right)$. Die Variante 8-40 (UUU) ist nun in beiden Parametern besser als der WT, dagegen war 8-40 (4UCC) nur in $\mathrm{k}_{\text {cat }}$ besser, aber im $K_{M}$ schlechter als der WT. Insgesamt erscheint die Änderung der Valylierungseffizienz nicht so deutlich wie bei WT (CC).

Im Folgenden sollen am Beispiel der Variante 8-40 (UUU) die kinetischen Parameter $\mathrm{k}_{\text {cat }}$ und $\mathrm{K}_{\mathrm{M}}$ berechnet werden. Als erstes wurde dafür in einem Diagramm der zeitliche Verlauf der Valylierung in Form der gemessenen Radioaktivitätszunahmen gegen die Reaktionszeit aufgetragen (Abb.: 45). 5 verschiedene RNA Konzentrationen (siehe oben) waren bei $30^{\circ} \mathrm{C}$ für $4 \mathrm{~min}$. mit jeweils ca. $1,25 \mathrm{nM}$ ValRS aus $S$. cerevisiae valyliert worden.

\section{Messung der Kinetik der Valylierung der TYMV-TLS-Variante 8-40 (UUU)}

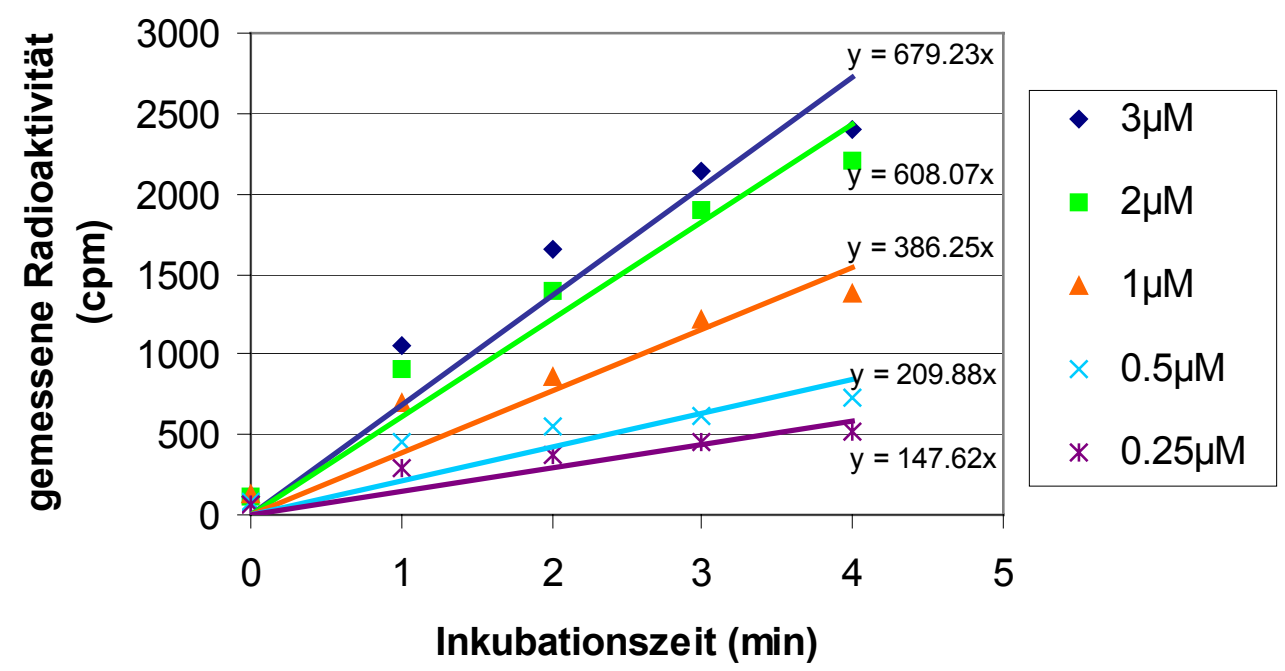

Abb.: 45,

Zeitliche Verläufe der Valylierungen verschiedener Konzentrationen von 8-40 (UUU)-RNA (85nt-TLS). Die Konzentrationen der RNA in den verschiedene Reaktionsansätzen sind in der Legende des Diagramms angegeben. Alle Valylierungen fanden bei $30^{\circ} \mathrm{C}$ mit ca. $1,25 \mathrm{nM}$ ValRS statt. Im Diagramm sind die Steigungen der Geraden mit angegeben. 
Die erhaltenen Meßkurven wurden mit einer Geraden gefittet. Die Steigung dieser Geraden stellt die Anfangsgeschwindigkeit dieser speziellen Valylierungsreaktion dar. Für die Berechnung von $\mathrm{k}_{\text {cat }}$ und $\mathrm{K}_{\mathrm{M}}$ wurde dann die Anfangsgeschwindigkeit (v) gegen die Anfangsgeschwindigkeit dividiert durch die RNA-Konzentration (v/S) in einem Diagramm aufgetragen (Abb.: 46). Diese Auftragung nach Eadie und Hofstee (Eadie, 1942; Hofstee, 1959) wurde gewählt, da sie nicht, wie die allgemein verwendete Lineweaver-BurkAuftragung Datenpunkte hoher Substratkonzentration in einer kleinen Region des Diagramms zusammenfaßt und damit zu gering wertet (Fersht, 1985).

Die Datenpunkte im Diagramm wurden wiederum mit einer Geraden gefittet. Die Geradengleichung wurde dann zur weiteren Berechnung benutzt. In der Eadie-HofsteeAuftragung gilt für die Geradengleichung $y=a x+b$, wenn $x=0$ ist, daß $y=v_{\max }$ entspricht. $\mathrm{v}_{\max }$ ist die maximale Umsatzgeschwindigkeit der ValRS bei der gegebenen Konzentration $(1,25 \mathrm{nM})$. Wenn $\mathrm{y}=0$ gegeben ist, dann gilt $\mathrm{x}=\mathrm{v}_{\max } / \mathrm{K}_{\mathrm{M}}$.

Für die Berechnung von $k_{\text {cat }}$ wurde folgende Formel benutzt $\left(b=v_{\max }\right.$, wenn $\left.x=0\right)$ :

$$
\mathrm{k}_{\mathrm{cat}}\left(\sec ^{-1}\right)=\frac{\mathrm{b}(\mathrm{cpm} / \mathrm{min} .) \cdot 1000(\mu \mathrm{l} / \mathrm{ml})}{60(\mathrm{sec} / \mathrm{min} .) \cdot 20(\mu \mathrm{l}) \cdot \mathrm{SA}(\mathrm{cpm} / \mathrm{pmol}) \cdot[\text { ValRS }](\mathrm{nM})}
$$

SA steht für die spezifische Aktivität der radioaktiven Aminosäure und wurde mit dem Wert 500 in die Gleichung eingesetzt. b ist 1019,8 und die ValRS-Konzentration betrug $1,25 \mathrm{nM}$. Der Wert für $\mathrm{k}_{\text {cat }}$ nach Auflösung der Gleichung beträgt 1,3597 $\mathrm{sec}^{-1}$.

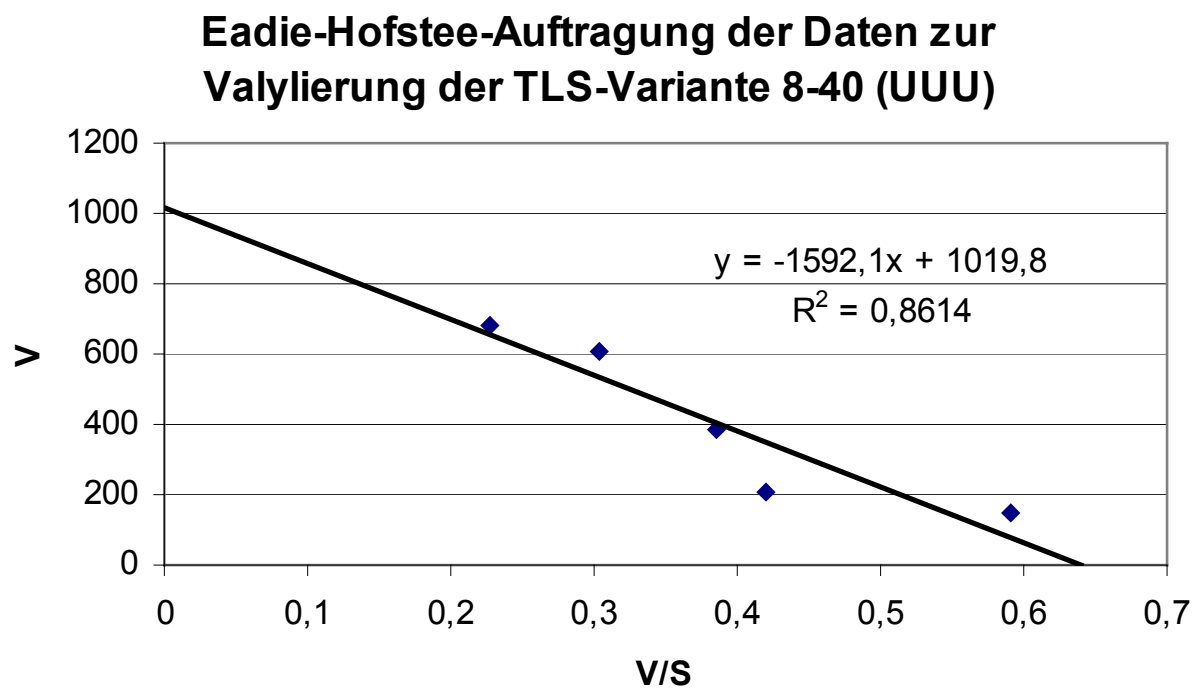

Abb.: 46,

Auftragung der Reaktionsgeschwindigkeiten (v) der ValRS bei verschiedenen RNA-Konzentrationen (S) gegen den Quotienten von v/S. Die Steigungen der Geraden zu den Valylierungskurven der Variante 8-40 (UUU) geben die jeweilige Reaktionsgeschwindigkeit , $\mathrm{V}^{\prime}$ bei einer bestimmten Substratkonzentration (S) an. 
Für die Berechnung von $K_{M}$ gilt $x=v_{\max } / K_{M}$, wenn $y=0$. Da $b=v_{\max }$ ist, gilt für die Geradengleichung: $a \cdot v_{\max } / K_{M}+v_{\max }=0$. Auf beiden Seiten der Gleichung wird nun nacheinander $\mathrm{v}_{\max }$ subtrahiert, mit $\mathrm{K}_{\mathrm{M}}$ multipliziert und durch $\mathrm{v}_{\max }$ dividiert. Abschließend erhält man: $\mathrm{a}=-\mathrm{K}_{\mathrm{M}}$ oder $\mathrm{K}_{\mathrm{M}}=-\mathrm{a}$. Da die RNA-Konzentrationswerte der Eadie-HofsteeAuftragung in $\mathrm{nM}$ angegeben worden sind, entspricht auch der $\mathrm{K}_{\mathrm{M}}$-Wert dieser Einheit. Für die Variante 8-40 (UUU) ergibt sich so $\mathrm{K}_{\mathrm{M}}=1592,1 \mathrm{nM}$.

Die entsprechenden Diagramme der Varianten WT (CC) und 8-40 (4UCC) sind im Anhang aufgeführt. 


\section{$\underline{\text { 4. Diskussion }}$}

\subsection{In vitro Selektion der Bibliothek Lib D}

\subsubsection{Einleitung}

Ziel der in vitro Selektion war, die Varianten einer in definierten Regionen randomisierten RNA-Bibliothek (Lib D) anzureichern, die möglichst optimale Eigenschaften für ihre Valylierung besitzen. Effizient valylierbare Varianten sollten sequenziert und die randomisierten Bereiche der verschiedenen Moleküle sollten auf Übereinstimmungen hin verglichen werden. Die Bibliothek war in der Schleife der Haarnadel II (,T-Schleife“, 8nt), der Scharnier-Region (4nt) und der Schleife der Haarnadel IV („D-Schleife, 6nt) randomisiert.

In 7 Selektionsrunden wurde die Aminoacylierbarkeit der Bibliothek Lib D in verschiedenen Runden unterschiedlich stark gesteigert. Die Runden 3, 4 und 7 brachten in absteigender Reihenfolge die am effizientesten valylierbaren Populationen hervor (siehe Abb.: 26, Punkt 3.1.9.).

Die sequenzierten Bibliotheken enthielten mehrheitlich vermutlich inaktive Varianten (siehe Punkt 4.1.3.) und es traten relativ viele zusätzliche Mutationen außerhalb der randomisierten Bereiche auf.

Das Ziel, optimal valylierbare TYMV-TLS-Varianten $\mathrm{zu}$ isolieren und KonsensusSequenzen in den randomisierten Bereichen $\mathrm{zu}$ finden, konnte bei der gewählten Moleküllänge und der benutzten Methode nicht erreicht werden.

\subsubsection{Die in vitro Selektionsmethode}

Zur Selektion funktionaler Varianten aus einer teilrandomisierten RNA-Population (Bibliothek Lib D) wurde eine im Labor etablierte in vitro Methode benutzt. Sie basiert auf dem Konzept des erworbenen Affinitätstags des zu selektierenden RNA-Moleküls (Pütz et al., 1997). Im Gegensatz zur Darwinschen Evolution, die aus Selektion, Amplifikation und Variation (Einführung zusätzlicher Mutationen) besteht, werden hier einzelne Individuen mit erwünschten Eigenschaften aus einer fest vorgegebenen Menge primär nur selektiert, wobei aber neu auftretende Mutationen nicht streng ausgeschlossen sind.

Diese in vitro Selektionsmethode wurde vor allem deshalb ausgewählt, da sie im Vergleich zu anderen Methoden (Peterson et al., 1993a; Ribeiro et al., 1995; Sampson and Saks, 1996) weniger arbeitsaufwendig, technisch einfacher und daher schneller durchzuführen war. Mit ihr konnten bereits funktionale Moleküle aus einer großen Anzahl („Lib B“ mit ca. $10^{7}$ und „Lib C“ mit ca. $10^{10}$ ) verschiedener Varianten der tRNA-ähnlichen Struktur des TYMV isoliert werden (Klug, 2000; Wientges et al., 2000). Experimente zur Selektion 
von tRNA-Varianten waren ebenfalls erfolgreich (persönliche Mitteilung A. Schwienhorst und J. Pütz).

Zur Isolierung effizienter Varianten wurden nur die, unter den vorgegebenen Bedingungen aminoacylierten Moleküle an der $\alpha$-Aminogruppe der gebundenen Aminosäure spezifisch biotinyliert. Auf diese Weise wurden nur aktive Moleküle mit einem Marker versehen. Dieser Marker (Biotin) ermöglichte es, durch seine Affinität zu Streptavidin (kovalent gebunden an magnetischen Kügelchen), die aktiven RNA-Moleküle von der restlichen Population zu separieren. Um anschließend die RNA von den Streptavidin gekoppelten, magnetischen Kügelchen abzulösen und eine neue RNA-Bibliothek herzustellen, wurde eine reverse Transkription, PCR und anschließende T7-Transkription durchgeführt (Punkt 3.1.2.).

Mit der hier angewandten Selektionsmethode wurden pro Zyklus funktionale Varianten 250 fach und mehr gegenüber inaktiven angereichert. Als ,inaktiv“ eingestuft wurden dabei Varianten, die eine etwa 1000fach geringere relative Valylierbarkeit aufwiesen (Pütz et al., 1997; Wientges, 1998).

Begleitende Experimente wiesen außerdem darauf hin, daß von den zur Valylierung eingesetzten 100pmol RNA im Laufe des Gesamtprozesses bis zu 40\% der als aktiv einzustufenden Moleküle verloren werden. Dieser Anteil wurde mit unterschiedlich spezifischen tRNA's und den jeweils zugehörigen Synthetasen ermittelt (Wientges, 1998). Da im Falle der Lib D aber jede Variante bereits in der Initialbibliothek in mehreren hundert Kopien vorlag, sollten Verluste dieser Größenordnung keinen Einfluß auf das Ergebnis einer Selektion haben.

Die eingesetzte Bibliothek Lib D umfaßte $\mathrm{N}=18$ randomisierte Positionen, von denen potentiell jede gleich wahrscheinlich durch eine von 4 Basen besetzt sein konnte. Sie bestand folglich aus $4^{\mathrm{N}}=6,9 \cdot 10^{10}$ möglichen Varianten. In eine Selektionsrunde wurden dabei 100pmol (ca. 6·10 13 ) Moleküle eingesetzt. Jede Variante liegt folglich über 800 mal vor. Sowohl Verluste in der Selektion, als auch das Auftreten unterrepräsentierter Varianten durch ungleichmäßigen Einbau der 4 Nukleotide an den randomisierten Positionen, sollten durch die hohe Kopienanzahl kompensiert werden (Nukleotidverteilung in der Initialbibliothek: $A=29,4 \%, T=29,4 \%, C=16,1 \%, G=24,4 \%$ ).

Im, für die Isolierung aktiver Varianten, wichtigen Schritt der Immobilisierung werden inaktive Varianten durch unspezifische Bindung an die magnetischen Kügelchen nur zu einem Anteil von 0,25\% verschleppt (Pütz et al., 1997). Dies sollte ebenfalls dazu beitragen, daß die möglichen Verluste von aktiven Varianten während der Selektionsrunden das Ergebnis nicht entscheidend beeinflussen.

Bei der Transkription von DNA durch T7-RNA-Polymerase können bei bestimmten Polymerasepräparationen zu einem geringen Anteil Moleküle entstehen, die ein bis zwei zusätzliche Nukleotide am 3'-Ende aufweisen (Milligan et al., 1987; Milligan and Uhlenbeck, 1989b) und die nicht durch Größenausschluß-HPLC entfernt werden können. 
Allerdings wurde während eigener Arbeiten bei keiner Auftragung von Transkriptionsprodukten auf analytische PAA-Gele eine entsprechende Doppelbande festgestellt. Dieses Ergebnis deckt sich mit gleichlautenden Hinweisen in einer früheren Arbeit (Wientges, 1998). Zusätzlich sollten solche Varianten in der Aminoacylierung nicht aktiv sein und würden somit keinen Einfluß auf die Selektion an sich haben.

Insgesamt führt diese Methode einfacher und schneller zum erwünschten Ziel, als die mit ähnlichem Selektionsziel beschriebene Methode von E. Peterson, bei der durch Phenylalanin-spezifische Synthetase (PheRS) tRNA-Varianten aminoacyliert wurden. Zur Separation der aktiven Varianten mußte dann ein zweites Protein (EF-Tu•GTP-Komplexe) eingesetzt werden, wodurch der Arbeitsaufwand und die Fehleranfälligkeit der Methode erhöht wurde (Peterson et al., 1993b).

\subsubsection{Stringenz bestimmende Faktoren}

Das Ziel der in vitro Selektion ist es, durch Anlegen eines durch den Forscher frei wählbaren Selektionsdruckes Individuen mit gewünschten Eigenschaften aus einer Population anzureichern und zu isolieren.

Der Anreicherungsfaktor der hier angewandten Selektionsmethode beträgt unter den publizierten Bedingungen ca. 250 pro Zyklus (Pütz et al., 1997). Wenn man von idealen Bedingungen ausgeht, so würde es 3 bis 4 Runden dauern, bis eine aktive Variante auf Bibliothekstärke angereichert ist (auch mit 40\%igen Verlusten pro Runde). Da aber davon auszugehen ist, daß viele Varianten mäßig aktiv und nur einige wenige hoch aktiv sind, werden sich vermutlich viele verschiedene Individuen anreichern, die z.T. nicht erwünscht sind, wenn die Bedingungen der Selektion (Stringenz) nicht entsprechend gewählt werden. Die Stringenz der ersten Runden darf dabei nicht zu hoch sein, da auch sehr aktive Varianten die gewünschte Funktion in einer zu kurzen Zeitspanne nicht ausüben können und folglich verloren gehen (Green et al., 1991). Ein weiterer Effekt, der durch zu hohen Selektionsdruck verursacht werden kann, ist die Erhöhung des inaktiven Hintergrundes. Durch den Verlust von aktiven Varianten wird ihr Anteil an der Bibliothek verringert, während der Anteil von unspezifisch mitgeschleppten, inaktiven Molekülen in der gleichen Methode immer gleich bleibt (Ellington and Conrad, 1995). Ein zu geringer Selektionsdruck führt dagegen nicht zur ausschließlichen Anreicherung der optimal angepaßten Varianten. Es ist also sinnvoll, die Stringenz des Experimentes rundenweise von gering nach hoch zu steigern.

Durch Variation der Bedingungen im selektionsbestimmenden Schritt der Valylierung kann die Stringenz gut beeinflußt werden (Ellington and Conrad, 1995). Im Experiment wurde durch die Verkürzung der Inkubationszeit der Bibliothek mit der Valyl-tRNASynthetase die Konkurrenz der RNA's um das Enzym gesteigert. Zusätzlich wurde in 
späteren Zyklen die Konzentration der ValRS reduziert, wodurch ebenfalls die Konkurrenz der Varianten gesteigert wurde.

Zur Erhöhung des Selektionsdruckes könnte außerdem die Ionen-Konzentration des Puffers der Aminoacylierung erhöht werden, um negative Ladungen der RNA teilweise zu neutralisieren und damit die Bindung an das Enzym zu erschweren. Ebenfalls denkbar ist die Zugabe von Kompetitoren zum Aminoacylierungsansatz. Die Zugabe von tRNA ${ }^{\text {Val }}$ (aus S. cerevisiae) in geringer molarer Menge, als die der ValRS selbst, würde die Anzahl der Enzym-Moleküle verringern, aber die Aminoacylierung nicht vollständig verhindern (bisher konnten keine Varianten selektiert werden, die effizienter als tRNA ${ }^{\text {Val }}$ valyliert werden). Die Zugabe von Wildtyp-TLS-RNA hätte den Vorteil, daß alle weniger effizienten Varianten verdrängt würden, allerdings wäre dieses Molekül nicht mehr aktiv aus der Population zu entfernen. Dieser Kompetitor könnte allerdings erst dann eingesetzt werden, wenn das Valylierungsplateau der Bibliothek über dem des Wildtyps liegt, da ansonsten die effizienteren Varianten in der Population nicht ausreichend angereichert sein könnten und eventuell verloren gehen würden.

Zusätzlich zum erwünschten Selektionsdruck können in der Methode noch weitere unerwünschte Selektionsdrücke auftreten. In der PCR könnten Varianten bevorzugt werden, die schnell amplifiziert werden und in der Reversen Transkription kann es vorkommen, daß hoch strukturierte RNA's nicht effizient umgesetzt werden (Wientges, 1998). Varianten könnten auch darauf selektiert werden, daß sie effizient an die magnetischen Kügelchen des Immobilisierungsschrittes binden. Um diese Einflüsse zu beherrschen, sollte, wie hier der Fall, der Anreicherungsfaktor im selektiven Schritt ausreichend groß sein, damit der Einfluß der beschriebenen Selektionsdrücke relativiert wird. Im Fall der Bindung an die magnetischen Kügelchen könnte eine „Gegen-Selektion“ die unerwünschten Varianten aussortieren (Ellington and Conrad, 1995; Wientges, 1998).

\subsubsection{Verlauf des Experimentes / Entwicklung der Valylierungsplateaus}

Die RNA-Initialbibliothek, auf die die in vitro Selektionsmethode angewendet werden sollte, mußte über die Generierung einer DNA-Matrize für die anschließende T7Transkription hergestellt werden (Milligan et al., 1987). Eine kommerziell erhaltene, chemisch synthetisierte und in den definierten Positionen randomisierte einzelsträngigeDNA wurde daher mittels Polymerase-Kettenreaktion (Mullis et al., 1986; Mullis and Faloona, 1987; Saiki et al., 1988) modifiziert und vervielfältigt. Da aufgrund der chemischen Synthesemethode (Phosphoramidit-Chemie) DNA-Moleküle mit vertretbaren Ausbeuten nur bis zu einer Länge von etwa 100nt erzeugt werden können (Zon et al., 1985), wurden die fehlenden Nukleotide in der PCR mittels eines Oligonukleotids („Primer“) angefügt. Die Hybridisierungstemperatur der ersten und der nachfolgenden 
Temperaturzyklen des Experimentes war daher verschieden. Sie ist grundsätzlich von der Länge und Sequenz der bindungsfähigen Regionen von Matrize und Primer abhängig.

Die Temperatur, die Menge der Matrize und die Anzahl der Amplifikationsrunden bestimmen dabei die Spezifität der Reaktion (Watson et al., 1993).

In die PCR wurde viel Matrize eingesetzt, um die Diversität der synthetischen Initialbibliothek zu erhalten. Damit stieg aber auch die Möglichkeit zur unspezifischen Hybridisierung von Primern und Matrize (,Kettenamplifikation“) untereinander. Mit der Anwendung einer hohen Hybridisierungstemperatur schon im ersten Zyklus, und wenigen Zyklen insgesamt, sollte eine geringe Spezifität und der unerwünschte Fehlereinbau der Taq-Polymerase (aus Thermus aquaticus; rekombinant hergestellt und ohne Fehlerkorrektur-Aktivität) minimiert werden. Trotzdem ist in den analytischen PAA-Gelen besonders der Eingangs-PCR und geringer auch in mehreren späteren PCR's erkennbar, daß größere Produkte als erwünscht aufgetreten waren. Diese Produkte stellen vermutlich nicht funktionale Moleküle dar, die, falls transkribierbar, durch die nachfolgende Größenausschluß-Gelfiltration aus der Bibliothek entfernt worden sein sollten. In der Aminoacylierung sollten diese Moleküle wegen der unspezifisch rekombinanten Sequenz ebenfalls keine bedeutende Aktivität besitzen. In der Tat wurde in keiner der durchgeführten Sequenzierungen ein vergrößertes Fragment gefunden.

Die Kontamination in der 2. PCR (in Reaktionsansatz und Negativ-Kontrolle) weist auf die hohe Empfindlichkeit der PCR-Methode hin. Potentiell kann schon ein einziges Molekül, das teilweise mit den Nukleinsäuren, die im Reaktionsansatz vorhanden sind, hybridisiert, amplifiziert werden (Watson et al., 1993). Hier zeigte sich, daß eine von außen eingetragene Kontamination in die PCR nicht ,überlebensfähig“ in der Selektion war, da die 3. PCR wieder keine zusätzliche Bande der entsprechenden Größe zeigte. Kritisch wäre nur die Kontamination mit tRNA's, die aber unwahrscheinlich ist.

Ungewöhnlich war das Auftreten eines zusätzlichen PCR-Produktes in der 6. PCR. Neben dem gewünschten Produkt von 112 Basenpaaren trat ein weiteres bei ca. 65 Basenpaaren auf. Eine Kontamination der PCR war hier unwahrscheinlich, da die Negativ-Kontrolle ohne DNA-Zusatz, aber mit den gleichen Primern, kein Produkt ergab. Denkbar ist hier das Auftreten von sogenannten „,selbstsüchtigen-RNA's“ oder „RNA Z“, deren spontanes Evolvieren bereits für verschiedene in vitro Selektionsexperimente berichtet wurde (Mills et al., 1967; Biebricher and Orgel, 1973; Konarska and Sharp, 1989; Konarska and Sharp, 1990; Breaker and Joyce, 1994). Solche RNA's besitzen im Allgemeinen die Eigenschaft, den Selektionsdruck zu umgehen, indem sie statt der gewünschten Funktion allein die Fähigkeit zur schnellen Replikation optimiert haben. Typisch ist dabei die Beibehaltung von Primer-Bindungstellen und die Deletion von ursprünglich funktionstragenden Regionen der Ribonukleinsäure. Sie können sogar alle gewünscht funktionalen Moleküle aus der Population verdrängen (Breaker and Joyce, 1994). Ein Hinweis auf diese Art von 
spontan evolvierender RNA besteht darin, daß das zusätzliche PCR-Produkt nach einer wiederholten Selektionsrunde (ausgehend von der 5. PCR) nicht noch einmal auftrat.

Passend zu dieser Theorie ist bereits im analytischen Gel der zuerst durchgeführten 5. Transkription eine verkürzte RNA-Spezies erkennbar (Abb.: 22, Punkt 3.1.8.).

Bei der Analyse der Transkriptionsprodukte der Bibliotheken der verschiedenen Runden waren vor allem in der 0., 3., 4. RNA-Bibliothek ein bis zwei deutlich größere Banden im Gel sichtbar, als erwartet. Ihre Länge lag bei etwas über 500nt, weshalb man annehmen kann, daß es sich hier um Pentamere der TLS-RNA's (5 - 93nt $=\sim 540 \mathrm{nt})$ handelt. Diese Aggregationen konnten sich bilden, da die analytischen Gele nativ waren und diese zusätzlichen Banden nur bei offensichtlich hoher Konzentration an RNA in der aufgetragenen Lösung sichtbar waren.

Die Stringenz im Experiment wurde grundsätzlich, ähnlich $\mathrm{zu}$ früheren in vitro Selektionen, von Runde zu Runde erhöht (Klug, 2000; Wientges et al., 2000). Eine Ausnahme bildete die 3. Runde, die die gleiche Stringenz wie die 2. Runde aufwies. Aber im Gegensatz zu J. Wientges, der bei Beibehaltung der Stringenz fast keine Effizienzerhöhung seiner Bibliothek beobachtete, ist im vorliegenden Fall die Erhöhung des Plateaus auf etwa das doppelte der Vorgängerbibliothek überraschend.

Die 3. und 4. Bibliothek ist auch die aktivste des gesamten Experimentes. Diese Tatsache würde mit der theoretischen Selektion der aktivsten Varianten nach 3-4 Runden übereinstimmen (siehe Punkt 4.1.3.). Die sequenzierte Stichprobe der 4. Bibliothek zeigt allerdings keine Konsensus-Sequenzen, dagegen aber einen über 50\%igen Anteil von vermutlich nicht aktiven Varianten (die Determinante $\mathrm{A}_{56}$ ist durch eine andere Base ersetzt). Eine Variante ist doppelt vorhanden, dies ist aber eher wahrscheinlich auf die benutzten Klonierungsverfahren zurückzuführen, als auf eine Selektion (diese Variante wurde in der 7. Bibliothek nicht wieder gefunden).

Die Aktivität der Lib D-Population nimmt von der 4. zur 5. Runde ab und steigt dann bis zur 7. Runde wieder an. Dies könnte dadurch verursacht sein, daß die Stringenz der Selektion in der 4./5. Runde zu hoch wurde, in der Folge aktive Varianten in ihrer Anzahl vermindert wurden und sich in Runde 6. und 7. Varianten anreicherten, die primär an einen ungewollten Selektionsdruck angepaßt waren (z.B. Bindung an magnetische Kügelchen (Ellington and Conrad, 1995)). Solche angepaßten Varianten, die eher zufällig auch eine gewisse Valylierungseffizienz besitzen würden, müßten dann in der Sequenzierung der 7. Runde zu Konsensus-Sequenzen führen. Diese traten aber nicht auf.

Die bisher beschriebenen Umstände weisen darauf hin, daß die Selektion nicht erfolgreich war, obwohl die Valylierungsaktivität der Bibliothek bis auf Wildtyp-Niveau gesteigert wurde. Die insgesamt geringe Aktivität der Bibliothek Lib D in allen Selektionsrunden und der Vergleich des Wildtyp-Moleküls in der Länge der Lib D mit dem Wildtyp der Länge der Lib C (85nt, Punkt 3.1.3.) zeigt, daß die Moleküllänge der Lib D offenbar die Valylierungseffizienz beeinflußt hat. 


\subsubsection{Initialbibliothek und selektierte Varianten}

Unter der Prämisse, daß alle möglichen Varianten einer bestimmten Länge im Experiment realisiert werden sollen, sollte die Zahl der randomisierten Positionen der Initialbibliothek die Anzahl 24 nicht überschreiten (Schwienhorst, 1999). Daher wurde eine sogenannte „doped library“ konstruiert, die neben konservierten Molekülregionen randomisierte Bereiche enthielt, die näher untersucht werden sollten (Tomandl et al., 1997). Die Sequenzen der T-Schleife, D-Schleife und der Scharnier-Region waren in der Lib D willkürlich gesetzt. Es sollte beobachtet werden, welche Sequenzen selektiert werden, wenn die Funktion der optimalen Valylierbarkeit allein ausschlaggebend ist.

In einer früheren Selektion hatte man fast nur die Wildtyp-Sequenz in T-Schleife und Scharnier-Region erhalten (Klug, 2000). Die in Lib D randomisierten Regionen sollten kaum Kontakt (nur $\mathrm{U}_{38}$ in der T-Schleife) mit der Valyl-tRNA-Synthetase aus $S$. cerevisiae haben (Florentz and Giegé, 1986). Daher sollten selektierte Sequenzen vor allem strukturerhaltende Wirkung haben. Es ist bekannt, daß die Mutation von $\mathrm{U}_{43}$ nach $\mathrm{C}_{43}$ in der Scharnier-Region die Konformation des Moleküls verändert und die Valylierungseffizienz verringert (Giegé et al., 1990). Außerdem wurde im Jahr 2002 berichtet, daß für die Struktur der TYMV-TLS 2 Basenpaare zwischen T- und D-Schleife $\left(\mathrm{C}_{36}-\mathrm{G}_{75}\right.$ und $\mathrm{G}_{37}-\mathrm{A}_{76}$ oder alternativ in Revertanten $\left.\mathrm{U}_{37}-\mathrm{G}_{76}\right)$ so wichtig sind, daß in vivo keine systemischen Symptome ohne die Anwesenheit dieser Nukleotide in den eingesetzten Varianten auftraten. Diese Interaktionen innerhalb der „Ellbogen-Region“ scheinen auch in tRNA's und vielen TLS anderer Viren konserviert zu sein (de Smit et al., 2002).

Die Sequenzen der 7. Bibliothek zeigen praktisch keine Übereinstimmungen mit oben beschriebenen Nukleotidpositionen. Nur an Position 38 ist ein $U$ in $50 \%$ der Varianten gefunden worden. Diese Varianten besitzen aber gleichzeitig meist kein $\mathrm{A}_{56}$ (Hauptdeterminante für Valylierung (Ebel et al., 1973; Florentz and Giegé, 1986)) und sind sehr wahrscheinlich nicht aktiv.

Bei knapp 50\% der Varianten ist ein $\mathrm{A}_{56}$ vorhanden. Da aber viele dieser und anderer Moleküle der 7. Runde zusätzlich unerwünschte Mutationen tragen und die Nukleotidverteilung sehr der Initialbibliothek entspricht, kann nicht von einer Selektion ausgegangen werden. Die Nukleotidverteilung der 7. Runde ist: $A=28,7 \%, T=33,9 \%$, $\mathrm{C}=14,4 \%, \mathrm{G}=21,5 \%$, die der Initialbibliothek: $\mathrm{A}=29,4 \%, \mathrm{~T}=29,4 \%, \mathrm{C}=16,1 \%, \mathrm{G}=24,4 \%$. Es wurde beobachtet, daß die Länge von $91+2$ nt der Bibliothek sich negativ auf die Valylierungseffizienz auswirkt. Dies ist eine neue Erkenntnis, da bisher nur von unspezifischen Wechselwirkungen in der Nukleotidregion 86-91 berichtet wurde, die keinen bedeutenden Einfluß auf die Valylierung mit ValRS aus Hefe haben (Florentz and Giegé, 1986) oder eher aktivitätsverbessernd wirken sollten (Dreher et al., 1988). Es gibt aber auch Hinweise, daß weniger virale wie artifizielle Nukleotide am 5'-Ende der WTTLS sich günstig auf die Valylierungseffizienz auswirken (Mans et al., 1990). 
Abschließend läßt sich sagen, daß die ausgewählte in vitro Selektionsmethode effizient funktionale Moleküle aus einer RNA-Bibliothek anreichern kann. Es ist aber notwendig, die Bedingungen des Experimentes sorgfältig einzustellen. Im Fall der Bibliothek Lib D war die Valylierungseffizienz der Wildtypsequenz mit entsprechender Länge bereits relativ niedrig. Die Stringenz im Selektionsexperiment sollte daher auch relativ niedrig angesetzt werden. Außerdem sollten alle Lösungen und Enzyme auf Aktivität und Kontaminationsfreiheit getestet werden. Bei Auftreten von „selbstsüchtigen“ RNA's sollten diese sofort entfernt werden, indem die Runde ausgehend von einer nicht betroffenen Bibliothek wiederholt wird.

\subsection{Experimente zur in vitro Replikation}

\subsubsection{Einleitung}

Die Untersuchung von Replikationseigenschaften von TYMV-TLS-Varianten wurde in vitro mittels einer Bestimmung der Effizienz der (-)-Strang Synthese (Transkription) mit viraler RNA-abhängiger RNA-Polymerase durchgeführt.

In den Experimenten sollte vor allem der Einfluß der Valylierungseffizienz verschiedener TLS-Varianten auf die (-)-Strang Synthese bestimmt werden. Außerdem sollte die Transkriptionseffizienz von Varianten bestimmt werden, die in der Sequenz, bzw. Länge der L1-Schleife oder der Sequenz der Anticodon-Schleife voneinander verschieden waren (siehe Punkt 3.2.1./2.).

Es war zunächst beabsichtigt, das Verhalten von 25 nach Fragestellung verschiedenen Varianten in der (-)-Strang Synthese zu beobachten (Endpunktbestimmung). Im Weiteren sollte die valylierte und nicht valylierte Form einzelner Varianten verglichen werden (Bestimmung des zeitlichen Verlaufs der (-)-Strang Synthese). Zuletzt sollte der Effekt verschiedener, zum Experiment zugegebener Substanzen getestet werden, die als Kompetitoren $\mathrm{zu}$ den Varianten wirken könnten und damit Hinweise auf die Substratanforderungen der RdRp ergeben sollten (Endpunktbestimmung).

Der Vergleich unvalylierter Varianten ergab dabei kaum deutliche Hinweise auf Unterschiede in der Transkriptionseffizienz. Ein geringer, effizienzsteigernder Einfluß einer für effiziente Valylierbarkeit bekannten Sequenz in der L1-Schleife (KonsensusSequenz aus der in vitro Selektion Lib B (Wientges et al., 2000)) konnte beobachtet werden. Die Variante 8-40 (4UCC) zeigte dagegen in einem späteren Experiment eine fast doppelt so hohe Transkriptionseffizienz, als bei den anderen Varianten beobachtet.

Im Vergleich der valylierten zu nicht valylierten Varianten zeigte sich allgemein eine leicht reduzierte Effizienz in der (-)-Strang Synthese für valylierte TLS-RNA's. Für die 4 untersuchten Varianten WT, 8-40, WT (C) und 8-40 (4UCC) war dieser Unterschied der Transkriptionseffizienzen aber nicht signifikant. 
Von den als Kompetitoren eingesetzten Substanzen hatte Gesamt-tRNA aus Saccharomyces cerevisiae stark inhibitorischen Effekt in der (-)-Strang Synthese. Zugabe von EF-Tu•GTP zeigte dagegen keinen Effekt, wie auch Puromycin keine Änderung der Transkriptionseffizienz bewirkte.

\subsubsection{Die Methode der in vitro (-)-Strang Synthese}

Die in abgewandelter Form in allen in vitro (-)-Strang Synthesen verwendete Methode (Deiman et al., 1997a) benutzt als aktives Enzym die grob aufgereinigte virale RdRp aus systemisch infizierten Chinakohlblättern (Deiman et al., 1997b).

Diese in vitro Methode der RNA-Synthese wurde ausgewählt, weil sie der in vivo Replikation sehr nahe kommt, während störende Einflüsse, wie sie in Pflanzenzellen durch deren Proteine (z.B. RNasen) auftreten, größtenteils ausgeschlossen werden können. Mit Experimenten in lebenden Zellen kann man dagegen nur die über alle Teilprozesse gemittelte Amplifikationsfähigkeit beobachten.

Vermutlich wird mit der RdRp-Präparation nicht das Gesamt-Enzym der Replikase aufgereinigt, da bei der Verwendung der Enzym-Lösung nur (-)- und keine (+)-Strang Synthese stattfindet (Deiman et al., 1997b). Es wurde bereits vermutet, daß Wirtsproteine, insbesondere eEF1A Bestandteil der Replikase sein könnten (Hall, 1979; Mouchès et al., 1984; Giegé, 1996). EF-Tu, bzw. eEF1A wurde dagegen nicht in der Präparation gefunden (Punkt 3.3.6.). Auch mit einer früheren RdRp-Präparationsmethode wurde kein eEF1A mit aufgereinigt (Joshi et al., 1986; Pulikowska et al., 1988). Der Nachteil dieser RdRpPräparationsmethode zur hier angewandten war, daß sie, trotz der ebenfalls nur partiellen Aufreinigung des Enzyms, sehr zeit- und technikaufwendig durchzuführen gewesen wäre (Mouchès et al., 1974).

Für die hier benutzte Methode muß beachtet werden, daß verschiedene Präparationen zu verschieden aktiven Enzym-Lösungen führen können und die Vergleichbarkeit von entsprechend unterschiedlich behandelten Transkriptionsexperimenten nur über eine jeweils mitgeführte Referenz gegeben ist. Unterschiedliche Präparationen wurden für die Transkription der 25 unvalylierten Varianten (Punkt 4.2.2.) und allen nachfolgenden in vitro Experimenten benutzt.

Die Referenz ( ${ }^{32} \mathrm{P}$-markiertes RNA- oder DNA-Fragment), die nicht durch die virale RdRp erkannt werden konnte, wurde außerdem benötigt, um Verluste des RNA-Produkts während verschiedener Aufreinigungsschritte bestimmen zu können.

Die Benutzung von Mikrococcen Nuklease gewährleistete die Entfernung der mit dem Enzym aufgereinigten, intrinsischen TYMV-RNA. Diese RNA beeinflußte vermutlich die Ergebnisse früherer Experimente, die eine RdRp-Präparation verwendeten, die nach der Methode von Mouchés aufgereinigt worden war (Garbouri-Bouzid et al., 1991; Deiman et al., 1997b). 
Das Antibiotikum Actinomycin D interkaliert in doppelsträngige DNA (Brown et al., 1984) und hemmt dadurch potentiell mitaufgereinigte DNA-abhängige RNA-Polymerasen aus der Pflanze. In vivo Daten zeigten, daß Actinomycin $\mathrm{D}$ die virale RdRp nicht beeinflußt (Mamoun and Bové, 1976; Renaudin and Bove, 1977).

Abschließend betrachtet stellt die hier verwendete Methode der (-)-Strang Synthese das optimale in vitro Experiment für die detaillierte Untersuchung der tRNA-ähnlichen Struktur des TYMV dar. Es war im Labor von Prof. Pleij (Leiden, Niederlande) bereits etabliert.

\subsubsection{Vergleichende in vitro (-)-Strang Synthese der 25 TYMV-TLS-Varianten}

25 verschiedene Varianten wurden nach Erkenntnissen früherer in vitro Selektionen ausgewählt, um verschiedene Fragen (Punkt 3.2.1./2.) beantworten zu können (Klug, 2000; Wientges et al., 2000). Alle Varianten waren in L1- und Anticodon-Schleife vom Wildtyp verschieden (die Wildtypsequenz wurde aber ebenfalls mitgeführt). Die RNA-Varianten wurden in der Länge der selektierten Bibliotheken (Lib B, Lib C) mit 83+2nt konstruiert, da es sich hier um das kleinste noch effizient valylierbare Fragment des TYMV-Genoms handelt (Joshi et al., 1982a) und die RdRp-Präparation diese Länge stabil transkribieren kann (Deiman et al., 1997b). Zusätzlich waren von einigen Varianten dieser Länge die Valylierungseigenschaften bekannt.

Varianten wurden nach deutlich höherer oder geringerer relativer Valylierbarkeit $\left(\mathrm{k}_{\mathrm{cat}} / \mathrm{K}_{\mathrm{M}}\right)$ als der des Wildtyps ausgewählt. Vier Varianten wurden aus bekannten KonsensusSequenzen der auf optimale Valylierbarkeit selektierten Varianten der Bibliothek Lib B oder der entsprechend entgegengesetzten Sequenz konstruiert. Alle anderen Varianten wurden nach Möglichkeit aus Sequenzen konstruiert, die jeweils verschiedenen Molekülen der Lib B entnommen wurden. Ihre Valylierungseffizienz war daher nicht bekannt.

Die Sequenz des Wildtyps ist hier die des australischen „Blue Lake“-Stammes (Keese et al., 1989), die sich von dem in der in vitro Selektion verwendeten in der L1-Schleife (L1 = CUUU, statt L1 = CUCU) unterscheidet (Blok et al., 1987; Morch et al., 1988; Dreher and Bransom, 1992).

Das Ergebnis des Vergleichs der Transkriptionsprodukte der Varianten zeigte, anders als frühere vorläufige Versuche (Klug, 2000), für alle Varianten keine deutlichen Unterschiede. In vivo ermittelte Hinweise auf den Einfluß der Valylierungseffizienz auf die Replikation (Tsai and Dreher, 1991) wurden hier nicht abschließend bestätigt. Nur im Fall der Varianten mit Konsensus-, bzw. Anti-Konsensus-Sequenzen kann ein leichter, positiver Effekt einer Konsensus-Sequenz in der L1-Schleife nachgewiesen werden (Abb.: 31, Punkt 3.2.5.). Es ist dabei wahrscheinlich, daß die Anti-Konsensus-Sequenz negativ auf die Stabilität oder Struktur des Pseudoknotens einwirkt und der Effekt damit nur 
indirekt mit der Aminoacylierungseffzienz zusammenhängt (Deiman et al., 1997a; Deiman et al., 1998).

Insgesamt stimmt dieses Ergebnis mit publizierten Daten überein, wonach die Effizienz der Initiation der (-)-Strang Synthese vor allem vom freien 3'-ACCA-Ende und in geringerem Maße auch von der Stabilität des Pseudoknotens abhängig ist (Singh and Dreher, 1997; Deiman et al., 1998; Singh and Dreher, 1998). Außerdem hatten in vivo durchgeführte Experimente mit chimären TYMV-Genomen 1997 Hinweise ergeben, daß die Valylierung der TLS nicht unbedingt notwendig ist, um noch relativ effizient amplifiziert zu werden (Goodwin et al., 1997).

Zur näheren Untersuchung des Effekts der Valylierungseffizienz, bzw. des Valins am 3'Ende der TLS, sollte nun eine Aminoacylierung der (-)-Strang Synthese vorgeschaltet werden. Es wurde eine Valylierung (mit ValRS aus E. coli) bis zum Plateau durchgeführt, so daß die maximal mögliche Anzahl an RNA's aminoacyliert wurde (Bonnet and Ebel, 1972). Die Reaktionsbedingungen unterschieden sich dabei etwas von bekannten Daten zur Valylierung, es wurden $2,5 \mu \mathrm{M}$ ValRS und $2,6 \mu \mathrm{M}$ RNA bei $30^{\circ} \mathrm{C}$ benutzt $(40 \mathrm{~min}$. Inkubation). Für tRNA ${ }^{\mathrm{Val}}$ aus $S$. cerevisiae konnten unter ähnlichen Bedingungen bereits 90-100\% Valylierung erreicht werden (Giegé et al., 1978). Der bekannte Anteil valylierter TYMV-TLS unter vergleichbaren Bedingungen beträgt ca. $60 \%$ nach $15-20 \mathrm{~min}$. bei $30^{\circ} \mathrm{C}$, $2 \mu \mathrm{M}$ ValRS (E. coli) und ca. 0,2 $\mu \mathrm{M}$ RNA (persönliche Mitteilung S. Barends, Labor Prof. Pleij, Niederlande). Die Wildtyp-TLS wurde mit ValRS aus S. cerevisiae mit 20nM ValRS und $1 \mu \mathrm{M}$ RNA nach $15 \mathrm{~min}$. zu 34\% valyliert (Wientges et al., 2000). Die eigenen Versuche zeigten in guter Übereinstimmung, daß das Valylierungsplateau ohne Zugabe von Replikationsansatz (siehe Punkt 2.2.3.1. und 3.2.6.) bereits nach 20min. erreicht war. Um den Verlust an RNA, Aminosäurebindung und den Einfluß von zugesetzten Substanzen (z.B. Puffer, ValRS) in der Transkription zu minimieren, wurde ein $100 \mu 1$ Valylierungsansatz (Protokoll erhalten durch die Arbeitsgruppe Prof. Pleij, Niederlande) modifiziert und in $20 \mu \mathrm{l}$ benutzt (Punkt 2.2.3.1.). Die Tests zur Valylierung der TYMVTLS und der Stabilität der Esterbindung zwischen Aminosäure und RNA während der anschließenden Transkription verliefen erfolgreich. Der auf $80 \mu \mathrm{l}$ modifizierte Transkriptionsansatz erhöhte sogar noch die Anzahl der aminoacylierten RNA's (Erhöhung des Plateaus). Es erscheint daher möglich, daß die RdRp die aminoacylierte Form der TLS stabilisiert.

Die Produkte der (-)-Strang Synthese durch die RdRp sollten also bei einem ausreichend großen Effekt der Aminoacylierung voneinander unterscheidbar sein.

In den weiteren Experimenten erfolgte eine Konzentration auf 4 Varianten (WT, 8-40, WT (C), 8-40 (4UCC)), die ebenfalls in in vivo Experimente eingesetzt worden waren, damit deren Ergebnisse in vitro und in vivo vergleichbar blieben. 
Die (-)-Strang Synthesen zeigten, daß bei fast allen Varianten die valylierte RNA weniger effizient transkribiert wurde, als die nicht valylierte (nur WT (C) zeigte im Endwert keine Unterschiede). Tatsächlich ist bekannt, daß die valylierte TLS durch eEF1A•GTP gebunden wird (Litvak et al., 1973a) und es wurde vermuted, daß folglich die (-)-Strang Synthese inhibiert wird (Hall, 1979; Dreher, 1999). Es ist nicht auszuschließen, daß geringe Mengen eEF1A•GTP in sehr geringen Mengen mit der RdRp-Präparation aufgereinigt wurden, es konnte in einem Western Blot mit EF-Tu-Antikörpern aber nicht nachgewiesen werden (Punkt 3.3.6.) und auch in der Literatur wurden keine CoAufreinigungen gefunden (Mouchès et al., 1984; Pulikowska et al., 1988).

Das Ergebnis, daß die Valylierung eher negative Auswirkung hat (WT, 8-40, 8-40 (4UCC)) und geringe Valylierungseffizienz kaum Einfluß zeigt (WT(C) ist etwa so effektiv wie 8-40), korreliert nicht mit in vivo Befunden bei ineffizient valylierbaren Varianten, die geringer als der Wildtyp amplifizieren (Tsai and Dreher, 1991; Goodwin et al., 1997).

Nach den ersten (-)-Strang Synthesen mit 25 Varianten war kein Effizienzunterschied zwischen den nicht valylierten Varianten zu erwarten. Es war daher überraschend, daß im Fall der 8-40 (4UCC) nach 60min. Transkription etwa doppelt so viel Produktradioaktivität gefunden wurde, als bei den anderen Varianten. Auch im Ansatz mit teilweise valylierter 8-40 (4UCC) wurde eine $\mathrm{zu}$ den anderen Varianten etwa 50\%ig erhöhte Produktradioaktivität gefunden. Dies kann vermutlich nicht durch die Valylierungseffizienz der Variante verursacht worden sein, da diese in Umsatzgeschwindigkeit und Affinität zum Enzym geringere Werte (relative Valylierungseffizienz ist 5,3x besser als der Wildtyp) aufweist und somit unterhalb der Werte von 8-40 liegt (die relative Valylierungseffizienz ist hier 53x).

Auffällig waren die hohen Nullwerte der ${ }^{32} \mathrm{P}$-Messung, die vom Transkriptionsverlauf abhängen. Die entsprechenden Werte der valylierten Varianten lagen dagegen relativ gut bei Null. Dieser Unterschied deutet auf einen methodisch bedingten Fehler hin. Wenn Nukleotide unspezifisch über ihre Phosphatreste an das im Versuch verwendete Filterpapier binden können, so wäre davon auszugehen, daß im Ansatz mit valylierter RNA mehr solcher Reste vorhanden sind, als im Ansatz mit nicht valylierter. Für die Aminoacylierung wird das zugesetzte ATP zu AMP + PPi umgesetzt, das AMP wird dann durch die Pyruvat-Kinase wieder zu ATP regeneriert. Dadurch sind mehr nicht radioaktive Phosphatreste im Ansatz vorhanden, die unspezifische Bindungsstellen auf den Filterpapier besetzen können und der radioaktive „Hintergrund“ wäre somit geringer. Wenn dies der Fall wäre, so müßte von allen ${ }^{32} \mathrm{P}-$ Werten der nicht valylierten Varianten der gleiche Betrag abgezogen werden, der den Nullwert bei 40min. auf den Wert „Null“ bringt. Dann wäre kaum noch ein Unterschied zwischen den Ansätzen erkennbar, bzw. die valylierten Ansätze wären außer bei 8-40 (4UCC) nicht weniger effizient transkribierbar. 
Abschließend bewertet läßt sich durch dieses Experiment nicht eindeutig zeigen, daß die Valylierung von TLS-Varianten deren Transkriptionseffizienz negativ beeinflußt. Dieses Ergebnis steht im Gegensatz zu in der Literatur beschribenen Befunden, die in vivo eher auf den umgekehrten Effekt hinweisen (Tsai and Dreher, 1991). Selbst wenn man der Hypothese folgt, daß die Valylierung der TLS als Schalter anzusehen ist, der von Transkription auf Translation umschaltet (ähnlich zum Alfalfa Mosaik Virus (Olsthoorn et al., 1999)), würde der negative Effekt in der Transkription nur durch die Bindung von eEF1A•GTP zustandekommen (Dreher, 1999; Filichkin et al., 2000), das, wie in Punkt 3.3.6. beschrieben, im Ansatz aber nicht detektiert werden konnte. Nicht ganz auszuschließen ist allerdings, daß ein noch nicht bekannter Faktor die valylierte TLS bindet und den beobachteten Effekt erzeugt (Giegé, 1996).

Neueste Forschungen zeigten, daß das Valin der TLS in ein Virusprotein eingebaut wird (Barends et al., 2003). Es ist daher möglich, daß die Aminosäure der TLS nicht die Initiation der Transkription, sondern nur die der Translation begünstigt.

Der negative Effekt der Aminoacylierung auf die (-)-Strang Synthese ist, wenn überhaupt signifikant, dann doch relativ gering (nicht mehr als 1,6fach). Er könnte damit erklärt werden, daß die am 3'-Ende der RNA befindliche Aminosäure sterisch die RdRp behindert, die Initiationsregion zu erkennen. Möglicherweise ist dieser Effekt in vivo durch eventuell in der Replikation beteiligte Wirtsproteine (z.B. durch eEF1A oder ein diesen Faktor simulierendes Protein (Giegé, 1996)) nicht ausgeprägt.

Frühere Theorien beschrieben die Möglichkeit, daß eEF1A in der Replikation des TYMV die virus-RNA der RdRp zuführen könnte (Hall, 1979; Dreher et al., 1996; Giegé, 1996). Für den Bakteriophagen $\mathrm{Q} \beta$ ist bekannt, daß EF-Tu, das bakterielle Homolog zu eEF1A, Bestandteil der viralen Replikase ist (Blumenthal and Carmichael, 1979). Damit wäre erklärt, warum die relative Aminoacylierbarkeit der TYMV-TLS wichtig für die Amplifikation des Virus ist (Tsai and Dreher, 1991) und warum andererseits die Identität der Aminosäure keinen Einfluß auf die Replikationseffizienz zu haben scheint (Dreher et al., 1996).

Es stellte sich nun die Frage, wenn im Transkriptionsansatz kein eEF1A vorhanden ist, kann durch Zugabe von eEF1A (bzw. aus technischen Gründen EF-Tu; siehe Punkt 3.2.6.), die (-)-Strang Synthese gesteigert werden? Oder wird sie, wie Hall und Dreher vermuteten, erniedrigt werden (Hall, 1979; Dreher, 1999)?

Sollte EF-Tu keinen Einfluß auf die (-)-Strang Synthese haben, könnte es möglich sein, daß die virale RdRp allein zur effizienten Erkennung von Aminoacylierter TLS-RNA fähig ist. In diesem Fall müßte sie die Aminosäure am RNA-3'-Ende wie eEF1A nur unspezifisch erkennen. Das dies für die virale RdRp vorteilhaft sein kann, ist dadurch zu erklären, daß die TYMV-TLS relativ häufig, z.B. mit Histidin „fehlbeladen“ werden könnte. In vitro Studien haben die effiziente Histidinylierbarkeit von bis zu $25 \%$ der 
eingesetzten 264nt-RNA-Fragmente (vom 3'-Ende des TYMV-Genoms) gezeigt (Rudinger et al., 1992). Puromycin, das das äußerste 3'-Ende einer Tyrosyl-tRNA imitiert (Kawakami et al., 1975), könnte daher durch die Bindungstasche des viralen Enzyms erkannt werden und die (-)-Strang Synthese inhibieren.

Wenn valylierte TLS-RNA direkt durch die RdRp erkannt wird, dann sollte auch valylierte tRNA gebunden werden können. Bekannt ist, daß nicht aminoacylierte, aber modifizierte tRNA $^{\text {Phe }}$ und tRNA ${ }^{\text {His }} /$ tRNA $^{\text {Thr }}$ keine Substrate für die TYMV-RdRp sind (Deiman et al., 1997a; Singh and Dreher, 1997). Interessant ist nun, ob valylierte oder nicht valylierte tRNA besser mit valylierter oder nicht valylierter TLS-RNA um die RdRp konkurrieren kann. Fraglich ist also, ob die Aminosäure am 3'-Ende der RNA's die Bindung an die RdRp verstärkt (mit dem Effekt der Inhibition bei aminoacyl-tRNA und nicht valylierter TLS), bzw. die Transkriptionseffizienz erhöht (keine Inhibition bei aminoacyl-TLS und nicht valylierter tRNA's).

$\mathrm{Zu}$ diesen Fragen wurden (-)-Strang Synthesen mit der Wildtyp-TLS durchgeführt, denen jeweils eine der besprochenen Substanzen zugegeben wurde. In einer Endpunktbestimmung wurden dann die radioaktiven RNA-Produkte relativ zueinander verglichen (Abb.: 35, Punkt 3.2.6.).

Für den Wildtyp ohne Zusatz zeigte sich wiederum kein deutlicher Effizienzunterschied zwischen valylierter und nicht valylierter Form. Die nicht valylierte TLS wurde, wie in den zuvor besprochenen Versuchen zum zeitlichen Verlauf der Transkription, geringfügig effizienter durch die RdRp transkribiert. Mögliche Ursachen wurden bereits oben beschrieben.

Die Zugabe von EF-Tu hatte überraschenderweise ebenfalls keinen deutlichen Effekt in der (-)-Strang Synthese. Dies erscheint ungewöhnlich, da das verwendete EF-Tu aus E. coli unter bestimmten Bedingungen mit der TYMV-TLS interagieren kann (Joshi et al., 1984). Die Beobachtung könnte dadurch begründet sein, daß zu wenig EF-Tu zugegeben wurde, da die Konzentration des Proteins über Gel und Western Blot abgeschätzt worden war. Außerdem sind zwar keine Dissoziationskonstanten bekannt, aber die relative Affinität der TYMV-TLS zu EF-Tu ist ca. 5x geringer, als zu eEF1A (Joshi et al., 1986). Der molare Überschuß von EF-Tu zur valylierten RNA sollte daher idealerweise 10:1 betragen, damit mindestens 50\% der aminoacyl-RNA gebunden werden kann (allerdings ist auch der exakt Anteil der aminoacylierten RNA zur Gesamt-RNA nicht bekannt).

Anzumerken ist aber auch, daß der negative Effekt der Valylierung der TLS in der Transkription umgekehrt wurde. Valylierte Varianten wurden hier leicht bevorzugt transkribiert. Es ist dabei vorstellbar, daß EF-Tu die TLS-RNA gebunden hat und diese sofort bei Kontakt mit der RdRp ,abgibt“". Der Unterschied der Transkriptionsprodukte von valylierter und nicht valylierter TLS ist aber wiederum zu gering, um EF-Tu definitiv in die Replikation mit einordnen zu können. Es erscheint zumindest unwahrscheinlich, daß EF-Tu, bzw. eEF1A als „Schalter“ für die Replikation oder Transkription der RNA dient, 
da es die Translation begünstigt (Barends et al., 2003) und auch in der (-)-Strang Synthese keinen (negativen) Einfluß aufweist. Dies schließt ebenfalls die Möglichkeit aus, die Aminosäure könnte als Markierung der „transkriptionswürdigen“ (+)-Strang-RNA dienen, wie es schon früh vermutet wurde (Litvak et al., 1973a).

Puromycin hat offensichtlich keinen Einfluß auf die Transkriptionseffizienz der WildtypTLS. Dieses Ergebnis zeigt, daß die Binderegion der viralen RdRp keine ausgeprägte Ähnlichkeit zu der von EF-Tu hat. Würde Puromycin grundsätzlich erkannt werden und nur die imitierte Aminoacylierung des Antibiotikums würde die Affinität zur RdRp verringern, so sollte im Ansatz mit valylierter TLS moderate Inhibition sichtbar sein.

Die Zugabe von Gesamt-tRNA, bzw. Gesamt-tRNA mit valylierter tRNA ${ }^{\text {Val }}$ (beide aus $S$. cerevisiae) führte zur deutlichen Inhibition der RdRp. Offensichtlich werden schon unvalylierte tRNA's gut genug gebunden, um die RdRp folglich $\mathrm{zu}$ inhibieren (modifizierte tRNA's sind kein Substrat (Deiman et al., 1997a; Singh and Dreher, 1997)). Andererseits scheint auch valylierte TLS nicht in der Lage die tRNA von der RdRpBindestelle zu verdrängen.

Abschließend können die in vitro Experimente dahingehend zusammengefaßt werden, daß die Valylierungseffizienz, bzw. die Aminosäure selbst keinen positiven und höchstens einen geringfügig negativen Effekt in der (-)-Strang Synthese der viralen RdRp hat.

EF-Tu scheint nur wenig effizienzsteigernd zu wirken, so daß vermutet werden kann, daß er keinen Einfluß in der Replikation besitzt. Allerdings kann wegen der höheren Affinität von eEF1A zur TLS-RNA nicht direkt auf in vivo Bedingungen geschlossen werden.

\subsection{Amplifikation von TYMV-TLS-Varianten in Pflanzenzellen}

\subsubsection{Einleitung}

Die Infektion von Chinakohl-Pflanzen (Brassica pekinensis) sollte es ermöglichen, die Auswirkungen der Valylierungseffizienz im natürlichen „Umfeld“ zu untersuchen. Damit würden auch solche Funktionen der TYMV-TLS beeinflußt werden, die nicht durch die in vitro Experimente berücksichtigt sind. Die Gesamtheit aller Abläufe zur Amplifikation von Virus-Varianten sollte dann über die Symptomentwicklung der infizierten Pflanze und durch das Auftreten von Genom-Revertanten beobachtet werden. Die TLS-Varianten wurden zur Transfektion von Pflanzenzellen in den Kontext des Gesamt-Genoms des TYMV gebracht.

Die Varianten sollten zeigen, in welchem Maße ihre in vitro Valylierungseffizienz und die Länge der L1-Schleife die Amplifikationseffizienz beeinflussen.

Beobachtet wurde die etwa gleich effiziente Amplifikation des Wildtyps und der Variante 8-40 (Abb.: 38, Punkt 3.3.4.). Beide zeigten in vitro relativ gute Valylierungseffizienzen 
(8-40 allerdings 53x besser als WT) und umfassen gleich lange L1-Schleifen. Die Variante WT (C) verursachte fast ausschließlich lokale Symtpome, was mit geringer in vitro Valylierungseffizienz und nur einem Nukleotid in der L1-Schleife einher geht. Es entwickelte sich unabhängig voneinander zweimal die Revertante WT (CC). Die Variante 8-40 (4UCC) konnte die meisten Wirtspflanzen nicht transfizieren. Nur wenige Pflanzen entwickelten lokale oder mit Verzögerung z.T. auch systemische Symptome. Es konnte die Revertante 8-40 (UUU) isoliert werden.

Mit der Transfektion von Protoplasten aus der Ackerschmalwand (Arabidopsis thaliana) wurde ein einfacheres in vivo-System ausgewählt. Aufgrund der in jedem Versuch gleichen Zellzahl konnte hier die relative Virusproduktion der einzelnen Varianten miteinander verglichen werden (Kaper and Litjens, 1966; Schirawski et al., 2000).

Sowohl RNA-, als auch Hüllprotein-Mengen korrelierten gut mit den Symptomentwicklungen in ganzen Pflanzen (Abb.: 40 und 41, Punkt 3.3.5.). Die Variante 8-40 wurde hier tendenziell sogar besser amplifiziert, als der Wildtyp. Die Varianten WT (C) und 8-40 (4UCC) wiesen beide deutlich geringere Werte auf.

Die Ergebnisse zeigten, daß die Valylierungseffizienz der Varianten Einfluß auf ihre Amplifikationseffizienz hat. Die Revertante WT (CC) war deutlich in ihrer Valylierungseffizienz gegenüber WT (C) gesteigert. Die Variante 8-40 (4UCC), die bereits effizienter als der Wildtyp valylierbar ist, führte nur zu einer geringen Verbesserung der Valylierungseffizienz für die Revertante 8-40 (UUU). Vermutlich waren eher sterische Probleme durch die lange L1-Schleife der Grund für das Auftreten der Variante.

\subsubsection{Methoden der Transfektion von Pflanzenzellen}

Die Infektion ganzer Pflanzen ermöglicht es, die Summe aller Abläufe zur Replikation von TYMV-Varianten im Wirt, an der Symptomentwicklung der Pflanze zu beobachten. Das Auftreten von Revertanten gibt weitere Einsichten, welche Anforderungen für eine erfolgreiche Amplifikation an den mutierten Genomteil des Virus gestellt werden.

Es ist bekannt, daß die tRNA-ähnliche Struktur des TYMV mit vielen unterschiedlichen tRNA-spezifischen Proteinen interagieren kann (Litvak et al., 1973a; Litvak et al., 1973b; Prochiantz and Haenni, 1973; Joshi et al., 1986) und es wurde bereits mehrfach vermutet, daß Wirtsproteine Bestandteil der TYMV-Replikase sein könnten (Litvak et al., 1973a; Hall and Wepprich, 1976; Hall, 1979; Joshi et al., 1986). In den in vitro (-)-Strang Synthesen wurde daher vermutlich nur die virale RdRp als ein Bestandteil der Replikase eingesetzt. Zur Zeit ist es also nur in vivo möglich, mit der gesamten TYMV-Replikase Genom-Varianten des Virus replizieren zu lassen.

Ein Nachteil der Pflanzeninfektion ist die fehlende Fokussierungsmöglichkeit auf die Replikation. Auch andere Abläufe, wie Translation oder Verpackungseffizienz der viralen RNA, beeinflussen die Entwicklung von Symptomen an der Pflanze. Das Verhalten von 
Varianten im Wirt kann daher nur indirekt beobachtet werden (über Symptome und Revertanten). Das frühe Auftreten von systemischen Symptomen setzt dabei voraus, daß eine effiziente Replikation der RNA der Virus-Variante stattgefunden haben muß. Das fehlende Auftreten von Symptomen kann dagegen von verschiedenen Faktoren verursacht sein. Bei solchen amplifikationsdefizienten Varianten können aber bevorzugt Revertanten auftreten, die durch geänderte in vitro Eigenschaften Rückschlüsse auf die Ursachen ihrer geringen Infektiösität zulassen.

Von den Kreuzblütlern, die von TYMV infiziert werden können, wurde Chinakohl ausgewählt, da er große Blätter entwickelt, auf denen die Entwicklung von Symptomen gut verfolgt werden kann. Chinakohl ist wenig arbeitsintensiv und wird schon seit langem für TYMV-Infektionen genutzt (Faed and Matthews, 1972). Zusätzlich war die Methode in der Abteilung von Prof. Pleij (Niederlande) gut etabliert (Hellendoorn et al., 1997; Deiman et al., 1998; Barends et al., 2003).

Eine bessere Vergleichbarkeit der Amplifikationseffizienz verschiedener Varianten ermöglicht die Transfektion von Protoplasten. Immer gleiche Zellzahlen können mit annähernd gleichen RNA-Mengen transfiziert werden, wodurch die Virusproduktion von TYMV-Varianten nach entsprechender Inkubation vergleichbar wird. Dieses in vivoSystem stellt eine Vereinfachung dar, da die infizierte Zelle nicht mehr im Kontext der gesamten Pflanze steht, die verschiedene Gewebearten unterschiedlich beeinflussen kann.

Die Flüssig-Zell-Kultur der Ackerschmalwand wurde aus technischen Gründen benutzt. Eine ähnliche Ausprägung der Virusproduktion in den beiden verwendeten Wirtspflanzen des TYMV ist zu erwarten, da beide Pflanzen genetisch relativ nah verwandt sind (Lim et al., 2000; Tiffin and Hahn, 2002).

Jeweils frisch aus Blättern präparierte Protoplasten aus Chinakohl- (Weiland and Dreher, 1989), Raps- (Boyer et al., 1993) und Rübenpflanzen (Weiland and Dreher, 1993) wurden bereits mit TYMV-Virionen und -Genom-Transkripten inokuliert. Die dort verwendeten Protokolle hatten das Problem, daß die Qualität der Protoplasten sehr von Alter und Gesundheit der Ausgangspflanzen abhing, zusätzlich konnte auch die Jahreszeit eine Rolle spielen (Schirawski et al., 2000). Die hier angewandte Methode benutzte dagegen eine etablierte Arabidopsis thaliana-Suspensionskultur (Axelos et al., 1992) als Ausgangsmaterial (fast) immer gleicher Qualität. Die Methode ermöglicht eine schnellere, reproduzierbarere Isolierung von großen Mengen an Protoplasten. Zusätzlich wurde diese Methode bereits auf erfolgreiche Transfektion mit TYMV getestet (Schirawski et al., 2000). 


\subsubsection{Transfektion/Infektion von Brassica pekinensis und Arabidopsis thaliana- Protoplasten durch 4 ausgewählte TYMV-TLS-Varianten}

Der zeitliche und technische Aufwand speziell für Pflanzenexperimente (bis zu 14 Chinakohlpflanzen pro Variante wuchsen für 3 Wochen bis zur Infektion und anschließend wurde die Symptomentwicklung für ca. 4 weitere Wochen beobachtet) schränkte die Anzahl der untersuchbaren Varianten ein. Es wurden 4 TLS-Varianten ausgewählt, deren in vitro Valylierungseffizienz deutlich unterhalb (WT(C); 0,005x), geringfügig oberhalb (8-40 (4UCC); 5x) oder deutlich oberhalb (8-40; 53x) von der des Wildtyps (WT) lag.

Die Variante 8-40 verursachte im Allgemeinen Symptome, die denen des Wildtyps ähnlich sind. Die frühere Entwicklung von Symptomen in den Pflanzen der 3. Generation ist vermutlich darauf zurückzuführen, daß die Pflanzen früher (nach 2 bis 2,5 Wochen nach Keimung) infiziert wurden, als sonst. Pflanzen, die als Positiv-Kontrolle gleichzeitig mit dem Wildtyp-Virus infiziert worden waren, zeigten ebenfalls früher Symptome.

Die Variante 8-40 mit ihrer sehr hohen Valylierungseffizienz scheint in einzelnen Zellen effizienter zu amplifizieren (Ergebnisse der Protoplasten-Infektionen), als der Wildtyp. Sie kann in ganzen Pflanzen aber keine frühere Symptomentwicklung auslösen.

Die hohe Valylierungseffizienz der Variante 8-40 (gemessen mit der ValRS aus der Bäckerhefe (Wientges et al., 2000)) steht in Übereinstimmung mit Erkenntnissen zu Bedingungen hoher Effizienz bei einer pflanzlichen Valyl-tRNA-Synthetase aus Weizenkeim-Extrakt (Dreher et al., 1992; Mans et al., 1992). Hierfür ist außer den Nukleotiden $\mathrm{A}_{56}, \mathrm{C}_{55}$ und $\mathrm{C}_{53}$ der Anticodon-Schleife auch die Struktur und Stabilität des Pseudoknotens der TLS verantwortlich (Mans et al., 1992). Das die Sequenz der L1Schleife dabei geringen Einfluß hat, zeigt sich auch an der geringen Konservierung der L1Schleifen-Sequenzen zwischen verschiedenen tRNA-ähnlichen Strukturen von aminoacylierbaren Pflanzenviren (Mans et al., 1991). Da diese Variante also auch in vivo vermutlich sehr effizient valylierbar ist, dürfte sie auch effizienter mit eEF1A•GTP der Pflanzenzelle interagieren (Litvak et al., 1973a; Joshi et al., 1984; Joshi et al., 1986; Browning, 1996). Die effiziente Valylierbarkeit der TLS könnte so zur Folge haben, daß die Translation des viralen offenen Leserahmens 1 („ORF1“ oder „ORF-206“), der zwei für die Replikation wichtige Proteine codiert (Weiland and Dreher, 1989; Bransom et al., 1996; Prod'homme et al., 2003), stimmuliert wird (Matsuda et al., 2002; Barends et al., 2003). Eventuell wird zur Stimmulierung aber kein Initiations- oder Elongationsfaktor benötigt (Barends et al., 2003). Da die virale Replikase nun früher und in größerer Menge produziert wird, ist erklärbar, warum in Protoplasten, die mit 8-40 transfiziert wurden, teilweise größere Mengen an Virionen gefunden worden sind (im Vergleich zum Wildtyp). Die Tatsache, daß dieser Unterschied in Pflanzen nicht anhand der Symptomentwicklung nachvollzogen werden konnte, wurde vermutlich dadurch verursacht, daß nur die Translation des Polyproteins des ORF1 stimmuliert wurde. Als Folge würde mehr Replikase auch mehr RNA synthetisieren. Während die genomische RNA aber wiederum 
nur zur gesteigerten ORF1-Expression führt und die des „Bewegungsproteins“ („MP“, ORF2) nicht in der gleichen Intensität beeinflußt (Barends et al., 2003), könnte das, über eine subgenomische RNA (693nt) exprimierte (Gargouri et al., 1989; Giegé et al., 1993a), Hüllprotein („CP“, ORF3) trotzdem vermehrt exprimiert werden. Auf diese Weise könnten vollständige Viren in der infizierten Zelle akkumulieren, während die Ausbreitung in der Pflanze normal abläuft. Die eventuell leicht erhöhte Expression des „Bewegungsproteins“ ist dann entweder nicht relevant (zu gering) oder die Bedingungen für eine Ausbreitung über die ganze Pflanze sind bereits für den Wildtyp optimal und können nicht mehr gesteigert werden.

Die Fähigkeit zur vermehrten Replikation könnte außerdem von der (durchschnittlich gleichen) Anzahl und Größe der Chloroplasten in der Zelle abhängen, da in der inneren Chloroplastenmembran, die bei Infektion der Zelle zu kleinen Vesikeln eingestülpt ist, die Replikase des TYMV lokalisiert ist (Garnier and Bové, 1976; Hatta and Matthews, 1976; Prod'homme et al., 2001; Prod'homme et al., 2003) und damit der „Replikationsraum“ beschränkt bleiben würde.

Mit der oben beschriebenen Theorie der differenzierten Expression stimmen Daten von 1992 überein, die aussagen, daß das „Bewegungsprotein“ für die Replikation entbehrlich, für die Etablierung einer systemischen Infektion in Pflanzen aber essentiell notwendig ist (Bozarth et al., 1992). Dieses „Bewegungsprotein“ hat dabei keine Ähnlichkeit zu anderen bekannten oder vermuteten pflanzenviralen Proteinen mit ähnlicher Funktion (Atabekov and Taliansky, 1990). Ein Beispiel eines Pflanzenvirus, dessen Pseudoknoten in der 3'nicht translatierten Region (UTR) in die Amplifikation involviert ist, ist BMV (Brome Mosaic Virus) (Miller et al., 1986; Lahser et al., 1993). Seine TLS kann ebenfalls mit dem Elongationsfaktor 1 aus Weizenkeim interagieren (Bastin and Hall, 1976).

Die Replikation der Variante durch die virale RdRp dürfte wenig verändert sein, da gezeigt werden konnte, daß Valylierung in vitro, auch EF-Tu vermittelt, keine Effizienzsteigerung verursacht. Die Replikation dürfte vor allem von der Stabilität des Pseudoknotens abhängig sein, die durch die L1-Schleife im allgemeinen nicht stärker beeinflußt wird (Van Belkum et al., 1989; Deiman et al., 1997a; Singh and Dreher, 1997; Kolk et al., 1998a; Kolk et al., 1998b).

Die Variante 8-40 mußte unter den beschriebenen Bedingungen keinem extremen Selektionsdruck ausweichen. Daher konnte wohl auch keine Evolution von Revertanten während der 3 Passagen durch Chinakohlpflanzen beobachtet werden.

Die Variante WT (C) hat in Pflanzen kaum zu systemischen Infektionen geführt und auch in Protoplasten wurden nur geringe Virusmengen synthetisiert. Die Valylierungseffizienz dieser Variante war, in vitro gemessen mit der ValRS aus Bäckerhefe (und 85nt-RNA), mit 0,005x bezogen auf den Wildtyp, sehr niedrig (Wientges et al., 2000). 1992 ergab die Messung der gleichen Variante mit der Länge 93nt plus 10 nicht-virale Nukleotide und der 
ValRS aus Weizenkeim dagegen eine leicht erhöhte Effizienz (Mans et al., 1992). Diese Erhöhung der Effizienz erscheint unerwartet, da die deutlich verkürzte L1-Schleife, die durch die große Furche der quasi-kontinuierlichen A-Helix (Puglisi et al., 1990) des Pseudoknotens läuft (genauer: Stamm 2), die Struktur des Akzeptorarms so verdrehen sollte, daß die Affinität zur Synthetase verringert sein müßte. Die Klasse I Valin-tRNASynthetase bindet gegenüber der L1-Schleife in der kleinen Furche, nahe des dann deplazierten 3'-ACCA-Endes (Mans et al., 1992; Kolk et al., 1998b). Der K $\mathrm{M}$-Wert, der die Affinität der TLS zur Synthetase wiedergibt, ist für das Enzym aus der Bäckerhefe

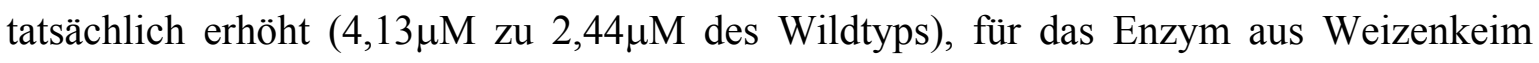

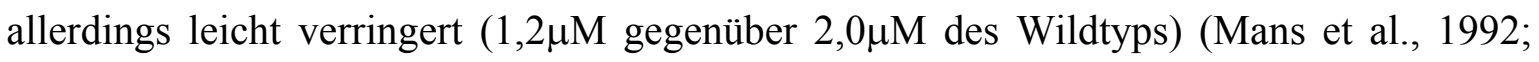
Wientges et al., 2000). Die Deletion des letzten Nukleotids der L1-Schleife (C) verhinderte dann die Aminoacylierung aber vollständig (Mans et al., 1992). In wieweit der $\mathrm{K}_{\mathrm{M}}$-Wert mit Weizenkeim-Synthetase tatsächlich die Realität in vivo wiederspiegelt, kann nicht direkt abgeschätzt werden, da bekannt ist, daß viele nicht virale Nukleotide am 5 '-Ende der TLS (speziell untersucht wurde 5'-GGGAGA-3'), negativen (Mans et al., 1990), aber vielleicht auch positiven Einfluß auf die Aminoacylierung haben können (1992 waren 10nt mit der Sequenz 5'-GGGCGGUACC-3' an die virale RNA angefügt worden) (Dreher et al., 1988). Zusätzlich wurde berichtet, daß Gesamt-tRNA aus Weizenkeim nicht mit der TLS um die TYMV-RdRp kompetitieren kann (Singh and Dreher, 1997). Dagegen kann dies tRNA ${ }^{\text {Phe }}$, tRNA $^{\text {His }}+$ tRNA $^{\text {Thr }}$ (Deiman et al., 1997a; Singh and Dreher, 1997) und Gesamt-tRNA (Punkt 3.2.6.) aus der Bäckerhefe. Dies könnte darauf hinweisen, daß die Valyl-tRNA-Synthetase aus Weizenkeim den Synthetasen der TYMV-Wirtspflanzen nicht so ähnlich ist, wie das Hefe-Enzym.

Während der selbst durchgeführten Infektionen von Chinakohl-Pflanzen evolvierten in der 3. Pflanzengeneration unabhängig voneinander 2 sequenzgleiche Revertanten (WT(CC)), die in der relativen Valylierungseffizienz deutlich (über 200fach) gegenüber der eingesetzten Variante gesteigert waren $\left(\mathrm{k}_{\mathrm{cat}} / \mathrm{K}_{\mathrm{M}}=0,122\right.$ gegenüber 0,0005$)$. Diese Steigerung wurde durch erhöhten Substratumsatz bei erniedrigter Affinität erhalten. Ob die Affinität tatsächlich erniedrigt wurde, ist nicht definitiv zu sagen, da die Variante WT (C) so ineffizient valylierbar ist, daß bereits kleine Meßfehler den Unterschied in der Affinität erzeugt haben könnten. T. Dreher beschreibt 1996 methionylierbare TLS-Varianten, die bei unterschiedlich verkürzter L1-Schleife ihre $\mathrm{K}_{\mathrm{M}}$-Werte nur wenig ändern (Dreher et al., 1996).

Die ausgeprägte Steigerung der Valylierungseffizienz der Variante WT (CC) bis auf das Wildtyp-Niveau deutet darauf hin, daß die Valylierung wichtig für eine effiziente Amplifizierung des TYMV ist.

Diese Beobachtung wäre nach der vorgestellten Theorie damit erklärbar, daß nur eine valylierte TLS effizient mit eEF1A•GTP (Litvak et al., 1973a) oder direkt zur Initiation der Translation mit dem Ribosom interagieren kann. Die Variante WT (C) würde folglich 
nur geringe Mengen an Replikase produzieren können, wodurch die Infektion von Protoplasten und Pflanzen gleichermaßen beeinträchtigt, bzw. verzögert wäre.

Übereinstimmend dazu ist schon mehrfach davon berichtet worden, daß geringe Aminoacylierungseffizienz auch zu geringer Amplifikation führt (Tsai and Dreher, 1991; Dreher et al., 1996). Speziell die Variante WT (C) zeigte bei T. Dreher ähnlich geringe Amplifikationseffizienz. Dort konnten weder Hüllprotein aus Rübenprotoplasten isoliert, noch lokale Symptome an Chinakohlpflanzen beobachtet werden (Dreher et al., 1996).

Die Variante 8-40 (4UCC) verhielt sich in Protoplasten ähnlich gering amplifizierend, wie WT (C). An Brassica pekinensis, der mit der Variante 8-40 (4UCC) infiziert worden war, zeigte sich, wenn überhaupt, sogar eine noch geringere Symptomausprägung.

Die relative Valylierbarkeit dieser Variante ist mit 5x der des Wildtyps allerdings relativ hoch. Dies war nicht unbedingt zu erwarten, da bei R. Mans eine Insertion von 4 AdeninNukleotiden in die L1-Schleife eines 93nt+10 Fragmentes (,i4A“, ansonsten WildtypSequenz) die Reduktion der Valylierungseffizienz auf etwa $60 \%$ des Wildtyps verursachte (Mans et al., 1992). Außerdem ist die längste bisher gefundene L1-Schleife einer valylierbaren tRNA-ähnlichen Struktur eines Virus die 5 Nukleotide umfassende Schleife des Kennedya Yellow Mosaic Virus (KYMV) (Van Belkum et al., 1987; Mans et al., 1991).

Die erhöhte Valylierungseffizienz könnte hier durch eine erhöhte Flexibilität des Akzeptorarmes der TLS für die Erkennung durch die Synthetase entstanden sein.

Da die relativ gute Valylierungseffizienz keinen zusätzlichen Selektionsdruck in dieser Funktion der TLS vermuten läßt, ist der Grund für die schlechte Amplifikation der Variante vermutlich eher in der Struktur und Stabilität des Pseudoknotens zu suchen. Die überlange L1-Schleife kann wahrscheinlich nicht mehr, wie im Wildtyp, in der großen Furche des S2-Stammes des Pseudoknotens „,verstaut“ werden (Mans et al., 1992). Der überhängende Teil der Schleife könnte dann sterisch die Erkennung der Initiationsregion durch die Replikase behindern (Deiman et al., 1997a).

Tatsächlich hat sich in der Revertante 8-40 (UUU) die relative Valylierungseffizienz vor

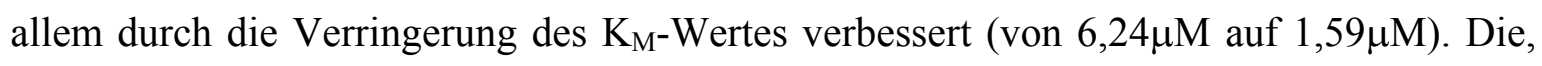
wenn auch geringe, Erhöhung der Valylierungseffizienz könnte entweder andere beeinträchtigte Funktionen kompensieren oder sie ist der Nebeneffekt der Affinitätsverbesserung zu Replikase, Elongationsfaktor oder Ribosom.

\subsubsection{Zusammenfassende Darstellung}

Die TYMV-TLS-Varianten verhielten sich in den in vitro (-)-Strang Synthesen und in den in vivo Transfektionsexperimenten unterschiedlich. Während in vitro die Valylierungseffizienz, bzw. die Valylierung selbst, keine bedeutende Rolle zu spielen 
schien (Punkt 3.3.), war in vivo dagegen die Ausprägung der Virus-Amplifikation durchaus mit der Valylierungseffizienz gekoppelt (Punkt 3.4.). Dies ist vermutlich darauf zurückzuführen, daß die Aminosäure am 3'-Ende nicht effizienzsteigernd auf die RNASynthese, sondern auf die selektive Translationsstimmulierung des Polyprotein-Gens (ORF1) einwirkt (Barends et al., 2003). Die Aminosäure wird dabei N-terminal in das entstehende Protein eingebaut.

Für die effiziente Interaktion der tRNA-ähnlichen Struktur des TYMV mit der viralen RNA-abhängigen RNA-Polymerase ist vor allem das ungepaarte 3`-ACCA-Ende der RNA wichtig (Deiman et al., 1998; Singh and Dreher, 1998). Geringeren Einfluß besitzt die Stabilität des Pseudoknotens der TLS, die in Varianten nicht zu hoch oder niedrig sein sollte (Deiman et al., 1997a; Singh and Dreher, 1997; Singh and Dreher, 1998). Da in den eigenen Varianten nicht die hauptsächlich für die Stabilität verantwortliche Haarnadel I oder II der TLS modifiziert wurde (Kolk et al., 1998a; Kolk et al., 1998b), konnten kaum Unterschiede bei der Transkriptionseffizienz der verschiedenen Moleküle gefunden werden (Punkt 3.3.).

Valylierte TLS konnte nicht mit unvalylierter tRNA um die RdRp kompetitieren (die tRNA wirkte inhibitorisch) und umgekehrt vermochte Puromycin nicht die TLS von der RdRp zu verdrängen (Punkt 3.2.6.). Diese Ergebnisse bestätigen, daß die Valylierung der TLS keinen größeren Einfluß auf die (-)-Strang Synthese und damit vermutlich auch nicht auf die Replikation hat.

Da EF-Tu•GTP nicht mit der RdRp um die TLS kompetitieren konnte, ist anzunehmen, daß dieses Protein weniger Affinität zur TLS besitzt, als die virale RdRp. Daher ist EF-Tu, bzw. eEF1A vermutlich kein „Schalter“ zwischen Replikation und Translation, wie es vermutet worden ist (Dreher, 1999) und würde dann auch nicht den (+)-, vom (-)-Strang der viralen RNA unterscheiden können, wie Litvak postulierte (Litvak et al., 1973a).

Die Effizienzsteigerung der Translation des ORF1 durch die TLS (in Weizenkeim-Lysat) soll, wie S. Barends und B. Kraal beschrieben haben, vor allem durch die Existenz des Anticodon-Arms (Haarnadel III/IV) der TLS und ohne die Anwesenheit von Initiationsfaktoren zustandekommen (Barends et al., 2003). Die Aminosäure am 3'-Ende der TLS würde so direkt die Bindung an das Ribosom begünstigen.

Dagegen wurde beobachtet, daß Weizenkeim eEF1A von der Val-TLS etwa 5x besser gebunden wird, als bakterielles EF-Tu (Joshi et al., 1986), EF-Tu hat dabei keinen Einfluß auf die Replikation (Punkt 3.2.6., Punkt 4.2.3.). Zusätzlich ist die Valylierung aber zumindest zu einem gewissen Grad wichtig für die Amplifikation des Virus (Punkt 3.3., Punkt 4.3.3.; Tsai and Dreher, 1991; Dreher et al., 1996). Eine Funktion der Interaktion der TYMV-TLS mit eEF1A in der Translation erscheint daher trotzdem als möglich.

Abschließend soll noch bemerkt werden, daß die absoluten Werte der durchgeführten Messungen der kinetischen Parameter für die Valylierung der TLS-Varianten (85nt) mit 
einem gewissen Fehler behaftet sind (Dreher and Goodwin, 1998), schon weil eine andere Enzympräparation benutzt wurde (Wientges et al., 2000).

\subsubsection{Ausblick}

Die Ergebnisse der vorliegenden Arbeit und ihre Einordnung in die Literatur lassen die Frage nach der Funktion von eEF1A im Lebenszyklus des TYMV offen. Um dem nachzugehen, könnten in einem ersten Versuch TLS-Varianten hergestellt werden, die nicht mehr von eEF1A gebunden werden, aber noch valyliert werden. Dies erscheint möglich, da relativ viele Mutationen in den Pseudoknoten eingebracht werden können, ohne das die Valylierbarkeit vollständig verloren geht (Mans et al., 1992). Solche Varianten könnten dann vielleicht durch in vitro „Gegen“-Selektion einer teilrandomisierten TLS-Bibliothek auf eEF1A-Bindung, ähnlich wie bei Nazarenko und Hornung, gefunden werden (Nazarenko and Uhlenbeck, 1995; Hornung et al., 1998). Nicht bindende Varianten der Bibliothek könnten dann wiederum in vitro auf effiziente Valylierbarkeit selektiert werden. Wenn Varianten, die auf diese Weise erhalten wurden, in Pflanzenzellen effizient amplifizieren, ist die Bindung an eEF1A vermutlich nicht von Bedeutung und eher Nebeneffekt des tRNA-Mimikry der TLS.

Zusätzlich wäre es sicher interessant, die TYMV-RdRp aus infizierten Pflanzen oder in vitro translatiert (Zagorski et al., 1983) vollständig aufzureinigen, um über ein „TwoHybrid“-System (Fields and Sternglanz, 1994) die Bindungsfähigkeit zu eEF1A zu untersuchen.

Das 5'-Ende des TYMV-Genoms (5'-UTR) weist Haarnadelschleifen auf, die (nur) bei leicht saurem pH der Umgebung virales Hüllprotein binden können (Hellendoorn et al., 1996; Hellendoorn et al., 1997). Es ist bisher nicht bekannt, ob auch die $3^{\prime}$-UTR, die ebenfalls viele Haarnadelschleifen aufweist, Hüllprotein binden kann. Für den Pflanzenvirus BMV konnte gezeigt werden, daß die 3'-tRNA-ähnliche Struktur für die Verpackung des Virus-Genoms essentiell notwendig ist (Choi et al., 2002).

Für den Fall, daß auch bei TYMV die TLS in die Verpackung involviert ist, könnte man untersuchen, ob die Valylierung des Genoms vielleicht als Signal dient, die RNA nicht zu verpacken, sondern $\mathrm{zu}$ replizieren oder zu translatieren. Übereinstimmend dazu fehlt genomischer RNA, die aus Viren aufgereinigt wurde, das 3'-Adenosin-Nukleotid der TLS und ist folglich nicht valyliert (Briand et al., 1977; Silberklang et al., 1977). 


\section{Zusammenfassung}

Die vorliegende Arbeit beschäftigte sich mit dem Zusammenhang zwischen der Valylierung der tRNA-ähnlichen Struktur (TLS) des Rübengelbmosaikvirus (TYMV) und der Replikation, bzw. Amplifikation des Virus. Es wurde der Frage nachgegangen, ob effizient valylierbare TLS-Varianten sich entsprechend effizient in vitro replizieren, bzw. in vivo amplifizieren lassen (und umgekehrt).

In einem ersten in vitro Versuch konnte gezeigt werden, daß zwei 3'-Genom-Fragmente des TYMV (RNA) mit den Längen $83 n t+2 G$ und $91 \mathrm{nt}+2 \mathrm{G}$ unterschiedlich effizient valylierbar sind. Dabei ist das, mit 83nt fast ausschließlich die virale TLS (82nt) umfassende, kürzere Molekül etwa 4x effizienter valylierbar.

Zusätzlich wurden in vitro (-)-Strang Synthesen mit der viralen RNA-abhängigen RNAPolymerase (RdRp) durchgeführt, in die 85 Nukleotide-lange TLS-Varianten mit unterschiedlichen Valylierungseigenschaften eingesetzt worden waren. Sie waren außerdem in Anticodon-Schleife und L1-Schleife verschieden und die Transkriptionseffizienzen wurden in nicht valyliertem und valyliertem Zustand ermittelt. Mit diesen in vitro Experimenten sollte untersucht werden, ob die Länge und Sequenz der beschriebenen Regionen der TLS oder die Valylierungseffizienz (bzw. die Aminosäure am 3 '-Ende) Einfluß auf die (-)-Strang Synthese und damit auch auf die Replikation haben.

Es wurden in vitro keine signifikanten Unterschiede zwischen den untersuchten Varianten gefunden. Diese Ergebnisse stehen in Übereinstimmung mit den bisher bekannten Eigenschaften der RdRp, wonach diese vor allem ein ungepaartes 3'-ACCA-Ende der TLS benötigt (Deiman et al., 1998; Singh and Dreher, 1998).

Auch zugesetztes EF-Tu (E. coli) oder das Antibiotikum Puromycin hatten keinen Einfluß auf die Transkription. EF-Tu scheint also keine Markierungs- $((+) /(-)-S t r a n g)$ oder Schalterfunktion (Transkription/Translation) für TYMV auszuüben.

Mit der Transfektion von Wirtspflanzen (Brassika pekinensis) und Protoplasten (Arabidopsis thaliana), sollte der Frage nachgegangen werden, ob Anticodon- oder L1Schleife oder Valylierungseffizienz der Varianten unter ,naturnäheren“ Bedingungen Einfluß auf die Amplifikation von ganzen Viren nehmen können. Die TLS-Varianten wurden dazu in den Kontext des gesamten TYMV-Genoms gebracht.

Die Ergebnisse zeigten übereinstimmend, daß die Valylierungseffizienz der TLS-Varianten wichtig für die Amplifikationsfähigkeit des TYMV ist. Geringe Valylierungseffizienz führte zu geringer Amplifikation und umgekehrt. Alle isolierten Revertanten besaßen außerdem eine gegenüber dem Ausgangsmolekül gesteigerte relative Valylierungseffizienz. Im Fall der Variante 8-40 (4UCC), die als relativ effizient valylierbar gemessen wurde und trotzdem nur geringe Amplifikationseffizienz zeigte, war vermutlich die Faltung/Konformation der TLS-RNA in der Weise ungünstig beeinflußt, 
daß eine nicht bekannte Funktion (eventuell eine Proteinbindung) nicht mehr optimal ausgeführt werden konnte.

Die in vitro und in vivo erhaltenen Ergebnisse führten $\mathrm{zu}$ der Annahme, daß die Valylierung der TYMV-TLS eher indirekt Einfluß auf die Replikation hat. Vermutlich werden nur Varianten, die in ihrer Struktur nicht allzusehr von der des Wildtyps verschieden sind, effizient repliziert und aminoacyliert. Im valylierten Zustand besitzt die TLS dann direkt effizienzsteigernden Einfluß auf die Translation des viralen PolyproteinGens (ORF1) (Barends et al., 2003). 


\section{Anhang}

Berechnung der Basenverteilung in der Lib D-Initialbibliothek.

Prozentualer Anteil der Basen an ihren definierten Positionen innerhalb der randomisierten Bereiche der Lib D. Berechnungsgrundlage sind die 22 sequenzierten Varianten der Lib DInitialbibliothek. Anhang zu den Ergebnissen unter Punkt 3.1.6.

Tab.: 6
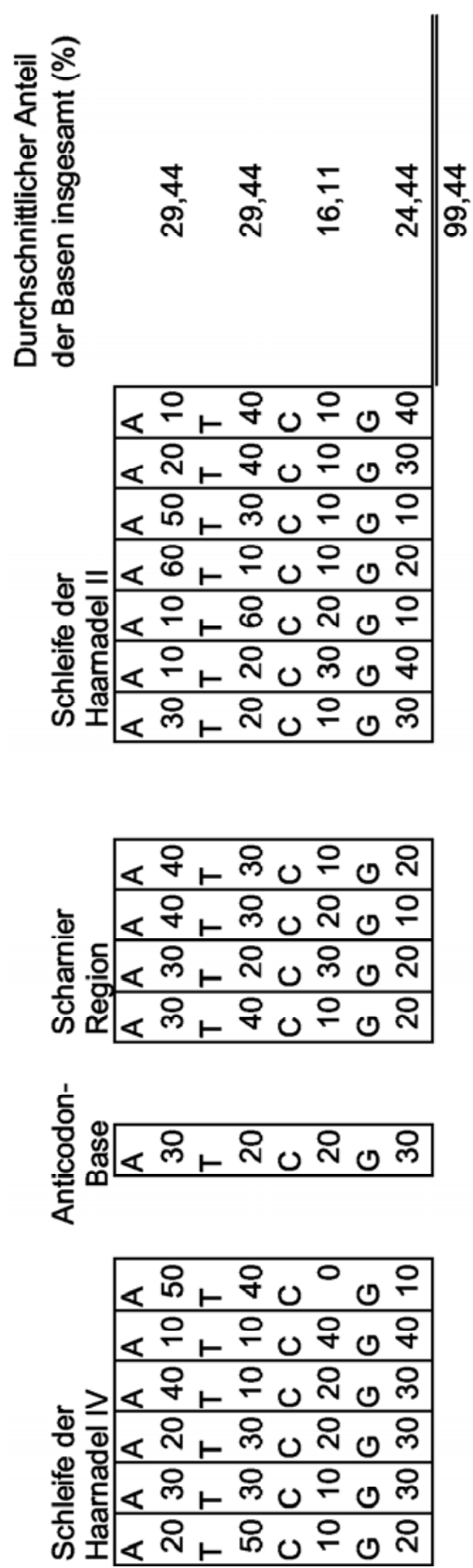


\section{Berechnung des mittleren Paarabstandes der Lib D-Initialbibliothek}

Auflistung der jeweiligen Anzahl der Moleküle mit nicht übereinstimmenden Basen an den gleichen Positionen. Nur die Basen in den randomisierten Bereichen der Lib D wurden zwischen den sequenzierten Molekülen verglichen (Tab.: 7):

\begin{tabular}{|c|c|c|c|c|c|c|c|c|c|c|c|c|c|c|c|c|c|c|c|c|c|c|}
\hline & $0-1$ & $0-3$ & \begin{tabular}{|c|}
$0-6$ \\
\end{tabular} & \begin{tabular}{|l|}
$0-8$ \\
\end{tabular} & $0-10$ & $0-11$ & $0-13$ & $0-14$ & $0-16$ & $0-17$ & $0-18$ & $0-29$ & $0-19$ & $0-20$ & $0-21$ & $0-22$ & $0-23$ & $0-27$ & $0-28$ & $0-15$ & $0-25$ & $0-26$ \\
\hline $0-1$ & - & & & & & & & & & & & & & & & & & & & & & \\
\hline $0-3$ & 13 & - & & & & & & & & & & & & & & & & & & & & \\
\hline $0-6$ & 15 & 11 & - & & & & & & & & & & & & & & & & & & & \\
\hline \begin{tabular}{|l|}
$0-8$ \\
\end{tabular} & 11 & 15 & 16 & - & & & & & & & & & & & & & & & & & & \\
\hline $0-10$ & 15 & 11 & 0 & 16 & - & & & & & & & & & & & & & & & & & \\
\hline $0-11$ & 13 & 13 & 13 & 13 & 13 & - & & & & & & & & & & & & & & & & \\
\hline $0-13$ & 12 & 13 & 17 & 13 & 17 & 15 & - & & & & & & & & & & & & & & & \\
\hline $0-14$ & 13 & 12 & 13 & 13 & 13 & 14 & 9 & - & & & & & & & & & & & & & & \\
\hline $0-16$ & 13 & 13 & 15 & 12 & 15 & 13 & 12 & 13 & - & & & & & & & & & & & & & \\
\hline $0-17$ & 13 & 15 & \begin{tabular}{|l|l}
12 \\
\end{tabular} & \begin{tabular}{|l|}
11 \\
\end{tabular} & 12 & 15 & 11 & 12 & 8 & - & & & & & & & & & & & & \\
\hline $0-18$ & 15 & 13 & \begin{tabular}{|l|}
14 \\
\end{tabular} & \begin{tabular}{|l|}
14 \\
\end{tabular} & 14 & 14 & 15 & 13 & 9 & 11 & - & & & & & & & & & & & \\
\hline $0-29$ & 13 & 14 & \begin{tabular}{|l|}
11 \\
\end{tabular} & 15 & 11 & 16 & 15 & 14 & 11 & 11 & 5 & - & & & & & & & & & & \\
\hline $0-19$ & 15 & 12 & 10 & \begin{tabular}{|l|}
12 \\
12
\end{tabular} & 10 & 10 & 15 & 15 & 13 & 13 & 12 & 11 & - & & & & & & & & & \\
\hline $0-20$ & 12 & 16 & 18 & 12 & 18 & 15 & 10 & 10 & 11 & 12 & 14 & 14 & 15 & - & & & & & & & & \\
\hline $0-21$ & 13 & 13 & \begin{tabular}{|l|}
11 \\
\end{tabular} & 12 & 11 & 16 & 12 & 11 & 11 & 11 & 11 & 13 & 15 & 14 & - & & & & & & & \\
\hline $0-22$ & 12 & 12 & \begin{tabular}{|l|}
11 \\
\end{tabular} & \begin{tabular}{|l|}
14 \\
\end{tabular} & 11 & 11 & 15 & 13 & 16 & 16 & 14 & 15 & 11 & 15 & 13 & - & & & & & & \\
\hline $0-23$ & 12 & \begin{tabular}{|l|}
14 \\
\end{tabular} & 15 & \begin{tabular}{|l|}
13 \\
\end{tabular} & 15 & 17 & 11 & 6 & 10 & 10 & 8 & 9 & 15 & 10 & 8 & 14 & - & & & & & \\
\hline $0-27$ & 15 & 13 & \begin{tabular}{|l|}
13 \\
\end{tabular} & 13 & 13 & 13 & 10 & 10 & 15 & 12 & 14 & 14 & 15 & 12 & \begin{tabular}{|l|}
11 \\
\end{tabular} & 14 & \begin{tabular}{|l|}
10 \\
\end{tabular} & - & & & & \\
\hline $0-28$ & 14 & 16 & \begin{tabular}{|l|}
16 \\
\end{tabular} & 10 & 16 & 13 & 8 & 11 & 12 & 9 & 14 & 15 & 14 & 9 & 15 & 15 & \begin{tabular}{|l|}
12 \\
\end{tabular} & 15 & - & & & \\
\hline $0-15$ & 15 & 13 & \begin{tabular}{|l|}
14 \\
\end{tabular} & \begin{tabular}{|l|}
14 \\
\end{tabular} & 14 & 17 & 13 & 11 & 9 & 10 & 13 & 14 & 14 & 10 & 11 & 16 & \begin{tabular}{|l|}
11 \\
\end{tabular} & 16 & 12 & - & & \\
\hline $0-25$ & 13 & 10 & \begin{tabular}{|l|}
13 \\
\end{tabular} & \begin{tabular}{|l|}
12 \\
12
\end{tabular} & 13 & 12 & 15 & 14 & 14 & 14 & 14 & 15 & 9 & 13 & \begin{tabular}{|l|}
14 \\
\end{tabular} & 14 & \begin{tabular}{|l|}
16 \\
\end{tabular} & 13 & 15 & 12 & - & \\
\hline $0-26$ & 13 & 14 & \begin{tabular}{|l|}
18 \\
\end{tabular} & 12 & 18 & 15 & 11 & 10 & 11 & 13 & 12 & 13 & 15 & 12 & 13 & 14 & \begin{tabular}{|l|}
12 \\
\end{tabular} & 13 & 14 & 13 & 12 & - \\
\hline
\end{tabular}

Summe der unterschiedlichen Positionen:

Summe aller Vergleiche:

Quotient beider Summen, Mittlerer Paarabstand:

12,86

Erwarteter Mittlerer Paarabstand: 
Valylierungskurven und Eadie-Hofstee-Auftragungen zur Berechnung der kinetischen Parameter $k_{\text {cat }}$ und $K_{M}$ der TLS-Varianten 8-40 (4UCC) und WT (CC).

Anhang zu den Ergebnissen unter Punkt 3.4.

Abb.: 47, A, B

A

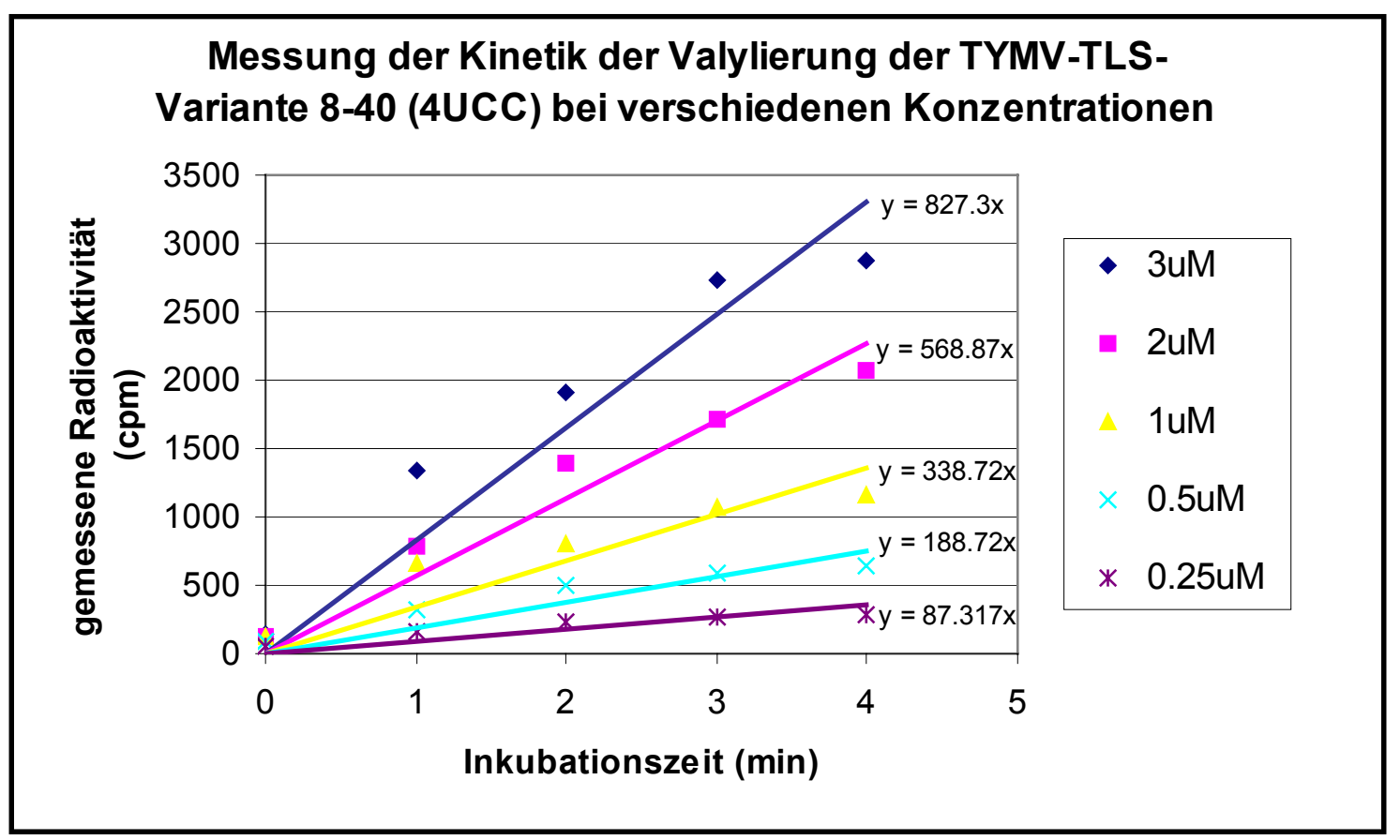

B

Eadie-Hofstee-Auftragung der Daten zur

Valylierung der TLS-Variante 8-40 (4UCC)

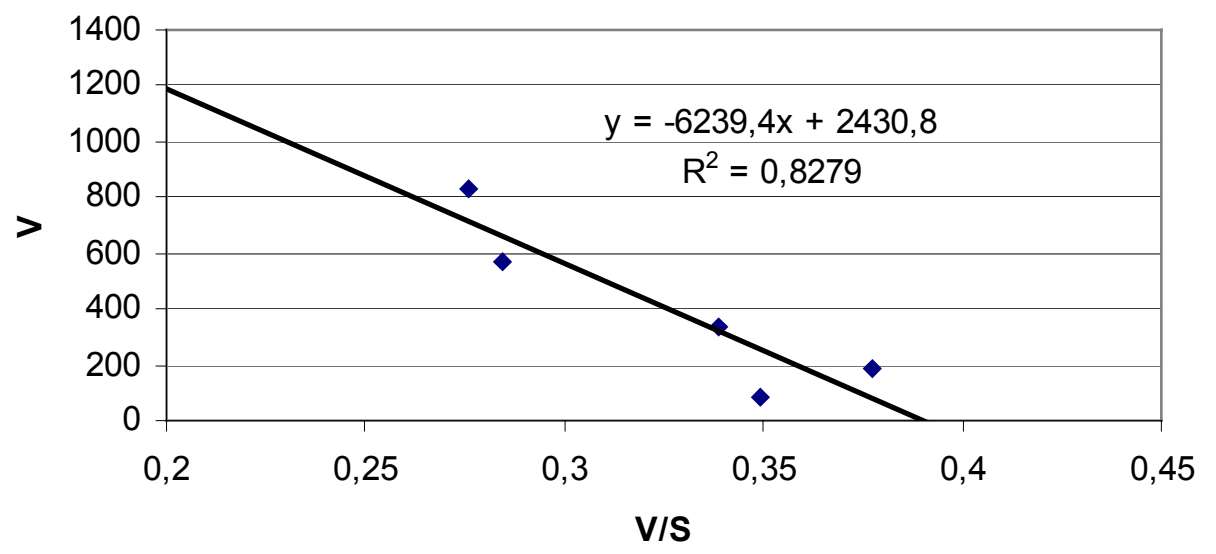


Abb.: 48, A, B

A

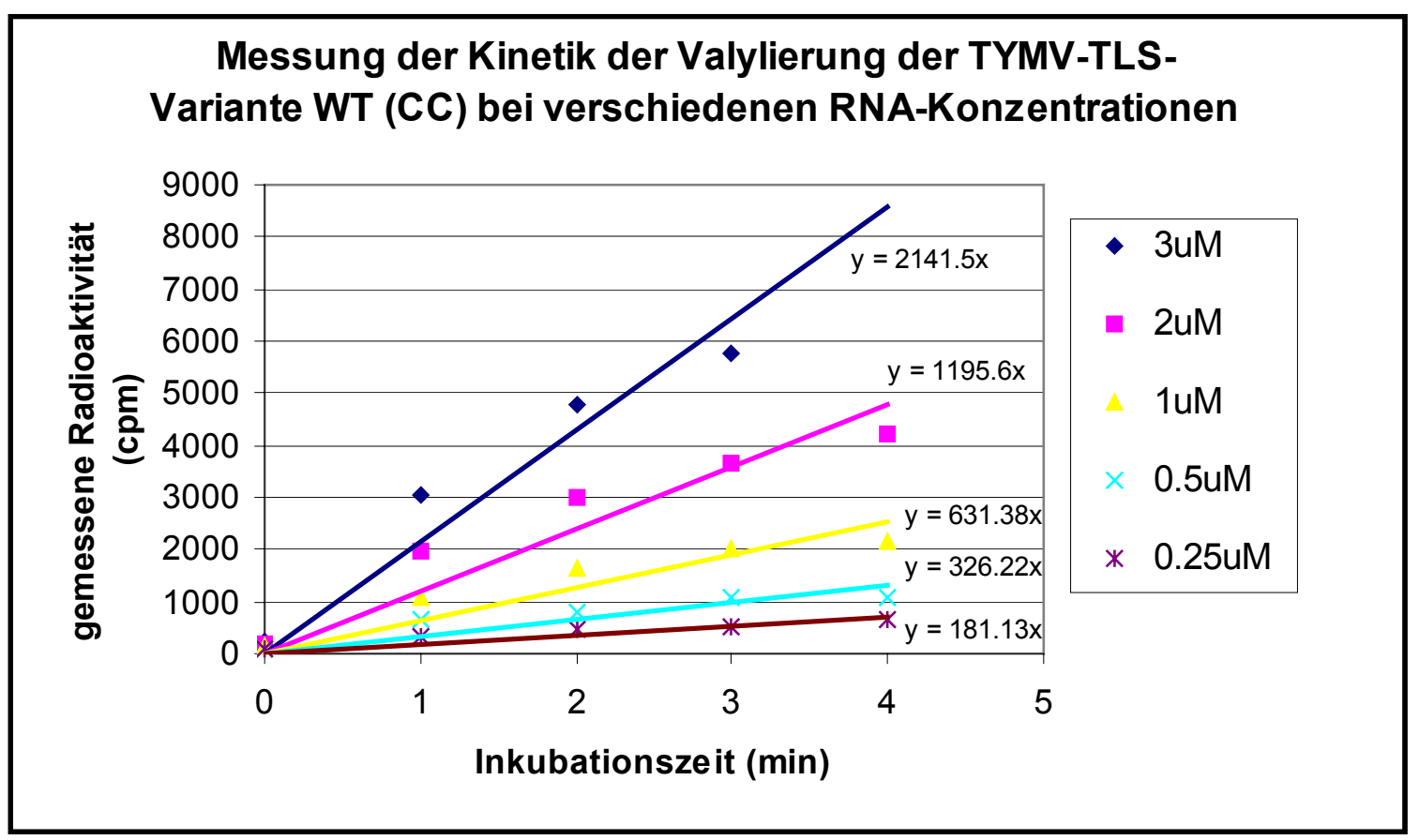

B

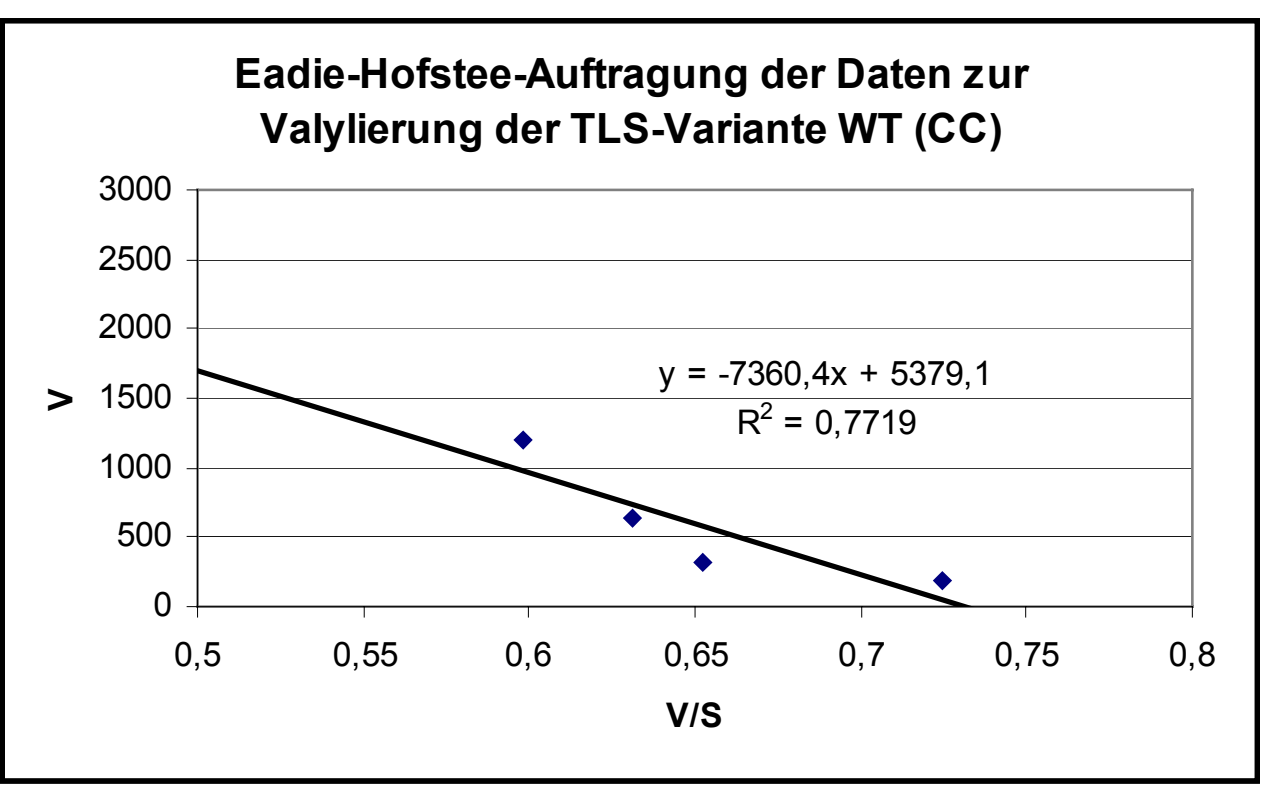




\section{Literaturverzeichnis}

Abrahams, J.P., Van Raaij, M., Ott, G., Kraal, B. and Bosch, L.: Kirromycin drastically reduces the affinity of Escherichia coli elongation factor Tu for aminoacyl-tRNA. Biochemistry 30 (1991) 6705-6710.

Adamiak, R.W. and P., G.: Hypermodified nucleosides of tRNA: synthesis, chemistry, and structural features of biological interest. Prog. Nucl. Acid Res. Mol. Biol. 32 (1985) 27-74.

Adrian, M., Timmins, P.A. and Witz, J.: In vitro decapsidation of turnip yellow mosaic virus investigated by cryo-electron microscopy: a model for the decapsidation of a small isometric virus. J. Gen. Virol. 73 (1992) 2079-2083.

Agranovsky, A.A., Dolya, V.V., Gorbulev, V.G., Kozlov, Y.V. and Atabekov, J.G.: Aminoacylation of barley stripe mosaic virus RNA : polyadenylate containing RNA has a 3' terminal tyrosine accepting structure. Virology 113 (1981) 174-187.

Ames, B.N., Tsang, T.H., Buck, M. and Christman, M.F.: The leader mRNA of the histidine attenuator region resembles tRNAHis; possible general regulatory implications. PNAS 80 (1983) 5240-5242.

Anborgh, P.H. and Parmeggiani, A.: New antibiotic that acts specifically on the GTPbound form of elongation factor Tu. EMBO J. 10 (1991) 779-784.

Arai, K., Kawakita, M., Kaziro, Y., Kondo, T. and Ui, N.: Studies on the polypeptide elongation factors from E. coli. 3. Molecular characteristics of EF-Tu-guanosine diphosphate, EP-Ts, and EF-Tu-Ts complex. J. Biochem. (Tokyo) 73 (1973) 1095 1105.

Arai, K.I., Kawakita, M. and Kaziro, Y.: Studies on polypeptide elongation factors from Escherichia coli. II. Purification of factors Tu-guanosine diphosphate, Ts, and TuTs, and crystallization of Tu-guanosine diphosphate and Tu-Ts. J. Biol. Chem. 247 (1972) 7029-7037.

Arcari, P. and Browlee, G.G.: The nucleotide sequence of a small (3S) seryl-tRNA (anticodon GCU) from beef heart mitochondria. Nucl. Acids Res. 8 (1980) 52075212.

Arnez, J.G. and Moras, D.: Structural and functional considerations of the aminoacylation reaction. TIBS 22 (1997) 211-216.

Atabekov, J.G. and Taliansky, M.E.: Expression of a plant virus-coded transport function by different viral genomes. Adv. Virus Res. 38 (1990) 201-248.

Axelos, M., Bardet, C., Liboz, T., Le Van Thai, A., Curie, C. and Lescure, B.: The gene family encoding the Arabidopsis thaliana translation elongation factor EF-1 alpha: molecular cloning, characterization and expression. Mol. Gen. Genet. 219 (1989) 106-112. 
Axelos, M., Curie, C., Mazzolini, L., Bardet, C. and Lescure, B.: A protocol for transient gene expression in Arabidopsis thaliana protoplasts isolated from cell suspension cultures. Plant. Physiol. Biochem. 30 (1992) 123-128.

Barat, C., Lullien, V., Schatz, O., Keith, G., Nugeyre, M.T., Grüninger-Leitch, F., BarréSinoussi, F., LeGrice, S.F.J. and Darlix, J.-L.: HIV-1 reverse transcriptase specifically interacts with the anticodon domain of its cognate primer tRNA. EMBO J. 8 (1989) 3279-3284.

Barends, S., Bink, H.H.J., van den Worm, S.H.E., Pleij, C.W.A. and Kraal, B.: Entrapping Ribosomes for Viral Translation: tRNA Mimicry as a Molecular Trojan Horse. Cell 112 (2003) 123-129.

Bastin, M. and Hall, T.C.: Interaction of elongation factor 1 with aminoacylated brome mosaic virus and tRNA's. J. Virol. 20 (1976) 117-122.

Beachy, R.N., Zaitlin, M., Bruening, G. and Israel, H.W.: A genetic map for the cowpea strain of TMV. Virology 73 (1976) 498-507.

Becker, H.F., Motorin, Y., Florentz, C., Giegé, R. and Grosjean, H.: Pseudouridine and ribothymidine formation in the tRNA-like domain of turnip yellow mosaic virus RNA. Nucl. Acids. Res. 26 (1998) 3991-3997.

Beer, S.V. and Kosuge, T.: Spermidine and spermine--polyamine components of turnip yellow mosaic virus. Virology 40 (1970) 930-938.

Beljanski, M.: L'ARN isolé du virus de la mosaïque jaune du navet accepteur des L-acides aminés en présence d'enzymes bactériens. Bull. Soc. Chim. Biol. 47 (1965) 16451652.

Biebricher, C.K. and Orgel, L.E.: An RNA that multiplies indefinitely with DNAdependent RNA polymerase: selection from a random copolymer. Proc. Natl. Acad. Sci. USA 70 (1973) 934-938.

Bink, H.H., Schirawski, J., Haenni, A.L. and Pleij, C.W.: The 5'-proximal hairpin of turnip yellow mosaic virus RNA: its role in translation and encapsidation. J. Virol. 77 (2003) 7452-7458.

Bishop, J.M.: Retroviruses. Ann. Rev. Biochem. 47 (1978) 35-88.

Björk, G.R.: The role of modified nucleosides in tRNA interactions. In: Hatfield, D.L., Lee, B.J. and Pirtle, R.M. (Eds.), Transfer RNA in Protein Synthesis. CRC Press., Boca Raton, 1992, pp. 23-85.

Björk, G.R., Ericson, J.U., Gustafsson, C.E.D., Hagervall, T.G., Jönsson, Y.H. and Wikström, P.M.: Transfer RNA modification. Annu. Rev. Biochem. 56 (1987) 263287.

Blok, J., Mackenzie, A., Guy, P. and Gibbs, A.: Nucleotide sequence comparisons of turnip yellow mosaic virus isolates from Australia and Europe. Arch. Virol. 97 (1987) 283-295. 
Blumenthal, T.: The Enzymes. In: In Boyer, H. (Ed.). Academic Press, NY, 1982, pp. $267-$ 279.

Blumenthal, T. and Carmichael, G.G.: RNA replication: function and structure of Qbreplicase. Ann. Rev. Biochem. 48 (1979) 525-548.

Blumenthal, T., Landers, T.A. and Weber, K.: Bacteriophage Q $\beta$ replicase contains the protein biosynthesis elongation factors EF Tu and EF Ts. PNAS 69 (1972) 13131317.

Bonnet, J. and Ebel, J.P.: Interpretation of incomplete reactions in tRNA aminoacylation. Aminoacylation of yeast tRNAValII with yeast valyl-tRNA synthetase. Eur. J. Biochem. 31 (1972) 335-344.

Boyer, J.C., Zaccomer, B. and Haenni, A.-L.: Electro-transfection of turnip yellow mosaic virus RNA into Brassica leaf protoplasts and detection of viral RNA products with a non radioactive probe. J. Gen. Virol. 74 (1993) 1911-1917.

Bozarth, C.S., John, J.W. and Dreher, T.W.: Expression of ORF-69 of turnip yellow mosaic virus is necessary for viral spread in plants. Virology 187 (1992) 124-130.

Bransom, K.L., Wallace, S.E. and Dreher, T.W.: Identification of the cleavage site recognized by the turnip yellow mosaic virus protease. Virology 217 (1996) 404406.

Bransom, K.L., Weiland, J.J. and Dreher, T.W.: Proteolytic maturation of the 206-kDa nonstructural protein encoded by turnip yellow mosaic virus RNA. Virology 184 (1991) 351-358.

Breaker, R.R. and Joyce, G.F.: Emergence of a replicating species from an in vitro RNA evolution reaction. Proc. Natl. Acad. Sci. USA 91 (1994) 6093-6097.

Briand, J.P., Bouley, J.P., Jonard, G., Witz, J. and Hirth, L.: Low pH RNA-protein interactions in turnip yellow mosaic virus. II. Binding of synthetic polynucleotides of TYMV capsids and RNA. Virology 63 (1975) 304-311.

Briand, J.P., Jonard, G., Guilley, H., Richards, K. and Hirth, L.: Nucleotide sequence $(n=159)$ of the amino-acid-accepting 3'-OH extremity of turnip-yellow-mosaicvirus RNA and the last portion of its coat-protein cistron. EJB 72 (1977) 453-463.

Brown, S.C., Mullis, K., Levenson, C. and Shafer, R.H.: Aqueous solution structure of an intercalated actinomycin D-dATGCAT complex by two-dimensional and onedimensional proton NMR. Biochemistry 23 (1984) 403-408.

Browning, K.S.: The plant translational apparatus. Plant Mol. Biol. 32 (1996) 107-144.

Canady, M.A., Larson, S.B., Day, J. and McPherson, A.: Crystal structure of turnip yellow mosaic virus. nat. struct. biol. 3 (1996) 771-781.

Candresse, T., Mouches, C. and Bové, J.M.: Characterization of the virus encoded subunit of turnip yellow mosaic virus RNA replicase. Virology 152 (1986) 322-330. 
Chapeville, F., Lipman, F., Ehrenstein, G.V., Weisblum, B., Ray, W.H. and Benzer, S.: On the role of soluble ribonucleic acid in coding for amino acids. PNAS 48 (1962) 1086-1092.

Chapman, M.R. and Kao, C.C.: A minimal RNA promotor for minus-strand RNA synthesis by the brome mosaic virus polymerase complex. J. Mol. Biol. 286 (1999) 709-720.

Choi, Y.G., Dreher, T.W. and Rao, A.L.N.: tRNA elements mediate the assembly of an icosahedral RNA virus. Proc. Natl. Acad. Sci. USA 99 (2002) 655-660.

Crick, F.H.C.: On degenerate templates and the adaptor hypothesis: A note for the RNA tie club; cité par M. B. Hoagland (1960). In: Chargaff, E. and Davidson, J.N. (Eds.), The Nucleic Acids. Academic Press, New York, 1955, pp. 349.

Crothers, D.M., Seno, T. and D. G. Söll: Is there a discriminator site in transfer RNA? Proc. Natl. Acad. Sci. 69 (1972) 3063-3067.

Cusack, S., Yaremchuk, A., Krikliviy, I. and Tukalo, M.: tRNA(Pro) anticodon recognition by Thermus thermophilus prolyl-tRNA synthetase. Structure 6 (1998) 101-108.

Cusack, S., Yaremchuk, A. and Tukalo, M.: The crystal structure of T. thermophilus lysyltRNA synthetase complexed with E. coli tRNA(Lys) and a T. thermophilus tRNA(Lys) transcript: anticodon recognition and conformational changes upon binding of a lysyl-adenylate analogue. EMBO J. 15 (1996) 6321-6334.

Dardel, F., Panvert, M. and Fayat, G.: Transcription and regulation of expression of the Escherichia coli methionyl-tRNA synthetase gene. Mol. Gen. Genet. 223 (1990) 121-133.

de Bruijn, M.H.L. and Klug, A.: A model for the tertiary structure of mammalian mitochondrial transfer RNAs lacking the entire 'dihydrouridine' loop and stem. EMBO J. 2 (1983) 1309-1321.

de Duve, C.: The second genetic code. Nature 333 (1988) 117-118.

de Smit, M.H., Gultyaev, A.P., Hilge, M., Bink, H.H., Barends, S., Kraal, B. and Pleij, C.W.A.: Structural variation and functional importance of a D-loop-T-loop interaction in valine-accepting tRNA-like structures of plant viral RNAs. Nucl. Acids Res. 30 (2002) 4232-4240.

Deiman, B.A.L.M., Koenen, A.K., Verlaan, P.W.G. and Pleij, C.W.A.: Minimal template requirements for initiation of minus-strand synthesis in vitro by the RNA-dependent RNA polymerase of turnip yellow mosaic virus. J. Virol. 72 (1998) 3965-3972.

Deiman, B.A.L.M., Kortlever, R.M. and Pleij, C.W.A.: The role of the pseudoknot at the 3' end of turnip yellow mosaic virus RNA in minus-strand synthesis by the viral RNA-dependent RNA polymerase. J. Virol. 71 (1997a) 5990-5996.

Deiman, B.A.L.M., Séron, K., Jaspars, E.M.J. and Pleij, C.W.A.: Efficient transcription of the tRNA-like structure of turnip yellow mosaic virus by a template-dependent and 
specific viral RNA polymerase obtained by a new procedure. J. Virol. Meth. 64 (1997b) 181-195.

Derrick, W.B. and Horowitz, J.: Probing structural differences between native and in vitro transcribed Escherichia coli valine transfer RNA: evidence for stable base modification-dependent conformers. Nucleic Acids Research 21 (1993) 4948-4953.

Dirheimer, G., Keith, G., Dumas, P. and Westhof, E.: . In: Söll, D. and RajBhandary, U. (Eds.), tRNA structure, biosynthesis and function. ASM press, Washington DC., 1995, pp. 93-126.

Dreher, T.C. and Bransom, K.L.: Genomic RNA sequence of turnip yellow mosaic virus isolate TYMC, a cDNA-based clone with verified infectivity. Plant Molecular Biology 18 (1992) 403-406.

Dreher, T.W.: Functions of the $3^{\prime}$-untranslated regions of positive strand RNA viral genoms. Annu. Rev. Phytopathol. 37 (1999) 151-174.

Dreher, T.W., Florentz, C. and Giegé, R.: Valylation of tRNA-like transcripts from cloned cDNA of turnip yellow mosaic virus RNA demonstrate that the L-shaped region at the 3'-end of the viral RNA is not sufficient for optimal aminoacylation. Biochimie 70 (1988) 1719-1727.

Dreher, T.W. and Goodwin, J.B.: Transfer RNA mimicry among tymoviral genomic RNAs ranges from highly efficient to vestigial. Nucleic Acids Res. 26 (1998) 4356-4364.

Dreher, T.W., Tsai, C.-H., Florentz, C. and Giegé, R.: Specific valylation of turnip yellow mosaic virus RNA by wheat germ valyl-tRNA synthetase is determined by three anticodon loop nucleotides. Biochemistry 31 (1992) 9183-9189.

Dreher, T.W., Tsai, C.-H. and Skuzesi, J.M.: Aminoacylation identity switch of turnip yellow mosaic virus RNA from valine to methionine results in an infectious virus. PNAS 93 (1996) 12212-12216.

Dugaiczyk, A., Boyer, H.W. and Goodman, H.M.: Ligation of EcoRI endonucleasegenerated DNA fragments into linear and circular structures. JMB 96 (1975) 171184.

Dunn, D.B. and Hitchborn, J.H.: The use of bentonite in the purification of plant viruses. Virol. 25 (1965) 171-192.

Eadie, G.S.: The Inhibition of Cholinesterase by Physostigmine and Prostigmine. J. Biol. Chem. 146 (1942) 85.

Ebel, J.P., Giegé, R., Bonnet, J., Kern, D., Befort, N., Bollack, C., Fasiolo, F., Gangloff, J. and Dirheimer, G.: Factors determining the specificity of the tRNA aminoacylation reaction. Biochimie 55 (1973) 547-557.

Eigen, M.: New concepts for dealing with the evolution of nucleic acids. Cold Spring Harb. Symp. Quant. Biol. 52 (1987) 307-320. 
Eigner, E.A. and Loftfield, R.B.: Kinetic techniques for the investigation of amino acid: tRNA ligases (aminoacyl-tRNA synthetases, amino acid activating enzymes). Methods Enzymol. 29 (1974) 601-619.

Ellington, A.D. and Conrad, R.: Aptamers as potential nucleic acid pharmaceuticals. Biotechnol. Ann. Rev. 1 (1995) 185-214.

Eriani, G., Delarue, M., Poch, O., Gangloff, J. and Moras, D.: Partition of tRNA synthetases into two classes based on mutually exclusive sets of sequence motifs. Nature 347 (1990) 203-206.

Faed, E.M. and Matthews, R.E.: Leaf ontogeny and virus replication in Brassica pekinensis infected with turnip yellow mosaic virus. Virology 48 (1972) 546-554.

Favorova, O.O., Fasiolo, F., Keith, G., Vassilenko, S.K. and Ebel, J.P.: Partial digestion of tRNA-aminoacyl-tRNA synthetase complexes with cobra venom ribonuclease. Biochemistry 20 (1981) 1006-1010.

Fechter, P., Rudinger-Thirion, J., Florentz, C. and Giegé, R.: Novel features in the tRNAlike world of plant viral RNAs. Cell. Mol. Life Sci. 58 (2001) 1547-1561.

Felden, B., Himeno, H., Muto, A., McCutcheon, J.P., Atkins, J.F. and Gesteland, R.F.: Probing the structure of the Escherichia coli 10Sa RNA (tmRNA). RNA 3 (1997) 89-103.

Fersht, A.: Enzyme, Structure and Mechanism., new edition ed. W. H. Freeman and Company, New York, 1985.

Fields, S. and Sternglanz, R.: The two-hybrid system: an assay for protein-protein interactions. Trends Genet. 10 (1994) 286-292.

Filichkin, S.A., Bransom, K.L., Goodwin, J.B. and Dreher, T.W.: The infectivities of turnip yellow mosaic virus genomes with altered tRNA mimicry are not dependent on compensating mutations in the viral replication protein. J. Virol. 74 (2000) 8368-8375.

Flint, J.: Molecular biology of animal viruses. Cell 8 (1976) 151-162.

Florentz, C., Briand, J.-P. and Giegé, R.: Possible functional role of viral tRNA-like structures. FEBS Lett. 176 (1984) 295-300.

Florentz, C., Dreher, T.W., Rudinger, J. and Giegé, R.: Specific valylation identity of turnip yellow mosaic virus RNA by yeast valyl-tRNA synthetase is directed by the anticodon in a kinetic rather than affinity-based discrimination. Eur. J. Biochem. 195 (1991) 229-234.

Florentz, C. and Giegé, R.: Contact areas of the turnip yellow mosaic virus tRNA-like structure interacting with yeast valyl-tRNA synthetase. JMB 191 (1986) 117-130.

Florentz, C. and Giegé, R.: tRNA-like structures in plant viral RNAs. In: Söll, D. and RajBhandary, U. (Eds.), tRNA: Structure, Biosynthesis, and Function. American Society for Microbiology, Washington, 1995, pp. 141-163. 
Forster, C., Limmer, S., Zeidler, W. and Sprinzl, M.: Effector region of the translation elongation factor EF-Tu.GTP complex stabilizes an orthoester acid intermediate structure of aminoacyl-tRNA in a ternary complex. Proc. Natl. Acad. Sci. (USA) 91 (1994) 4254-4257.

Francklyn, C., Musier-Forsyth, K. and Martinis, S.A.: Aminoacyl-tRNA synthetases in biology and desease: new evidence for structural and functional deversity in an ancient family of enzymes. RNA 3 (1997) 954-960.

Francklyn, C., Shi, J.P. and Schimmel, P.: Overlapping nucleotide determinants for specific aminoacylation of RNA microhelices. Science 255 (1992) 1121-1125.

Freist, W.: Mechanisms of aminoacyl-tRNA synthetases: A critical consideration of recent results. Biochemistry 28 (1989) 6787-6795.

Fukai, S., Nureki, O., Sekine, S., Shimada, A., Tao, J., Vassylyev, D.G. and Yokoyama, S.: Structural basis for double-sieve discrimination of L-valine from L-isoleucine and L-threonine by the complex of tRNA(Val) and valyl-tRNA synthetase. Cell 103 (2000) 793-803.

Garbouri-Bouzid, R., David, C. and Haenni, H.L.: The 3' promotor region involved in RNA synthesis directed by turnip yellow mosaic virus genome in vitro. FEBS Lett. 294 (1991) 56-58.

Gargouri, R., Joshi, R.L., Bol, J.F., Astier-Manifacier, S. and Haenni, A.L.: Mechanism of synthesis of turnip yellow mosaic virus coat protein subgenomic RNA in vivo. Virol. 171 (1989) 386-393.

Garnier, M. and Bové, J.M.: Autoradiographical studies on RNA synthesis in healthy and TYMV infected Cinese cabbage: effect of actinomycin D. Ann. Microbiol. 127A (1976) 69-73.

Giegé, R.: Interplay of tRNA-like structures from plant viral RNAs with partners of the translation and replication machineries. Proc. Natl. Acad. Sci. USA 93 (1996) 12078-12081.

Giegé, R., Briand, J.P., Mengual, R., Ebel, J.P. and Hirth, L.: Valylation of the two RNA components of turnip yellow mosaic virus and specificity of the aminoacylation reaction. EJB 84 (1978) 251-256.

Giegé, R., Florentz, C. and Dreher, T.W.: The TYMV tRNA-like structure. Biochimie 75 (1993a) 569-582.

Giegé, R., Puglisi, J.D. and Florentz, C.: tRNA structure and aminoacylation efficiency. Prog. Nucleic Acid Res. Mol. Biol. 43 (1993b) 129-206.

Giegé, R., Rudinger, J., Dreher, T., Perret, V., Westhof, E., Florentz, C. and Ebel, J.-P.: Search of essential parameters for the aminoacylation of viral tRNA-like molecules. Comparison with canonical transfer RNAs. Biochem. Biophys. Acta 1050 (1990) 179-185. 
Gold, L.: The SELEX process: a surprising source of therapeutic and diagnostic compound. Harvey Lectures 91 (1995) 47-57.

Goodwin, J.B. and Dreher, T.W.: Transfer RNA mimicry in a new group of positive-strand RNA plant viruses, the furoviruses: differential aminoacylation between the RNA components of one genome. Virology 246 (1998) 170-178.

Goodwin, J.B., Skuzeski, J.M. and Dreher, T.W.: Characterization of chimeric turnip yellow mosaic virus genomes that are infectious in the absence of aminoacylation. Virology 230 (1997) 113-124.

Green, R., Ellington, A.D., Bartel, D.P. and Szostak, J.W.: In vitro genetic analysis: selection and amplification of rare functional nucleic acids. Methods 2 (1991) 7586.

Grosjean, H., Sprinzl, M. and Steinberg, S.: Posttranscriptionally modified nucleosides in transfer RNA: their locations and frequencies. Biochimie 77 (1995) 139-141.

Guerrier-Takada, C., Van Belkum, A., Pleij, C.W.A. and Altman, S.: Novel reactions of RNAase P with a tRNA-like structure in turnip yellow mosaic virus RNA. Cell 53 (1988) 267-272.

Haenni, A.L., Joshi, S. and Chapeville, F.: tRNA-like structures in the genomes of RNA viruses. Prog. Nucleic Acid Res. Mol. Biol. 27 (1982) 85-104.

Hale, S.P., Auld, D.S., Schmidt, E. and Schimmel, P.: Discrete determinants in transfer RNA for editing and aminoacylation. Science 276 (1997) 1250-1252.

Hall, K.B., Sampson, J.R., Uhlenbeck, O.C. and Redfield, A.G.: Structure of an unmodified tRNA molecule. Biochemistry 28 (1989) 5794-5801.

Hall, T.C.: Transfer RNA-like structures in viral genomes. Int. Rev. Cytol. 60 (1979) 1-26.

Hall, T.C., Shih, D.S. and Kaesberg, P.: Enzyme mediated binding of tyrosine to brome mosaic virus ribonucleic acid. Biochem. J. 129 (1972) 969-976.

Hall, T.C. and Wepprich, R.K.: Functional possibilities for aminoacylation of viral RNA in transcription and translation. Ann. Microbiol. (Paris) 127A (1976) 143-152.

Hartman, K.A., McDonald-Ordzie, P.E., Kaper, J.M., Prescott, B. and Thomas, G.J.: Studies of virus structure by laser Raman spectroscopy. Turnip yellow mosaic virus and capsids. Biochemistry 17 (1978) 2118-2123.

Hatta, T., Bullivant, S. and Matthews, R.E.F.: Fine structure of vesicles induced in chloroplasts of Chinese cabbage leaves by infection with turnip yellow mosaic virus. J. gen. Virol. 20 (1973) 37-50.

Hatta, T. and Matthews, R.E.F.: Sites of coat protein accumulation in turnip yellow mosaic virus-infected cells. Virology 73 (1976) 1-16.

Hecht, S.M.: 2'-OH vs 3'-OH specificity in tRNA aminoacylation. In: Schimmel, P.R., Söll, D. and Abelson, J.N. (Eds.), Transfer RNA: Structure, Properties and Recognition. Cold Spring Harbor Laboratory., Cold Spring Harbor, NY., 1979, pp. 345-360. 
Hellendoorn, K., Michiels, P.J.A., Buitenhuis, R. and Pleij, C.W.A.: Protonatable hairpins are conserved in the 5' untranslated region of tymovirus RNAs. Nucleic Acids Res. 24 (1996) 4910-4917.

Hellendoorn, K., Verlaan, P.W.G. and Pleij, C.W.A.: A functional role for the conserved protonatable hairpins in the $5^{\prime}$-untranslated region of TYMV-RNA. J. Virol. 71 (1997) 8774-8779.

Helm, M., Brulé, H., Degoul, F., Cepanec, C., Leroux, J.-P., Giegé, R. and Florentz, C.: The presence of modified nucleotides is required for cloverleaf folding of a human mitochondrial tRNA. Nucleic Acids Res. 26 (1998) 1636-1643.

Hirth, L. and Givord, L.: Tymoviruses. In: Koenig, R. (Ed.), The Plant Viruses. Plenum Publishing Corporation, 1988, pp. 163-212.

Hoagland, M.B., Stephenson, M.L., Scott, J.F., Hecht, L.I. and Zamecnik, P.C.: A soluble ribonucleic acid intermediate in protein synthesis. J. Biol. Chem. 231 (1958) 241257.

Hofstee, B.H.J.: Non-inverted versus inverted plots in enzyme kinetics. Nature 184 (1959) 1296-1298.

Hoober, J.K.: Chloroplasts. Plenum Press, New York, 1984

Hopfield, J.J.: Kinetic proofreading: a new mechanism for reducing errors in biosynthesis processes requiring high specificity. PNAS 71 (1974) 4135-4139.

Hornung, V., Hofmann, H.-P. and Sprinzl, M.: In vitro selected RNA molecules that bind to elongation factor Tu. Biochemstry 37 (1998) 7260-7267.

Horton, R.M., Hunt, H.D., Ho, S.N., Pullen, J.K. and Pease, L.R.: Engineering hybrid genes without the use of restriction enzymes: gene splicing by overlap extension. Gene 77 (1989) 61-68.

Jacrot, B., Chauvin, C. and Witz, J.: Comparative neutron small-angle scattering study of small spherical RNA viruses. Nature 266 (1977) 417-421.

Jakubowski, H.: Proofreading and the evolution of a methyl donor function. JBC 268 (1993) 6549-6553.

Jonard, G., Briand, J.P., Bouley, J.P., Witz, J. and Hirth, L.: Nature and specificity of the RNA-protein interaction in the case of the tymoviruses. Philo. Trans. R. Soc. London Ser. B 276 (1976) 123-129.

Joshi, R.L., Faulhammer, H., Chapeville, F., Sprinzl, M. and Haenni, A.L.: Aminoacyl RNA domain of turnip yellow mosaic virus Val-RNA interacting with elongation factor Tu. NAR 12 (1984) 7467-7478.

Joshi, R.L., Ravel, J.M. and Haenni, A.L.: Interaction of turnip yellow mosaic virus ValRNA with eukaryotic elongation factor EF-1a. Search for a function. EMBO J. 5 (1986) 1143-1148. 
Joshi, S., Chapeville, F. and Haenni, A.L.: Length requirements for tRNA specific enzymes and cleavage specificity at the $3^{\prime}$ end of turnip yellow mosaic virus RNA. NAR 10 (1982a) 1947-1962.

Joshi, S., Chapeville, F. and Haenni, A.L.: Turnip yellow mosaic virus RNA is aminoacylated in vivo in Chinese cabbage leaves. EMBO J. 1 (1982b) 935-938.

Joshi, S., Haenni, A.L., Hubert, E., Huez, G. and Marbaix, G.: In vivo aminoacylation and 'processing' of turnip yellow mosaic virus RNA in Xenopus laevis oocytes. Nature 275 (1978) 339-341.

Kadaré, G., Rozanov, M.N. and Haenni, A.-L.: Expression of the turnipt yellow mosaic virus proteinase in Escherichia coli and determination of the cleavage site within the $206 \mathrm{kDa}$ protein. J. Gen. Virol. 76 (1995) 2853-2857.

Kaper, J.M.: Chemical basis of virus structure, dissociation and reassembly. In: Neuberger, A. and Tatum, E.L. (Eds.), Frontiers of biology. North-Holland Publishing Co., Amsterdam, The Netherlands, 1975.

Kaper, J.M. and Litjens, E.C.: The Ribonucleic Acid Content of Turnip Yellow Mosaic Virus. Biochemistry 5 (1966) 1612-1617.

Katouzian-Safadi, M. and Berthet-Colominas, C.: Evidence for the presence of a hole in the capsid of turnip yellow mosaic virus after RNA release by freezing and thawing. Decapsidation of turnip yellow mosaic virus in vitro. Eur. J. Biochem. 137 (1983) 47-53.

Katouzian-Safadi, M., Charlier, M. and Maurizot, J.-C.: A circular dichroism study of the turnip yellow mosaic virus-RNA. Biochimie 67 (1985) 1007-1013.

Kawakami, M., Tanada, S. and Takemura, S.: Properties of alanyl-oligonucleotide, puromycin, and Staphylococcus epidermidis glycyl-tRNA in interaction with elongation factor Tu:GTP complex. FEBS Lett. 51 (1975) 321-324.

Keeling, J. and Matthews, R.E.F.: Mechanism for release of RNA from turnip yellow mosaic virus at high $\mathrm{pH}$. Virology 119 (1982) 214-218.

Keese, P., Mackenzie, A. and Gibbs, A.: Nucleotide sequence of the genome of an australian isolate of turnip yellow mosaic tymovirus. Virology 172 (1989) 536-546.

Keiler, K.C., Waller, R.H. and Sauer, R.T.: Role of a peptide tagging system in degradation of proteins synthesized from damaged messenger RNA. Science 271 (1996) 990-993.

Kern, D., Giegé, R., Robbe-Saul, S., Boulanger, Y. and Ebel, J.P.: Complete purification and studies on the structural and kinetic properties of two forms of yeast valyltRNA synthetase. Biochimie 57 (1975) 1167-1176.

Kim, S.H., Suddath, F.L., Quigley, G.J., McPherson, A., Sussman, J.L., Wang, A.H.J., Seeman, N.C. and Rich, A.: Three dimensional tertiary structure of yeast phenylalanine transfer RNA. S 185 (1974) 435-440. 
Klug, C.: Struktur-Funktionsbeziehungen in tRNAs und tRNA-ähnlichen Ribonukleinsäuren, Institut für präparative Mikrobiologie und molekulare Genetik. Georg-August-Universität, Göttingen, 2000.

Kohl, R.J. and Hall, T.C.: Aminoacylation of RNA from several viruses : amino acid specificity and differential activity of plant, yeast and bacterial synthetases. J. gen. Virol. 25 (1974) 257-261.

Kolk, M.H., van der Graaf, M., Fransen, C.T.M., Wijmenga, S.S., Pleij, C.W.A., Heus, H.A. and Hilbers, C.W.: Structure of the 3 '-hairpin of the TYMV pseudoknot: preformation in RNA folding. EMBO J. 17 (1998a) 7498-7504.

Kolk, M.H., van der Graaf, M., Wijmenga, S.S., Pleij, C.W.A., Heus, H.A. and Hilbers, C.W.: NMR structure of a classical pseudoknot: interplay of single- and doublestranded RNA. Science 280 (1998b) 434-438.

Konarska, M.M. and Sharp, P.A.: Replication of RNA by the DNA-dependent RNA polymerase of phage T7. Cell 57 (1989) 423-431.

Konarska, M.M. and Sharp, P.A.: Structure of RNAs replicated by the DNA-dependent T7 RNA polymerase. Cell 63 (1990) 609-618.

Koonin, E.V.: The phylogeny of RNA-dependent RNA polymerase of positive-strand viruses. J. Gen. Virol. 72 (1991) 2197-2206.

Koonin, E.V. and Dolja, V.V.: Evolution and taxonomy of positive-strand RNA viruses. Crit. Rev. Biochem. Mol. Biol. 28 (1993) 375-430.

Kornberg, A. and T.A., B.: DNA Replication. Freeman and Company, New York, 1992, pp. 303-306.

Lafleche, D. and Bové, J.M.: Virus de la mosaique jaune du navet: site cellulaire de la réplication du RNA viral. Physiol. Vég. 9 (1971) 487-503.

Lahser, F.C., Marsh, L.E. and Hall, T.C.: Contribiutions of the brome mosaic virus RNA-3 3' nontranslated Region to replication and translation. J. Virol. 67 (1993) 32953303.

Lapointe, J. and Giegé, R.: Transfer RNAs and aminoacyl-tRNA synthetases. In: Trachsel, H. (Ed.), Translation in Eukaryotes. CRC Presss Inc. Boca Raton, F.L., 1991, pp. 35-69.

Leberman, R.: The isolation of plant viruses by means of "simple" coacervates. Virol. 30 (1966) 341-347.

Leimkuhler, M., Goldbeck, A., Lechner, M.D., Adrian, M., Michels, B. and Witz, J.: The formation of empty shells upon pressure induced decapsidation of turnip yellow mosaic virus. Arch. Virol. 146 (2001) 653-667.

Lewin, B.: Molekularbiologie der Gene, 6. Auflage ed. Spektrum Akademischer Verlag, Heidelberg, Berlin, 1998.

Lim, J.Y., Shin, C.S., Chung, E.J., Kim, J.S., Kim, H.U., Oh, S.J., Choi, W.B., Ryou, C.S., Kim, J.B., Kwon, M.S., Chung, T.Y., Song, S.I., Kim, J.K., Nahm, B.H., Hwang, 
Y.S., Eun, M.Y., Lee, J.S., Cheong, J.J. and Choi, Y.D.: Analysis of expressed sequence tags from Brassica rapa L. ssp. pekinensis. Mol. Cells 10 (2000) 399-404.

Limbach, P.A., Crain, P.F. and McCloskey, J.A.: Summary: the modified nucleosides of RNA. NAR 22 (1994) 2183-2196.

Limbach, P.A., Crain, P.F., Pomerantz, S.C. and McCloskey, J.A.: Structures of posttranscriptionally modified nucleosides from RNA. Biochimie 77 (1995) 135138.

Litvak, S., Tarrago, A., Tarrago-Litvak, L. and Allende, J.E.: Elongation factor-viral genome interaction dependent on the aminoacylation of TYMV and TMV RNAs. Nature New Biol. 241 (1973a) 88-90.

Litvak, S., Tarrago-Litvak, L. and Chapeville, F.: TYMV-RNA as a substrate of transfer RNA nucleotidyl-transferase. II. Incorporation of cytidine 5' monophosphate and determination of a short nucleotides sequence at the 3'end of the RNA. J. Virology 11 (1973b) 238-242.

Loesch-Fries, L.S. and Hall, T.C.: In vivo aminoacylation of brome mosaic and barley stripe mosaic virus RNAs. Nature 298 (1982) 771-773.

Mamoun, R. and Bové, J.M.: Biochemical studies on RNA synthesis in healthy and TYMV infected chinese cabbage: effect of actinomycin D. Ann. Microbiol. 127 A (1976) 65-67.

Mans, M.W., Pleij, C.W.A. and Bosch, L.: tRNA-like structures. Structure, function and evolutionary significance. EJB 201 (1991) 303-324.

Mans, R.M.W., Van Steeg, M.H., Verlaan, P.W.G., Pleij, C.W.A. and Bosch, L.: Mutational analysis of the pseudoknot in the tRNA-like structure of turnip yellow mosaic virus RNA. Aminoacylation efficiency and RNA pseudoknot stability. J. Mol. Biol. 223 (1992) 221-232.

Mans, R.M.W., Verlaan, P.W.G., Pleij, C.W.A. and Bosch, L.: Aminoacylation of 3' terminal tRNA-like fragments of turnip yellow mosaic virus RNA : the influence of 5 ' nonviral sequences. Biochem. Biophys. Acta 1050 (1990) 186-192.

Markham, R. and Smith, K.M.: Studies on the virus of turnip yellow mosaic. Parasitology 39 (1949) 330-342.

Matsuda, D., Zeenko, V., Gallie, D. and Dreher, T.W.: A new role for the turnipt yellow mosaic virus tRNA-like structure: translation enhancement that is dependent on aminoacylation. American Society for Virology Abstr. Book 21st Annual Meeting (2002) W22-28.

Matthews, R.E.F.: Plant Virology, 3rd ed. Academic Press, San Diego, 1991.

McClain, W.H.: Rules that govern tRNA identity in protein synthesis. J. Mol. Biol. 234 (1993a) 257-280.

McClain, W.H.: Transfer RNA identity. FASEB J. 7 (1993b) 72-78. 
Mellema, J.E. and Amos, L.A.: Three-dimensional image reconstruction of turnip yellow mosaic virus. J. Mol. Biol. 72 (1972) 819-822.

Miller, W.A., Bujarski, J.J., Dreher, T.W. and Hall, T.C.: Minus-strand initiation by brome mosaic virus replicase within the 3' tRNA-like structure of native and modified RNA templates. JMB 187 (1986) 537-546.

Milligan, J.F., Groebe, D.R., Witherell, G.W. and Uhlenbeck, O.C.: Oligoribonucleotide synthesis using T7 RNA polymerase and synthetic DNA template. Nucleic Acids Res. 15 (1987) 8783-8798.

Milligan, J.F. and Uhlenbeck, O.C.: Determination of RNA-protein contacts using thiophosphate substitutions. Biochemistry 28 (1989a) 2849-2855.

Milligan, J.F. and Uhlenbeck, U.C.: Synthesis of small RNAs using T7 RNA polymerase. Methods Enzymol. 180 (1989b) 51-62.

Mills, D.R., Peterson, R.L. and Spiegelman, S.: An extracellular Darwinian experiment with a self-duplicating nucleic acid molecule. Proc. Natl. Acad. Sci. USA 58 (1967) 217-224.

Moine, H., Romby, P., Springer, M., Grunberg-Manago, M., Ebel, J.P., Ehresmann, C. and Ehresmann, B.: Messenger RNA structure and gene regulation at the translational level in Escherichia coli: the case of threonine:tRNA ligase. PNAS 85 (1988) 78927896.

Moras, D., Comarmond, M.B., Fischer, J., Weiss, R., Thierry, J.C., Ebel, J.P. and Giegé, R.: Crystal structure of yeast tRNAAsp. Nature 288 (1980) 669-674.

Morch, M.D., Boyer, J.C. and Haenni, A.L.: Overlapping open reading frames revealed by nucleotide sequencing of turnip yellow mosaic virus genomic RNA. NAR 16 (1988) 6157-6173.

Morch, M.D., Drugeon, G., Szafranski, P. and Haenni, A.L.: Proteolytic origin of the 150kilodalton protein encoded by turnip yellow mosaic virus genomic RNA. J. Virol. 63 (1989) 5153-5158.

Mouchès, C., Bové, C. and Bové, J.M.: Turnip yellow mosaic virus-RNA replicase: partial purification of the enzyme from the solubilized enzyme-template complex. Virology 58 (1974) 409-423.

Mouchès, C., Candresse, T. and Bové, J.M.: Turnip yellow mosaic virus RNA replicase contains host and virus-encoded subunits. Virology 134 (1984) 78-90.

Mullis, K., Faloona, F., Scharf, S., Saiki, R., Horn, G. and Erlich, H.: Specific enzymatic amplification of DNA in vitro: the polymerase chain reaction. Cold Spring Harb. Symp. Quant. Biol. 51 (1986) 263-273.

Mullis, K. and Faloona, F.A.: Specific synthesis of DNA in vitro via a polymerasecatalyzed chain reaction. Methods Enzymol. 155 (1987) 335-350.

Muto, A., Ushida, C. and Himeno, H.: A bacterial RNA that functions as both a tRNA and an mRNA. TIBS 23 (1998) 25-29. 
Mutombo, K., Michels, B., Ott, H., Cerf, R. and Witz, J.: The thermal stability and decapsidation mechanism of tymoviruses: A differential calorimetric study. Biochimie 75 (1993) 667-674.

Nakajima, N., Ozeki, H. and Shimura, Y.: Organization and Structure of an E. coli tRNA Operon Containing Seven tRNA Genes. Cell 23 (1981) 239-249.

Nazarenko, I.A. and Uhlenbeck, O.C.: Defining a smaller RNA substrate for elongation factor Tu. Biochemistry 34 (1995) 2545-2552.

Nureki, O., Vassylyev, D.G., Tateno, M., Shimada, A., Nakama, T., Fukai, S., Konno, M., Hendrickson, T., Schimmel, P. and Yokoyama, S.: Enzyme structure with two catalytic sites for double-sieve selection of substrate. Science 280 (1998) 578-582.

Öberg, B. and Philipson, L.: Binding of histidine to tobacco mosaic virus RNA. Biochem. Biophys. Res. Commun. 48 (1972) 927-832.

Ogden, R.C. and Adams, D.A.: Electrophoresis in agarose and acrylamide gels. Meth. Enzymol. 152 (1987) 61-87.

Olsthoorn, R.C.L., Mertens, S., Brederode, F.T. and Bol, J.F.: A conformational switch at the $3^{\prime}$ end of a plant virus RNA regulates viral replication. EMBO J. 18 (1999) 4856-4864.

Osman, T.A., Hemenway, C.L. and Bucl, K.W.: Role of the 3- tRNA-like structure in tobacco mosaic virus minus-strand RNA synthesis by the viral RNA-dependent RNA polymerase In vitro. J. Virol. 74 (2000) 11671-11680.

Perret, V., Florentz, C., Puglisi, J.D. and Giegé, R.: Effect of conformational features on the aminoacylation of tRNAs and consequences on the permutation of tRNA specificities. JMB 226 (1992) 323-333.

Peterson, E.T., Blank, J., Sprinzl, M. and Uhlenbeck, O.C.: Selection for active E. coli tRNA(phe) variants from a randomized library using two proteins. EMBO J. 12 (1993a) 2959-2967.

Peterson, E.T., Blank, J., Sprinzl, M. and Uhlenbeck, O.C.: Selection of active E. coli

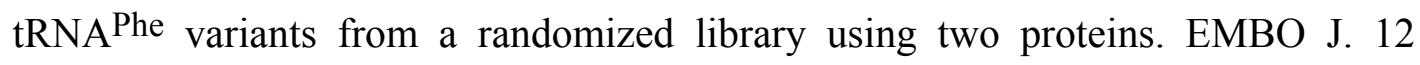
(1993b) 2959-2967.

Pinck, M., Chan, S.K., Genevaux, M., Hirth, L. and Duranton, H.: Valine specific tRNAlike structure in RNAs of two viruses of turnip yellow mosaic virus group. Biochimie 54 (1972) 1093-1094.

Pinck, M., Yot, P., Chapeville, F. and Duranton, H.: Enzymatic binding of valine to the 3' end of TYMV RNA. Nature 226 (1970) 954-956.

Pleij, C.W.A.: RNA pseudoknots. Curr. Opin. Struct. Biol. 4 (1994) 337-344.

Pleij, C.W.A., Eecen, H.G., Bosch, L. and Mandel, M.: The formation of fast sedimenting turnip yellow mosaic virus RNA: Structural rearrangement inside the capsid. Virology 76 (1977) 781-786. 
Pleij, C.W.A., Neeleman, A., van Vloten-Doting, L. and Bosch, L.: Translation of turnip yellow mosaic virus RNA in vitro: a closed and an open coat protein cistron. Proc. Natl. Acad. Sci. (USA) 73 (1976) 4437-4441.

Prochiantz, A. and Haenni, A.L.: TYMV RNA as a substrate of the tRNA maturation endonuclease. Nature (London) 241 (1973) 168-170.

Prod'homme, D., Jakubiec, A., Tournier, V., Drugeon, G. and Jupin, I.: Targeting of the turnip yellow mosaic virus $66 \mathrm{~K}$ replication protein to the chloroplast envelope is mediated by the 140K protein. J. Virol. 77 (2003) 9124-9135.

Prod'homme, D., Le Panse, S., Drugeon, G. and Jupin, I.: Detection and subcellular localization of the turnip yellow mosaic virus $66 \mathrm{~K}$ replication protein in infected cells. Virology 281 (2001) 88-101.

Puglisi, J.D., Wyatt, J.R. and Tinoco, I.: Conformation of an RNA pseudoknot. JMB 214 (1990) 437-453.

Pulikowska, J., Wojtaszek, P., Korez, A., Michalski, Z., Candresse, T. and Twaerdowski, T.: Immunochemical properties of elongation factors 1 of plant origin. EJB 171 (1988) 131-136.

Pütz, J., Florentz, C., Benseler, F. and Giegé, R.: A single methyl group prevents the mischarging of a tRNA. Nature Struct. Biol. 1 (1994) 580-582.

Pütz, J., Wientges, J., Sissler, M., Giegé, R., Florentz, C. and Schwienhorst, A.: Rapid selection of aminoacyl-tRNAs based on biotinylation of $\alpha-\mathrm{NH}_{2}$-group of charged amino acids. NAR 25 (1997) 1862-1863.

Quadt, R. and Jaspars, E.M.: Purification and characterization of brome mosaic virus RNA-dependent RNA polymerase. Virology 178 (1990) 189-194.

Ransom, W.D., Lao, P.C., Gage, D.A. and Boss, W.F.: Phosphoglycerylethanolamine posttranslational modification of plant eukaryotic elongation factor 1alpha. Plant Physiol. 117 (1998) 949-960.

Rao, A.L.N., Dreher, T.W., Marsh, L.E. and Hall, T.C.: Telomeric function of the tRNAlike structure of brome mosaic virus RNA. PNAS 86 (1989) 5335-5339.

Ravindra, N., Dreher, S. and Dreher, T.W.: Tunrip Yellow Mosaic Virus RNA-Dependent RNA Polymerase: Initiation of Minus Strand Synthesis in Vitro. Virology 233 (1997) 430-439.

Renaudin, J. and Bove, J.M.: The effect of actinomycin D on the production of viruses by the protoplasts of Chinese cabbage infected in vitro by the yellow mosaic virus of turnips. C. R. Acad. Sci. Hebd. Seances Acad. Sci. D. 284 (1977) 783-786.

Renaudin, J., Gandar, J. and Bove, J.M.: Proceedings: Replication of TYMV in Chinese cabbage protoplasts. Ann. Microbiol. 127A (1976) 61-63.

Ribeiro, S., Nock, S. and Sprinzl, M.: Purification of aminoacyl-tRNA by affinity chromatography on immobilized Thermus thermophilus EF-Tu.GTP. Analytical Biochemistry 228 (1995) 330-335. 
Rietveld, K., Pleij, C.W.A. and Bosch, L.: Three-dimensional models of the tRNA-like 3' termini of some plant viral RNAs. EMBO J. 2 (1983) 1079-1085.

Rietveld, K., Van Poelgeest, R., Pleij, C.W.A., Van Boom, J.H. and Bosch, L.: The tRNAlike structure at the 3 ' terminus of turnip yellow mosaic virus RNA. Differences and simularities with canonical tRNA. NAR 10 (1982) 1929-1946.

Robertus, J.D., Ladner, J.E., Finch, J.T., Rhodes, D., Brown, R.S., Clark, B.F.C. and Klug, A.: Structure of yeast phenylalanine tRNA at $3 \AA$ resolution. Nature 250 (1974) 546-551.

Rochaix, J.D.: Molecular genetics of chloroplasts and mitochondria in the unicellular green algae Chlamydomonas. FEMS Microbiol. Rev. 46 (1987) 13-34

Rohozinski, J. and Hancock, J.M.: Do light-induced pH changes within the chloroplast drive turnip yellow mosaic virus assembly? J. Gen. Virol. 77 (1996) 163-165.

Rould, M.A., Perona, J.J., Söll, D. and Steitz, T.A.: Structure of E. coli glutaminyl-tRNA synthetase complexed with tRNA ${ }^{\mathrm{Gln}}$ and ATP at $2.8 \AA$ resolution. Science 246 (1989) 1135-1142.

Rozanov, M.N., Drugeon, G. and Haenni, A.-L.: Papain-like proteinase of turnip yellow mosaic virus: a prototype of a new viral proteinase group. Arch. Virol. 140 (1995) 273-288.

Rudinger, J., Florentz, C., Dreher, T. and Giegé, R.: Efficient mischarging of a viral tRNAlike structure and aminoacylation of a minihelix containing a pseudoknot : histidinylation of Turnip Yellow Mosaic Virus RNA. NAR 20 (1992) 1865-1870.

Ruff, M., Krishnaswamy, S., Boeglin, M., Poterszman, A., Mitschler, A., Podjarny, A., Rees, B., Thierry, J.-C. and Moras, D.: Class II aminoacyl transfer RNA synthetases: crystal structure of yeast aspartyl-tRNA synthetase complexed with tRNAAsp. Science 252 (1991) 1682-1689.

Saiki, R.K., Gelfand, D.H., Stoffel, S., Scharf, S.J., Higuchi, R., Horn, G.T., Mullis, K.B. and Erlich, H.A.: Primer-directed enzymatic amplification of DNA with a thermostable DNA polymerase. Science 239 (1988) 487-491.

Saks, M.E., Sampson, J.R. and Abelson, J.N.: The transfer RNA identity problem: a search for rules. Science 263 (1994) 191-197.

Sambrook, J., Fritsch, E.F. and Maniatis, T.: Molecular cloning: A laboratory manual. Cold Spring Harbor Laboratory Press, 1989.

Sampson, J.R. and Saks, M.E.: Selection of aminoacylated tRNAs from libraries having randomized acceptor stem sequences: using old dogs to perform new tricks. Methods in Enzymology 267 (1996) 384-410.

Sanger, F., Nicklen, S. and Coulson, A.R.: DNA sequencing with chain terminating inhibitors. PNAS 74 (1977) 5463-5467. 
Schimmel, P.: Aminoacyl-tRNA synthetases: general scheme of structure-function relationships in the polypeptides and recognition of transfer RNAs. Annu. Rev. Biochem. 56 (1987) 125-158.

Schirawski, J., Planchais, S. and Haenni, A.-L.: An improved protocol for the preparation of protoplasts from an established Arabidopsis thaliana cell suspension culture and infection with RNA of turnip yellow mosaic tymovirus: a simple an reliable method. j. Virol. Meth. 86 (2000) 85-94.

Schmidt, E. and Schimmel, P.: Residues in a class I tRNA synthetase which determine selectivity of amino acid recognition in the context of tRNA. Biochemistry 34 (1995) 11204-11210.

Schmitt, E., Meinnel, T., Panvert, M., Mechulam, Y. and Blanquet, S.: Two acidic residues of Escherichia coli methionyl-tRNA synthetase act as negative discriminants towards the binding of non-cognate tRNA anticodons. JMB 233 (1993) 615-628.

Schwienhorst, A.: Molekulare Evolution funktionaler Nukleinsäuren. Chemie in unserer Zeit 33 (1999) 110-119.

Shuman, S.: Novel approach to molecular cloning and polynucleotide synthesis using vaccinia DNA topoisomerase. J. Biol. Chem. 269 (1994) 32678-32684.

Silberklang, M., Prochiantz, A., Haenni, A.L. and RajBhandary, U.L.: Studies on the sequence of the 3 ' terminal region of Turnip Yellow Mosaic Virus RNA. EJB 72 (1977) 465-478.

Singh, R.N. and Dreher, T.W.: Turnip Yellow Mosaic Virus RNA-dependent RNA polymerase: Initiation of minus strand synthesis in vitro. Virology 233 (1997) 430439.

Singh, R.N. and Dreher, T.W.: Specific site selection in RNA resulting from a combination of nonspecific secondary structure and -CCR- boxes: initiation of minus strand synthesis by turnip yellow mosaic virus RNA-dependent RNA polymerase. RNA 4 (1998) 1083-1095.

Skotnicki, M.L., Mackenzie, A.M. and Gibbs, A.J.: Turnip yellow mosaic virus variants produced from DNA clones encoding their genomes. Arch. Virol. 127 (1992) 2535.

Skuzeski, J.M., Bozarth, C.S. and Dreher, T.W.: The turnip yellow mosaic virus tRNA-like structure cannot be replaced by generic tRNA-like elements or by heterologous 3' untranslated regions known to enhance mRNA expression and stability. J. Virol. 70 (1996) 2107-2115.

Smith, D., Kirschenheuter, G.P., Charlton, J., Guidot, D.M. and Repione, J.E.: In vitro selection of RNA-based irreversible inhibitors of human neutrophil elastase. Chemistry \& Biology 2 (1995) 741-750. 
Springer, M., Graffe, M., Dondon, J. and Grunberg-Manago, M.: tRNA-like structures and gene regulation at the translational level/ a case of molecular mimicry in E. coli. EMBO J. 8 (1989) 2417-2424.

Sprinzl, M. and Cramer, F.: Site of aminoacylation of tRNAs from Escherichia coli with respect to the 2'- or 3'-hydroxyl group of the terminal adenosine. PNAS 72 (1975) 3049-3053.

Sprinzl, M., Horn, C., Brown, M., Ioudovitch, A. and Steinberg, S.: Compilation of tRNA sequences and sequences of tRNA genes. Nucl. Acids Res. 26 (1998) 148-153.

Stout, C.D., Mizuno, H., Rao, S.T., Swaminathan, P., Rubin, J., Brennan, T. and Sundaralingam, M.: Crystal and molecular structure of yeast phenylalanine transfer RNA. Structure determination, difference Fourier refinement, molecular conformation, metal and solvent binding. Acta Crys. B34 (1978) 1529-1544.

ten Dam, E., Pleij, K. and Draper, D.: Structural and functional aspects of RNA pseudoknots. Biochemistry 31 (1992) 11665-11676.

Tiffin, P. and Hahn, M.W.: Coding sequence divergence between two closely related plant species: Arabidopsis thaliana and Brassica rapa ssp. pekinensis. J. Mol. Evol. 54 (2002) 746-753.

Tomandl, D., Schober, A. and Schwienhorst, A.: Optimizing doped libaries by using genetic algorithms. J. Comp.-Aided Mol. Design 11 (1997) 29-38.

Tsai, C.H. and Dreher, T.W.: Turnip yellow mosaic virus RNAs with anticodon loop substitutions that result in decreased valylation fail to replicate efficiently. J. Virol. 65 (1991) 3060-3067.

Tuerk, C. and Gold, L.: Systematic evolution of ligands by exponential enrichement : RNA ligands to bacteriophage T4 DNA polymerase. Science 249 (1990) 505-510.

Van Belkum, A., Bingkun, J., Rietveld, K., Pleij, C.W.A. and Bosch, L.: Structural similarities among valine-accepting tRNA-like structures in tymoviral RNAs and elongator tRNAs. Biochemistry 26 (1987) 1144-1151.

Van Belkum, A., Wiersema, P.J., Joordens, J., Pleij, C., Hilbers, C.W. and Bosch, L.: Biochemical and biophysical analysis of pseudoknot-containing RNA fragments. Melting studies and NMR spectroscopy. Eur. J. Biochem. 183 (1989) 591-601.

Virudachalam, R., Low., P.S., Argos, P. and Markley, J.L.: Turnip yellow mosaic virus and its capsid have thermal stabilities with opposite $\mathrm{pH}$ dependence: studies by differential scanning calorimetry and $31 \mathrm{P}$ nuclear magnetic resonance spectroscopy. Virology 146 (1985) 213-220.

Watson, J.D., Gilman, M., Witkowski, J. and Zoller, M.: Rekombinierte DNA, 2. Aufl. ed. Spektrum Akademischer Verlag GmBH, Heidelberg, 1993.

Weiland, J.J. and Dreher, T.C.: Infectious TYMV RNA from cloned cDNA. Effects in vitro and in vivo of point substitutions in the initiation codons of two extensively overlapping ORFs. NAR 17 (1989) 4675-4687. 
Weiland, J.J. and Dreher, T.W.: Cis-preferential replication of the turnip yellow mosaic virus RNA genome. PNAS 90 (1993) 6095-6099.

Weiner, A.M. and Maizels, N.: tRNA-like structures tag the $3^{\prime}$ ends of genomic RNA molecules for replication : Implications for the origin of protein synthesis. PNAS 84 (1987) 7383-7387.

Weiner, A.M. and Maizels, N.: The genomic tag hypothesis: modern viruses as molecular fossils of ancient strategies for genomic replication, and clues regarding the origin of protein synthesis. Biol. Bull. 196 (1999) 327-328.

Westhof, E., Dumas, P. and Moras, D.: Crystallographic refinement of yeast aspartic acid transfer RNA. J. Mol. Biol. 184 (1985) 119-145.

Westhof, E. and Jaeger, L.: RNA pseudoknots : structural and functional aspects. Current Opinion Struct. Biol. 2 (1992) 327-333.

Wientges, J.: In vitro Selektion spezifisch aminoacylierbarer RNA's, Department of microbiology and molecular genetics. Universität Bayreuth, Fachbereich Biologie, Chemie und Geowissenschaften, 1998.

Wientges, J., Pütz, J., Florentz, C., Giegé, R. and Schwienhorst, A.: Selection of viral RNA derived tRNA-like structures with improved valylation activities. Biochemistry 39 (2000) 6207-6218.

Witz, J., Timmins, P.A. and Adrian, M.: Organization of turnip yellow mosaic virus investigated by neutron small angle scattering at $80 \mathrm{~K}$ : An intermediate state preceding decapsidation of the virion. Proteins 17 (1993) 223-231.

Wolf, H., Assmann, D. and Fischer, E.: Pulvomycin, an inhibitor of protein biosynthesis preventing ternary complex formation between elongation factor Tu, GTP and aminoacyl-tRNA. Proc. Natl. Acad. Sci. USA 75 (1978) 5324-5328.

Woo, N.H., Roe, B.A. and Rich, A.: Three-dimensional structure of Escherichia coli initiator tRNA fMet. Nature 286 (1980) 346-351.

Yokohama, S. and Nishimura, S.: tRNA structure, biosynthesis and function. In: Söll D., R.U. (Ed.). ASM press, Washington D.C., 1995.

Yokoyama, S., Watanabe, K. and Miyazawa, T.: Dynamic structures and functions of transfer ribonucleic acids from extreme thermophiles. Adv. Biophys. 23 (1987) 115-147.

Yot, P., Pinck, M., Haenni, A.L., Duranton, H. and Chapeville, F.: Valine-specific tRNAlike structure in turnip yellow mosaic virus RNA. PNAS 67 (1970) 1345-1352.

Zagorski, W., Morch, M.D. and Haenni, A.L.: Comparison of three different cell-free systems for turnip yellow mosaic virus RNA translation. Biochimie 65 (1983) 127133.

Zon, G., Gallo, K.A., Samson, C.J., Shao, K.-I., Summers, M.F. and Byrd, R.A.: Analytical studies of 'mixed sequence' oligodeoxyribonucleotides synthesized by competitive 
coupling of either methyl- or $\beta$-cyanoethyl-N,N-diisopropylamino phosphoramidite reagents, including 2'-deoxyinosine. Nucl. Acids Res. 13 (1985) 8181-8196. 


\section{Danksagungen}

Diese Arbeit wurde an der Georg-August-Universität zu Göttingen am Institut für Mikrobiologie und Genetik, in der Abteilung Molekulare Genetik und Präparative Molekularbiologie unter Herrn Prof. Dr. H.-J. Fritz in der Arbeitsgruppe von Herrn PD Dr. A. Schwienhorst angefertigt.

Ich möchte Herrn PD Dr. A. Schwienhorst danken, daß er mir die vorliegende Dissertation in seiner Arbeitsgruppe ermöglicht hat.

Ihm und der Arbeitsgruppe möchte ich für die freundliche Aufnahme und Unterstützung und für das großzügige Gewähren von Sachmitteln danken. Insbesondere Dr. René Hempel, Dennis Wegener und Dr. Milena Ninkovic danke ich für die informativen und unterhaltsamen Gespräche.

Ich danke Herrn Prof. Dr. C.W.A. Pleij für die freundliche Aufnahme und Unterstützung in seiner Abteilung für Biochemie im Chemischen Institut der Leidener Universität (Niederlande) mit ihrer langen wissenschaftlichen Tradition. Vor allem das Erlernen und Durchführen der Infektion von Pflanzen und die Aufreinigung der TYMV-RdRp wurde mir dort ermöglicht. Auch der Arbeitsgruppe um Prof. Pleij möchte ich für ihre Unterstützung während meines Aufenthaltes in Süd-Holland danken.

Frau Prof. Dr. C. Gatz möchte ich danken, daß ich in ihrer Abteilung (Allgemeine und Entwicklungsphysiologie der Pflanze, Universität Göttingen) den größten Teil der Protoplasten-Experimente durchführen konnte. Ich danke der Arbeitsgruppe um Herrn PD Dr. W. Dröge-Laser für die Unterstützung dabei.

Herrn Prof. Dr. F. Mayer (Abteilung für strukturelle Mikrobiologie) möchte ich für die Überlassung der EF-Tu-Präparation und das Anfertigen von elektronenmikroskopischen Aufnahmen danken. 


\section{Liste der Veröffentlichungen und Vorträge}

Veröffentlichungen

Eigene Vorträge
B. F. Lindemann, C. Klug, A. Schwienhorst, 2002; Evolution of Bacteriophage in Continous Culture: a Model System to Test Antiviral Gene Therapies for the Emergence of Phage Escape Mutants; Journal of Virology; Vol. 76, No.11: 5784-5792;

R. Welz, K. Bossman, C. Klug, C. Schmidt, H.-J. Fritz, S. Müller, 2003; Site-Directed Alteration of RNA Sequence Mediated by an Engineered Twin Ribozyme; Angewandte Chemie Int. Ed.; Vol. 42, Issue 21: 2424-2427

C. Klug, A. Schwienhorst, 2003; Structurefunction-relationships in the tRNA-like structure of TYMV; In Vorbereitung

28.02.-01.03.2000 DFG-Workshop „Selection in RNA Biochemistry", Vortrag: "Selection of valylatable tRNA-like structures from partially randomised turnip yellow mosaic virus RNA", in Kahla/Jena (Thüringen)

23.03.-25.03.2000 Kolloquium des EUSchwerpunkts "RNA structure and function", Vortrag: "Structure-function-relationships in tRNA-like structures", in Munster (Elsaß, Frankreich) 


\section{$\underline{\text { 10. Lebenslauf }}$}

Persönliche Daten

Name

Geburtsdatum

Geburtsort

Familienstand

\section{Schulausbildung}

August 1980 - Juli 1984

August 1984 - Juli 1993

\section{Wehrdienst}

Juli 1993 - Juni 1994

\section{Studium}

September 1994

Oktober 1996

Februar 2000

Mai 2000 bis heute
Christian Klug

18.06.1973

Uelzen

ledig

Grundschule Ihringshausen

Friedrichsgymnasium Kassel

Abschluß: Abitur

Grundwehrdienst

Studium der Biologie an der

Georg-August-Universität Göttingen,

Vordiplom

Diplom, Thema:

„Struktur-Funktionsbeziehungen in tRNAs und tRNA-ähnlichen Ribonukleinsäuren"

Promotion an der Georg-August-Universität zu Göttingen

Thema: „Untersuchungen zu Struktur-

Funktionsbeziehungen in der tRNA-ähnlichen

Struktur des Rüben-Gelbmosaik-Virus“

Arbeiten außerhalb der Universität

März 1997 - Juli 1998

Anstellung als studentische Hilfskraft am

Max-Planck-Institut für Experimentelle Medizin

in Göttingen

Thema: „Molekularbiologische und

proteinchemische Charakterisierung der

Glutaminylcyclase aus der Maus"

\section{Auslandsaufenthalt}

Januar - April 2002

Forschungsarbeit im Rahmen der Promotion zum

Erlernen neuer Techniken in der

Pflanzenvirologie und deren Durchführung im Labor von Prof. C.W.A. Pleij, Universität Leiden, Niederlande 